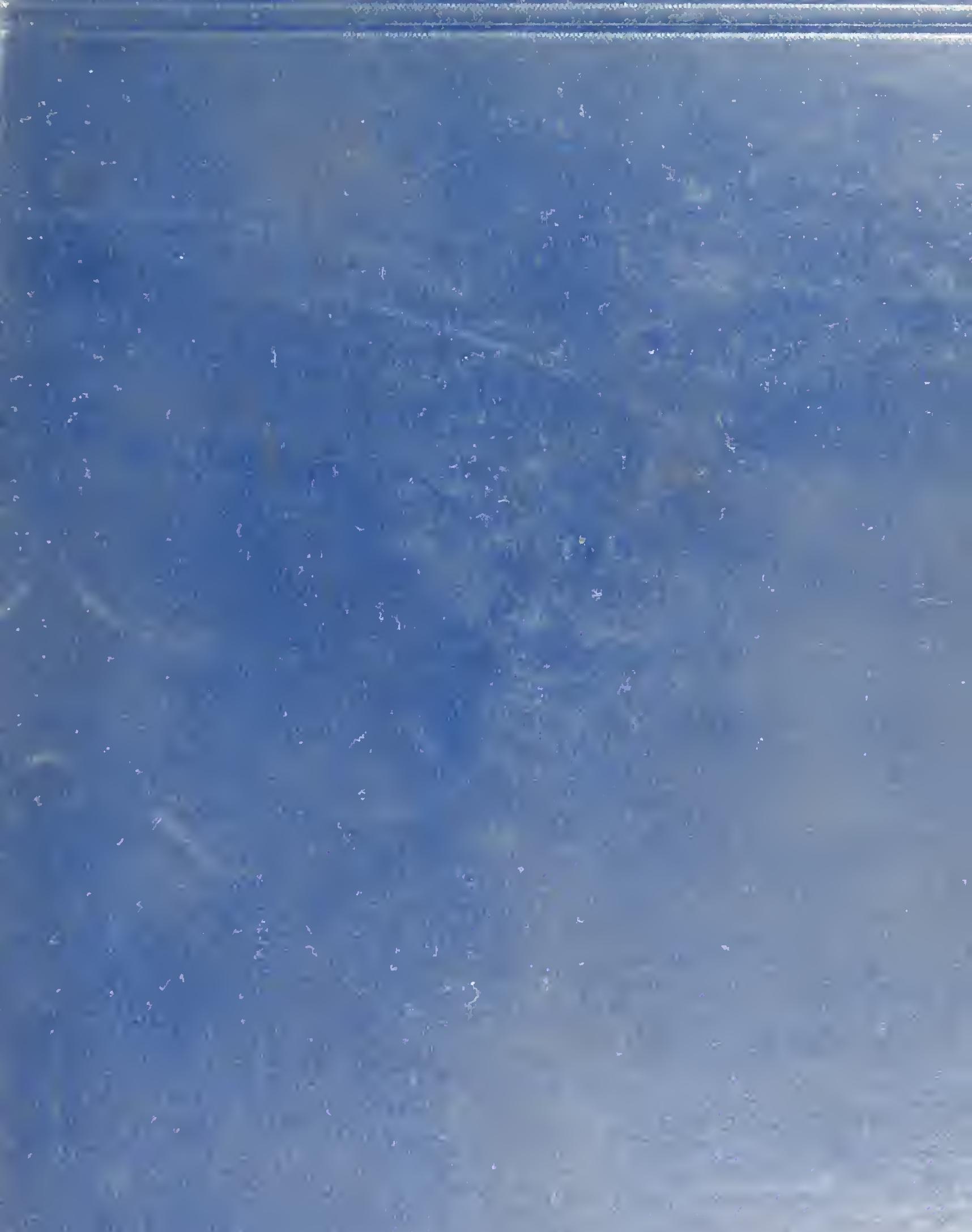






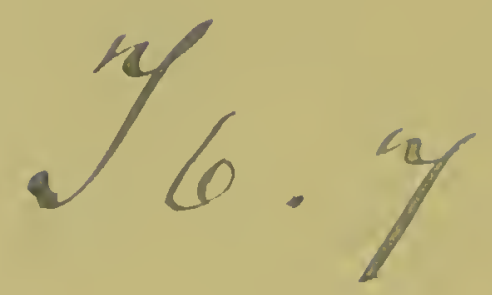




\section{THE FOUNDATIONS OF ZOÖLOGY}

A COURSE OF LECTURES

DELIVERED AT COLUMBIA UNIVERSITY

ON THE PRINCIPLES OF SCIENCE

AS ILLUSTRATED BY ZOÖLOGY 


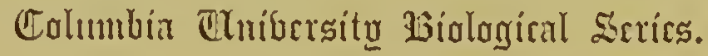

\section{EDITED BY}

HENRY F. OSBORN AND EDMUND B. WILSON.

1. FROM THE GREEKS TO DARWIN.

By Henry Fairfieid Osborn, Sc.D. Princeton.

2. AMPHIOXUS AND THE ANCESTRY OF THE VERTEBRATES.

By Arthur Wiliey, B.Sc. Lond. Univ.

3. FISHES, LIVING AND FOSSIL. An Introductory Study.

By Bashford Dean, Ph.D. Coiumbia.

4. THE CELL IN DEVELOPMENT AND INHERITANCE.

By Edmund B. Wilson, Ph.D. Johns Hopkins.

5. THE FOUNDATIONS OF ZOÖLOGY.

By Wiiliam Keith Brooks, Ph.D. Harvard, LL.D. Wiiliams. 


\section{THE}

\section{FOUNDATIONS OF ZOÖLOGY}

BY

\section{WILLIAM KEITH BROOKS, Ph.D., LL.D.}

PROFESSOR OF ZOÖLOGY IN THE JOHNS HOPKINS UNIVERSITY
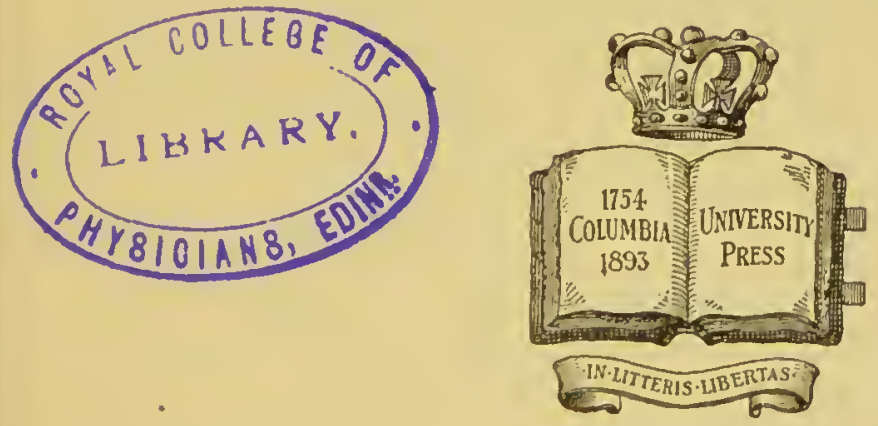

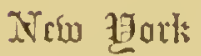

PUBLISHED FOR THE COLUMBIA UNIVERSITY PRESS BY THE MACMILLAN COMPANY

LONDON : MACMILLAN \& CO., LTD.

I 899 
COPYRIGITT, I899,

BY THE MACMILLAN COMPANY. 


\section{To agobart College}

WHERE I LEARNED TO STUDY, AND, I HOPE, TO PROFIT BY BUT NOT TO BLINDLY FOLLOW, THE WRITINGS OF THAT GREAT THINKER ON THE PRINCIPLES OF SCIENCE GEORGE BERKELEY

I HAVE, BY PERMISSION, DEDICATED THIS BOOK 



\section{CONTENTS}

LECTURE I

INTRODUCTORY

LECTURE II

Huxley, and the Problem of the Naturalist

LECTURE III

Nature AND NURTure

\section{LECTURE IV \\ LECTURE IV}

LAMARCK

\section{LECTURE V}

MigRation IN ITS BEARING ON LAMARCKisi 101

\section{LECTURE VI - PART I}

Zoölogr, ANd the Philosophy of Evolution

\section{LECTURE VI - PART II}

A Note on the Views of Galton and Weismann on Inheritance - i43

\section{LECTURE VII}

Galton, and the Statistical Study of Inheritance.

LECTURE VIII

Darwin, AND THE ORIGIN OF SPECIES

LECTURE IX

Natural Selection, A.id the Antiquity of Life. 
LECTURE X

PAGE

Natural Selection and Natural Theology . . . . . . . 24 I

LECTURE XI

Paley, and the Argument from Contrivance . . . . . 269

LECTURE XII

The Mechanism of Nature . . . . . . . . . 287

LECTURE XIII

Louis Agassiz and George Berkeley . . . . . . . 317 


\section{LECTURE I}

INTRODUCTORY 
"The doctrine of idols bears the same relation to the interpretation of nature as that of sophisms does to common logie. It is the peeuliar and perpetual error of the human understanding to be more moved and excited by affirmations than by negations; whereas it ought duly and regularly to be impartial; nay, in establishing any true axiom the negative instance is the most powerful." - Francis BaCon. 


\section{LECTURE I}

\section{INTRODUCTORY}

IN this course of lectures I shall give, on many questions, the Scotch verdict of "not proven," and experience warns us that this will be interpreted as an assertion that they are proved or disproved, although no one can, in justice, interpret an admission that a thesis may some time be proved or disproved as belief that either of these things will come about, or as an admission of anything else except a suspension of judgment, for all must hold it the height of folly to found a scientific opinion on lack of evidence.

If I sometimes speak of things that are not commonly held to fall within the province of zoölogy, - if I try now and then for soundings in waters which able pilots tell us are far out of the course of our ship, - I hope they who follow me to the end of our voyage will admit that I have not wandered from our true course; although it may be well to show now, by way of introduction, how it is that zoölogists find themselves face to face with many problems which other men of science have agreed to lay aside as insoluble or irrelevant.

I shall try to show that life is response to the order of naturein fact, this thesis is the text of most of the lectures; but if it be admitted, it follows that biology is the study of response, and that the study of that order of nature to which response is made is as well within its province as the study of the living organism which responds, for all the knowledge we can get of both these aspects of nature is needed as a preparation for the study of that relation between them which constitutes life. Our interest in all branches of science is vital interest. It is only as living things that we care to 
know. Life is that which, when joined to mind, is knowledge, knowledge in use; and we may be sure that all living things with minds like ours are conscious of some part of the order of nature, for the response in which life consists is response to this order. The statement that physical phenomena are natural seems to mean little, but the phenomena of life are so wonderful that many hesitate, even at the present day, to believe that nature can be such a wonderful thing as it must be if the actions of all living things are natural; and, as I shall try to find out in this course of lectures what we mean by the assertion that living nature is natural, I shall now attempt, by a few illustrations, to give a broad outline of some of the most notable features of the nature of living things.

The outer surface or shell of a crab is an excretion that is formed once for all; for while it may stretch a little at the joints, it does not grow, and as the living body must in time become too large for it, new shells, one size larger, are formed from time to time under the old one, which is then thrown off. The frequency of these moultings conforms to the rate of growth. The little crab sheds its shell either before or a few minutes after it is hatched from the egg, and a second moulting takes place within forty-eight hours, but the next interval lasts four or five days, and each successive shell remains useful for a longer time, until a mature crab may pass a year or even longer without moulting. The process is natural or mechanical, for nothing the crab can do for itself retards or hastens its growth or the secretion of a new shell; nor can any part of the process be attributed to its own actions, except so far as these actions are due to its nature, although it will not grow unless it seeks and finds food, nor will the old shell take itself off, unless the crab draws its limbs out by bodily movements which are both complex and violent.

Many enemies, man and the hard crab among them, prize the soft crab as a palatable delicacy, and as it is helpless and defenceless while moulting, and until the new shell has grown hard, the crab hides under the sand or among the grass of the marshes until the dangerous crisis is past. No one can say whether the crab is or is not conscious of its danger, or whether it hides voluntarily or involuntarily, but as no crab which has not escaped its enemies at the moulting season now survives, all the modern edible crabs hide by nature, just as they grow and shed their shells by nature. Some crabs pass 
most of their lives in places which seem to have been sought, at first, for shelter during the moulting period. A species of Porcellana clings to the lower surface of the broad shell of Limulus, and the Pinnixas live in the burrows which annelids make in the floor of the ocean. I have found a species of Pinnixa living on the shoals at Beaufort, N.C., in the parchment-like tubes with which the annelid Chretopterus lines its burrow, and as the opening of this tube is too small for a Pinnixa to pass, it must enter while small and pass the rest of its life there.

The period of moulting is dangerous, not only because of enemies, but also because of its critical nature, for many crabs die in the act, while others lose their limbs and their gills. The general constitutional disturbance is so great that it is difficult to carry a full-grown crab safely through it in an aquarium. The power to replace lost parts which is so well developed in crabs is an adjustment to meet and compensate for this danger among others. Most of the direct danger comes from the stony hardness and inflexibility of the old shell, and the shells of crabs like the Pinnixa, and the female Pinnotheres which lives within the shell of the oyster, are softer than those of more exposed crabs.

The hermit-crabs and soldier-crabs live in the spiral shells of gasteropod mollusks, and, as these houses are strong enough to furnish ample protection, all the hinder part of the body of these crabs is covered by a thin flexible shell which may be stripped off without danger, although the claws and other exposed parts are covered by very hard strong shell. When born, the little hermit-crab is straight and its hind-body carries swimming feet, but when it is about as large as a mosquito, these become converted into knobs for clinging to the inside of the house, and the hindbody becomes twisted into a spiral to fit the inside of the spiral shell. Crabs outgrow the shells of mollusks just as children outgrow their clothes; and hermit-crabs are always on the watch for new shells, and exhibit what the human observer finds himself disposed to call a lively interest in shells. If half a dozen of them are placed in an aquarium, they soon begin to measure and compare shells, and even to make vacant one that secms eligible, by pulling out its occupant piece by piece and eating him. One 
that has found or emptied a shell that seems to suit, measures it earefully inside and out, and then, bringing the openings close together, quickly pops out of the old into the new. Then the old shell is compared with the new, and often the body is slipped into each of them repeatedly, and each is allowed to slip nearly off and is then pulled on again, somewhat as a man settles himself into a new coat. Running is now tried in each shell, a claw keeping a tight cluteh on the empty one and dragging it along; and the movement of drawing the body far into the shell, so that it drops on the sand as if it were empty, is tried in both. It is often many hours before a ehoice is made, and then the decision often is that the old one is best.

It is difficult to witness or to deseribe this performance without attributing to the erab feclings and motives like our own; yet, while no one ean say whether the crab knows what it is about or not, nothing is more certain than that its actions are due to its nature, and not to knowledge of the value of a house, drawn from experienee. When I was working as a student in the marine laboratory of Alexander Agassiz, he reared from eggs, in an aquarium, a brood of hermit-crabs which had never seen a shell. I had in my aquarium young gasteropods which I had reared from eggs. Some of them had died, and their empty shells were, at his suggestion, dropped into the water with the crabs, which seized them, almost as soon as they touehed the water, and beginning to explore their interior as they were carried to the bottom by the weight of the shells, eonducted themselves as if they had many years of experienec in the use of molluscan shells as houses. I have seen very young hermit-erabs make houses for themselves out of the cast skins of others, although these afforded no protection; and I have found a full-grown one in the bowl of a elay pipe so badly broken that it exposed the soft abdomen and was useless; but the impulse to inhabit shells is almost universally protective and beneficial, although it is as strictly a part of the nature of hermit-crabs as is the twisted abdomen, or the legs and claws, or any other part of the crab's body.

The external world presents such variety that few natural adjustments are so exact and definite that they may not under some 
circumstances prove disadvantageous or even destructive instead of beneficial, although the perfection of many of the adjustments of crustacea and insects is marvellous. Some hunting wasps store living spiders in the cells with their eggs to serve as food for their young, but each spider, while alive, is paralyzed and helpless, for when the wasp captures it she stings it through the nerve-centre which directs the movements of the limbs, severely enough to produce paralysis without destroying life; and Mivart says ("Lessons from Nature," p. 202) that the female wasp does this by nature or without experience.

It is often said that the natural activities of living things are innate; but, so far as this word implies that they take place without a stimulus, it is obviously erroneous. The hermit-crab is said to seek a house by nature, and the egg to grow into a specific organism in virtue of its inherent potency; but this is not strictly true, for while some vital changes may be spontaneous, in one of the many meanings of this word, there is no reason to believe that any change ever takes place, either in living things or any where else, without antecedents which stand in that peculiar relation which we call physical causation.

The new-born child is said to seek the breast instinctively, but every nurse knows that it does not seek the breast at all without experience, although it does suck by nature and without instruction the first time the nerves of its lips and tongue are stimulated by contact with the nipple. The instinct of the young hermit-crab cannot be called spontaneous, if, by this word, we mean arbitrary, although it is so promptly called forth by the first sight of a shell.

The bodily movements of which the purpose is most obvious are, as a rule, called out in response to changes in the external world, and they are excited by stimuli which come through the senses; although many responsive actions are called forth by stimuli which arise within the body and do not reach it through any of the organs of special sense, as the stretching of our limbs while awakening is excited by the vague discomfort of the body; and this is true not only of many bodily movements but of most physiological changes.

"To call mind a function of the brain," says Maudsley ("Responsibility in Mental Disease," p. I7), "may lead to much mis- 
apprehension if it be thereby supposed that the brain is the only organ which is concerned in the function of mind. There is not an organ in the body, which is not in intimate relation with the brain by means of its paths of nervous communication, ... and which does not, therefore, affect more or less plainly and specifcally its function as an organ of mind. It is not merely that a palpitating heart may cause anxiety and apprehension, or a disordered liver gloomy feelings, but there are good reasons for believing that each organ has a specific influence on the constitution and function of mind; an infuence not yet set forth scientifically, because it is exerted on that unconscious mental life which is the basis of all that we consciously feel and think. Were the heart of one man," says Maudsley, "to be placed in the body of another, it would probably make no difference in the circulation of the blood, but it might make a real difference in the temper of his mind. So close is the physiological sympathy of parts in the commonwealth of the body, that it is necessary, in the physiological study of mind, to regard it as a function of the whole organism, as comprehending the whole bodily life."

A most notable illustration of the way a complicated adaptive mechanism may be thrown into beneficial response by a physiological stimulus, is found in the shad, which, when its bodily structure is excited by the reaction of approaching sexual maturity, leaves its home in the ocean and enters upon a journey which, before its path was obstructed by dams, carried it across the broad states of Virginia, Maryland, and Pennsylvania, to its spawning ground in central New York.

The excitement of adaptive vital changes in one part of the body by changes in another part is not restricted to the channels afforded by the nervous system. Florists make their plants bloom before their time by confining their roots in small pots. The seeds of an apple are new beings, but the apple itself is part of the substance of the mother-tree, yet the blossoms will not set fruit unless they are. fertilized.

When a duck's egg is put under a hen, it undergoes a long series of wonderful changes, which all prove, in the end, to be in responsive adjustment to the normal life of ducks; and as the production of a duck by the mere heat of a hen, or that of a lamp in an incu- 
bator, is incredible, we say the egg is developed by its inherent potency; but we must use these words with care, for the assertion that the changes which make up this long and marvellous series take place spontaneously is as incredible as the assertion that they are determined by the heat of the hen; and there is reason to believe that each change in the series transmits to the natural or inherent adaptive mechanism a stimulus which excites in it the performance of the responsive actions which bring about the next change in order.

Embryonic development is so delicate and so complicated that we cannot hope to trace, far less to imitate, the action of these stimuli in anything like their natural perfection; yet we can, now and then, rudely imitate some of them, while, in other cases, we can demonstrate their presence and influence indirectly by preventing them from acting. Some eggs which have begun their development by division into two, four, or eight cells, may be shaken apart without destroying their vitality, and when thus separated, a cell which would normally have given rise to half or quarter of an embryo, may give rise to a whole one of one half or one quarter the natural size. Embryologists are rapidly adding, by experimental methods, to our knowledge of the mechanics of development, and it has been known, since the day of Aristotle, that some of the latest stages in the development of the higher animals and of man do not take place in the absence of certain normal physiological stimuli.

Male mammals, for example, do not attain bodily perfection until the approach of sexual maturity. In man the beard begins to grow at what is accordingly called the age of pubescence; the larynx enlarges; the voice assumes a manly tone; the shoulders grow broad; the chest deepens; and the trunk and limbs begin to differ in relative length from those of women and children. At the same period in the life of a bull his neck and shoulders grow massive and sturdy; his forehead broadens and becomes cushioned with hair; and he becomes pugnacious and subject to fits of violent rage.

The cock acquires his spurs, his brilliant plumage and other ornaments, and begins to crow. Aristotle pointed out that when young male mammals or birds are prevented from becoming sexually mature, they fail to acquire the distinctive characteristics of their species, and this shows that the completion of this, the final stage 
in their physical development, is dependent, to a great degree at least, on some constitutional stimulus which is afforded by the changes which take place in the reproductive organs.

The existence of rudimentary organs and provisional larval stages is one of the most suggestive facts in the whole range of zoölogy, and the evidence that these things are a record of past history seems conclusive; although those who hold that their existence is accounted for by the discovery that they are a "recapitulation" add nothing, after all the centuries, to Aristotle's declaration that they are "for a token."

They who are most convinced that the historical significance of these structures is an adequate explanation of their presence, are also most emphatic in their repudiation of teleology, and in the rejection of the belief of Louis Agassiz, that they are part of the language in which the Creator tells us the history of creation; yet the assertion that their history accounts for their existence is as teleological as anything in Paley.

They who believe that inheritance is not the transmission of responsive actions, but the transmission of an adaptive mechanism, and that each change which enters into the history of development is a response to a stimulus, will have no difficulty in understanding that organs which were once adjusted to the external world may, after this adjustment has lost its meaning, be still retained, because they furnish physiological stimuli, which excite developmental changes in the organic mechanism.

If a physiological stimulus from the male reproductive organs excites the growth of weapons of defence, would the preservation of rudiments of these organs, by natural selection, for this useful purpose, be anything more than might be expected; even if some change in the method of reproduction should make their primary function useless?

Is there any evidence that any change which is due to nature, from the segmentation of the egg to old age, ever takes place without a stimulus, or are the actions which are due to nature beneficial, except so far as the environment is, on the average, like the ancestral environment? Since the gentle stimulation of the lips and tongue has been associated, in the past history of human infants, with the presence of milk which may be extracted 
by sucking, the adjustment is beneficial; although the infant does not, as a matter of fact, obtain any milk at first, and although a finger or a rubber nipple on an empty bottle, or any other object of suitable size and texture, in the mouth of a hungry infant, excites the nerves and muscles so as to call forth the act of sucking, and, so far, to satisfy the calls of nature.

Preyer says "when I put into the mouth of the screaming child, whose head alone was as yet born, the ivory pencil or a finger, the child began to suck, opened its eyes, and seemed, to judge from its countenance, to be most agreeably affected. In the case of another child, which cried out immediately after its head emerged from the womb, I put my finger, three minutes later, into the child's mouth, and pressed it on the tongue. At once all crying ceased, a brisk sucking began, and the expression of the countenance, which had been hitherto discontented, became suddenly altered. The child, not yet fully born, seemed to experience something agreeable, and therewith - during the sucking of the finger - the eyes were widely opened."

Although changes which are directly due to nature do not take place" without a stimulus, they do take place mechanically, or independently of experience, under the natural stimulus, or under any other which is applied in the same way. The blowfly, which is stimulated by the odor of putrid flesh to lay its eggs where the larvæ will find abundant food, sometimes lays them on the stinking arum, misled by its odor. In this case the deceptive stimulus resembles the normal one in certain sensible qualities, but it is most important, for reasons which will be given later, to note that the natural responses of living things may be called forth by any stimulus which is similar in its mode of application to the normal or natural stimulus, whether it is or is not similar in any sensible properties except those which act as the stimulus. The finger, which feels like a nipple, stimulates the infant and calls out the sucking response, but electrical stimulation of the lips and tongue, if applied with sufficient skill, might give the same result, although this does not resemble the nipple in any sensible qualitics except the ones which effect the stimulation.

In the order of nature each stimulus is a sign with a significance, and our own reason, which consciously apprehends the 
significance of natural signs, generally approves the responsive actions of living things, although we find that these living things are often misled by signs which we know to be illusions, which, while similar in some respects to those to which the organic mechanism is adjusted, signify something quite different from the normal or customary course of events.

As the nature of living things often leads to injurious or destructive actions, instinct is said to be blind or mechanical; for while no one can say whether the actions of the hermit-crab or those of the blow-fly, or those of the human infant, are voluntary or not, they are no more than the nature of these living things would lead one to expect, and this is as true when they are beneficial as it is when they mislead.

If the adjustments between living things and the external world were always beneficial, I do not see how the question whether or not their actions are voluntary could present itself; but the complexity of external nature is inexhaustible, and few natural adjustments are beneficial under all circumstances, for even a response to gravitation may mislead.

A growing plant needs the moisture and the soluble food which it may find under ground, in course of nature, by following the stimulus of gravity, and it also needs the sunlight and the air which, in the normal or natural order of things, are to be reached by upward growth. As the seed germinates, the radicle, stimulated by gravity, grows downwards, while the plumule, which does not differ essentially from the radicle in specific gravity, is impelled by its nature to grow upwards under the same stimulus; but each part grows by means of internal energy, and, while gravity is the stimulus which throws it into action, it is not the means by which the vital changes are brought about.

The response is beneficial, and the stimulus seems as trustworthy as anything in nature; yet the seeds often fall into places where it misleads, and if a germinating seed be placed on the edge of a horizontal wheel which turns slowly at a rate which makes the centrifugal force somewhat greater than the weight of the seed, the plumule grows towards and the radicle away from the centre, although no seeds which act thus can grow up to produce seeds in their turn. If plants think, a matter on which 
I do not here express an opinion, they must know the order of nature to which they respond, and in that case the seed on the wheel would seem to be not only misled but deceived, exactly as a brood of chicks seems to us to be deceived by an imitation of the call of the mother hen; but the essential point is that, whether they know it or not, the changes in living things which are directly due to nature are beneficial only so far as the conditions of their life are, on the average, essentially like those in which the lives of their ancestors were passed.

Now the order of nature presents infinite diversity: the different ways in which events may.be combined are innumerable; and no natural response can be judicious or beneficial under all circumstances. We accordingly find, in all the living things we know best, and are most intimately concerned with, a wonderful provision of their nature, by means of which those of their actions which are most apt to mislead are improved and perfected and developed by normal use, so that we are no longer able to tell what they will do from knowledge of their nature alone, since their actions are in part dependent on their training and experience, and on their individual contact with the world.

The question whether capacity for improvement through contact with the world is natural or not is much easier to ask than to answer. Are the benefits that attend training and education and experience part of the nature of living things, or do they add to nature something it did not before contain? Is knowledge of the world around us part of our nature, or does it add something new on to our nature? If it is natural, do we simply find or discover our nature, or do we make it or any part of it ourselves? Any answer we try to give is attended with difficulties. If living things make any part of their nature, the word must mean much more than is recognized in common usage; and yet the assertion that knowledge and experience and training add nothing to the nature of living beings is beset by difficulties which at first sight seem equally grave.

In some cases we can show that improvement by training is no more than might have been expected, for we can imitate it by means of stimuli which have nothing in common with the natural stimuli except the manner of their application. Normal 
use strengthens muscles and increases their aptitude for doing their work, but as muscles may also be strengthened by massage, their improvement by use is no more than their nature might have led us to look for; nor do we find any more difficulty in attributing this beneficial response to nature than we find in the same explanation of the house-hunting actions of crabs.

All who have to do with animals admit that training can do no more for them than to make the best of their natural capacity, for they differ greatly in power to profit by experience; and the nature of each species sets impassable bounds to the power of individual animals to improve by practice. No one hesitates to attribute to deficient structure the inability of idiots to learn, and all admit that men of genius are born and not made, yet many hesitate to confess that their own more commonplace capacity for profiting by practice and growing wiser with experience is strictly limited by their nature, although this may be quite obvious to others. All know too well also that a dose of alcohol may make a man remember what never happened outside his own disordered brain, and perform responsive actions which, while criminal, might be prudent and commendable if the remembered experience were not a delusion; although the effects of contact with the world are usually far too complicated and diversified to be artificially imitated. As we are quite unable to tell with any minute accuracy what an animal with capacity for training will do under a stimulus, we must rely upon indirect evidence to show what the real significance of experience is.

If a chick is stung by the first honey-bee it catches, its future actions may be adjusted to the natural law that bees are dangerous; but if, before it is stung, it has captured and eaten stingless drones, it may act in accordance with the wider law that while bees are good for food some are dangerous. A careful observer, Mr. Gilman Drew, tells me that the chicks that are most destructive to bees pick out the drones, and he believes that these are the chicks which, before they were stung, learned to catch and eat bees, and that they have afterwards learned to let the stinging workers alone.

If slight differences in the mere order of events which are otherwise so much alike may lead to such differences in the con- 
duct of individual animals of the same species, it is clear that even if we believe that sufficient knowledge of their nature would enable us to predict their conduct, this knowledge is unattainable, for we cannot possibly know all the complicated personal history of any one animal. We must also remember that even if we prove that individual animals acquire, by contact with the external world, nothing but what their nature provides for, this does not show that they are compelled to make of themselves all that their nature permits, for the effects of experience are often injurious or destructive. There is, unfortunately, no incompatibility between the system of things and unprofitable experience, for it is, to say the least, no harder to corrupt or injure nature by injudicious or pernicious training than it is to make the best of it.

Romanes tells us ("Mental Evolution in Animals," p. 215) of a hen that had reared three successive broods of ducklings in successive years, and then hatched out a brood of nine chickens: "The first day she was let out she disappeared, and after a long search my sister," his informant writes, "found her beside a little stream, which her successive broods of ducklings had been in the habit of frequenting. She had got four of her chickens into the water, which, fortunately, was very shallow at the time. The other five were all standing on its margin, and she was endeavoring by all sorts of coaxing hen-language, and by pushing each chicken in turn with her bill, to get them into the water also."

In the normal course of the history of chicks, the response to the order of nature which experience is said to have called out in this hen, would be rapidly fatal to her posterity; and it would be easy to give other illustrations to show that the changes which are called forth in living things by the influence of the world around them, are beneficial only so far as this external world is, on the average, substantially the same as that to which the actions of their ancestors were adjusted. The snake that swallows hens' eggs, like its ancestors, profits like them; but the snake that swallows a china nest-egg dies from indigestion. I shall try to show that this fact, and others like it, mean that while the changes would not take place without practice or training, their character is due to nature, and not to experience.

It is almost impossible to contemplate the actions of animals 
that profit by experience, without attributing them to conscious intelligence, and it is even harder to speak or write of them, without using words which imply that they are altogether such as human actions would be under like conditions, for our words are adapted to human needs; but, hard as it is, we must, so far as possible, distinguish what we actually observe from what we infer from our knowledge of ourselves.

He who considers the relation between mind and matter should try to determine clearly what he knows and does not know about the distribution of mind. Is not the view of the matter to which all should agrec, about as follows? I know my mental state and the things I see and feel by the best of all evidence. While I have not this sort of evidence for anything else, doubt that my fellow-men are rational would be regarded as insane; for he who acts as if his fellow-men have no feclings, is justly abhorred by all, unless, indeed, he is held in honor as a military hero. "A close study of the dog," says Agassiz, "might satisfy every one of the similarity of his impulses with those of man, and those impulses are regulated in a manner which discloses psychical faculties in every respect of the same kind as those of man; moreover, he expresses by his voice his emotions and his feclings; with a precision which may be as intelligible to man as the articulate speech of his fellow-men. His memory is so retentive that it frequently baffles that of man. And though all these faculties do not make a philosopher of him, they certainly place him, in that respect, upon a level with a considerable proportion of poor humanity."

"When animals fight with one another, when they associate for a common purpose, when they warn one another in danger, when they come to the rescue of one another, when they display pain or joy, they manifest impulses of the same kind as those which are considered among the moral attributes of man. The range of their passions is even as extensive as that of the human mind, and I am at a loss to distinguish a difference in kind between them, however much they may differ in degree and in the manner in which they are expressed."

"I confess," says Agassiz, "I could not say in what the mental faculties of a child differ from those of a young chimpanzee." 
While the evidence does not have that highest degree of value which I find in my own feelings, good common sense seems to demand that the burden of proof fall on those who hold that apes and dogs and elephants are not rational.

"Who," asks Agassiz, "is the investigator, who having once recognized such a similarity between certain faculties of man and those of the higher animals, can feel prepared, in the present stage of our knowledge, to trace the limit where this community of nature ceases?"

As for myself, I try to treat all living things, plants as well as animals, as if they may have some small part of a sensitive life like my own, although I know nothing about the presence or absence of sense in most living things; and am no more prepared to make a negative than a positive statement. While it is nonsense to regard trees and rocks and lakes as endowed with mind, it is nonsense because we know nothing about it, and not because it is untrue; for it is no less nonsense to assert that stones are unconscious than to assert that they are conscious.

Morgan says ("Habit and Intelligence," p. 4I), "To some chicks I threw cinnabar larvæ, distasteful caterpillars conspicuous by alternating rings of black and golden yellow. They were seized at once, but dropped uninjured; the chicks wiped their bills - a sign of distaste - and seldom touched the caterpillars a second time. The cinnabar larvæ were then removed, and thrown in again towards the close of the day. Some of the chicks tried them once, but they were soon left. The next day the young birds were given brown loopers and green cabbage-moth caterpillars. These were approached with some suspicion, but presently one chick ran off with a looper, and was followed by others, one of which stole and atc it. In a few minutes all the caterpillars were cleared off. Later in the day they were given some more of these edible caterpillars, which they ate freely; and then some cinnabar larva. One chick ran, but checked himself, and, without touching the caterpillar, wiped his bill-a memory of the nasty taste being apparently suggested at the sight of the yellow and black caterpillar; another seized one and dropped it at once. A third subsequently approached a cinnabar as it crawled along, gave the danger note, and ran off. Then I threw in more edible 
caterpillars, which again were eaten freely. The chicks had thus learnt to distinguish by sight between the nice and nasty caterpillars."

"The cinnabar caterpillars are, as I have said, conspicuously marked with alternating yellow and black rings. It would seem that the end of this conspicuousness is to render association in the individual experience of young birds more rapid and more certain; there does not appear to be any congenital and instinctive avoidance of such caterpillars with warning colors. The net result of these observations is that, in the absence of parental guidance, the young birds have to learn for themselves what is good to eat, and what is distasteful, and have no instinctive aversions."

In his discussion of these most instructive observations, the author says, p. I50: "A chick sees for the first time in its life a cinnabar larva, instinctively pecks at it under the influence of the visual stimulus; seizes it, and under the influence of the tastestimulus instinctively shrinks. So far we have instinct and automatism. Presently we throw to it another similar caterpillar. Instinct and automatism alone would lead to a repetition of the previous series of events; seeing, seizing, tasting, and shrinking. The oftener the experiment was performed, the more smoothly would the organic mechanism work, the more definitely would the same sequence be repeated - seeing, scizing, tasting, shrinking. Is this what we actually observe? Not at all. On the second occasion the chick, under the influence of the previous experience. acts differently. Though he sces, he does not seize, but shrinks without seizing. We believe that there is a revival in memory of the nasty taste. And in this we seem justified, since we may observe that sometimes the chick on such occasions wipes the bill on the ground as he does on experiencing an unpleasant taste, though he has not touched the larvæ. The chick, then, does not continue to act mercly from instinct and like an automaton. His behavior is modified in the light of previous experience."

So far as our senses tell us, actions of this sort are, in all respects, like many we observe in our fellow-men, and attribute to consciousness and memory and reason; and as a mistaken belief 
that the brutes are conscious can do no harm, while belief that they are unconscious might, if mistaken, bring untold misery upon dumb brutes from brutal men, it seems well that we should continue to describe their actions in subjective language; although nothing is more obvious than that, while we know their actions, we only infer the existence of mental accompaniments. For all any one knows to the contrary young chicks may learn what is good to eat and what is umpleasant, and may readily associate the appearance with the taste, and those who hold that they are unconscious may justly be called upon by Morgan to prove their opinion; but I cannot agree with him that his studies show that they are conscious, for in sober and scientific truth all they show is that the chicks rapidly acquire power to respond to certain optical stimuli by actions which are adjusted to those flavors which in course of nature are associated with certain optical properties.

They who live in the hope that the actions which the chick performs only after what we call experience, will sometime be proved as mechanical as the response of the growing seedling to gravitation, may appeal to the rapid progress which physiologists are making in the localization of the functions of the brain, as evidence that their hope is well founded. They may say that there is good reason to believe that, if the localized and specialized brain-cells which are stimulated through the eyes and the optic nerves by the yellow and black rings of the cinnabar caterpillar, could be stimulated by electricity or in any other way with sufficient delicacy and skill, all the other changes which make up the response would follow mechanically; that the nervous discharge from these cells would be accompanied, as it has been before, by the stimulation of those localized cells which were originally stimulated by the pernicious flavor, and that the nervous discharge from them would inhibit the seizing movements, and that whether the chick is conscious or not, the establishment of the response by experience is no more than might have been expected from our knowledge of the functions of the nervous system.

If we answer that this is as yet unproved, inasmuch as no one is able now, or is at all likely to soon be able, to even demon- 
strate, far less to imitate, in the brain of the chick, any structural equivalent to its experience, we may be told that no one expects complete inductive proof of any scientific generalization; that he who refuses to admit that all water consists of $\mathrm{H}_{2} \mathrm{O}$ until chemists have decomposed every drop of water in the ocean is lacking in good sense; and that it is equally unreasonable to demand the artificial imitation of all the responses of living things before we admit that all response is mechanical.

To this we must answer that no great harm can be done if the chemist interprets the admission that we have not the slightest reason to doubt that every drop of water is decomposable into hydrogen and oxygen as an assertion that all water is so decomposable, since, for all the ordinary purposes of chemistry, the negative admission and the positive assertion may be treated as if they were synonymous. The case is very different when the subject under consideration is not chemistry, but the nature of knowledge, for we are about to enter a field where we may easily lose our way unless we distinguish inference from perception, to the best of our ability. The utmost the physiologist is warranted in asserting is that, for all one knows to the contrary, every response may be mechanical; and I think all thoughtful students must so far agree with him as to admit that belief that any of the responsive actions of living beings are not mechanical is highly unwise and precarious, in view of the condition and prospects of modern physiology; although we must, in my opinion, also admit that not one single vital response has as yet been completely analyzed, or resolved, from beginning to end, into phenomena of matter and motion; for I am myself unable to discover, in the present status of biology, any demonstration of error in the assertion that life is different from matter and motion.

However this may be, we know, by evidence which no one can question, that many actions are attended by memory, and by conscious experience, and by volition and reason and a sense of moral responsibility. Many beneficial responses are known to be judicious and reasonable, and many voluntary acts are known to be right or wrong.

As these convictions seem, at first sight, to be contradictory to the opinion that, for all we know to the contrary, all response may 
be mechanical, we must ask whether this contradiction is real or only apparent. As this question has, in one form or another, vexed the mind of man for untold ages, no one would be so bold as to attempt a final answer in few words; but I hope all who follow me to the end may find reason to ask themselves whether the contradiction may not, after all, be a matter of words rather than a real difficulty, for I shall try to review, at one time and another, some of the evidence which has convinced many thoughtful men that this apparently insoluble puzzle has arisen from an erroneous and unscientific conception of the meaning of the mechanism of nature. This evidence seems so clear and conclusive that I cannot see how any one who has mastered it can find any contradiction between anything we find in our nature and the ultimate reduction of all nature, including all the phenomena of life and of mind, to mechanical principles; for most students of the principles of science agree that natural knowledge is no more than the discovery of the order of nature; although a moment's thought is enough to show that the fact that events do take place in order is no reason why they should, or even why they should take place at all. Order is no explanation, but a thing to be explained.

The proof that there is no necessary antagonism between mechanical explanations of human life and belief in volition and duty and moral responsibility seems to me to be very simple and easy to understand. If the subject takes us into deep waters, this is because we are compelled to examine the reason why the impression that these things are antagonistic has so widely prevailed; for the view of the matter to which I hope to call your attention is, in itself, by no means difficult or obscure.

Science is still in its infancy, and we know so little that I have no sympathy with those who discount the possibilities of future discovery and assert that life is merely a question of matter and motion, although I know no reason why this should not, some day, be proved, nor am I able to see why any should find this admission alarming.

However this may be, I am convinced that they stand on treacherous ground, who base positive opinions on negative evidence, and believe that anything in our nature is inconsistent with mechanics. 
"Conscience, the last acquired faculty," says Maudsley, "is the first to suffer when disease invades the mental organization. One of the first symptoms of insanity - one which declares itself before there is any intellectual derangement, before the person's friends suspect even that he is becoming insane - is a deadening or complete perversion of the moral sense. In extreme cases it is observed that the modest man becomes presumptuous and exacting, the chaste man lewd and obscene, the honest man a thief, and the truthful man an unblushing liar. Short of this, however, there is an observable impairment of the finer moral feelings-a something different, which the nearest friends do not fail to feel, although they cannot always describe it. Now these signs of moral perversion are really the first symptoms of a mental derangement which may, in its further course, go through all the degrees of intellectual disorder, and end in destruction of mind, with visible destruction of the nervecells which minister to mind. Is the end, then, dependent upon organization, and is the beginning not?"

"Note, again, the effect which a severe attack of insanity sometimes produces upon the moral nature of the individual. The person entirely recovers his reason; his intellectual faculties are as acute as ever, but his moral character is changed; he is no longer the moral man that he was; the shock has destroyed the finest part of his organization. Henceforth his life may be as different from his former life as, in an opposite direction, was the life of Saul of Tarsus from the life of Paul the Apostle to the Gentiles. An attack of epilepsy has produced the same effects, effacing the moral sense as it effaces the memory sometimes, and one of the most striking phenomena observed in asylums is the extreme change in the moral character in the epileptic which precedes and heralds the approach of his fits. A fever or an injury to the head has, in like manner, transformed the moral character."

Passing this subject by for the present, it is clear that, consciously or unconsciously, arbitrarily or naturally, freely or of necessity, every living thing responds to some part of the order of nature, and that the study of this order is part of biology; for there are many reasons, besides those we have considered, why the biologist should have peculiar interest in the principles of science. His studies bring him into intimate contact with certain conceptions which play such a 
subordinate part in the other sciences that it falls to him to asscrt their importance, since they are so little regarded outside his circle that students in other lines often fail to catch what he has in mind. Among these are the principle of genetic continuity and the principle of fitness, with all that they imply. For all I know to the contrary, the principle of fitness may be universal, and the order of nature may be the order of fitness; and again, for all I know to the contrary, all significant resemblances between the phenomena of nature may be due to genetic continuity; but, at the present day, these principles hold no prominent place in the minds of those who deal with the not-living, and their introduction among the principles of science is due to the biologists. Now only a moment's thought is needed to discover how great are the difficulties that attend the application of these principles. What do we mean by the genetic continuity of life? How are we to interpret the facts of embryology? How many perplexing intricacies face us if we undertake, with William Harvey, "to seek the truth regarding the following difficult questions: Which and what principle is it whence motion and generation proceed? Whether is that which in the egg is cause, artificer, and principle of generation, and of all the vital and vegetative operations, - conservation, nutrition, growth, - innate or superadded? and whether does it inhere primarily, of itself, and as a kind of nature, or intervene by accident, as a physician in curing disease? Whether is that which transfers an egg into a pullet inherent or acquired?"

"In truth," says Harvey, "there is no proposition more magnificent to investigate or more useful to ascertain than this: How are all things formed by an univocal agent? How does the like ever generate its like? Why may not the thoughts, opinions, and manners now prevalent, many years hence return again, after an intermediate period of neglect?" 1

As we find embryologists, two hundred and fifty years after these words were written, still vexing thcmselves over the question, Whether is that which transfers an egg into a pullet inhercnt or acquired? - it is clear that we cannot hope for much progress in the investigation of this magnificcnt proposition unless we can determine what we mean by that metaphysical notion, inherent potency.

1 Harvey, "De Generatione," pp. 274-582. 
"By way of escape from the metaphysical Will-o'-the-Wisps generated in the marshes of literature and theology, the serious student is sometimes bidden," says Huxley, "to betake himself to the solid ground of physical science. But the fish of immortal memory, who threw himself out of the frying-pan into the fire, was not more ill advised than the man who seeks sanctuary from philosophical persecution within the walls of the observatory or the laboratory; for metaphysical speculation follows as closely upon physical theory as black care upon the horseman." 1

If, as modest biologists, we were to assert that the biological aspects of the physical sciences are the only basis for rational interest in these sciences, our good friends in physical and chemical laboratories would, no doubt, charge us with arrogance, although I think they must admit that the principles of science, as distinguished from the concrete sciences, are part of biology.

We cannot investigate response to the order of nature without asking what the order of nature is. What are the properties of things and of thought that convince us of its existence? What is this conviction worth? What are the methods by which knowledge of this order is acquired and perfected and extended? How far are these methods and instruments trustworthy? Are any limits to their application known, and, if so, how known?

To all these questions the zoölogist has a peculiar right to ask answers, in addition to the right which he shares with other students of science.

"The Mind, her acts and faculties," says Berkeley, "furnish a new and distinct class of objects, from the contemplation whereof arise other notions, principles, and verities. It may therefore be pardoned if this rude essay doth, by insensible transitions, draw the reader into remote inquiries and speculations, that were not, perhaps, thought of either by him or by the author at first setting out."

Some, who believe they at least are rigorously scientific, may here feel impelled to cry out that these inquiries are not scientific, but metaphysical, and that modern men of science have nothing to do with them. For my own part, I might be disposed to agree with them if the average human mind were, on these difficult 
matters, a tabula rasa; but ignorance and prejudice and education all conspire to predispose us to some form of a priori philosophy, and most men who have not given hard thought to the subject hold fast, consciously or unconsciously, to belief in the universal and necessary conservation of energy, to belief in a necessary law of universal progress or evolution, to belief in the arbitrary and absolute freedom of the will, or to belief in some other a priori notion which they hold necessary and ultimate, or arbitrary and absolute.

"The maxim that metaphysical inquiries are barren of result," says Huxley, "and that the serious occupation of the mind with them is a mere waste of time and labor, finds much favor in the eyes of many persons who pride themselves on the possession of sound common sense; and we sometimes hear it enunciated by weighty authorities, as if its natural consequence, the suppression of such studies, had the force of a moral obligation."

"In this case, however, as in so many others, those who lay down the law seem to forget that a wise legislator will consider, not merely whether his proposed enactment is desirable, but whether obedience to it is possible. For if the latter question be answered negatively, the former is surely hardly worth debate."

"Here, in fact, lies the pith of the reply to those who would make metaphysics contraband of intellect. Whether it is desirable to place a prohibitory duty upon philosophical speculations or not, it is utterly impossible to prevent the importation of them into the mind. And it is not a little curious to observe that those who most loudly profess to abstain from such commodities are, all the while, unconscious consumers, on a great scale, of one or another of their multitudinous disguises or adulterations. With mouths full of the particular kind of heavily buttered toast which they affect, they inveigh against the eating of plain bread. In truth, the attempt to nourish the human intellect upon a diet which contains no metaphysics is about as hopeful as that of certain Eastern sages to nourish their bodies without destroying life."

"Everybody has heard the story of the pitiless microscopist, who ruined the peace of mind of one of these mild enthusiasts by showing him the animals moving in a drop of the water with which, in the innocency of his heart, he slaked his thirst; and the unsuspect- 
ing devotee of plain common sense may look for as unexpected a shock when the magnifier of severe logic reveals the germs, if not the full-grown shapes, of lively metaphysical postulates rampant amidst his most positive and matter of fact notions." 1

Kant has shown, as Berkeley showed before him, that, instead of discovering truth, philosophy has only the modest merit of preventing error, and if men never made mistakes, but always reasoned wisely and acted rightly, we should little need to study the nature of knowledge; but while few men think, all have opinions; and there are certain perennial errors, idols, as Bacon calls them, which find in the mind of man a dwelling-place so congenial that the doctrine of idols bears the same relation to the interpretation of nature as that of sophisms does to common logic.

As we are forced, by the imperfection of our nature, to study the principles of knowledge in order to guard ourselves from error, it makes little difference whether we call the principles of science metaphysical or not.

We speak of physical science, but it would surely be more repugnant to the usage of common specch to call the principles of science physical than to call them metaphysical; for, while the data of science are things known to sense, we must ask, with Berkeley, whether it is not certain that the principles of science are neither objects of sense nor of the imagination; whether they do not arise in the mind itself; whether the sensible world is anything more than the stimulus which calls forth the innate or latent powers of the mind. We assuredly have no sense-organ by which a principle may be perceived, except so far as we have by nature an organ of common sense. If the principles of science are perceived at all, rather than apprehended, they must be perceived by some inner sense, for which we know no sense-organ.

"As understanding perceiveth not, that is, doth not hear, or sce, or feel, so sense knoweth not; and although the mind may use both sense and fancy, as means whereby to arrive at knowledge, yet sense or soul, so far forth as sensitive, knoweth nothing. For, as it is rightly observed in the 'Theretetus' of Plato, science consisteth not in the passive perceptions, but in the reasoning about them."

1 Huxlcy, "Collected Essays," VI., pp. 288, 289. 
Some, who so far agree with Plato, may be led to remind Berkeley that objects of sense are not only first considered by all men, but most considered by most men; and that the possession of opinions may be no evidence of reason.

Truth, he tells us, is the cry of all, but the game of few; and while there may be wisdom in a multitude of counsellors, Huxley reminds us that it is in but one or two of them.

Some may assert that, admitting that we have no sense-organ by which we perceive the relation between a pattering sound on the roof and a shower, the connection between the sound of rain and the falling drops is nevertheless physical and not mental; and that response to the order of nature is no evidence of reason, since we do not attribute judgment to the mimosa, which, stimulated by the falling drops, folds its leaves that the rain may reach its roots.

They may also assert that, if the structure and history of all parts of our own organic mechanism were fully known, we should be able to show that the principles of science are physical; that we apprehend them because our minds are the ones which have survived the struggle for existence; and that these principles are no more than natural selection would lead one to expect; although we must ask whether we find in nature any reason why what we expect must happen; whether natural selection is an efficient cause, or only a generalization from experience; and whether experience is not itself a state of mind. We may point out that hope is not science, and that no one has, as yet, deduced the principles of science from brain anatomy; and we may ask whether, if this were accomplished, the anatomical structure of the brain, and of the other organs which we study by our senses, is not a thing perceived; whether perception is not mental; and whether a thing perceived by sense is not a phenomenon of mind. We may also ask whether proof that our organ of common sense has come about, like our eyes and ears, by the survival of the fittest, would tell us any more about the relation between mind and matter than our eyes and ears tell us now.

I am not able to answer the question whether, in ultimate analysis, the principles of science are physical or metaphysical. I know nothing about things ultimate. I do not know what the 
relation between mind and matter is. I do not know whether the distinction between "things perceived by sense" and "relations apprehended by the mind" is founded in nature or not; but I am sure that natural knowledge is useful to me, that it is pleasant, and profitable, and instructive; and I must ask whether all this does not show that nature is intended.

This introductory summary of some of the topics I shall try to handle in the following lectures shows that these topics are neither few nor simple, nor am I so bold as to think that I can set any one of them on a firm foundation; for, like William Harvey, I do not wish what I say "to be taken as if I thought it a voice from an oracle"; although I hope it may "stir up the intellects of the studious to search more deeply into so obscure a subject."

I shall make no attempt at originality, but shall try to give you some of the results of my own study of the thoughts of others. Bacon tells us indeed that it is seldom in our power to both admire and surpass our author; since, like water, we rise not higher than the springhead whence we have descended; but I cannot agree with him that the attempt to put the thoughts of others in a new dress necessarily leads to the great injury of learning, for we often fail to master the wise thoughts of one who is not of our own times because his turn of words does not fit our point of view.

All I have to say is anticipated in invention and is varied only by the method of treating it. "For," like Montaigne, "I make others to relate (not after my own fantastie, but as it best falleth out) what I cannot so well express, either through unskill of language or want of judgement. I number not my borrowings, but I weigh them. And if I would have made their number to prevail, I would have had twice as many." But I trust that, Bacon notwithstanding, I have neither corrupted the labors of my predecessors nor contributed to the slavery of the sciences.

The lectures which follow have been prepared at different times, and for various reasons; but I hope that, as I have arranged them, they will exhibit unity of purpose, and the logical development of that purpose, which, in a word, is this: To show to them who think with Berkeley, that "it is a hard thing to suppose 
that right deductions from true principles should ever end in consequences which cannot be maintained or made consistent," that, in my opinion, there is nothing in the prevalence of mechanical conceptions of life, and of mind, or in the unlimited extension of these conceptions, to show that this hard thing to suppose is true. 

LECTURE II

HUXLEY, AND THE PROBLEM OF

THE NATURALIST 



\section{LECTURE II ${ }^{1}$}

HUXLEY, AND THE PROBLEM OF THE NATURALIST

All thoughtful students will prize the essays and addresses on Education which make up the third volume of Huxley's "Collected Essays." When written, these were regarded by most readers as special pleas for scientific education; but nothing could be farther from the truth, although the prominence of "science" in their titles gives some ground for this impression. They who read them now, after scientific education has become an assured fact, will find that Huxley shows, here as elsewhere, that he is no radical, seeking to sweep away the ancient landmarks, but an enthusiastic admirer of all that is good in the old, as well as a zealous advocate for the new in education.

While he improves every opportunity to set forth the need for scientific education, he tells the student that he is a man and a citizen as well as a student; and the delights and the discipline of literature and art and history are emphasized again and again, and each essay is a plea for liberal culture; although he never fails to demand the removal of the accumulated ashes, and the rekindling of the pure flame, until the very air the student breathes shall become "charged with that enthusiasm for truth, that fanaticism of veracity, which is a greater possession than much learning; a nobler gift than the power of increasing knowledge."

No one - Huxley least of all - would dream of attributing the "New Reformation" to any one man, and he speaks of himself as "a full private who has seen a good deal of service in the ranks" of the army ranged around the banner of physical science; but the object to which he tells us he has devoted his life - the diffusion among men of the scientific spirit of "organized common sense" -

1 This lecture is part of a Review of Iuxley's Essays, which was printed in the Forum, November, 1895 . 
has made notable progress during his lifetime, and in this assurance he tells us at its end that he "shall be content to be remembered, or even not remembered," as one among the many who have brought it about.

Of all Huxley's essays, those which deal with the development rather than the application of the method of using one's reason rightly in the search for truth are of most value to the student. Among them are the whole of Volume VI., "Hume; with Helps to the Study of Berkeley"; as well as the one "On Descartes' Discourse Touching the Method of Using our Reason Rightly; and of Secking Scientific Truth" (I. iv.), and many others, such as "Possibilities and Impossibilities" (V. vi. I89I), and "Scientific and Pseudo-Scientific Realism" (V. ii. I887).

The opening paragraph of the book on Hume's Philosophy (VI. 57) may be taken as a statement of the purpose of all these essays: "Kant has said that the business of philosophy is to answer three questions: What can I know? - What ought I to do? - and, For what may I hope? But it is pretty plain that these three resolve themselves in the long run into the first. For rational expectation and moral action are alike based upon belief, and a belief is void of justification unless its subject-matter lies within the boundaries of possible knowledge, and unless its evidence satisfies the conditions of credibility. . . . Fundamentally, then, philosophy is the answer to the question, What can I know ?"

Huxley is not drawn into this province by the fierce joy of controversy, nor by any desire to join those who flit forever over dusky meadows, green with asphodel, in vain search for some reality which is not within the reach of all. His motive is the most practical and serious one we know, - " to learn what is true in order to do what is right." This, he tells us, "is the summing up of the whole duty of man, for all who are not able to satisfy their mental hunger with the east wind of authority." The conclusion of the whole matter is that "there is but one kind of knowledge and but one method of acquiring it." This is the melody which runs through all the nine volumes; now loud and clear, now hidden by the minor interest of a scientific topic, or by the heat of controversy or by the charm of literary genius; but always present, and easy - for one who listens - to detect. It is because scientific education helps us to acquire the method of using our reason rightly in the search 
for truth, and not because science is the one thing worth knowing, that he pleads for it so eloquently. It is because the improvement of natural knowledge is conclusive testimony to the value of this method that he devoted his life to the popularization of science. It is because his right to use this method - the right which is also the highest and first of duties - was disputed, that he entered the stormy waters of controversy.

"If I may speak of the objects I have had more or less definitely in view,... they are briefly these: To promote the increase of natural knowleclge, and to forward the application of scientific methods to all the problems of life, to the best of my ability, in the conviction, which has grown with my growth and strengthened with my strength, that there is no alleviation for the sufferings of mankind except veracity of thought and action, and the resolute facing of the world as it is when the garment of make-believe with which pious hands have hidden its uglier features is stripped off."

To what nobler end could life be devoted than the attempt to show us how we may "learn to distinguish truth from falsehood, in order to be clear about our actions, and to walk surefootedly in this life"? If he has succeeded, and every zoölogist who is free to fol. low Nature wherever she may lead is a witness that he has succeeded, - if, as the end of his lifelong labor, intellectual freedom is established on a firmer basis, - this is his best monument, even if the man should quickly be forgotten in the accomplishment of his end. No memorial could be more appropriate than the speedy establishment of that intellectual liberty which is not intellectual license on a basis so firm that the history of the struggle to obtain it shall become a forgotten antiquity.

Huxley's lifelong devotion to the task of teaching the right method of using our reason in the search for truth has been so fruitful that the success or failure of his attempts to teach the application of this method to specific problems is a matter of very subordinate importance.

As he was not only a man and a citizen, but, above all, a naturalist, peculiar interest attaches to his utterances on the problems of biology, although his various essays on this subject differ so much in perspective that their effect upon many thoughtful readers has proved to be practically equivalent to inconsistency. It is easy 
to show that, in this case, as in others, the responsibility rests with the reader and not with the author; but, however this may be, the opinion that his utterances are inconsistent is real and therefore a proper subject for examination. Huxley's frame of mind in I854 is embodied in the essay "On the Educational Value of the Natural History Sciences" (III. ii.), from which I copy the following passage (p. 43):-

"What is the cause of this wonderful difference between the dead particles and the living particles of matter appearing in other respects identical? - that difference to which we give the name of life? I, for one, cannot tell you. It may be that by and by philosophers will discover some higher laws of which the facts of life are particular cases, - very possibly they will find out some bond between physico-chemical phenomena on the one hand and vital phenomena on the other. At present, however, we assuredly know of none; and I think we shall exercise a wise humility in confessing that for us, at least, ... this spontaneity of action ... which constitutes so vast and plain a distinction between living bodics and those which do not live is an ultimate fact: indicating, as such, the existence of a broad line of demarcation between the subject-matter of biological and that of all other sciences."

Between I 854 and the publication of the essay "On the Physical Basis of Life" in I868, natural science advanced with strides which have no parallel, and the "Origin of Species" brought about a revolution in our conceptions of the history of living nature. It is not surprising that Huxley's point of view undergoes significant change, and that a new aspect of nature now excites his interest and absorbs his attention. The establishment of the doctrine of the continuity of life on a firm basis, and the acceptance of the generalization that all living things are related by birth, had given new meaning to the familiar truth that they are all fundamentally identical in structure; and the essay of 1868 deals with this aspect of living organisms. The essay is regarded by many readers both those who look upon it with horror and those who make it the basis of a biological creed - as contradictory to the essay of I 854 ; but I, for one, am unable to find in it any basis for this opinion. Its motive - the truth that "protoplasm is the basis of life"; that "it is the clay of the potter, which, bake it and paint 
it as he will, remains clay, separated by artifice and not by nature from the commonest brick or sundried clod," is no novelty. In fact, the essay is nothing more than a statement in modern terms of the new evidence which modern science furnishes in confirmation of the familiar conviction that, so far as his physical basis is concerned, man hath no preëminence above the beasts; that they all have one breath; that is, the rain on the earth which causes the bud of the tender herb to spring forth; that as for the earth, it giveth us bread; that the vital spark is soon quenched unless it is kept alive by fuel from without; that the living machine must soon break down and wear out; and that then shall return the dust to the earth as it was. Huxley says: "Past experience leads me to be tolerably certain that when the propositions I have just placed before you are accessible to public comment and criticism they will be condemned by many zealous persons, and perhaps by some few of the wise and thoughtful." They who remember the reception of the essay are aware that this expectation was not disappointed, but it is hard to understand why; for its substance, if not its modern language, has been the common property of some of the wise and thoughtful for ages.

I do not see why any one should challenge Huxley's statement that "it seems to me that we are logically bound to apply to protoplasm or the physical basis of life the same conceptions which are held to be legitimate elsewhere. If the phenomena exhibited by water are its properties, so are those presented by protoplasm its properties." We may have practical objections, based on expediency and not on logic, to the further statement that "we live in the hope and in the faith that by the advance of molecular physics we shall, by and by, be able to see our way as clearly from the constituents of water to the properties of water as wc arc now able to deduce the operation of a watch from the form of its parts and the way they are put together." Faith and hope are good things no doubt, and "expectation is permissible when belief is not" (VIII. 1870); but experience teaches that the expectation or faith of the master is very apt to become belief in the mind of the student, and "scicnce warns us that the assertion which outstrips evidence is not only a blunder, but a crime." (III., IV., I50, I880). In order to avoid all danger of adding to the criminal classes it 
is perhaps as well for those who are teachers to keep their faith outside the laboratory as much as possible.

With this qualification I have nothing but approval for the passage quoted, as well as for the rest of the essay. Like Huxley, I hold that we are logically bound to apply to protoplasm the same conceptions as those which are held to be legitimate elsewhere. Without believing, I certainly sce no reason for doubting that all the properties of organisms may possibly be some day deduced from the nature and disposition of their constituent molccules. If I should live to see this proved, I should believe it without remodelling any belicfs I now hold; for most assuredly I do not believe that these activitics are the result of anything else than physical structurc. I simply do not know, and have no belief whatever on the subject, although I wclcome every addition to our knowledge of the properties of the physical basis of life, in the conviction that this knowledge is a necessary condition for progress. I must also insist, however, that nothing secms more obvious to me than that we might study the form of the parts of a watch, and the way they are put together, till the crack of doom, without understanding it in any sense worthy the name. To understand it we must study not only its mechanism and the movements to be deduced from it, but the movements of the carth as well; and then we must study a third thing, - that relation between the two which fits a watch for man's scrvice. I hold that, in this scnse of the word, we can "understand" watches, and that good common sensc forces us to admit not only that the fitness of a watch is real, but that it is the only basis for rational interest in watches. Analogies arc dangcrous weapons, becausc of our fondness for pushing them farther than the facts warrant, and for assuming that rescmblance in one feature involves resemblance in other features. The fact that living things are like watches in their fitness, in their adjustment to the phenomena of the external world, at once suggests many interesting questions with which I have no intention to deal at present. This particular resemblance is obvious, and I hold that whatever may be possible to the zoölogist of future ages, the only method of studying this fitness which is available at the present day is like that which we apply to watches.

Huxley says: "If the properties of water may be properly said 
to result from the nature and disposition of its component molecules, I can find no intelligible ground for refusing to say that the properties of protoplasm result from the nature and disposition of its molecules."

I know no reason why any one should "refuse to say" this, except that "the assertion which outstrips evidence is a crime." When it has been proved, I, for one, shall say it cheerfully; but I cannot forget that we have been taught for two thousand years and more that life is not a property of the physical basis like the properties of water, but a relation, an adjustment between the properties of the organism and of those of the environment, between the changes which take place in the body and those which go on in the world around it; that this adjustment serves to promote the welfare of the species, and that we know nothing comparable to it in water or in anything else except living beings, and their products, such as watches, and spiders' webs, and birds' nests.

The author of our oldest book on zoölogy opens it with the following statement of its purpose:-

"To say what are the ultimate substances out of which an animal is formed . . . is no more sufficient than would be a similar account in the case of a couch. For we should not be content with saying that the couch was made of bronze or of wood, or whatever it might be, but should try to describe its design or mode of composition in preference to the material. . . I It is plain that the teaching of the old physiologists is inadequate, and that the true method is to state what the definite characters are that distinguish the animal as a whole. ... In fact, to proceed in exactly the same way as we should do if we were giving a complete description of a couch." 1

If this is true, if life is not a property like those of water, but an adjustment between properties, it must be clear that no amount of knowledge of any properties of the physical basis except the property of fitness can ever give us a science of life, although it must be equally clear that knowledge of all its properties is a necessary condition for progress. My comment on the essay "On the Physical Basis of Life" is that, while I fully agree with it, I hold with Aristotle that it is "inadequate," although I am quite prepared to admit the possibility that this inadequacy may be due

1 Aristotle, "Parts of Animals," 1. i. 
to my own limitations, and not to the nature of the subject. While I find nothing in the essay which need give any one a moment's "nightmare," I am equally unable to find in it any warrant except "faith" for the dogma that biology - the science of life - now is, or is at all likely soon to be, the study of the physical and chemical properties, or any other property except fitness, of the physical basis.

The partial failure of training in biological laboratories to make naturalists of the students, or to excite in them that interest in the homes of living things which has so often proved a greater delight than art or literature; its failure to stimulate the investigation of those relations between animals and plants and the world around them which constitute life, - has begun to attract attention and to excite comment. Among the many reasons assigned for this failure "microtomes" have occupied a prominent place and have been held to be the seat of the mischief, although no one can treat seriously the assertion that we can have too many or too refined means for research into structure. From long acquaintance with many students and from much discussion with them I have satisfied myself that the belief that our biology (the biology of the present day, and not that of the unknown future) ends with the study of the structure and functions of the physical basis - the belief that biology is "nothing but" the discovery of its physical and chemical properties - has much to do with it. My experience also tells me that the essay "On the Physical Basis of Life" is appealed to as a scientific warrant for this belief, although we have seen that it affirms nothing more than a "hope" for this consummation.

This ground was all worked over before Aristotle's day, and perhaps it may not be too much of a flight of the imagination to inquire what he might have thought of this essay. Do not his reflections in the "Parts of Animals" warrant the assertion that his comment would be something like this? -

"Your natural science interests me more than anything else in your modern world; and your century is distinguished beyond all others for progress in the history of life. I am delighted with this essay, and no other pleasure could compare with that which I should find in a course of study in the properties of living things with the aid of your appliances for research; but are you quite sure 
that the whole case is stated in the essay? While clay is the physical basis of the potter's art, its essence is fitness for the use of man: and what concerns us is not that he uses clay, but that he makes from it now a foundation-brick and now an ornamental coping; now a homely kitchen pot, and now a graceful urn. I have studied your wonderful chronometers until I am 'able to deduce the operations of a watch from the form of its parts and the way they are put together'; but I failed to understand them until I perceived that relation between their movements and those of the earth which constitutes their fitness for man's service. I tried, long ago, to show that something very similar is true of living things. We may sometime be able to foresee or deduce all their actions from their structure, but at present, as in my own day, the only available way to understand them is to study their relations to the world around them.

"My teaching that the essence of a living being is not what it is made of, or what it does, but why it does it, has been rendered by one of your contemporaries into the statement that life is the continuous adjustment between internal and external relations. If this is true, is not the biology which restricts itself to the physical basis, and forgets the external world, like your play of 'Hamlet' without the Hamlet? Is not the biological laboratory which leaves out the ocean and the mountains and meadows a monstrous absurdity? Was not the greatest scientific generalization of your times reached independently by two men who were eminent in their familiarity with living things in their homes?

"You ask, "What better philosophical status has vitality than aquosity?' - and I ask you in turn what better status has volition than vitality? - yet you find the employment of this word 'both useful and justifiable.' You can separate water into its elements and then, by recombining them, you can get water again; and this you may repeat as often as you choose; but can you, as yet, do anything of the sort with living things? When by the methods of the laboratory you have made a living being; when you have made not merely protoplasm, - nor even protoplasm capable of nutrition, growth, reproduction, and contraction, - but protoplasm able to maintain persistent adjustment to the shifting world around it, - then, and not till then, will I admit that my word 
'vitality' ( $\left.\psi v \chi \epsilon^{\epsilon}\right)$ has reached the end of its long career of usefulness.

"I admitted long ago that it is as truly a property of a bird to build a nest as it is a property of water to freeze; but our interest in the nest lies in its fitness for maintaining the species. I hear it said among you that science has nothing to do with the Why, but only with the How; but we can surely give answers to the questions 'Why do men make and buy watches?'- 'Why do birds pursue their prey?' - 'Why do they flee their enemies?' - and 'Why do they make nests?' - answers which are good and sensible, although they are incomplete.

"The naturalists of your day are adding continually to the overwhelming evidence for a truth which was unsuspected in mine - the mutability of species and the continuity of life. If I could now publish a new edition of the 'Parts of Animals,' I should treat with more considcration than they seemed to merit two thousand years ago the views of my contemporaries who held that extermination and survival have a good deal to do with fitness, but I should still contend that the study of fitness is the true aim of biology."

This comment on the current interpretation of the essay on "The Physical Basis of Life" seems to me to be good common sense and therefore good science; and it also seems to me to be a legitimate application of the teachings of the "Parts of Animals."

Huxley makes many references to the problems of biology in later essays, but space will permit us to examine none except the last. In 1894 I find certain Prolegomena (IX. I, I894) in which it is easy to read between the lines clear indications that, notwithstanding the period represented by the essay on "The Physical Basis of Life," Huxley ended as he began, - almost, if not altogether, in the old-fashioned conviction that living things do, in some way and in some degree, control or condition inorganic nature; that they hold their own by setting the mechanical properties of matter in opposition to each other, and that this is their most notable and distinctive characteristic. He says the flora of the rcgion where he writes was in a "state of nature" until three or four years before, when the "state of nature was brought to an end, so far as a small patch of soil is concerned, by the interven- 
tion of man. The patch was cut off from the rest by a wall. In short, it was made into a garden. . . . It will be admitted that the garden is as much a work of art or artifice as anything that can be mentioned. The energy localized in certain human bodies, directed by similarly localized intellects, has produced a collocation of other material bodies which could not be brought about in a state of nature. The same proposition is true of all the works of man's hands, from a flint implement to a cathedral or a chronometer: and it is because it is true that we call these things artificial, term them works of art or artifice, by way of distinguishing them from the products of the cosmic process, working outside man, which we call nature, or works of nature. The distinction thus drawn between the works of nature and those of man is universally recognized, and it is, as I conceive, both useful and justifiable."

I trust that the thoughtful reader will perceive that the legitimate pursuit of this line of reflection leads straight back to the Aristotelian statement, in the essay of 1854 (III. ii. 40), that "to the student of life [as contrasted with the student of physics] the aspect of nature is reversed. Here incessant and, so far as we know, spontaneous change is the rule; rest the exception-the anomaly to be accounted for. Living things have no inertia and tend to no equilibrium."

Many biologists find their greatest triumph in the doctrine that the living body is a "mere machine"; but a machine is a collocation of matter and energy working for an end, not a spinning toy; and when the living machine is compared to the products of human art, the legitimate deduction is that it is not merely a spinning eddy in a stream of dead matter and mechanical energy, but a little garden in the physical wilderness; that the energy localized in living bodies, directed by similarly localized vitality, has produced a collocation of other material bodies which could not be brought about in a state of physical nature, and that the clistinction thus drawn between the works of non-vital nature and those of life is both useful and justifiable.

What this distinction may mean in ultimate analysis I know no more than Aristotle or Huxley; nor do I believe that any one ever will know until we find out. One thing we may be sure it 
does not mean - that the living world is anything but natural; for all men of science must agree with Aristotle ("Parts of Animals," III. ii. I6) that "in all our speculations, therefore, concerning nature, what we have to consicler is the general rule" (not forces, or causes, or necessary laws). "For that is natural zwhich holds good either universally or generally." If we are to understand this fitness which is so distinctive of living things, this must be brought about, not by keeping it locked out of sight as a chamber of horrors, but by bringing it into the bright light of day; by "intending the mind" upon it; by attacking it with Descartes' method of using one's reason rightly for the discovery of truth. Whether this method is or is not aclequate, we shall know when we find out; but we have no other, and the discoveries of Wallace and Darwin give a basis, not for a belief, but for a hope that it may some day prove adequate.

Times are changed since Huxley warned his hearer in 1868 that, in accepting protoplasm as the physical basis of life, he was "placing his foot on the first rung of a ladder which, in most people's estimation, is the reverse of Jacob's and leads to the antipodes of heaven." Nowadlays "Scientific Rip Van Winkle" and "Aristotelian" are the mildest phrases applied to him who holds that life is izore than a basis, - to him who doubts whether the essay states the whole or even the most essential part of the case; and he is lucky if he is not told that he is a "Spiritualist," "false to the spirit of Science"; or at the very least that he is "illogical." In this case he can only say with Huxley (IX. IO, I894) that "if it is urged that the . . cosmic process cannot be in antagonism with that... which is part of itself, I can only reply that if the conclusion that the two are antagonistic is logically absurd, I am sorry for the logic, because, as we have seen, the fact is so"; or, as Aristotle expresses it, it holds good.

My own interest in this distinction is entirely practical and not philosophical. Whatever philosophical basis it may have or may not have, it seems to me that no one can question its practical bearing on the study of biology at the present day and for many ages to come. If it is urged that our knowledge of the external world is destined to be resolved, in the long run, into our consciousness of changes in the physical basis of our minds, and 
that the "external world" to which plants and animals respond is also to be resolved into changes in their physical basis, I am quite willing to admit this possibility; as I am ready to admit that, for anything I know to the contrary, the reality of both the external world and the physical basis itself may consist in being perceived or known, but I hold it unwise to forget that the same daily experience which justifies our confidence in the orderly sequence of external nature also warrants the assumption that their external world is the same as ours. The question whether its reality is ideal or material or both has no more to do with this purely practical confidence than has the presence or absence in a dog or an oak tree of conscious belief in it.

They who hold the faith that science will some day be able to demonstrate, in the structure of the brain, the origin of such actions as writing a review of Huxley's Essays, are quite welcome to their faith; but I hold, as a purely practical matter, that they may find out in a much shorter way why I have written this article; and I also hold that this is likely to be the case for some considerable time. I also believe with Aristotle that the most practical way within our reach of studying that adjustment between the organism and the external world - that fitness - which constitutes life, is to learn all we can about the physical basis and all we can about its fitness; and I hold fast to this purely practical confidence without any faith in the unknown biology of the distant future, and most assuredly without any desire to discount it.

I must ask, however, what reason there is for thinking that belief that my volition is both real and part of the cosmic process is logically absurd.

The greatest of all my many great debts to Huxley is the clear perception that there is no antagonism between belief that all the phenomena of nature, including those of life and mind, are mechanical, and my confidence in the value of my reason. If Huxley is right in the assertion that mechanical principles are nothing more than generalized statements of our experience, - as I am convinced that he is, - and if the widest of all generalizations from my experience is that my volition counts; how can belief in the value of my reason be logically absurd? May not the logical absurdity lie with them who hold that proof that my 
rational actions are no more than might have been expected from the working of the mechanism of my body; would also prove that my reason is "as completely without any power to modify that working, as the steam-whistle which accompanies the work of a locomotive engine is without influence upon its machinery"? 
LECTURE III

NATURE AND NURTURE 



\section{LECTURE III}

NATURE AND NURTURE

THis chapter, which all who have attended my lectures during the last ten years will find familiar, does not deal with the interminable question whether "acquired characters" are inherited, but, granting that this may be the case, it is an attempt to weigh the value of this "factor" in natural history.

Herbert Spencer tells us that the segmentation of the backbone is the inherited effect of fractures, caused by bending, but Aristotle has shown ("Parts of Animals," I. i.) that Empedocles and the ancient writers err in teaching that the bendings to which the backbone has been subjected are the cause of its joints, since the thing to be accounted for is not the presence of joints, but the fitness of the joints for the needs of their possessor.

It is an odd freak of history that we of the end of the nineteenth century are called upon to reconsider a dogma which was not only repudiated two thousand years ago, but was even then called antiquated. "Is there anything whereof it may be said: See! this is new? It hath been already of the old time which was before us."

In this day of laboratories, are we not in danger of forgetting the first principle, so clearly put by Aristotle, that the thing to be explained is not the structure of organisms, but the fitness of this structure for the needs of living things in the world in which they pass their lives? We must be on our guard lest the great discovery that protoplasm is the physical basis of life obscure the truth that what Huxley has called the physical basis is one thing, while what Aristotle has called the essence of life is quite another thing. The physical basis of a locomotive engine is the expansion of steam, but its essence is fitness for the service of man. 
Since we accept the utility of steam-engines as a fact that does not call for explanation, we say we understand them when we have discovered that they do neither less nor more than their mechanical structure would lead us to expect. It is also clear that we might understand them, in this sense of the word, even if they grew, like animals, ready made; although it is equally clear that we should ask, in this case, how they became fitted for human needs; and that we should not admit that we understand them so long as this question is unanswered. So it is, not only with the works of man and other living things, but with the living things themselves. All they do may sometime prove no more than might be expected from their physical basis; but this proof would not show why the things they do are useful to the beings that do them, or to their species.

While there is nothing novel in Herbert Spencer's well-known dictum, that life is adjustment, it should help the modern reader to grasp the significance of Aristotle's teaching, to the effect that the essence of a living being is not protoplasm, but purpose. A living being is a being with properties which are useful to the possessor or to his species.

If, like Paley, I kick a stone, I may change its position, raise its temperature, and bring about other changes that might all be computed from a few simple data. What happens if, instead of a stone, I kick a dog?

In addition to certain changes which are obviously mechanical, like those in the stone, I start a new set of changes which could never be computed from the study of the kick alone. But note this remarkable fact: Show me the dog, and I may be able to tell you what he will do. If he have short hair, a pink skin, a big occipital crest, great cheek muscles, a long mandibular bone, a short nose with little pigment, small red eyes and crooked legs, he will not act like a dog with silky ears, curly hair, large dark eyes, a long, black pointed nose, a bushy tail, and long legs with big feet.

What has the color of a dog's nose or the size of his feet to do with the effect of the kick? Obviously, nothing at all; but the changes in the dog which follow the kick are not its effect, for they might follow an unsuccessful attempt to kick precisely as 
they follow an actual blow. The color of his eyes and the other marks are racial characteristics which show what his ancestry has been; how his parents and more remote progenitors have behaved under similar assaults. With this scientific knowledge of dogs we may conjecture, with some confidence, how this one will behave; but in order to compute his conduct with anything like accuracy, we must have still more information. If his master habitually beat or bully him, he will not act like a dog brought up with more discretion. If he be young, and have not learned independence and self-reliance and distrust of strangers, he will not act like an older and wiser dog; and if eyes and teeth and limbs be failing from old age, his conduct will be still different. If the kick wake him from sleep, he will not act like a dog disturbed while eating; nor will a lost dog, oppressed by a sense of his own friendlessness, act like one whose master is near; nor one assaulted at home like one on strange ground, where he has no rights; nor one attacked in the discharge of his duty like one detected in forbidden pleasure or in theft. The attitude of the assailant, or even such little things as the size of the pupil of his eye, or the contraction of one or another facial muscle, will tell the dog what emotions accompany the kick; and, if I myself be accompanied by a dog, this third party may modify the result without any share in the assault.

What a difference between a kick against a dog and one against a stone! In one case the simple conditions may be stated in few words, and the result may be computed; while in the other, a book would not suffice for the statement of all the facts, and the best science of our day is powerless to compute the result.

I am fully prepared to believe, whenever it is proved, that all the conditions which modify the result are embodied, in one way or another, in the structure of the dog; for I know no reason why we should seek them anywhere else. While there will be plenty of time for a positive opinion when it is proved, I see no reason to doubt that, if the dog's body could be preserved without change, it might, some day in the ages to come, be studied by a naturalist who would be able to tell what conduct would have followed the kick, just as we foresee the effect of an opened valve 
in a steam-engine. If absence of disproof were proof, they who assert that, so far as complexity is in question, the difference between the actions of a stone and those of a dog is merely a difference of degree, not of kind, may have some ground for their belief, inasmuch as no one can say it may not some day be demonstrated. I, for one, see no other reason, than that no one knows, for doubt whether sufficient knowledge might not enable us to foresee or deduce the actions of the dog from the structure of his body; but we have not yet noted the most essential characteristic of his actions. They are significant. They have a meaning. They stand in judicious adjustment to the canine world; and their meaning can never, so far as I can see, be learned by studying his body; for if the meaning which our minds apprehend is embodied in any structure, it must be in our own, rather than in that of the dog. It may be that all that makes up the dog's external world is imprinted in his organization, and that the naturalist of some distant age may be able to there exhibit it, just as the photographer brings out the picture on his negative; but even if this were done, the picture would still remain only an image of an external world which, while more limited, is otherwise practically the same as our own. However this may be, the only way to study the meaning of the dog's actions, at the present day, is to seek it in his environment; in the conditions under which he and his ancestors have lived; nor, in order to study this meaning, need one know whether the dog is aware of it.

While there seems to be good ground for reasonable confidence that the dog is conscious and rational, we know nothing whatever concerning the presence or absence of consciousness in most living things, although we do know that their actions are beneficial to them and such as our reason approves; and that this is the real difference between them and a stone; for while the actions of the stone may, for all I know to the contrary, be useful to the stone, my reason does not approve the statement that this is the case, for it is a matter about which I know nothing.

Science may some day enable us to predict the actions of the dog from the study of his body; but I do not see how we are to understand them without studying the conditions under which he 
and his ancestors have passed their lives. Whether he shut his eyes, throw back his ears, and, straightening his tail, plant his teeth in my leg, or crouch at my feet, with his muscles relaxed, his ears pendent, and his tail trailing on the ground, or, putting his tail between his legs, run away howling, the reason for his conduct is not the pain of the blow, but the importance of escape from the further injury which may follow. The means he adopts are those which have been favorable to this result in the past history of dogs.

The dog, no doubt, knows, just as we do, that, in the ordinary course of events, the attack is a sign of a disposition to do him farther harm; and he also knows he may arrest or avert this by doing something, on his own part, to meet it; but, in case of most organisms, we know only the response and not the consciousness of it.

The kick is a sign of something which may follow, and the actions which do follow are not the effect of the kick, for they are directed or adjusted, either consciously or unconsciously, to an event of which it is only the forerunner. This is what we mean, or, at least, an essential part of our meaning, when we say the dog is alive, while the stone is not. It is possible that the properties of the stone may be useful to the stone, but these words are meaningless to us; although we do know that the properties of the $\operatorname{dog}$ are useful to the $\operatorname{dog}$ or to his species. The changes in the stone. are the effect of the blow; while those in the dog are, in some way, the result of the past history of the dog and of his ancestors ; for, all through this history, violent assaults have been associated with danger of further violence. This difference is as wide as the difference between life and its absence; and the independence of biology as a science is due to its existence. It is what Herbert Spencer means by the statement that life is adjustment, and it is what Aristotle means by teaching that the essence of a living being is not what it is made of nor what it does, but why it does it.

A living thing is a being which responds to the changes which go on in the world around it; for life consists in the maintenance of adjustment between the changes which occur in the external order of nature and those which go on in the living body. Life is response to the established order of external nature; and, so 
far as it is joined to consciousness and volition and reason, it is identical with the practical application of scientific knowledge. If we were sure that all living things are conscious and endowed with memory and volition, as they may be for all I know to the contrary, we might define life as knowledge in use; for the responsive actions of living things are such that our reason approves them as judicious and beneficial. This truth has often found expression in the statement that living things use the properties of the world around them for their own good or the good of their species.

The same thought may be cxpressed by the statement that life is the use of the natural language of signs; for each stimulus to a vital act is a sign with a significance; and the act is itsclf a response to the significance of which, in course of nature, the stimulus is a sign.

To study life we must consider three things: first, the orderly sequence of external nature; second, the living organism and the changes which take place in it; and, third, that continuous adjustment betweęn the two sets of phenomena which constitutes life.

The physical sciences deal with the external world, and in the laboratory we study the structure and activities of organisms by very similar methods; but if we stop here, neglecting the relation of the living being to its environment, our study is not biology or the science of life. Now, whatever its equivalent in the structure of organisms may be, the reality in our own minds behind such words as use, fitness, and response, is not a phenomenon, which can, in this century at least, be weighed or measured or made manifest to sense, but a relation, apprehended by our thinking minds; for beneficial response is one thing, and conscious apprehension of the benefit of response quite another thing. Men who know nothing of the sciences of optics and acoustics profit, like philosophers, by seeing and hearing; as do also the snail and the jelly-fish, whether they know they have eyes and ears or not.

While biology presents endless opportunities for the profitable application of the methods of research which are cmployed in physical science, it also brings before us a new problem, the problem of fitness, which demands new methods of inquiry, and is different from the physics and chemistry of the living body. 
The origin of those useful properties in the employment of which life consists is one of the most fascinating and instructive subjects in the whole range of human inquiry, for to it knowledge itself owes its significance.

While there is so much that we do not know, we do know that the qualities which fit the $\operatorname{dog}$ for his place in nature, and enable him to respond to the changes which go on in the world around him, are, in part, transmitted from his ancestors, while they are, in part, the result of his individual training and experience and education and contact with the world.

The opinion that the effects of his individual history may be transmitted to his descendants, the belief that he may inherit the effects of the experience and education and training of his ancestors, has come to be formulated as "the inheritance of acquired characters"; although I, for my own part, never use this form of words without protest. If any assert that the dog inherits anything which his ancestors did not acquire, their words seem meaningless; for, as we use words, everything which has not existed from the beginning must have been acquired; although one may admit this without admitting that the nature of a dog is, wholly or to any practical degree, the inherited effect of the environment of his ancestors.

Francis Galton, borrowing, I suppose, from "The Tempest," many years ago contrasted the nature and the nurture of living things; and I propose to examine the question whether the nature of a dog or of any other living being is inherited nurture.

This is very different from the question whether the effects of nurture are ever inherited, and $I$ have no desire or intention to discuss this interminable subject; for I find as little value in the a priori arguments of those who hold that "acquired characters" cannot be inherited as I find in Haeckel's assertion that "belief in the inheritance of acquired characters is a necessary axiom of the Monistic creed."

So far as the question is whether the nature of organisms is wholly or to any practical degree inherited nurture, I think it no more than right to say that my own view of the matter was formed many years ago, before the recent revival of discussion, and that, while I have followed this, I have found no reason for 
making any essential change. One morning, some time ago, I found in my mail two papers by naturalists whose well-earned reputation in their own fields would seem to entitle them to speak with authority. In one I read that American indifference to the destruction of our valuable timber is the inherited effect of the long war with the primeval forest which our ancestors were forced to carry on in order to make a home in the new world. The author of the second paper accounts for the great size of the eyes of certain deep-sea fishes by attributing their enlargement to the efforts of many generations to see in "total" darkness.

Conrad Gesner tells us, in his "Book of Animals," that no book is so bad the thoughtful reader may not learn something from it; and if these speculations can be made to point a moral, they are not quite in vain, as they may help us to fix attention on certain first principles which seem so obvious that one would think all must admit them.

Familiar experience teaches that living things are often greatly modified by the conditions to which they are exposed during their individual life, and that the modifications which are thus produced are often useful; for if this were not the case, no beneficial effect could come from training or education. We all know that the congenital or natural powers and faculties of children and of those who grow up in ignorance are very limited, and that it is practice which makes perfect. That judicious use often develops and strengthens the parts which are used is unquestionable and the efficiency of neglected organs often becomes impaired. We are born with a nature that makes the normal use of our powers a pleasure, and while aceticism may despise mere bodily delights, more generous wisdom sees, in the keen enjoyment of normal organic life, and in the discomfort or pain which attends repression, especially in the young, some of those wonderful adjustments which are the very essence of natural science.

While hard work is exhausting, and while the organic machine is easily damaged by abuse, and is, at last, worn out by use, normal use is a condition of its perfect development, and the amount of normal work it may do without deterioration is astonishing. In the highly civilized and self-indulgent, it is much more likely to wear out than to rust out; and nothing could be more short- 
sighted than impatience with the restlessness of children, although no effeminacy can wholly repress the joyous exuberancy of childhood; nor can any thoughtful person fail to see that the impulsc which leads young animals to train and develop their bodies by sports and gambols is adaptive.

All this, and more, is implied by the admission that there is such a thing as nurture; and one of the first questions to present itself, when we consider the matter, is why living things are not like the imaginary Caliban; how they come by a nature on which nurture will stick; for it is plain that, far from being an explanation of nature, nurture is a fact which itself calls for explanation.

The most stable organs may be modified by novel or exceptional use, and the most profound structural changes may be brought about by nurture. After Hunter had fed a sea-gull on grain for a year, he found that the inner coat of its stomach had grown hard, and its muscles had thickened, thus forming a true gizzard, although the sea-gull normally has a soft stomach, as it lives upon the soft flesh of fishes. It is well known that living things are often changed by mechanical influences. The skull of a hornless ram has been found to weigh only one-fourth as much as the skull of a ram with horns; and the wholc configuration of the skull of lop-eared rabbits is altercd by the mechanical pressure of the drooping ears. Hemp seed causes bulfinches and some other birds to become black; and we know, from the observations of many naturalists, that change of food sometimes changes the colors of caterpillars, or even those of the moths which they produce. Many curious cascs of this sort have becn recorded, in birds and insects, and it scems rcasonable to bclieve that, if unnatural food may change the normal colors of a species, the normal colors may thcmselves, in some cases, bc duc to the dircet action of the natural food.

Sometimes the effect of the conditions of life is injurious, sometimes neutral, but often it is uscful to a notable degrec; and it is this usefulness - the power to respond to changed conditions by adaptive modification - which is most worthy of considcration. Cold weather promotes the growth of hair on mammals, and thus protects them from the cold. The muscle which is used grows stronger, and the hand becomes skilful by training. 
Look at a young pine tree and examine its mode of growth. No one can doubt that the long, straight, tapering trunk, and the successive circles of branches, uniformly decreasing in length from the spreading base to the pointed crown, serve a useful end; that the arrangement offers great resistance to storms, exposes a great area of foliage to sun and air, and has other advantages. Now examine the arrangement of the buds. At the tip of the central axis is a terminal bud, pushing straight upwards and building the crown of the tree, and giving off lateral buds which build the branches, and, becoming their terminal buds, leave behind them their own series of lateral buds to repeat the same process. The shape of the tree, so characteristic that it may be identified miles away, is the result of this simple law of growth; and this itself is, in a certain sense, a result of the mechanical conditions of life. The bud at the top of the crown is the only one which is symmetrically placed with reference to the sources of light and air and food, and its symmetry is the result; while the unequal distribution of these conditions of growth results in the one-sided development of the other buds. If the crown of the young pine tree be destroyed by lightning or storm, or by an enemy, a bud that would otherwise have played a subordinate part, may fall heir to its advantages and build up a new crown. If the tree be prostrated by an accident, a new trunk, with its tapering crown, may spring, in time, from a bud far down the trunk.

From one point of view the shape of the pine tree seems to be the effect of the mechanical conditions under which it grows, for unnatural or exceptional changes in these conditions may be followed by abnormal deviations from the type; but from another point of view the type of the pine tree is fixed by the constitution or inherent tendency of the tree itself, and is independent of external conditions; for when a pine, a spruce, and a larch grow side by side under the same conditions, each conforms to its own type. The so-called conditions of individual life are stimuli, without which normal growth does not take place, but they are not determining factors, for the change that follows is due to something prior to and independent of the stimulus.

While it is a matter of familiar experience, in every moment of our lives, that the stimulus under which a vital action takes place 
is one thing, while the character of the action itself is quite another thing, this fact tends from its very familiarity, to slip out of the minds of students; and two views of the nature of the process of development of the living thing out of the germ, which have been argued for centuries, illustrate this tendency. One school of embryologists has long held that the egg or germ produces the living thing in virtue of its inherent potency, or specific constitution, which is, in some way, an embodiment of all that is to be unfolded out of it; while the other school finds, in the stimulus which is given by nurture, in the influence of the external world, and in that which the parts of the segmenting egg and those of the growing organism exert on each other, the explanation of each successive step in the process of development.

Advocates of these two views have regarded themselves as opponents, but except that latent potency is hard to lay hold of, while mechanical conditions readily lend themselves to experiment, I cannot see why there should be any real antagonism; for the evidence that each may be true seems ample. Every change that takes place in the living being, from the beginning to the end of individual life, may be called forth by some mechanical stimulus, either within the body or without; and yet the outcome of the whole process may be no more than exhaustive knowledge of the nature of the germ would lead one to expect.

The gun does not go off until the cap is exploded, but it hits the mark because it is aimed. While the distinction between the stimulus to a vital change and the nature of the change itself is obvious enough in simple cases, we may easily become confused and lose sight of it in handling complicated problems.

A hen's egg will not develop without heat and fresh air, and when these are properly supplied it becomes a chick, although belief that the heat causes the chick is too grotesque for the sane mind; for the production of a duckling from a duck's egg in the same nest proves, if any proof be needed, that while the egg will not develop without incubation, the outcome of the process of incubation is the result of the inherent capacity of the egg itself.

The most notable peculiarity of this inherent tendency or specific constitution of living things is its fitness. The egg not only gives rise to a specific organism, but to one that is beautifully and 
wonderfully fitted for the normal life of its species. What interests us is not that the hen's egg becomes a chick while the duck's egg becomes a duckling; but that one grows into exquisite adjustment to the life of fowls, while the other becomes as admirably fitted for the life of ducks.

In truth, the assertion that the future chick is latent in the egg seems to be no more than a generalized statement of observed facts, and of our confidence that they may be repeated; although it by no means follows that the words, inherent potency, are useless; for they serve a useful purpose if they fix attention on the fact that, while that which was an egg may under certain conditions become a chick adapted for the life of fowls, knowledge of these conditions fails to show us why it should.

Here the stimulus comes from the external world, but the case is just the same when it is internal. The well-known results of castration prove that the normal development of many male mammals and birds depends upon some constitutional stimulus which comes from the reproductive organs to the parts of the growing body; but who can believe this an adequate explanation of the short, sharp horns, the thick neck, and the ferocity of the bull, or of the bright colors, the sharp spurs, and the high courage of the cock?

Have we any reason for a different opinion when the result varies with the stimulus? Under one internal stimulus a bud becomes a jelly-fish, while, under others, it may become a hydranth or a machopolyp or a blastostyle, but the real problem, in this case as in the others, is the production of a beautifully coördinated organism, with the distinctive characteristics of its species, and with exquisite fitness for a life like that of its ancestors.

I showed, some years ago, that a small crustacean, Alphcus hctcrochclis, develops according to one plan at Beaufort in North Carolina, according to a second at Key West in Florida, while it has still a third life history at Nassau in the Bahama Islands; but no one can believe that the influences which cause this diversity in the metamorphosis of Alpheus have anything to do with the final outcome, which is the same in all three places. The case is exactly the same when a cell which would normally give rise to a half or a quarter of the body gives rise to the whole under a clifferent stimulus. 
All the machinery in a great industrial exposition may be started by a single electrical contact, but, however much the discovery of the button may interest us, it helps us but little to understand the result. So it is with living organisms. External conditions press the button, but it takes all the inherent potency of living matter to do the rest.

It is an error to suppose great knowledge is needful for a clear grasp of first principles. "The largest views are not always the clearest, for he who is short-sighted will be obliged to draw the object nearer, and may, perhaps, by a closer and nearer survey, discover that which had escaped far better eyes."

The riches of a great store of information "cannot be spared or left behind, but it hindereth the march; yea, and the care of it sometimes loseth or disturbeth the victory."

Students who are drifting on the sea of facts, with which the modern laboratory has flooded us, sometimes declare that the doctrine of adaptation is antiquated and unscientific and pernicious. They tell us that organisms have many properties which are not adaptive, and that we are often unable to tell whether a property is adaptive or not. Of course this is true. No one supposes that susceptibility to poisons, for example, is adaptive as such, and our knowledge of nature is incomplete beyond measure.

They tell us, too, that many attempts to explain the uses of parts are fanciful and worthless. Unfortunately this is true also, but the logic which makes it a reason for denying the reality of fitness is enough to raise Paley from his grave.

While protoplasm is, no doubt, the physical basis of life, the intellectual basis of biology is adjustment. I should like to see hung on the walls of every laboratory Herbert Spencer's definition, to the effect that life is not protoplasm, but adjustment; or the older teaching of the father of zoölogy, that the essence of a living thing is not what it is made of nor what it does, but why it does it.

It may seem to some that, since capacity for nurture is part of the nature of living things, the difference between nature and nurture is, after all, apparent rather than real. Since what is transmitted from parent to child is not actual or manifest nature, but only its latent potency, or, in other words, a capacity for 
nurture, the question whether nature is inherited nurture or not may seem a matter of words and definitions, rather than a real problem of things; although no one can lose sight of the truth that aptitude for nurture is not, unfortunately, the same as aptitude for beneficial nurture. It is, at most, no harder to acquire pernicious habits than to acquire good ones; no harder to cultivate bodily infirmity, or logical inconsequence, or mental imbecility, or moral obliquity, than to develop and make the best of our facultics and opportunities. He who has passed the plastic age without adding to his nature much nurture he would gladly be quit of, is either more fortunate or less particular than the bulk of mankind. While it may be true that we acquire no nurture but that which our nature permits, it is no less true that this nature permits a wide range of good and bad; and that it by no means binds us to make of our nature all that it permits. All this scems true of other living things as well, and the view that nature is inherited nurture throws no light on the problem of fitness.

Belicf that something is added to our nature by experience, and training, and education, rests on deliberate or unconscious acceptance of some such definition of nature as that which Alciphron gives; and, as the modern zoölogist, who regards nature as the inherited effect of past nurture, scems to lose sight of Euphranor's analysis of this definition, I beg leave to refresh his memory by a short quotation from the old dialogue.

Euphranor. You seem very much taken with the beauty of nature. Be pleased to tell me, Alciphron, what those things are which you esteem natural, or by what mark I may know them.

Alciphron. For a thing to be natural, for instance, to the mind of man, it must appear originally therein: it must be universal in all men: it must be invariably the same in all nations and ages. These limitations of original, universal, and invariable exclude all those notions of the human mind which are the effect of custom and education. The case is the same with respect to all other species of beings. A cat, for example, hath a natural inclination to pursue a mouse, because it agrees with the forementioned marks. But if a cat be taught to play tricks, you will not say these tricks are natural. For the same reason, if upon a plum tree peaches and apricots are engrafted, nobody will say they are the natural growth of the plum tree.

Euph. But to return to man: it seems you allow those things alone 
to be natural to him which show themselves upon his first entrance into the world; to wit, the senses, and such passions and appetites as are discovered upon the first application of their respective objects.

Alc. That is my opinion.

Euph. Tell me, Alciphron, if from a young apple tree, after a certain period of time, there should shoot forth leaves, blossoms, and apples, would you deny these things to be natural, because they did not discover and display themselves in the tender bud?

Alc. I would not.

Euph. And suppose that in a man, after a certain season, the appetite of lust, or the faculty of reason, shall shoot forth, open, and display themselves, as leaves and blossoms do in a tree; would you, therefore, deny them to be natural to him, because they did not appear in his original infancy?

Alc. I acknowledge I would not.

Euph. It seems, therefore, that the first mark of a thing's being natural to the mind was not warily laid down by you; to wit, that it should appear originally in it.

Alc. It seems so.

Euph. Again, inform me, Alciphron, whether you do not think it natural for an orange-plant tree to produce oranges?

Alc. I do.

Euph. But plant it in the north end of Great Britain, and it shall with great care produce, perhaps, a good salad; in the southern parts of the same island, it may, with much pains and culture, thrive and produce indifferent fruit; but in Portugal or Naples it will produce much better fruit with little or no pains. Is this true or not?

Alc. It is true.

Euph. The plant being the same in all places, doth not produce the same fruit - sun, soil, and cultivation making a difference.

Alc. I grant it.

Euph. And since the case is, you say, the same with respect to all species, why may we not conclude, by a parity of a reason, that things may be natural to humankind, and yet neither found in all men, nor invariably the same when they are found? And, as those fruits which grow from the most generous and mature stock, in the choicest soil, and with the best culture, are most esteemed; even so ought we not to think those sublime truths, which are the fruits of mature thought, and have been rationally deduced by men of the best and most improved understandings, to be the choicest productions of the rational nature of man? And, if so, being in fact reasonable, natural, and true, they ought not to be esteemed unnatural whims, errors of education, and groundless prejudices, because they are raised and forwarded by manuring and cultivating our tender minds, because they take early root, and sprout forth betimes by the care and diligence of our instructors. 
The belief that nature is inherited nurture so obviously fails to throw light on the problem of fitness that most of the modern advocates of this opinion claim no more than that nurture supplies the raw material from which natural selection picks out and preserves the good, the useful, the fit; while the bad, the injurious, the unfit, is neglected; but I hope my readers may find reason to ask whether we can be sure that nurture has even this amount of influence.

Living things are preëminently distinguished by what is best expressed by the word fitness; they are adjusted to the world around them in such a way as to force us to believe that the use to which their organization is put has, in some way, been the controlling factor in the production of the organization itself. There is no escape from the belief that the adjustment of the eye to the principles of optics, its fitness for vision, has, in some way, guided and controlled its history; that it has come into existence for seeing, or by seeing, or because it sees. Darwin and Wallace have shown how the use of a part determines its structure through the extermination of the relatively unfit, and the survival of the relatively fit; and I shall try, in another place, to show that this explanation is adequate and satisfactory; but at present we are concerned only with the opinion that the eye has been made, wholly or in part, by seeing.

Since the conditions of life often tend, as we have seen, to modify organisms in such a way as to fit them for these very conditions; since, for example, the trained eye sees more than the untrained eye; since, within certain limits, extra demands upon a muscle make it more able to do the extra work, - may not the specific constitution of each organism have been produced in somewhat the same way? May it not be the inherited result of the influence of the conditions under which its ancestors lived; preserved, it may be, by natural selection? Since the pine tree does not grow up without the mechanical influence of its environment, may not the inherited tendency to which its shape is due have been caused by the direct mechanical action of the environment of past generations?

This is a fair question, and if it were asked by a boy, or by one unfamiliar with the subject, I should welcome it as a sign of intelligent interest; but when it is asked by a naturalist, I can look at it 
only as an indication of culpable ignorance of history; for the hypothesis has been tried and found wanting, and it was rejected as inadequate more than two thousand years ago. To come down to modern times, Wallace, Darwin, Huxley, and Gray, men who were, assuredly, unprejudiced by opposition to the doctrine of the mutability of species, have all told us that they studied Lamarek with all diligence, and found, in his works on this subject, nothing of value.

The views of the Neo-Lamarckians, as I understand them, are somewhat broader than those of Lamarck, but fundamentally the same, and, briefly stated, are as follows: The useful changes which are produced in the structure, habits, instinets, and other faculties of living things, through contact with the world around them, are inherited by their children; and this inheritance, aided, it may be, by natural selection, is an efficient factor in the origin of species, and has gradually adjusted, or given material aid in adjusting, the characteristics of each organism to its needs. Stated still more briefly, it is the doctrine that organic evolution has been brought about, or at least greatly aided, by the inheritance of nurture.

We must now dwell upon a point which seems worthy of attention. Lamarck believed that the useful effects of the conditions of life are the ones which are inherited, and this is the only point worth notice; for if these effects may be indifferently useful, useless, or injurious, they can have no bearing upon the origin of adjustment. In inorganic nature it may be an even ehance, whether an external change be clestructive or preservative, but, when we remember how narrow the range of adjustment of each living being is, the probability that haphazard effects will be injurious or neutral rather than beneficial is prodigious. Even if they are inherited, the effects of nurture cannot cumulate in adaptation except as an accident so improbable that only the most conclusive evidence can prove such an event; unless indeed it can be shown that nurture is beneficial independently of seleetion.

While the chances seem all against adaptive modification by the direct aetion of the conditions of life, I think we may challenge the Lamarckian to show a single species which has been modified to its own disadvantage. There are species which 
have been thrown out of harmony with their environment by some external change to which they failed to respond, and individuals are often put at the greatest disadvantage, or even destroyed, for the good of the species as a whole, but there is not a single example of the disadvantageous modification of a species in a state of nature; although man is able to produce, for his own purposes, such monsters as double flowers, oranges and grapes without seeds, and laying hens which never sit, and thus to demonstrate that species present no inherent obstacle to injurious modification.

The Lamarckians have brought together a long list of examples of the useful modification of individuals by external influences, but no one has tabulated the neutral or hurtful modifications. Still we find reason to believe that organisms do tend to respond, in a favorable way, to certain external changes, and we may fairly call upon the Lamarckian to explain how this useful property was acquired. How, for example, did our muscles acquire the tendency to become strengthened by exercise?

Certain zealous Lamarckians tell us, as if it were a sufficient explanation, that the benefit which comes with the normal use of our muscles is due to the properties of living matter; although I am not aware that any modern naturalist attributes it to anything else. I shall try to show, Lectures VIII. and IX., that the only path in which we can have any well-grounded hope for progress in the explanation of adaptive types takes its departure from that conception of nature which leads us to seek for the origin of the properties which exhibit adaptation in the physical basis of living beings. If any interpret the opinion that the origin of these properties must there be sought as an assertion that it has there been found, I do not see that their impetuosity has any bearing on the point at issue, which here, as in other cases, is the question how the living being comes to exhibit these properties under normal stimuli in such a way as to be adaptive. The increased power to use our muscles, which comes with practice, is, no doubt, due, in the main, to improvement in the nervous system, although normal use is essential to the healthful development of the muscle itself, for its nutrition is promoted by normal exercise, and this result may be imitated by massage or by electrical stimulation. 
It has seemed to some that the pathological hypertrophy of certain muscles under abnormal conditions is evidence of an inherent or innate capacity for adaptive response. For example, pathological conditions which throw extra work upon the heart are often followed by the hypertrophy of the heart itself; and, as these conditions are abnormal or exceptional, it is said that the capacity of the heart for responding to them cannot be due to the survival, in past generations, of those ancestors whose hearts thus responded; but a moment's thought will show that the survival of every mammal does depend upon the power of its heart to respond to increasing demands by increasing efficiency. If the working capacity of the heart did not keep pace with the growth of the body, no mammal could grow up, but growth is a normal process, common to all. No mammal could survive the great changes which take place in the circulation before and at the time of birth, if the capacity of its heart for doing work did not keep pace with the normal changes in the amount of work which is required. As we have already seen, page $\mathrm{I}$, that the responsive activities of living things may be called out by either the normal stimulus or any other which acts in the same way, the pathological hypertrophy of the heart is no more than the past history of mammals would lead us to expect.

Improvement of our muscles under exercise is the outcome of structural adjustments for bringing this useful end about - it is an adaptation; and the heart is as obviously fitted for improvement by use as it is for propelling blood. Exercise fits a muscle for its normal work only so far as structural adjustments for bringing this about already exist, in the brain, and in the nervous system, and in the muscle itself; and the real problem, the origin of the adaptation, is in no way different from that presented by any other structural adjustment.

This is still further illustrated by the fact that while many organs are improved by normal or natural use, abnormal or unnatural use is well called abuse. When our bodies are used in what is popularly called the way they were intended to be used, use is beneficial; but injudicious or excessive training may be as pernicious as neglect.

If we acquire no nurture except that which our nature pro- 
vides for, what are we to say of the acquisition of knowledge? Does this come by nature and not by nurture?

The use of language is an acquired art, and not an innate faculty. Whitney reminds us ("Life and Growth of Language," p. 279) that "though possessing the endowments of a Homer or a Demosthenes, no man can speak any language until he has learned it, as truly learned it as he learns the multiplication table, or the demonstrations of Euclid."

I have tried to show, page 53, that since each vital act is a response to a sign with a significance, life is the use of the language of nature; and it follows, if this phrase is to be taken literally, that life is an acquired art, and not a natural inheritance. I have tried to show, page 9, that this may be the case, since it may be the adaptive mechanism, and not its responsive activity, which is inherited from parent by child.

While no one can come into possession of a language without learning it, and while each acquires the tongue which the accident of birth places within his reach, Whitney reminds us that man learns language because "he possesses, as one of his most marked and distinctive characteristics, a faculty or capacity of specch, - or, more accurately, various faculties and capacities which lead inevitably to the production of speech; but the faculties are one thing, and their elaborated products are another and very different one."

"It needs not only the inward power, but also the outward occasion, to make man what he is capable of becoming."

There is no place for a treatise on human knowledge, but I think that the mind to know truth seems, to most, as essential as truth to be known; for it does not seem good common sense to attribute our minds to either the direct or the indirect effects of knowledge. The general opinion seems to be that our minds come by nature, rather than by nurture, although some, who admit that our minds are ours by nature, strangely suppose that these same minds may be efficient causes of changes in our nature.

It is legitimate and relevant to ask the difficult question whether natural knowledge is the cliscovery of truth, or only the avoidance of error; and there is much to be said in favor of 
Berkeley's assertion, that "the work of science is to unravel our prejudices and mistakes, untwisting the closest connections, distinguishing things that are different; instead of confused and perplexed, giving us distinct views; gradually correcting our judgment and reducing it to a philosophical exactness."

Physical exercise corrects our bodily movements, and reduces them to exactness, by giving us distinct movements, instead of confused and perplexed ones; but we are unable to believe that training gives us any new muscles, and their fitness for improvement by exercise is itself an adaptation which calls for explanation.

If Berkeley is right, as he seems to me to be, and if what we call natural knowledge is no more than the correction of our judgment and its reduction to exactness, it seems clear that knowledge no more accounts for our judgment than training accounts for our muscles, and that physical culture and mental culture are, in this respect, exactly alike.

The modern zoölogist, who reflects upon the phenomena of nature, is forced, like all who have gone before him, to consider anew the ancient and difficult question whether there are "innate ideas"; and, even if his success be slight, and his conclusions indefinite, he may, perhaps, make use of his acquaintance with living things to focus the point at issue, and to show that this may be, in part at least, a matter of words and definitions.

"It is Plato's remark, in his 'Theætetus,' that while we sit still we are never the wiser, but going into the river, and moving up and down, is the way to discover its depths and shallows. If we exercise and bestir ourselves, we may even here discover something." 1

So far as it concerns the zoölogist, the question seems to be this : Is it something we find in our nature, or something we discover in the outer world, which justifies our confidence. in our mental states and in our responsive actions; or may there not be a sense in which each point of view is the true one?

I have tried to show, page 59, that, while the responsive activities of living things do not take place until they are called forth by a proper stimulus, the things thry do under stimulus are no more than their organic mechanism would lead us to expect; and that there

1 Berkeley, "Siris," p. 367. 
need be no necessary antagonism between those who attribute the development of the germ to mechanical conditions and those who attribute it to the inherent potency of the germ itself.

We must now ask whether there is any more necessary antagonism between those who attribute knowledge to experience and those who attribute it to our innate reason.

If this question could be considered in itself, it might not be formidable; but it is hedged about with complications, for some of which the modern zoölogist is responsible, although only a few of the perplexities by which his efforts are beset can be laid to his own charge.

Some zoölogists tell us that the value of our responses is equivalent to confidence in their value, although it is clear that our hearts had value before men studied anatomy, and that digestion was useful to them before they knew that it occurs.

We are also told, in effect, that confidence in the value of our mental states is the same as judicious confidence in their value, although we all know that while one who has led an uneventful life may clread all accidents, a life of adventure may teach that, while some accidents are to be avoided at any cost, the danger from others is trifling. The confidence of the man with little experience is no less strong than that of the adventurer, but it is less judicious; and, as we use words, we do not call it knowledge, but "ignorant" prejudice, or "unreasoning" cowardice, although there is no reason why those who wish should not use words in some other sense.

The question whether experience is or is not the only source of knowledge clearly turns, in part at least, on our definition of knowledge. An infant who has never known a tumble may act as they act who know the danger of a fall, and, if response to the order of nature were evidence of knowledge, it would be obvious that some knowledge is innate, or independent of experience; but it is not our custom to call the blind prejudice of ignorance and the prudent conservatism of the wise by the same name.

Some zoölogists hold that beneficial response to a stimulus is evidence that the stimulus is perceived, and that the response is made with knowledge, and, if this were admitted, it would be clear that some knowledge is innate in living things; for all admit that they may respond to the order of nature without experience, 
although few assert that every response is evidence of knowledge. The impulse to eat when we are hungry is useful, but we do not call it knowledge, although we do give this name to the physiology which tells us when and how far food is beneficial; and we distinguish our innate "moral sense" from knowledge of good and evil.

We are sometimes told by those who are not zoölogists, that, admitting that all the responsive actions of living things may be useful, rational responses may nevertheless be distinguished, by perfectibility, from fixed instincts and blind mechanical reflex acts. It is said that while mechanical responses are persistent, those which are due to knowledge are improvable; but no zoölogist can admit that any property of living things is immutable, or that perfectibility is evidence of knowledge. If the correction of our natural responses and their gradual reduction to exactness by the suppression of those which are confused and perplexed, and the survival of those which are distinct and useful were evidence of knowledge, might not the zoölogist ask, in this case, whether the whole history of the origin of species by means of natural selection may not be a history or the acquisition of knowledge? For it is a history of the acquisition of something which our reason approves, even if we are quite unable to tell, in most cases, whether it is accompanied by mind or not. Whether perfectibility be held to be evidence of knowledge or not, may not the zoölogist ask if the question whether knowledge is or is not innate may not depend upon the answer we give to the farther question whether it is the activity of the organic mechanism, or only the mechanism itself, that is transmitted from parent to child; for if no act is inherited, is it not hard to see how there can be any innate or hereditary knowledge?

No one who has propagated plants from cuttings or seen a seaanemone divide into two, can ask whether a material organism may be multiplied; but they who hold that actions may be transmitted and multiplied by inheritance seem to hold that the law of the conservation of energy does not here hold good. While all who hold that this law is empirical and experimental must stand ready to admit exceptions to it when proved, he must be of bold mind who holds that inheritance is an exception; and we have already, page 59, examined evidence which seems to show that, while the things which living beings do under stimuli are no more than their nature would 
lead one to expect, we have no reason to expect these things to take place in the absence of these stimuli or some equivalent.

If the believer in innate ideas tells us all this is quite consistent with his principles; if, while admitting that he knows no mental act or state without physical concomitants, he assert that the subjective or mental aspects of our responsive actions arise in us because of our inherent nature; if he tell us that the physical concomitants are only the "occasion" of the mental states, or the stimulus under which they arise in our minds, - I do not see why the zoölogist should not agree, and admit that he is, to this cxtent, an intuitionist after the ancient school of Plato; for, so far as science tells us, what we call the "causes" of physical events are no more than "occasions." In physical science all we mean, when we say we understand a thing, is that, certain conditions or occasions being given, it may be counted on with confidence, while we cannot judiciously expect it in their absence.

The question at issue between the Lamarckian and the Darwinian is not whether knowledge arises in the mind in the absence of experience, but whether experience is anything more than the "physical cause," or occasion, or stimulus, in the presence of which knowledge may be expected to arise in the mind, and in the absence of which it cannot reasonably be looked for. If this latter is the casc, is it not hard to see how experience can be either the efficient or the physical cause of the mind in which it arises?

It is hard to calmly ask whether training and education and experience add anything to our nature, for we know that a man educated is different from the same man uneducated. If, at first thought, the question seems repugnant to common sense, we must remember that it is also hard, when looking through a bit of colored glass at a neutral wall, to believe that no color is added, and that the effect is due to negative and passive exclusion by selection or sifting.

The assertion that there is no more redness on the wall, or on the retina, than there was before the red glass was interposed, seems, at first, to be contradicted by our sensations, and repugnant to common sense.

Who can imagine more color outside the limits of a rainbow 
than within the borders of the arch? When the rich colors of evening spread over the glowing clouds, after a dull, gray day, we feel that new wealth of beauty has been added at the end, and that the dying day has taken on new splendors, which were absent in our working hours.

The emotional value of nature, and its moral influence, gain so much strength as the day dies, that the impression of a corresponding gain in sensible value is irresistible, and effort to imagine all this glorious color in the common light of day is vain; yet there are more rays of crimson and red and purple at noonday than in the declining light of evening.

One modern zoölogist has defined life as "memory"; and while Plato's belief that learning may, in effect, be reminiscence seems repugnant to common sense, the zoölogist must hold it an approximation to the truth; although he cannot forget that, so far as natural selection is a physical explanation of the "archetype," or species, of which the germ becomes reminiscent in development, just so far is it a physical explanation of those "forms," or "necessities of intellect," of which the "soul" becomes reminiscent in knowledge; for improvement under experience is, as much as embryonic development, a part of the life history of a normal human being.

We are told that "it is a maxim of the Platonic philosophy that the soul of man was originally furnished with native inborn notions, and stands in need of sensible occasions, not absolutely for producing them, but only for awakening, rousing, or exciting into act what was already preëxistent, dormant, and latent in the soul; as things are said to be laid up in the memory, though not actually perceived until they happen to be called forth and brought into view by other objects."

The zoölogist of our clay may ask whether all that the living organism does may not be latent in its physical organization, ready to be called forth by that "sensible occasion" which we now call a stimulus; although, when pressed for an exhaustive definition of latent potency, he may find no better answer than an admission that these words are no more than a generalized statement of his observations on the actions of living things in general, and on the operations of his own mind in particular, 
joined to an expression of his confidence that these observations may be repeated, and are no more than might have been expected.

When the believer in innate ideas goes farther than this, and asserts that the "forms" or "archetypal ideas" which thus arise in the mind are universal or necessary, the zoölogist must ask him how this is known. Things that are innate, or natural, are not always universal or necessary, for while parental affection is natural, some parents are unnatural.

If the believer in innate ideas asserts that, while our latent or potential sensational knowledge does not become active or manifest until it is called forth by some change in the physical world, we are the ultimate and efficient causes of our own thoughts, the zoölogist must ask, once more, how this is known. If any assert that we know that our thoughts are ours because we can control them, the physiologist, while admitting the control, asks how we know that the way we control them is different from the way we control our visual sensations by going into a dark room, or by shutting our eyes.

All admit that all normal human beings who are not helpless infants, or aged dotards, are able to control their thoughts, and the actions which follow them, in some practical sense of the words.

"If I take things as they are and ask any plain, untutored man whether he acts or is free in any particular action, he readily assents, and I as readily believe him from what I find within. And if man be free, he is plainly accountable. But if you shall define, abstract, suppose, and it shall follow that according to your definitions, abstractions, and suppositions, there can be no freedom in man, and you shall therefore infer that he is not accountable, I shall make bold to depart from your metaphysical abstract sense and appeal to the common sense of mankind."

May not the modest zoölogist, who humbly admits that, while he does not know what the relation between mind and matter is, he would like to find out, also ask, in all sincerity, whether it is he who has perplexed our common sense by defining and abstracting and supposing? May he not also ask, not in a critical spirit, but in order that he may approach this difficult subject without prejudice, whether some of the responsibility for this 
perplexity may not be laid to the charge of those metaphysicians and theologians and philosophers who have told him that actions which are mechanical cannot be free, because they are necessary?

When we control our visual sensations by shutting our eyes, we employ physical means, and while one who is thus enabled to control some of his mental states by physical means may also be able to use these means or not as he chooses, how can this be evidence that his ability is independent of physical means?

Is it necessary to know what the relation between mind and matter is, in order to study mind? As we know what we mean by a plant, and may study botany, without knowing when or how plants become differentiated from animals, and without knowing any absolute diagnosis of a plant, so, too, may we not study knowledge, without knowing when or how it becomes differentiated from instinct and impulse and emotion and unperceived cerebration?

As we use the words, is knowledge equivalent to response, or to beneficial response, or to the improvement of response, or to response which is immediately controlled? Is it not rather the correction of our judgment and its reduction to exactness? Whether knowledge is innate or not, does any one believe that our judgment is ever corrected without a "sensible occasion"? May not the amount of this correction be measured by experience? If what we mean by knowledge is the correction of our judgment under the stimulus of experience, is it not idle to ask whether we may have knowledge without experience, for is not this a contradiction in terms? If any choose to define knowledge as response, and to thus use the word consistently, no one need object, for words are conventional symbols, which change their meaning continually, although no one who uses common words in an uncommon way, without defining them, can hope to be understood.

We are told that if the "Lamarckian factors" are in any degree operative at all, their great function "must be that of supplying to natural selection the incipient stages of adaptive modification, in all cases where, but for this agency, there would be nothing of the kind to select"; but unless these "factors" can be proved to have this function, they are unworthy of consideration as a contribution to the history of adaptive modification. 
I, for one, have found little to interest me in the interminable dispute as to the inheritance or non-inheritance of the effects of the conditions of individual life, because the gist of the whole matter has seemed to me to lie in the deeper question whether these effects are inherently adaptive; and I am forced to ask for evidence that the "Lamarckian factors" can give rise to even the incipient stages of adaptive modification, before I care to inquire whether they are or are not inherited. We are told that, "Inasmuch as we know to what a wonderful extent adaptive modifications are secured during individual lifetime, by the direct action of the environment on the one hand, and by increased or diminished use of special organs and mental faculties on the other, it becomes obvious of what importance even a small measure of transmissibility on their part would be, in furnishing to natural selection ready made variations in required directions, as distinguished from promiscuous variations in all directions."

This a priori argument to prove that the effect of these "factors" must be inherited, because if so, it would be so useful, has seemed plausible to many; but its fallacy is clear, unless the inheritance of nurture can be proved to be beneficial prior to selection; for, while the ways to use our bodies and our faculties are few and definite, the ways to abuse them are innumerable; and the inheritance of all the effects of the conditions of life would seem more likely to lead to cumulative destruction than to cumulative adaptation. Unless the "Lamarckian factors" can be shown to have, prior to selection, a determinate influence in beneficial lines, it seems, on the whole, rather fortunate than otherwise that evidence of the inheritance of their effects is so hard to find.

When bodily structure is improved and developed by use, we find structural adjustments, which themselves require explanation, for bringing this useful end about; nor does there seem to be any reason to believe the case is any different when intellectual and moral improvement are in question. Here, as elsewhere, we are benefited by training and practice and education because our nature fits us for improvement by judicious nurture.

Capacity for individual development and improvement, muscular or mental or moral, under the normal conditions of life, is an adaptation, - by far the most wonderful and admirable of adapta- 
tions, - and the beneficial influence of the "Lamarckian factors," so far as this influence is beneficial, is not an explanation, but a fact, that itself calls for explanation.

Is there any evidence that the influence of nurture is inherently beneficial? If there is not, must we not believe that all its effects, except those which result from preëxisting adaptive nature, will be haphazard, so far as their fitness for the needs of living things is in question? Will they not be identical with what Darwin has called "fortuitous variation"?

It scarcely seems necessary to point out, at this late day, that Darwin's assertion that an event is "fortuitous" is not to be interpreted as belief that it is due to Chance, or that it is out of the chain of natural causation. If, with Aristotle, we say the rain does not fall to make the farmer's corn grow, any more than it falls to spoil his corn, all we mean is that we discover no connection between the physical causes of the shower and the farmer's needs.

Few are bold enough to assert that what we fail to discover does not exist, although all must admit that it explains nothing.

The hypothesis that the rain falls to spoil the farmer's corn is inadmissible, not because we know it to be untrue, but because we find no evidence of its truth, and no value in its practical application. If, in the absence of an adaptive nature, we find no connection between the effects of nurture and the needs of living things, then nurture is fortuitous, so far as we are concerned, as an explanation of adaptive structure.

So far as I can see, there is no a priori reason why nurture might not give rise to adaptive structures, as perfect and admirable as the heart or the eye, although we find, as a matter of fact, that injurious nurture is just as compatible with the system of things as beneficial nurture. Nor is the difficulty at all diminished by the belicf that a necessary law of universal progress or evolution gives to nurture a beneficent impetus; for men of science repudiate the opinion that natural laws are rulers and governors over nature; looking with suspicion on all "necessary" or "universal" laws.

The production of words and sentences and great works of literature and science, by running type through a hopper, is not 
impossible, and, in the long history of living things, adaptive structures may have been produced, without selection, by the fortuitous coincidence of fortuitous variations, but many generations of readers have approved Swift's assertion that the attempt to advance knowledge by turning a crank failed to produce a single learned treatise. The presumption against the production of adaptations, incipient or otherwise, by nurture, seems so overwhelming that we are justified in demanding demonstrative evidence, before we accept this explanation of any adaptation.

They who think that the "inheritance of acquired characters" must be a factor in organic evolution, because we find, in living nature, so much that we cannot yet explain without it, would do well to ask themselves whether it would, after all, help them out of any of their difficulties, even if its occurrence were proved. If this is the case, would they not do well to rest on their oars, and to look about them? For that which they are in search of may prove to be plainly in the sight of those who have the eyes to see.

An English writer has recently formulated what, he tells us, is the Lamarckian answer to this sort of reasoning. He says: "The assimilation and growth of a muscle under stimulus must be ascribed to a fundamental property of protoplasn, which it is not the business of Lamarckians or evolutionists of any other school to explain."

"According to the Lamarckian view all adaptations, at any rate all adjustments concerning whose action and efficacy there is no dispute, have arisen in the same way as the enlargement of a muscle by exercise;" and, whereas "Brooks supposes that these structural adjustments have to be explained, Lamarckians suppose they are merely the fundamental properties of protoplasm."

As this writer also says "Brooks has quite failed to understand the Lamarckian view," I shall not attempt to interpret his belief that such an adaptation as the fitness of the eye for vision, concerning whose action and efficacy there does not seem to be any dispute, is merely a property of protoplasm; and I shall content myself with the admission that he is quite right in asserting that Brooks supposes this fitness has to be explained if it can be. He may be pleased, however, to know that a still shorter way with the Darwinian would be to ascribe all things to the cosmic vapor, and, 
closing our laboratories and observatories, to rest content with the assertion that things like those which distinguish men from turnips are merely the fundamental properties of primitive nebulosity.

If I understand this author, he believes the attributes of all living things are deducible from the properties of protoplasm; and as I myself believe nothing inconsistent with this creed, except that the assertion which outstrips evidence is a crime, I am quite ready to agree with him when he has deduced such things as his logic, for example, from protoplasm; although, if an Americanism may be permitted, his assertion seems a little previous.

After this has been proved, if it ever is proved, it seems clear that it will hold true of the properties of the unsuccessful, the unfit, and the exterminated, as well as those of the fit; and that the problem of fitness will still be as it was.

This problem is real. By recognizing and boldly facing it Darwin and Wallace succeeded in making one of the greatest strides in the whole history of human thought; and I must refuse to admit that any good thing can come from a denial of its existence, or from the creed that it is "universal" and beyond the reach of science. 



\section{LECTURE IV}

LAMARCK 
"Hcaven forfend me from Lamarck nonsense of a tendency to progression, adaptations from the slow willing of animals, etc.; but thc conclusions I am lcd to are not widcly chiffercnt from his; though the mcans of changc are wholly so. I think I have found out (here's presumption!) the simplc way by which specics becomc exquisitely adapted to various ends." - C. DARwin to J. D. HOOKER, Jan. II, I 848 .

"The hypothesis of Lamarck - that progrcssivc changes in species have been produced by the attempts of animals to incrcase the devclopment of their own organs, and thus to modify thcir structurc and habits - has bcen repcatedly and easily refuted by all writcrs on the suljject." - WALLACE: "On the Tendency of Varicties to dicpart indefinitcly from the Original Typc," Fourn. Proc. Linnean Soc.," August, I 858 .

"The Lamarckian hypothcsis has long sincc bcen justly condemned." - HuXLeY: "Collectcd Lssays," II., p. 12, I 859.

"It may be cloubtecl whether Lamarck has not suffered morc from his friends than from his focs." - Huxuly: "Collccted Essays," II., p. 69.

"Lamarck assigncd partly unrcal, partly insufficient causes; and the attempt to account for a progressive change in spccics through the dircct influencc of physical agcncics, and through the appetcncics and habits of animals rcacting upon their structurc, thus causing the production and the successivc modification of organs, is a conccded and total failure." - ASA GRAY : "The Origin of Species by Mcans of Natural Selcction," Amer. Fournal Science and Arts, March, 1860. 


\section{LECTURE IV}

\section{LAMARCK}

CoNCLUSIVE proof of the inheritance of the effects of the direct action of the conditions of life may be found at any moment, for all one knows to the contrary; but even if they who are acquainted with no positive evidence think, with the writer, that a dogmatic assertion, from negative evidence, or in the absence of all evidence, that these effects are not inherited, or cannot be inherited, would be rash and unscientific, they may, nevertheless, be interested in an attempt to test the value of the assumption that they are inherited; admitting, in the interest of clear thinking, that the assumption is reasonable and admissible.

That "inheritance of acquired characters" might produce some system of living nature seems probable; if we start with organisms with such constitution that this "factor" tends to produce modifications which are both adaptive and inherited. That it has not produced, or materially aided in producing, the system which we know seems certain.

Our business is to study that which is, not that which might be; and I shall try to show, as it has been shown again and again, that the adjustments which are exhibited by living things are such as to show that the "inheritance of acquired characters" has played no essential part in their production.

The most extreme Lamarckian must admit that no organism can transmit or inherit modifications produced by the conditions of any life except its own, or that of its ancestors. The nurture of A cannot be transmitted by B; nor can it be part of the inherited nature of B's descendants unless they are also descended from A. How, then, are we to explain such things as the bee's sting or the 
poison of serpents, - things which are useful only in their effect on other animals than the user?

How are we to explain adjustments to the life of other beings than the ones that exhibit the adjustment?

As the serpent which is able to destroy its prey, and the bee which is able to drive away its enemies, have an advantage in the struggle for existence, it is easy to understand how these powers may have arisen through selection; for the bee's sting is a modified ovipositor, and it is used by some of the Hymenoptera both as a weapon of defence, and as an organ for laying the eggs in the tissues of plants, thus exciting pathological changes in these tissues, so that they form galls, and store up, around the eggs, starch to serve as food for the larve which hatch from the eggs. While the origin of these adjustments by selection is quite intelligible, there does not seem to be any other way to account for them.

The white upturned tail of the rabbit is a danger-signal. When disturbed or alarmed on the feeding-ground, which they visit soon after sunset or on moonlight nights, the rabbits make for their burrows, and the white upturned tails of those in front serve as guides and signals to those more remote from home, to the young and fecble; and thus, each following the one or two before it, all are able, with the least possible delay, to reach a place of safety.

Many defenceless insects are protected by their resemblance to dangerous animals, or by some threatening or unusual appearance. The great green caterpillar, known in some of our Southern states as the "hickory-horned devil," has an immense crown of orangered tentacles, which, if disturbed, it erects and shakes from side to side in a manner so alarming that the negroes believe it is more deadly than a rattlesnake.

Who can believe that the inherited effect of the terror it excites has modified the hickory-horned devil? After giving the matter my best and most serious thought, I am unable to imagine any way in which the effect of the upturned tail of the hinder rabbit can act upon the tail of the rabbit in front, or any way by which the sight of the tail in front can modify the tail of the rabbit behind. I find the production of adaptations of this sort by the inheritance of the beneficial effects of use, or in any way except by selection, quite unthinkable. Most pelagic larvæe are transparent, even when the 
adults are beautifully and conspicuously colored, and their bodies are often drawn out into long spines and processes. In the zoea of Porcellana, for example, these spines are so long, as compared with the body proper, that this zoea when seen with a lens reminds one of an oarsman seated in the middle of a very long, sharp-pointed glass boat. Often the spines are strengthened by calcareous ladders formed of long parallel transparent side-strips, like glass threads, with cross-bars at regular intervals. No one who has strained his eyes to discover in a glass of water one of these transparent larva which he has captured, and, after repeated attempts to suck it into a dipping-tube for study under the microscope, fails, because, even when the end of the tube is at last brought directly over it, it catches across the end of the tube and permits the current of water to rush by without drawing it in, can doubt that the transparency of pelagic larvæ is protective, or that the spines and processes keep them out of the mouths of their enemies, just as a long ladder may keep the man who carries it from slipping through holes in treacherous ice.

The way the spines of a zoea, or the ladders of a pluteus, increase what may, figuratively, be called the angle of inciclence, is so clear that few students of marine zoölogy will hesitate to make still farther use of the language of the mathematicians, and to assert that the number of mouths large enough to swallow a pluteus decreases inversely as the square of the angle of incidence.

A naturalist was stopped, in the jungle of Java, by a dense bush, on a leaf of which he saw a butterfly sitting on what he took to be a bird's dropping, and, as he had often wondered at this habit, he approached with gentle steps and ready net, to see, if possible, how the insect was engaged. It permitted him to get quite close and even to seize it with his fingers, but he tells us that to his delighted surprise part of the body remained behind, adhering, as he thought, to the excreta; but looking more closely, and finally touching it with his finger, he found, to his astonishment, that his eyes had been most perfectly deceived, and that what secmed to be the cxcreta was a most artfully colored spider, lying on its back with its feet crossed over and closely pressed to its body, thus producing a living bait for butterflies and other insects so artfully contrived as to deceive a pair of human eyes, even when intently examining it. 
Who can believe that the transparent color and the long spines of pelagic larvæ have been produced by the direct action of these adjustments upon their enemies? When we remember that it is not the spider but the butterfly which is deceived, can we believe that the structure and habits of the Java spider are due, either wholly or in any degree, to the inheritance of the effects of the deception?

The brilliant colors and the pleasant fragrance of the flower are useful to the plant, or at least to its species, since they attract insects, and thus fertilize the seeds, and provide for its perpetuation.

There is no difficulty in understanding how these useful properties of the flower may have arisen by selection; but if they are directly due to the conditions of plant-life, their usefulness must be accidental, for no one has any reason to believe that, prior to selection, these conditions bear any relation to the feelings of an insect; nor can we believe that the visits of an insect will modify the color or odor of a flower in such a way as to suit the insect's taste, except by pure accident; unless, indeed, we choose to fancy that the insect designedly modifies the flower. Even if this hypothesis be admitted, it cloes not help the matter, unless we show that the insect intended to modify the flower in such a way as to benefit the plant.

Some may possibly be able to believe that the use of the color and perfume of the plant in attracting insects is accidental; but can any one believe this of the complicated and delicate machinery for securing insect-fertilization, which we find in the flowers of orchids?

For all I know, the Lamarckian may claim that the visits of insects have, in some way, modified the flower, to its own good, by their mechanical action, by pulling down this part, and by pushing up that, generation after generation, until they have caused adaptive modification in the flower. I do not know how much his ingenuity may be able to make out of this hypothesis; but no one can believe that the hooks and spines, which are so obviously adapted for distributing burrs and seeds, by fastening them to the fur of passing mammals, have been produced by the inheritance of the effects of this sort of mechanical contact; for these structures do not come into use until they are dead; and, most assuredly, dead things cannot transmit "acquired characters" to their descendants. 
When a drop of rain or dew falls on the dead, dry, twisted glume of the animated oat (Avena sterilis), it untwists in such a way as to push like the leg of a grasshopper, and, raising the seed, to send it off with a jump. After the seed has fallen, this process is repeated again and again, until the heavy end, where the seed is placed, falls at last into some roughness in the ground, when the glumes begin to kick and to struggle, and, catching in the grass and roots, or on the rough ground, to push the seed down and to plant it.

The seed is alive, but the glumes are dead and dry, and as completely out of the line of descent to future generations as the dead leaves which drop from a tree.

Is it not impossible to see how the effects of the use of dead things can be transmitted to their descendants? As the properties of the dead glumes are as useful to the species as the dead sticks with which a bird builds its nest are to the nestlings, is it any harder to see how the power to produce glumes which, after they are dead, shall have this useful property, may have arisen through selection, than to understand that an annual plant, which dies before its seeds ripen, may have thus arisen? Many organs have two functions, one accessory to the other. A muscle may be said to serve its purpose when it is used; and the opinion that its continual use has brought about, or helped to bring about, its useful structure, has seemed plausible to many; but consider organs such as the reproductive organs. They are useful to their possessors in many ways. The normal development of a male mammal is arrested if they are removed; so we must believe that this normal development is itself due to some stimulus, which is given, by these organs, to all parts of the body. It may be no harder to imagine the development of the reproductive organs by use, than it is to imagine the development of the muscle in the same way; for these organs are wonderfully adapted for gratifying one of the most intense natural passions of their possessors: but this use is only a means to an end; and it is evident that this end, an offspring, has no existence, as such, when they are used. Their true use is such that it brings to the user care and responsibility and loss of freedom, or even suffering and death.

In many species, sexual union ends the life of the male; while 
the female often dies in the act of laying her eggs. To most animals the impulse to use these organs comes before they can have any experience of its purpose, and the fulfilment of this purpose is separated, by such a length of time, from the act of use, that few animals can possibly have any knowledge of the relation between the two events. When this relation is most clearly understood, we find, instead of a clesire to increase the fitness of these organs for their purpose, a well-marked impulse to enjoy the gratification, without the burden of care and responsibility which comes, in course of nature, when their true purpose is accomplished.

How can the Lamarckian deal with a case like this where conscious effort is ruled out, and where the true use is the benefit of a being which was not in existence as such at the time when the organs were used?

The same thing is true of all our other natural passions and appetites. So far as the actions to which they lead are voluntary, they are attended with pleasure, or else their restraint is attended with discomfort, but we are usually quite unconscious of their real use, until this is discovered by the indirect methods of scientific inquiry. Hunger stimulates the animal to actions which satisfy the calls of hunger; but the mere satisfaction of hunger is of no use, and the real function of the digestive organs, the nutrition of the tissues, goes on in unconsciousness.

The snake's poisoned fang and the bee's sting and the perfume of the flower are useful, but the useful property is an effect on other organisms than the one which exhibits the adjustment. If any one thinks he can see how this sort of adjustment might be brought about, or even essentially aided, through the inheritance, by one being, of the influence of its structure on another being, I cannot reason with him; for I find his thesis quite unthinkable.

It is most important to note that this is not a special plea, based upon exceptional cases. I have called attention to these examples because, far from being exceptions, they are simple and obvious illustrations of a general law, for all of the adaptations of nature are of this sort.

In all cases, the structure, habits, instincts, and faculties of living things, from the upward growth of the plumule of the sprouting seed to the moral sense of man, are primarily for the good of other 
beings than the ones that manifest them; and there is nothing anomalous or exceptional in either the poison of serpents or the organs of reproduction, or in the altruistic moral sense of man.

The conditions of life can stand, prior to selection, in no causal relation to the life of any being except the one on which they act; but no fact in nature is more incontestable than the insignificance of the individual, as compared with the welfare of the species. While this has no existence apart from the series of individuals which composes it, the individual counts for nothing in nature while the species is supreme.

The contrast between what we may call the solicitude of nature to secure the production of new beings, and the ruthlessness with which they are sacrificed after they have come into existence, is a stumbling-block to the Lamarckian, and the crowning glory of natural selection is that it solves this great enigma of nature, by showing that it is itself an adaptation and a means to an end, for the sacrifice of individuals is the means for perfecting the adjustments of living things to the world around them and for thus increasing the sum of life.

The sacrifice of individuals is the means by which variety and diversity in living nature, and the number of living beings, are increased, and, if life is adjustment, as I believe to be the case, the perfection and improvement of the adjustments of living beings is in itself, and directly, an addition to the sum of life.

"And this," says Harvey, "is the round that makes the race [of the common fowl] eternal; now pullet, now hen, the series is continued in perpetuity; from frail and perishing individuals an immortal species is engendered. We therefore see individuals, males as well as females, existing for the sake of preparing eggs, that the species may be perennial though their authors pass away. And it is indeed obvious that the parents are no longer youthful, or beautiful, or lusty, and fitted to enjoy life, than while they possess the power of producing and fecundating eggs, and, by the medium of these, of engendering their like. But when they have accomplished this grand purpose of nature, they have already attained to the height of their being: the final end of their existence has been accomplished; after this, effete and useless, they begin to wither, and as if cast off and forsaken of nature and the Deity, they grow 
old, and a-weary of their lives they hasten to the end. How different the males when they make themselves up for intercourse, and swelling with desire are excited by the venereal impulse! It is surprising to see with what passion they are inflamed, and then how pugnacious they prove. But the grand business of life accomplished, how suddenly and with failing strength, and pristine fervor quenched, do they take in their swelling sails, and from late pugnacity grow timid and clesponding. Even during the season of jocund masking in Venus's domains, male animals in general are depressed by intercourse, and become submissive and pusillanimous, as if reminded that in imparting life to others they were contributing to their own destruction. The cock alone, replete with spirit and fecundity, still shows himself alert and gay, clapping his wings and crowing triumphantly, he sings the nuptial song at each of his espousals; yet even he, after some length of time in Venus's service, begins to fail; like the veteran soldier, he by and by craves discharge from active duty, and the hen, too, like the tree that is past bearing, becomes effete, and is finally exhausted."

Usefulness to one's kind is not entirely a matter of physiology. The wisdom and cunning which long years of conflict with the ways of the world have given to the old wolf is useful to the pack, even after his bodily powers begin to fail, but all must agree with Harvey that, with the loss of all usefulness or value to others, the final end of the existence of the individual, so far as this is recognized in nature, has been accomplished.

While the law that the adaptations of nature serve to promote the welfare of the species, rather than the good of the individual, is as universal as life, it is usually hidden from view because the welfare of the species is, in most circumstances, practically the same as that of the individuals which compose it in each generation, and it is only when the two come into conflict, that the law becomes manifest. When the welfare of the species demands the sacrifice of individuals, the adaptations for securing this useful end are as wonderfully perfect and efficient, and as obvious, as any in nature. Most of them, like the self-sacrificing devotion of the maternal instinct, relate to reproduction, and are so well known that illustrations drawn from other fields may be more novel, and therefore more impressive. 
The possibility that the queen may be lost exposes a hive of bees to great danger, for their social organization requires a queen. The danger is met by a reserve of queen-larva; but the presence in the hive, at one time, of a number of royal larvæ is a new source of danger; for the presence of two reigning queens, at one time, when there is no need to send out a swarm, to found a new hive, would be demoralizing. Queens are developed from larvæ which, under ordinary treatment, would have become workers, and the worker-bees themselves cause the selected eggs to develop into queens, by placing them in large cells which they construct for the purpose by tearing down partition walls, and by feeding the larvæ with an abundance of the highly nutritious food known as queenjelly. The workers tend the royal larvæ with unceasing care, until they are nearly ready to escape, when they gnaw away the wax until it becomes transparent and so thin as to permit ventilation; but if the queen-mother be still in the hive waiting for favorable weather to lead forth a swarm, the young queen is not permitted to leave her cell. The royal guard of workers is reenforced, and the cell is thickened by new layers of wax, perforated by a small opening, through which the prisoner thrusts her tongue, in order that her attendants may feed her; for the old queen is impelled by an implacable instinct to destroy all the young queens she can reach. For this reason the workers use every means to keep her away from the royal cells so long as there is a prospect of swarming. They guard every approach to the cell, and even, forgetting their allegiance, bite and strike and push her, and beat her off whenever she tries to approach. When the old queen has left the hive with a swarm, and one of the young queens is permitted to escape and take her place, she at once seeks to destroy her sisters, but is bitten, pulled, and shoved without ceremony until she is driven off. As the season advances, until it becomes too late for swarming, the impulses of the workers change completely. They cease to resist her, and even incite her to destroy her rivals. She now attacks the royal brood, and stings them to death, one after another, in their cells, while the workers, who are spectators of the carnage, share in the spoil, greedily devouring any food they may find in the cells, and even sucking the fluids from the carcasses before they toss them out of the cells and drag them away. 
Few things in nature are more wonderful than the perfection of the organization, in the hive, for ensuring the presence of one queen, and for destroying all the others; but the provision the royal larva makes for its own murder seems to claim a place among these few.

When a larval bee has completed its growth, and is about to assume the pupa-state, from which it is to emerge as a perfect bee, it spins, like the larvæ of many other insects, a protective cocoon of silk, around its body, but, as this is firm enough to offer some resistance to a sting, and as it might even injure the murderess, the royal larva spins an imperfect cocoon, open behind, and covering only the head, thorax, and first abdominal ring. Huber, who discovered this peculiarity, pointed out that the purpose of the imperfection is to expose the soft abdomen of the royal larva naked to the mortal sting of the reigning queen.

The supreme importance of the species, and the relative insignificance of the individual, are well illustrated by animals which have dropped their adult structure out of their life history, that the perpetuation of the species may be the more assured. The flying butterfly, with its highly perfected sense-organs, leads an active, independent life, which must, according to any standard, be held higher than the helpless creeping life of the blind caterpillar, yet many species of butterflies and moths have lost this most perfect stage in their life so that they cannot wander away from the plants which are best suited for their larvæ, or lay their eggs in any but the best spot. The active, swimming jelly-fish, with its complicated muscular apparatus, its centralized nerve-ring, and its well-developed organs of special sense, is a higher organism than the sessile plant-like hydroid; yet many hydroids which live in places where swimming adults might be swept out into the open ocean far away from any resting-place for the larvæ, have gradually lost the jelly-fish. stage, and they now pass their lives and reproduce their kind, in what was, at one time, their larval or immature condition. From the standpoint of the individual, the degeneration of the jelly-fish into a sexual larva is distinctly a step backwards, marked by disregard of all the best results of a long history of gradual progress and improvement. It is a sacrifice of all that is "best" in the life of the individual for the good of the species. 
Many other groups of animals, notably the crustacea and insects, furnish familiar examples of the loss of the adult structure, and of the broader life which it permitted, in order that the perpetuation of the species may be the more assured. They illustrate, in the clearest way, the supreme importance of the species, and the "indifference" of nature to the welfare of the individual when this welfare is incompatible with the good of the species as a whole. Whether we agree with Weismann that old age and natural death owe their existence to their usefulness or not, they are clearly useful to the species, but it is not necessary to dwell upon the subject, for the examples which we have considered are enough to illustrate the familiar fact that the end which the adjustments of living things bring about is the good of the species, rather than the success of individuals.

All the adaptations of living nature are like the bee's sting and the poison of serpents, inasmuch as their use is exhibited in the lives of other individuals than those which exhibit the structural adjustment. It also seems clear that, even if the direct effects of nurture are both beneficial and inherited, they can have no controlling or notable influence in the production of the sort of adjustments which actually exist, however competent they may be to produce others. Can any zoölogist say, with Lysicles: "Look throughout the universe, and you shall find birds and fishes, beasts and insects, all kinds of animals, with which creation swarms, constantly engaged by instinct in the pursuit of sensible pleasure; and shall man alone be the grave fool, who thwarts and crosses and subdues his appetites, while his fellow-creatures do all most joyfully and freely indulge them?"

Must he not rather, with Euphranor, "infer the excellency of animal bodics from observing the frame and fitness of their several parts, by which they mutually conspire to the well-being of each other as well as of the wholc"?

Certain Neo-Lamarckians assert, however, that while natural selection is the chief factor in the origin of species, it cannot act unless the conditions of life furnish the necessary "variations." I shall examine this proposition in another place, and shall now do no more than to point out that, unless the differences between individuals which are brought about by nurture are useful, prior to 
selection, they are fortuitous, so far as their fitness is in question. The mere fact that species change is no more remarkable than the change of seasons, or the melting of a snowdrift; nor do I suppose that any one believes that any change ever takes place in nature without those antecdent changes which we call physical causes. The thing to be explained is not that species change, but how the changes of species tend to establish harmony between them and the world in which they live. Since many species, many more in fact than all that now exist, have disappeared during the long history of life without leaving descendants; and since the early extinction of the blood of the vast majority of the individual organisms which now exist can be demonstrated, the adjustments of these which survive cannot be accounted for by any law of "necessary" or " universal" progress or evolution.

Living things, like everything else, act in accordance with the laws of matter and motion. Animals, like clouds, grow lighter as they ascend a mountain, and their volume increases as their temperature rises; but changes of this sort are all that external changes can produce prior to selection, unless they tend to bring about responsive modification, or adjustment; and it is begging the question to attribute the origin of this tendency to the inheritance of modifications in the right direction unless some reason why the right ones should be the ones which are inherited is pointed out.

I have tried to show, page 66 , that instead of a preliminary condition to selection, the adaptive influence of the environment, so far as this influence is adaptive, is the result of past selection, and Darwin's explanation of the origin of species by selection is the only one worth considering.

It scarcely seems necessary, at this late day, to point out that by fortuitous variations, Darwin means those differences between individuals which stand in no discoverable relation to the use to which they are turned by selection; for Darwin admits, as every one must, that if there were no changes in the external world we should have no reason to expect any difference between individual living things; but, whatever may be our opinion of the nature of those "variations" which are said to be a necessary preliminary to selection, it seems clear that the effects of the conditions of life cannot be transmitted to future generations, unless the organisms 
which are exposed to these conditions have children. If sterile organisms, which have no descendants, are ever gradually adapted to the conditions of their life, the mechanical effect of these conditions can have no part, direct or indirect, incipient or otherwise, in the production of the adjustment. As the sterile workers of allied species of social insects differ from each other in habits, in instincts, and in anatomical structure, more than the males and the fertile females, this diversity among the workers must have become established after the workers themselves had become sterile.

Whole books have been written on the marvellous fitness of the structure, the instincts, and the habits of the worker of the honey-bee for its life of active industry, a life in which the male has no share, and from which the female is cut off by her seclusion in the depths of the hive, and by her devotion to her own peculiar duties. While the queen and the drones are well fitted for their own parts in the social organization of the hive, these duties are quite simple, and very different from the duties of the workers; and as these latter do not normally have descendants, and as they never, under any circumstances, have female descendants, all the workers are the descendants of queens and not of workers.

Their wonderful and admirable fitness for their own most necessary part in the economy of the hive must, therefore, be inherited from parents who have never been exposed to those conditions to which the workers are adapted; and this adaptation cannot be due to the inheritance of the effect of these conditions; nor can we believe that they are inherited from some remote time, when the workers were perfect females, or when the queens were also workers; for the sterile workers of allied species differ among themselves, thus proving that they have undergone modification since they became sterile.

Here we have a most complicated and perfect adjustment, of marvellous efficacy, to external conditions which are of such a character as to prove that the inheritance of the effect of these conditions has had no part in the production of the adaptation.

This is not a solitary case, but a familiar illustration of a general law; for a little thought will show that most of the 
adaptations of living nature have much in common with those which are presented by a hive of bees.

Some of the members of the floating community known as a siphonophore have mouths and stomachs which furnish an abundant supply of food for all; and this food flows through tubes to the places where it is needed, as water flows to all the houses in a city. Other members of the community do the swimming for the whole, and are especially fitted for this work, which calls for an abundant supply of food to replenish the energy expended in swimming. As they have no mouths they take no food for themselves, but their bodies are supplied with branches from the main canal, distributed, like blood-vessels, in the course of the muscles. Other mouthless members are converted into protecting lids, and others into long poisonous arms for clestroying the prey or for repelling enemies. Others form floats from which the whole hangs suspended in the water, while still others are sexual, male or female, and carry on the work of reproduction.

A colony of siphonophores is both a community and a unit; for while the members are, to a certain degree, independent, they all work together for the common good, and find all the conditions for perfect life nowhere but in the community. A hive of bees is, also, a unit; for while each bee is able to live an independent life, the welfare of all depends upon the integrity of the community, although there is no physical continuity between its members, as there is in a siphonophore. A hive of bees has been called a "state" to distinguish it from communities like the siphonophore, in which the bond of union between the members is organic. As all the members of the siphonophore-community are physically bound together by structural continuity, into an organic unit, it is not possible to prove that some influence does not pass from the bodies of those which are specialized for the capture or the digestion of food, or from the bodies of these which are specialized for swimming, to the germ-cells in the bodies of those which are specialized for reproduction; but the history of the sterile workers among the bees shows that there is no need for imagining the transmission of any such influence, for there is no organic connection between the bodies of the workers and the 
germ-cells in the bodies of the queen or of the drones, and, therefore, no channel through which such an influence can be propagated.

I hope to show, in another place, that natural selection meets all the difficulties we find in the hive of bees. If so, it must also be an adequate explanation of the origin of the siphonophore as well; and the hypothesis that the germ-cells are affected by the conditions of the life of the sterile members of the community is as superfluous in the latter case as it in indmissible in the case of the bee.

While the siphonophore has, on the one hand, many features of resemblance to a hive of bees, it also, on the other hand, resembles the body of an ordinary animal, for this is, also, both an unit and a community. The cells which compose it have a certain individuality, and are specialized for different functions, as are the bees and the members of the hydroid community. Certain cells are set apart, very early in the history of the whole, in mammals long before birth, as germ-cells, destined to become, in time, the ova or the spermatoa of the adult, while all the other specialized cells are out of the line of descent to future generations, like the workerbee. The constituent cells of the body are much more intimately bound together, and are much more dependent for their welfare upon the integrity of the whole, than the bees in the hive, or the members of the siphonophore, and we cannot prove that they are not all in some sort of telegraphic or sympathetic connection with the germ-cells; in fact, there are reasons for believing that a connection of this sort does actually exist; but it is no more necessary to call in its aid to account for the origin of a cellular community, like the body of a dog, than it is to imagine anything of this sort to account for the origin of the worker-bees; and, in this case, the facts must be accounted for without this hypothesis or not at all.

Even if it should be proved, as scems not improbable, that the germ-cells are in some sort of responsive connection with all the other elements of the body, it would still remain true that the adjustments which we find in living things are of such a character as to prove that the "inheritance of acquired characters" has had no controlling influence in their production.

Some may ask whether it may not be possible that, while natural selection is the chief factor in the origin of species, there may still 
be a residuum to be accounted for by the "inheritance of acquired characters." For all I know this may be not only possible, but actually the case. I have never felt the slightest interest in a priori demonstrations of the impossibility of this sort of inheritance, and, for all I know to the contrary, proof of its occurrence may be found at any time, although I know no good evidence of its occurrence. I had satisfied myself, long before the recent revival of interest in the matter, that whether it be a real factor or not, the so-called Lamarckian factor has little value as a contribution to the solution of the problem of the origin of species; and renewed study has strengthened this conviction. 


\section{LECTURE V}

MIGRATION IN ITS BEARING ON LAMARCKISM 



\section{LECTURE $\mathrm{V}^{1}$}

\section{MIGRATION IN ITS BEARING ON LAMARCKISM}

IN the last lecture I tried to show that the adaptations of nature are primarily for the good of the species; that they are beneficial to individuals only so far as these individuals are essential to the welfare of the species; and that they often are injurious or destructive to the individual. I also pointed out that, since this is so, the nurture of the individual does not seem to have any bearing upon the origin of adaptation.

To my mind, no illustration of this great natural law is more simple or more easy to understand, than that afforded by some of the phenomena of migration.

The young salmon which is born in a mountain stream is soon impelled, by something in its nature, to journey downward, often many hundred miles, until it reaches the unknown ocean, where it would discover, if it had faculties for anything so subjective as discovery, that, while it was born in a mountain stream, it was made for life in the great ocean.

It has brought from its mountain home a natural aptitude for eluding all the strange enemies, and for avoiding all the novel dangers, which it finds in this new world; and it leads an active predatory life, fiercely pursuing and destroying its natural, but previously unknown, prey; growing rapidly; quickly acquiring all the characteristics of the adult salmon; and storing up the intense nervous energy, and the muscular strength, which will be needed for forcing its way up the rapids in the mountain torrents, leaping waterfalls, and fighting for its passage, where it had, long ago, darted down with the current. As sexual maturity approaches, some stimulus, which has its origin in the developing

1 Reprinted with slight changes from the Popular Science Monthly. April, I898. 
reproductive organs, impels it to leave the ocean, and, entering the mouth of a river, to journey on and on, often a thousand miles or more, to its sources in the mountains.

At this time the king of fishes, as it is well called, is in physical perfection, with few rivals in beauty, or strength, or fierce energy, or indomitable courage and perseverance; but its strength is soon exhausted in surmounting the obstacles, and in fighting the rivals, which oppose its progress; until, at last, worn and thin, torn and mangled by battle, and battered by rocks and whirlpools, with its skin in rags, its fins crippled and bleeding, and its whole body from nose to tail bruised and emaciated, nothing of its kingly nature remains except the indomitable impulse, which nothing can quench, still urging it onwards, until, if any life remain, it at last reaches the breeding ground.

One of the most magnificent species of this kingly genus was so abundant in the Columbia River, before canning houses had reduced its numbers, that the lower reaches were packed with salmon, while the surface was covered with the drifting bodies of those which had perished in fierce struggles with the crowd: yet there is good authority for the assertion that not a single one ever returns alive from the breeding grounds in the head-waters of the St. Cloud. The whole race is wiped out, utterly exterminated, as soon as it arrives at maturity and physical perfection, in order that the perpetuation of the species may be assured. The whole object and end of the beautifully coördinated body, which is provided for by such admirable and wonderful adaptations, which is built up so slowly and at so much cost, is rapid and total destruction.

The marvellous instinct which leads the young fish to the ocean; the organization and the habits which fit it for marine life - all, in a word, which makes of the salmon our ideal of a lordly fish - is worth nothing as compared with the welfare of generations yet unborn.

Scientific men who are not zoölogists are fond of telling us science has nothing to do with the Why? and is concerned only with the How? but, in zoölogy, it is often easy to discover why an action is performed, while we are very ignorant of the structural conditions under which it takes place. As all the indi- 
vidual California salmon seem to act alike, and as the young salmon has no opportunity for parental instruction, it seems probable that everything it does is the result of its structure, or of such nurture as this structure provides for; but we can safely say that no one now living is at all likely to discover or to predict its migration from the study of its body, although the reason why the migration takes place is obvious.

Whole books, and not a few of them, have been devoted to learned speculations on the nature of the impulse which leads to the migration of birds, and, while the subject is most fascinating, the value of the result has not, in all cases, been commensurate with the labor.

Newton "Encyclopædia Britannica," article Birds says: "We have here more than enough to excite our wonder, and indeed are brought face to face with perhaps the greatest mystery which the whole animal kingdom presents, - a mystery which attracted the attention of the earliest writers, and can in its chief point be no more explained by the modern man of science than by the simple minded savage or the poet or prophet of antiquity. Some facts are almost universally known and have been the theme of comment in all ages and in all lands. The hawk that stretches her wings toward the south is as familiar to the latest Nile-boat traveller or dweller on the Bosphorus, as of old to the author of the Book of Job.

"The autumnal thronging of myriads of water-fowl by the rivers of Asia is witnessed by the modern sportsman, as it was of old by Homer. Anacreon welcomed the returning swallow, in numbers which his imitators of the colder north, to whom the associations connected with it are doubly strong, have tried in vain to excel. The Indian of the fur-countries, in forming his rude calendar, names the recurring moons after the birds of passage whose arrival is coincident with their changes. But there is no need to multiply instances. The flow and ebb of the mighty feathered wave has been sung by poets and reasoned by philosophers, has given rise to proverbs, and entered into popular superstitions, and yet we may say of it still that our ignorance is immense."

While this author does not exaggerate either the interest or our 
ignorance of the life of birds, which goes on in regions which are almost inaccessible and unknown to us, there is no reason to suppose their migrations are any more mysterious than most biological problems; for it is doubtful whether the modern man of science is much more able than the simple-minded savage or the poet and prophet to tell how all the coördinated faculties of a predaceous animal are so thrown into action by the stimulus of hunger as to lead to the pursuit and capture of prey; yet there is no mystery in the physiology of hunger, for while there is much we do not understand, we do know that hunger incites to actions which are responsive, and adapted for satisfying hunger.

So also we may make progress in our study of migration notwithstanding ignorance of the nature of the impulse which excites and regulates it. While I gratefully acknowledge my debt to Newton for many of the facts in this chapter, I an not able to agree with him that there is any peculiar mystery in the subject.

While there is reason to believe almost every bird of temperate and arctic climates is migratory to some degree, those which simply range over a wider area at one season than at another present nothing notable, and it is only in regions which are almost or quite abandoned by birds for part of the year that their migrations attract the attention of students. As many birds which are most valued as food are found in temperate regions for only a short time in spring and fall, sportsmen and hunters and all who pursue them for food have been familiar with the habits of the birds of passage from the dawn of history; but most of the best literature on the subject is by northern ornithologists, and the home of the writer has had and still has great influence upon opinion as to the meaning and origin of the migratory habit.

Scandinavians, and Saxons, and Anglo-Saxons are home-loving folks who, in all their wanderings through this world of care, keep a warm affection for the fatherland, and are much given to the belief that their home is the choicest spot on earth.

A learned professor in the University of Upsala once wrote a book to prove that the Garden of Eden was in Sweden, by the simple and obvious argument that no one who knows the delights of life in that country can believe Paradise was anywhere else. He showed that the Atlantis of Plato, the country of the Hyper- 
boreans, the garden of the Hesperides, the Fortunate Islands, and the Elysian Ficlds are but faint and imperfect reminiscences of the lovely and favored climes of Sweden, from which the Greeks themselves derived their alphabet, their astronomy, and their religion.

To the men of the north home seems the natural refuge of the birds, and, as much of the literature of migration is northern, the birthplace of summer birds has been regarded as their true or natural home, and while their disappearance in winter has seemed to call for explanation, their return in summer has been regarded as a matter of course, for the intense love of home which many exhibit has seemed enough to draw them back when the season of scarcity is over.

It is the "homing" instinct which makes the carrier pigeon so useful to man; and one of the most impressive features of the migratory habit is the definiteness of the journey northwards, which often leads to a particular bush or ledge of rocks. Many species of our common birds lay their eggs year after year in the same nest, although they may spend the rest of the year in the heart of a strange country thousands of miles away, and although the chosen spot may have changed so much that it is no longer a judicious selection.

A bottle in the branches of a tree at Oxbridge in England is known to have been occupied every year, with only one exception, since 1785 , by a pair of blue titmice; and on a hill in Finland, well known to tourists as the most southern point in Europe where the sun may be seen at midnight, a nest is said to have been occupied by a pair of peregrine falcons ever since the visit of the French astronomer Maupertius in $\mathbf{1 7 3 6 .}$ There are other records of similar instances, and while it is not probable that the birds which visit a nest year after year for centuries are the same, the fact is all the more remarkable if they belong to successive generations.

According to folklore some of the summer birds do not go away, but hide near home, and Carus, in his history of zoölogy, refers to several learned writers who, early in the seventeenth century, quoted from the older literature much venerable authority for the belief that the swallows hide through the winter in holes and clefts in the rocks, or even under the water. 
Many writers on migration believe, as they have been told from childhood, that the birds go south to escape the rigors of a northern winter, although little reflection is needed to show that no animals are more thoroughly protected or more indifferent to changes of temperature, and that, while sea-birds are highly migratory, the open waters of arctic seas are little colder in winter than in summer. Nestlings are often killed by cold, and eggs require a high temperature, but old birds are, as a rule, very indifferent to cold.

When this fact is recognized, the prevailing belief is that birds leave their homes in search of food, and scarcity is most certainly an important factor in the origin of migration, but this view of the matter fails to show why, with the whole world to choose from, they do not settle in lands which are habitable the year round.

"The shuddering tenant of the frigid zone

Boldly proclaims that happiest spot his own ";

and to the Esquimaux the return of the birds seems only natural; but to us, who are not Esquimaux, the wonder is not that anything which can get away should do so, but why the birds pass by so many lovely and fertile regions to seek a home in the barren and desolate ends of the earth; and it is plain that, of the two journeys, which make up the migration, the spring and summer visit to northern lands and waters is at least as remarkable, and as well worthy of consideration, as the journey southwards in the fall.

Failure of food in the birthplace is no doubt the chief reason why the migratory birds do not spend the whole year there, and, so far, is a sufficient reason for migration, for no animals are better fitted for moving from regions of scarcity to regions of abundance, but they are little more able than creeping things to establish themselves in new lands which are already well stocked with inhabitants, and, like other animals, they are kept within the limits of their natural habitat by competitors and enemies, rather than by physical barriers, although their power to wander and to overcome physical barriers is without a parallel, for there are few oceanic islands, however remote, which are not inhabited by land 
birds, descended from lost wanderers who, finding these spots unoccupied, have been able to establish themselves.

The list of North American birds which are occasionally found in Europe is a long one, and stray specimens of the gray plover, whose summer home is the shore of the Arctic Ocean, have been found at the Cape of Good Hope, in Ceylon, in Australia, in New Zealand, and in Tasmania. Most of the wanderers are shore birds which make long migrations and, being much exposed to storms, are often driven far out of their path, but this is not always the case, for the great albatross follows ships across the whole breadth of the South Pacific, or nearly half the circumference of the earth. Many birds seem to make their whole journey by a single flight, for some which are common in the West Indies and in Nova Scotia are almost unknown within the limits of the United States, making the whole journey past our borders by water and probably by a single flight. The blue-throat, which breeds in the northern part of Scandinavia, is so seldom found in Europe south of the Baltic that there seems to be good evidence that it makes its whole journey to its winter quarters, which are in the region of the upper Nile, by a single flight.

There is no reason to suppose that all migratory birds inherit the habit from a common source, or that its purpose is always the same; and many birds of prey seem to have acquired the habit of ranging far in winter in search of food, and of following their prey into warmer regions, to return to their birthplace in seasons of reproduction. In thesc cases the birthplace may have been the original home, before the migratory habit was acquired, and the scarcity of food the rcason why it was acquired; and the influence of scarcity in causing migration is well shown by the occasional migrations of certain prolific animals which do not ordinarily leave their birthplaces, although, when these become overstocked, migrations take place, just as colonies are sent out by the people of thickly settled countries to find new room for growth in foreign lands. From time to time, at irregular intervals, great armies of the smaller and more prolific rodents, which usually spend their lives where they were born, are met with on the march from homes where overproduction has exhausted the food; and several of the older American naturalists have described 
the migration of our gray squirrels, although the phenomenon has been most carefully studied in the Norwegian lemmings, whose remarkable migrations have figured in literature for centuries.

The lemming is a small, restless, pugnacious, and very prolific rodent, somewhat like a guinea pig in shape, which, at uncertain intervals of from five to twenty years, migrates from its ordinary home in the central mountains of Norway and invades the low lands so suddenly and in such numbers that it is still popularly believed to drop from the sky, as in the day of Olaus Magnus, who wrote of it in 1490.

The great army of lemmings moves on in a straight line and overruns the cultivated country, swimming the lakes and rivers, and causing so much destruction that a special formula to be used against it was authorized by the church, which attempted to check its march by exorcism, as the Bishop of Montreal once tried to exorcise the wild pigeons. The lemmings journey at night, but their march is not continuous, for they make long stops in fertile spots, where they are even more prolific than they were at home, so that they become more and more numerous, although they are attended by bears and wolves, dogs, eagles, hawks, owls, and other birds and beasts of prey, and although even the cattle and reincleer are said to kill and eat them. The march may last for several years, but as they never go back, but continue to move forwards, they at last reach the ocean, and, attempting to swim this, as they have the rivers in their course, all are drowned, like the rats of Hamlin.

While the migration of the lemmings is undoubtedly due to scarcity, it is difficult to understand its use, for the only ones which profit by it are the ones which have it least developed and stay at home in the mountains, although it may have been useful before the low lands were occupied by man, who now destroys the stragglers and prevents them from scattering and finding permanent homes.

While the determining influence is the scarcity of food which comes from crowding, we have no reason to believe that the lemmings consciously and deliberately set out in search of a new feeding ground, or that they have traditions of the rich low lands which attract them as the wealth and luxury of China and Meso- 
potamia and Asia Minor and the Roman Empire attracted the Tartars and Scythians and Goths from their sterile and desolate northern lands into the fertile homes of southern civilization. Their journeys are no doubt initiated by an unconscious impulse, which, before it brought them into contact with man, was useful in some way to the species; and this seems to be true also of the migrations of certain prolific species of grasshoppers and locusts which, inhabiting sandy and sterile regions, often overflow the limits of their natural home, and invade more fertile regions where they are not usually found. While there is no reason to suppose that these movements are undertaken through a deliberate intention to find new feeding grounds, lack of food is no doubt the chief factor in the development of the migratory instinct of rodents, as well as that of grasshoppers and locusts, which resemble birds in their ability to make long journeys on the wing without rest. The African locust has been met with at sea, in great clouds, more than twelve hundred miles from land, and the species sometimes wanders from its home in Africa to England.

While the movements of rodents and insects show that the search for food has much to do with migration, they lack most of the features which make the migration of birds so remarkable. They occur at irregular intervals, while the movements of birds are almost as regular as the almanac; for while sea-birds seem much exposed to storms, the days of their arrival and departure may be predicted with as much certainty as if they were satellites revolving around the carth. "Foul weather and fair, hot or cold; the puffins make their appcarance at the proper day as promptly as if they were moved by clock work." While the course of the migration of rodents and locusts is determined by conditions so complicated and irregular that they may be called accidental, the northward journey of birds is often directed to a definite spot thousands of miles from the starting-point, and the resemblance between irregular migrations in search of food and the migrations of birds is too imperfect to tell us much about the latter, which is much more like the movements of certain fishes like the shad, which at a definite season enters upon a journey along a definite path to a spot hundreds of miles away, to return again after the purpose of the journey is accomplished. 
Since the number of shad which enter a river in the spring is out of all proportion to its resources as a feeding ground, we might say of them, as we are disposed to say of birds, that they leave their birthplace in search of food; but as they find so little proper food in the rivers that it may be said with almost literal exactness that they make their journey fasting, it is quite plain that this is the wrong point of view; that we must believe that they enter the rivers to lay their eggs, and that we must see in this, and not in the return journey to the ocean, the purpose of their migration.

As the shad is a marine fish which does its eating at sea, and as its visits to fresh water are only for the purpose of reproduction, the numbers which make their way up the rivers bears no comparison to the capacity of the streams for supplying them with food. When it visits our coast in the spring, it enters the mouths of our rivers in great schools, and it journeys up them to a surprising distance; the total length of the journey from the sea to the spawning ground and back again often exceeds a thousand miles, and this journey is made almost or quite without food. Many of them, and among these the largest ones, go on and on until they reach some insurmountable obstacle, such as a water-fall or a dam, or until they reach the sources of the river. Before dams were built in the Susquehanna River, many shad which entered the Chesapeak Bay at the Capes continued their long fasting journey across Virginia and Maryland and Pennsylvania, into the state of New York, and travelled through more than five hundred miles of inland waters before they reached the end of their journey upwards.

Fragments of Indian pottery, stamped with a pattern made by the impression of a shad's backbone have been found in southern New York, and the number of stone net-sinkers which have been picked up in the Wyoming valley shows that the Indians had known and used the shad-fisheries long before the first white settlers found them at work with their rude seines. In the early part of this century, before canals and the dams which supply them were made, there were forty fishing stations beyond the forks of the Susquehanna in northern Pennsylvania, and some of them were worth from $\$ I 000$ to $\$ \mathbf{I} 200$ a year to their 
owners, at a time when money represented much more than it does now. There is a record, which seems trustworthy, of the capture, at a single haul, of ten thousand shad at one of these fisheries, on Fish Island, near Wilkesbarre. Dams across the river have excluded the shad from more than two hundred miles of the course of the Susquehanna, and the profitable fisheries now reach for only a few miles above the boundary of Maryland, while the shad are excluded from many of the best breeding grounds, which are the sandy flats near the shores of streams and the sand-bars which lie in their course. The fishes run up on to these places in pairs, in the early evening, after sunset, and the eggs are thrown into the water while the fishes are swimming about, but they soon sink to the bottom, and develop very rapidly. The average number of eggs is about twenty-five thousand, but a hundred thousand have been obtained from a single large shad.

Few adult shad escape all the dangers of their journey, and these few are so battered and emaciated that they are of no value as food, and they are unknown in our markets, which are supplied with those which are caught on their way upward. The young fishes remain in the rivers until late in the fall, feeding upon small crustacea, the larva of insects, the young of other fishes, and other minute active animals, and they grow to a length of two or three inches by November, when they leave our waters for the ocean.

The shad is a marine fish which has gradually acquired the habit of depositing its eggs in fresh water, out of the reach of the innumerable enemies which abound on the shoals and sand-bars of the seashore. As the eggs are abandoned by their parents as soon as they are laid, prolonged residence at the breeding place is not necessary, and the shad has thus been able to utilize localities which supply no proper food, and are unfit for prolonged residence. If it were compelled to incubate its eggs and to guard and protect and feed its nestlings like a bird, it would have been restricted to some breeding place where conditions are favorable to a more prolonged residence, and we should then feel something of the same tendency to call its birthplace its true home that we have in the case of birds. We should refer the migration to this place as the starting-point, and should try to find some reason why they spend part of the year elsewhere. 
Most animals owe their existence to the occurrence, in their natural home, of all that their life requires, but the power to traverse great distances at great speed, and to pass over all the barriers of land and water, joined to their indifference to changes of temperature, permits birds to divide their time between two widely separated regions; and whether the choice be conscious or unconscious, the breeding places of migratory birds are selected on account of their safety and not because they furnish all that is needed for a permanent home.

If we believe, with Professor Marsh, that the power of flight was acquired by birds after they became arboreal, we must look for the ancestral home of the migratory birds in the great tropical and sub-tropical forests, where arboreal reptiles and arboreal mammals still abound, nor can we believe the great armies of northern birds which find abundant food in southern lands in winter, are driven out by scarcity on the approach of spring. Enemies are numerous in the tropics, but no animals are more alert, or have sharper senses, or better means of escape, than birds, and, trusting to their powers of flight, and their quick sight and hearing, they venture into danger with confidence, for the great charm of birds to us is the fearlessness with which they approach man, who is the most dreaded enemy of all other vertebrates. But while this is eminently true of adult birds, its opposite is true, in even greater degree, of nestlings; for no animals are at the same time more helpless and more exposed to danger than many young birds, while the exposed eggs are of course absolutely helpless, and very tempting and attractive to enemies, although there is no group of animals in which the safety of the eggs and young is more important. As their eggs are very large and heavy, a high birth-rate is incompatible with flight, and the preservation of each species imperatively demands that every egg shall be cared for with unceasing solicitude; for while in other animals increased clanger to eggs or young may be met and compensated by an increase in the birth-rate, the birth-rate of bircls cannot be much increased without a corresponding restriction of the power of flight. Every one knows how quickly birds may be exterminated by the destruction of their eggs or young, and the low birth-rate of all birds of power- 
ful flight is a sufficient reason for migration, for at the same time that their fitness for flight limits the birth-rate, it permits them to seek nesting places beyond the reach of their enemies; and as there is rigorous selection of the nestlings which are born in safe nests, it is easy to understand how the instinct has been gradually acquired by selection, and how, as it has become more and more firmly fixed, and as the safety of the eggs and young has become assured by the remoteness and isolation of the nests, the birth-rate has been still more reduced, and the power of flight still more extended. Many sea-birds, which make their nests on desolate rocks in mid-ocean, lay only a single egg each year and exhibit the power of flight in its highest perfection. The power of the storm-petrel to wander is as boundless as the ocean, and while it lays only a single egg, there is reason to believe that it is the most prolific of all birds, for the number of individuals is said to be greater than in any other genus.

We cannot believe that all migratory birds inherit the habit from some common parent which was migratory, nor is it probable that, in all cases, it owes its origin to the same influences; but if the view here advanced be correct, we must believe that, in most migratory birds, it has been brought about by the needs which arise in connection with reproduction, and not by the supply of food, and that the winter home in tropical and subtropical regions, and not the birthplace of modern birds, must be regarded as the original starting-point for the migratory habit.

While Wallace was the first to recognize the importance of selection in the formation of this as well as other habits and instincts, he seems to regard selection alone, without the assistance of geological changes, as inadequate to explain all the facts of migration. He says: "It appears to me probable that here, as in so many other cases, survival of the fittest will be found to have had a powerful influence. Let us suppose that in any species of migratory birds, breeding can as a rule be only safely accomplished in a given area; and farther, that during the greater part of the rest of the year sufficient food cannot be obtained in that area. It will follow that those birds which do not leave the breeding area at the proper season will suffer, and ultimately become extinct; which will also be the fate of those 
which do not leave the feeding area at the proper time. Now if we suppose that the two areas were, for some remote ancestor of the existing species, coincident, but by geological or climatic changes gradually diverged from each other, we can easily understand how the habit of incipient and partial migration at the proper season would at last become hereditary, and so firmly fixed as to become what we term an instinct. It will probably be found that every gradation still exists in various parts of the world, from a complete coincidence to a complete separation of the breeding and subsistence areas, and when the natural history of a sufficient number of species is thoroughly worked out, we may find every link between species which never leave a restricted area where they breed and live the whole year round, to those other cases in which the two areas are absolutely separated."

Modern zoölogy owes its basis to the work of Wallace and Darwin on the distribution of birds, which, in their hands, has led to a revolution in our conceptions of nature, and has given so much weight to all their utterances on the subject that no one would venture to differ from them inconsiderately, although, when we try to interpret the language which Wallace here uses in the light of his other works, it seems very doubtful whether he has carcfully weighed the words in which he here states that "the habit of incipient and partial migration" may "at last become hereciitary." We must also bear in mind that migration and distribution are distinct phenomena, and that while the geographical distribution of birds shows clear indications of the effect of past geological changes in the distribution of land and water, migratory birds, like other birds, are kept from invading other provinces than their own by competitors and enemies, rather than by geographical barriers. As so many birds move towards the poles of the earth to lay their eggs, and towards the equator to spend the winter, the view that their breeding area and their subsistence area have gradually become widely separated by changes of climate seems probable at first sight, but this rule is not universal, for many of the great breeding grounds of sea-birds are in temperate or tropical waters. The petrels and albatrosses, terns, gulls, and many other birds pass most of their lives scattered over the 
surface of the ocean, but this affords no nesting place, while the wastes of water which keep carnivorous mammals and reptiles and other enemies of nesting birds from approaching the remote and desolate rocks and sand-bars of the open ocean, are no obstacle to them. These spots are so secure that birds born in them are much more likely than those born on the shores of inhabited lands to survive, so that it has come about that all the modern members of these groups are descended from ancestors who shunned the dangerous nesting places, not because acquired characters have become inherited, nor because their feeding ground and their nesting places have been drawn apart by geological changes, but because those which did not instinctively seek safe places for the few eggs which are all that their fitness for continuous and rapid flight permits have been exterminated. These birds now gather from all parts of the ocean, on the few widely scattered rocks and islands where their young are safe, and the periodic assemblies of innumerable multitudes of wandering sea-birds in their "rookeries" are true migrations, for they are as regular as the almanac in the time of arrival and departure, although their feeding ground is almost as extensive as the ocean, and although the food-supply has nothing to do with their movements, and although they do not reach the rookeries by a single path.

In this case the needs of reproduction are the controlling influence, and the site of the rookery has been fixed by its safety; and while it is difficult to say how far the birds are guided by experience of the danger of other places, the well-known tameness of sea-birds in their breeding places, and their apparent ignorance of the existence of enemies, scem to show that they are quite unconscious of the advantages of the chosen spot, and that they resort to it automatically or naturally, since they owe their existence to its isolation and its safety.

Zoölogists are far too ready to resort to the boundless fields for speculation which geology affords, and Crotch has gravely suggested that the migration of the lemmings, and their death in the waters of the ocean, may be due to their efforts to reach the lost Atlantis which their ancestors inhabited during the Miocene period; although this opinion has no better basis than the belief of Olaus 
Magnus that they rain down from the clouds, where they are developed from decomposing exhalations impregnated with the semen of rats.

It is easy to understand how birds near the northern limit of their range may invade the territory of those whose home is a little further south, and compete with them for food as this becomes scarce on the approach of winter, and how this movement spreads until all the members of the species are involved, although many of these might have been able to satisfy all the necessities of life for some time longer in their breeding grounds, if they had been undisturbed.

We have noted that this has commended itself to northern naturalists as a sufficient reason for the acquisition of the migratory habit, and that the fondness for their birthplace which is so strongly developed in birds has been thought enough to draw them back; but the love of home is itself a result of natural selection, and the necessity for finding safe places for the eggs and young enough to account for the origin of migration without the aid of geological changes.

Even if we know little as to the means by which birds find their way over land and water, we know as a fact that they are able to do so; and we also know that the instinct which leads them to seek safe places for their nests is so strongly implanted in their nature that centuries of domestication weaken it but little, for it is still as strong in the guinea fowl and the turkey and the hen as it is in wild birds. As birds of powerful flight have a range of choice in the selection of places for their nests which is almost as wide as the earth itself, it is not surprising that the continual destruction of those born in the least safe nests has at last resulted in the survival of the ones which build their nests thousands of miles away from their ancestral home.

While most writers on the subject have thought that migration had its origin in an annual journey which, while short, was definite for all the members of the species, and while they have felt forced to call in the aid of geology to account for the gradual separation of the two termini, and the length of the journey from one to the other, the hypothesis of geological change seems gratuitous and unnecessary, since the known liabits and instincts and needs of 
the birds are, in themselves, a sufficient explanation of all the broader and more general characteristics of migration.

It seems much more simple, and much more consistent with our knowledge of the past history of living things, in general, to believe it had its origin in an intense but geographically indefinite impulse, which led birds to scatter at the breeding season, and to hunt out safe hiding places for their nests, and that, as enemies also improved in power to find the most accessible nests, the instinct gradually shaped itself into definiteness through selection and extermination, until, at last, safe breeding grounds far away from home, and far away from the enemies which there abounded, have become established, and until many species and all the surviving members of each species have come to share the impulse to resort to these selected breeding places on the approach of the period of sexual excitement, and to follow the same path between points far apart; that the increasing safety of the eggs and young has permitted a low birth-rate, and the improvement by selection of the power of rapid and long-continued flight; and that this has, in its turn, permitted the migration to become longer and longer, and more and more protective to the eggs and young.

The history of migratory birds has been long and complicated; and there has been time for great changes in the distribution of land and water, and for changes of climate, and these have, no doubt, left some permanent impression on the habits of birds.

They have not eluded all their enemies, for predaceous birds and their prey are found together in both the summer and the winter homes. New ways to escape enemies and new ways to find food are as important as they ever were, and birds undoubtedly have capacity for improving by experience and for forming new habits.

All these influences have, no doubt, had and still have, their effect on migration, so that the history of the subject is very complicated; although it seems clear that its broader outlines admit of explanation by natural selection without recourse to geology or to the inheritance of the direct effects of nurture.

In conclusion I wish to remind the reader that our present interest in migration lies in its value as an illustration of the general law that the adaptations of nature are for the good of the species and not for the benefit of the individual. This law 
is universal, but since the welfare of the species is usually identical with that of the constituent individuals it is not obvious unless the good of the species demands the sacrifice of individuals.

Long journeys are hazardous. Every California salmon which enters upon the long journey to the breeding ground is destroyed, and the whole race is wiped out of existence for the good of generations yet unborn. Very few shad ever return to the ocean, and storm and accident and ruthless enemies work their will on the migrating birds and decimate them without mercy, yet the dangerous return to safe breeding grounds still goes on in order that children which are yet unborn may survive to produce children in their turn.

The safeguards which nature throws around eggs, and infants, and immature animals, and the indifference to the fate of the mature animals which seems to be exhibited by the influences which have shaped species into fitness for their environment, are facts which must never be lost sight of; for if we forget them, our attempts to understand the history of the properties of living things or the meaning of our own nature are certain to mislead.

Transition from the migration of the salmon to the altruistic moral sense of ethical man may seem abrupt, yet the two subjects may not be so far apart as they seem, if the natural attributes of every living thing are primarily for the good of others, as I have sought to show in the last two lectures.

The fish owes its existence to the migratory impulse, which is therefore useful, although it is not useful to the fish that migrates. It has a utilitarian basis and a utilitarian history; but if the salmon were enlightened, its actions would exhibit enlightened self-sacrifice and not enlightened selfishness.

Many good and thoughtful people hold that proof that our moral sense has had a natural history would have very dreadful consequences; that it would show that duty is not duty, right and wrong neither right nor wrong, and that the significance man has attributed to this part of his nature a mistake.

I cannot believe anything so beneficial and wholesome as the increase of natural knowledge can lead to disaster, and while I do not suppose my own inability to see why these dreadful consequences should follow will count for much, this inability is 
real; for while I am convinced that the moral sense owes its existence to its utility, I fail to see what bearing its history has on its significance or its value.

They who perceive that all the nature of living things is primarily for the good of others, and that the poison of serpents and the ferocity of the tiger are as free from selfishness as the industry of the bee or the mother's love for her child, can no longer wonder if something in our own nature should impel us to acts which are not to our personal liking or advantage; nor need they fear lest the discovery of the natural history of the moral sense may destroy its value.

Should it not rather "seem to follow that reasonable creatures were, as the philosophical Emperor observes, made one for another; and, consequently, that man ought not to consider himself as an independent individual, whose happiness is not connected with that of other men; but rather as a part of a whole, to the common good of which he ought to conspire, and order his ways and actions suitably, if he would live according to nature"? "Will it not follow that a wise man should consider and pursue his private good, with regard to, and in conjunction with, that of other men? though, indeed, the sympathy of pain and pleasure, and the mutual affections by which mankind are knit together, have been always allowed a plain proof of this point; and though it was the constant doctrine of those who were esteemed the wisest and most thinking men among the ancients." 1

1 Berkeley, "Alciphron," I. I6 and II. I3. 



\section{LECTURE VI}

ZOÖLOGY, AND THE PHILOSOPHY OF EVOLUTION 
"I have nothing to say to any Philosophy of Evolution. . . A Attempts to construct such a philosophy may be .... useful, but in my judginent they are .... premature." —HuXLiY: "Collected Essays," V. 


\section{LECTURE VI-- PART I}

\section{ZOÖLOGY, AND THE PHILOSOPHY OF EVOLUTION}

THE facts given in the last two lectures seem to show that we cannot expect much from the "Lamarckian factors," even if they should prove to be factors; and while this impression may be wrong, it seems to be the rational frame of mind until it has proved wrong.

He who follows the current literature of zoölogy finds that many writers assure him, in effect, that the years which Darwin and Wallace gave to hard labor on the problem of species were thrown away, since all they tried to find out by hard work might have been deduced from the Philosophy of Evolution.

We were warned, long ago, that "whoever, unable to doubt and eager to affirm, shall establish principles, and, according to the unmoved truth of these, shall reject or receive others, . . . he shall exchange things for words, reason for insanity, the world for a fable, and shall be incapable of interpreting."

In "philosophy" current history is sometimes ancient history, and the ardent disciples of "philosophers" who, in modest carnestness, undertake to formulate the scientific knowledge of their day, often become bolder than their teachers, and, growing arrogant and reckless with success, find at last that they have sold their birthright in nature for what proves, when cxamined, to be no better than a mess of pottage.

The evidence that living matter is continuous, from beginning to end, is so conclusive that it convinces all who know its value. All living things are one by birth, and the system of living nature is, historically, a unit, a consistent whole; not a collection of isolated and independent species. How does it happen, then, that at every point in its history, we find it divided into detached groups, sep- 
arated by gaps, and characterized by fitness? Why is the system of living nature such that we cannot picture it as a circle, spreading in all directions from a common centre, and growing wider around its whole circumference? Why is it such that it is more exactly represented by a number of growing radii, independent at their outer ends?

This is the problem which Darwin undertook to solve, by showing that it results from extermination according to a standard of fitness. How does the Lamarckian meet it? Sometimes by denying the existence of fitness. Sometimes by asserting, even in the same breath, that fitness is miversal and necessary, and that there is no real problem.

He asserts that it is the outcome or expression of a deeper principle of necessary progress or evolution, which must result in fitness. The tendency to regard natural selection as more or less unnecessary and superfluous, which is so characteristic of our day, seems to grow out of reverence for the all-sufficiency of the philosophy of evolution, and pious belief that the history of living things flows out of this philosophy as a necessary truth or axiom.

"The inheritance of characters acquired during the life of the individual is an indispensable axiom of the monistic doctrine of evolution." 1

The writer yields to no one in admiration of the doctrine of evolution. So far as it is a scientific generalization from our knowledge of nature, it is one of the greatest triumphs of the human mind; rivalled only by its reciprocal, the doctrine of dissolution.

Experience seems to show, very clearly, that our system of nature is, on the whole, moving towards what commends itself to our minds as evolution, or progress to greater and greater perfection. While there is just as much evidence that each step in evolution is also a step toward dissolution, we have the same rational ground for expecting that this movement will continue, without any sudden radical change, that we have for other expectations which we base on knowledge of nature.

So far as the doctrine of evolution is based on knowledge, it is not only a part, but one of the most valuable and suggestive parts

${ }^{1}$ Haeckel, "Monism," p. 96. 
of the system of science, for the scientific law of evolution is part of science; but the philosophy of evolution is held by many as a creed, superior to and able to direct science. As men of science, we, like Huxley, have "nothing to say to any philosophy of evolution," except so far as it stands in the way of scientific progress.

We are sometimes told that while the other idols of which Bacon warned us are still worshipped, the idols of the theatre have been deserted, and their temples abandoned; although he himself lays peculiar stress on their persistency.

"Lastly, there are idols which have crept into men's minds from the various dogmas of particular systems of philosophy, . . and these we denominate iclols of the theatre. For we regard all the systems of philosophy hitherto received or imagined as so many plays brought out and performed, creating fictitious and theatrical worlds. Nor do we speak only of the present systems, or of the philosophy and sects of the ancients, since numerous other plays of a similar nature can still be composed."

They who worship this modern idol of the theatre hold that everything which has taken place and everything which can take place in our universe is deducible from the primal distribution of matter and energy. They tell us that everything in the past and everything in the future follows, of necessity, from this startingpoint, inasmuch as it might all have been predicted; but while science knows laws, - laws of evolution and others, - it knows no necessity except the logical necessity for stopping when evidence stops.

The evolutionist tells us that if we start with a homogeneous universe, with all the matter uniformly distributed, and all the energy kinetic; and if any break in this indefinite unstable homogeneity exist or be brought about, all the rest must follow of necessity, as a matter of course, from the nature of things; that all things must go on along their predetermined course until all the matter shall have fallen into stable equilibrium, and all the energy shall have become latent or potential.

As no one can say the basis for all this is not true, and as it seems much more consistent with scientific knowledge than other systems of philosophy, we must admit that, for all we know 
to the contrary, it may be true; and we must ask whether, if true, it is any substitute for science; although we must remember that there is no end to the things which, while no one treats them seriously, may nevertheless be true.

All the fancies of the poets, which do not involve a contradiction, may be true; but while anything which is not absurd may be good poetry, science is founded on the rock of evidence.

Many have found the opinion that all nature is conscious and endowed with volition, that the morning stars sing together, that the waters laugh, that trees talk, and that the wind bloweth where it listeth, worthy of belief; and it is clear that we cannot oppose any belief of this sort by evidence, or convert the sailor who believes that the wind obeys his whistle, by asking for proof.

The path of scientific progress is strewn with beliefs which have been abandoned for lack of evidence, as burst shells strew a battlefield, and it is our boast that they are abandoned, and not lugged along the line of march. As a shell which has failed to burst is, now and then, picked up on some old battlefield, by some one on whom experience is thrown away, and is exploded by him in the bosom of his approving family, with clisastrous results, so one of these abandoned beliefs may be dug up by the head of some intellectual family, to the confusion of those who follow him as their leader.

So far as the philosophy of evolution involves belief that nature is determinate, or due to a necessary law of universal progress or evolution, it seems to me to be utterly unsupported by evidence, and totally unscientific.

This system of philosophy teaches that, for purposes of illustration, our universe may be compared to an unstable, homogeneous, saturated solution; which remains unchanged so long as it is undisturbed, but crystallizes when shaken. The process of evolution must be supposed to start with a disturbance or shock. Something, inherent in the nature of things or outside, must press the button; but matter and its properties do all the rest, just as crystallization follows from the properties of the solution. Even if all this is granted, it is not apparent that the mind of the 
evolutionist has any power by the aid of which it could deduce anything whatever from homogeneity, even if it were present at the beginning.

There are homogeneous solutions of sugar and homogeneous solutions of brine, and no one without experience of similar facts has any way to tell what potencies are latent in a solution except by finding out. While we find no reason to suppose a homogeneous saturated solution has any power to initiate anything, we cannot think of it as inert. It is, as it were, alive with energy, and its inactivity is due to the exact balancing of all its powers. It is prepared to spring into energetic action the instant the bonds that chain it are broken by something that disturbs the balance and sets its forces free.

So, too, the primeval homogeneity of the evolutionist is imagined as instinct with world-producing energy, ready to evolve stars and systems and worlds and oceans and continents and living things and men, and all that is " in the round ocean, and the living air, and the blue sky, and in the mind of man," the instant it is set free; and so on to the end, which will come when all the energy has worked itself out in motion, and all the matter has found rest in stable equilibrium.

Unless he who worships this idol of the theatre is prepared to assert that there is only one kind of indefinite incoherent homogeneity; and unless he knows, in some way of which men of science are ignorant, what sort of homogeneous solution our universe was at the beginning; the only way for him to learn what potencies are latent in it is to find out by studying their products. It is hard to see how he can deduce anything whatever from his necessary law of universal progress except what he discovers. If his premises are admitted, all he can deduce from them regarding our subject is that, if he finds natural selection, the potency of natural selection was latent in his solution.

The philosophy of evolution is of no more use as a substitute for science than any other system of philosophy, although it is, no doubt, not only the latest, but the most consistent with our knowledge of nature, and although it may, for all I know to the contrary, be true. All this fails to give it any value as a short cut to natural knowledge. 
The true believer may say, however, that while our finite, imperfect minds may be unable to deduce anything from homogeneity, in the absence of knowledge drawn from experience, the outcome of the process must nevertheless be determinate. As it has all come out of the primeval homogeneity, he says this must have contained it all potentially.

I am no philosopher, but this does not seem obvious or necessary to me. Nature, as we know it, consists, in the main of permutations and combinations. "I do not know," is one thing, and "I do know not" is another, even if some fail to discriminate.

"It is easy to perceive that the prodigious variety which appears, both in the works of nature and in the acts of men, and which constitutes the greatest part of the beauty of the universe, is owing to the multitude of different ways in which its several parts are mixed with or placed near each other."

When we say three dice can be thrown in only two hundred and sixteen ways, all we mean is that we cannot throw them in any other way. We cannot throw three zeros, or three sevens, in any way, with ordinary dice without changing the marks; but we cannot attribute to the dice any latent capacity for being thrown in any way, or any capacity to do anything whatever as dice, even after we have becn informed by Haeckel that "the real maker of the organic world is, in all probability, a tetrahedron." 1

Except for a few odd thousands of quintillions of permutations and combinations no others can be formed from twenty-six letters, and if Galileo means any more than this by his remark that all truth is contained in the compass of the alphabet; if his words are more than figurative; if he intends to assert that the potency of literature is latent in the alphabet, independently of an author, -- it seems to me, with all respect for Galileo, that he is talking nonsense; for while the production of a learned treatise by the fortuitous concourse of letters may not be impossible, all the books we know of have come about in another way.

Twenty-eight figures are required to express the number of distinct deals in whist. "If the whole population of the world, say one thousand millions of persons, were to deal cards day and night for a hundred million years," they might justify Sarah Battle's criti- 
cism of the game, but "they would not in that time have exhausted one hundredth-thousandth part of the possible deals."

It is not clear to me that combinations are latent in the things combined. In fact, the bearing of these things on the matter seems to be negative and passive, rather than active or positive.

It is not clear that, with all their latent potency, a pack of cards would ever evolve a single hand without a dealer; but if a part of the universe, so trivial and insignificant, present opportunities so boundless, the matter and motion of our universe may present to a dealer opportunities for universes without end, no one like another. I do not see how one can assert that anything in the material universe is necessary or predetermined, except so far as it is one among an infinite number of possibilities.

Huxley tells us that, "if the fundamental proposition of evolution, that the whole world, living and not living, is the result of the mutual interaction, according to definite laws, of the forces possessed by the molecules of which the primitive nebulosity of the universe was composed," be true, "it is no less certain that the existing world lay, potentially, in the cosmic vapour; and that a sufficient intelligence could, from a knowledge of the properties of the molecules of that vapour, have predicted, say, the state of the fauna of Great Britain in 1868 , with as much certainty as one can say what will happen to the vapour of the breath in a cold winter's day."

The thoughtful reader will note that Huxley's assertion that, if this proposition be true, it is no less certain that the existing world lay, potentially, in the cosmic vapor is no admission that the proposition is true, or the deduction certain; nor must we forget that the most notable and valuable characteristic of $\mathrm{Hux}^{-}$ ley's teachings is the declaration, in all his works, of the truth that the scientific basis of our confidence in the order of nature is evidence.

Again and again, in words which are unmistakable, he tells us that, while we may have reasonable confidence what to expect from the vapor of our breath in a cold winter's day, we know nothing about it except what has happened. The scientific value of our confidence depends, he tells us, on the extent of our experience of the behavior of the vapor of our breath, and similar 
bodies, on a cold day, or under similar circumstances. As, in this case, our experience is pretty extensive, the deduction is safe and reasonable; but when a young man who had passed his life in the tropics spent the night on top of a high mountain with my students, he was so far from deducing anything from the frosty morning air that he was, at first, alarmed by the behavior of the vapor of his breath.

If Huxley is right, - if the logical basis for confidence in nature is evidence, - it seems clear that no amount of knowledge can ever give it any other basis; for nothing seems more obvious, or more strictly logical, than our inability to deduce anything from a single experience. The burnt child may dread the fire as much as if it had been burned twenty times, but the only way for it to learn whether, and to what degree, its dread is wise and prudent, without passing through the slow and painful process of selection, is to get knowledge, for a single experience affords no basis for any logical process.

While the emotional value of a sensation is, no doubt, limited by inherited structure, and dependent, to some degree, on intensity, its objective value as knowledge is regulated in accordance with the statistical law of probability.

If the history of what we call our universe were complete from beginning to end; if everything which exists in it were reduced to mechanical principles, and traced back to primitive nebulosity, - this history would be only a single experience in cosmogony, so far as the history of universes is in question. If we were to find, somewhere, a second nebulosity, we would not be able to infer anything, except from the worthless analogy of a single experience; nor would we be able to infer or deduce, from our own, anything, not already known, with more than reasonable confidence. If we were still ignorant of any part of our order of nature, we should have no way to find out but the way we have now; and while our confidence in its stability would be reasonable and judicious, it would not be necessary or absolute unless our experimental knowledge were also absolute.

It seems to me that the truth for which Huxley strives, and hits with imperfect aim, would be more correctly expressed by the statement that, if our knowledge of nature were to be made com- 
plete, from beginning to end, we should expect to find that our confidence in its stability had been reasonable, and judicious, and wise throughout, and that any other expectation would have been folly and suicide, bodily as well as mental; and that it is only in this sense that we could assert that it all lay potentially in the cosmic vapor.

It is not because I dread or fear the philosophy of evolution, that I refuse to accept it; but because it is not yet proved. When it is proved I shall accept it with cheerfulness; for I most assuredly hold no belief which is inconsistent with it; although I fail to see how the reduction of all nature to mechanical principles could show that nature is determinate; for if exhaustive knowledge of "primitive nebulosity" should sometime show that there is nothing in nature which might not have been expected, I cannot see how this could show why the things we expect should be the things which come about.

They who assert that complete knowledge would be foreknowledge, forget that, for minds like ours, the only source of knowledge, either complete or incomplete, is evidence; for evidence can tell us only what has happened, and it can never assure us that the future must be like the past. Even if we knew all that has happened, from the beginning down to the present moment, we should have to regard the unknown remainder as equal, in all probability, to the known past. To my mind, Jevons's demonstration that, if certainty be represented by unity, the utmost confidence we can ever reach by complete knowledge can never exceed a value of one-half, seems conclusive; but even if it be increased until it differ from certainty by less than any assignable quantity, it must still remain nothing but reasonable confidence.

There may be some unknown reason why the stone which I set free from my hand must fall, and it may be that, as my mind has been shaped by natural selection, I am unable to expect anything else than that it shall fall; but science affords no evidence that its fall is necessary or predetermined; for most thoughtful students assure us that the inductive study of nature tells us nothing about it, except that, so far as we know, all stones, so placed, have fallen according to Newton's laws, and that we have not the smallest reason to expect that any stone, so placed, will 
act differently; nor, so far as I can see, would proof that all nature is mechanical, from beginning to end, be inconsistent with belief that everything in nature is immediately sustained by Providence; nor am I able to see how it would be inconsistent with my conviction that my volition counts for something as a condition of the course of events.

I have tried to show, page 59, that, while the responsive activities of living things do not take place unless they are called forth by a stimulus, the things which they do under a stimulus are no more than their organic mechanism would lead one to expect; and that there is no necessary antagonism between those who attribute the development of the germ to mechanical conditions and those who attribute it to the inherent potency of the germ itself.

I have also tried to show, page 70 , that there need be no more antagonism between those who attribute knowledge to experience and those who attribute it to our innate reason; for, while knowledge does not arise in our minds without a sensible occasion, the knowledge which does thus arise may be no more than one who knew the whole natural history of our minds might have expected.

We must now ask whether proof that all nature was latent in the cosmic vapor would be inconsistent with belief that everything in nature is immediately intended rather than predetermined.

Certain monists tell us that the scientific doctrine of evolution is the same as Pantheism, for "since the simpler occurrences of inorganic nature and the more complicated phenomena of organic life are alike reducible to the same natural forces, and since, furthermore, these in their turn have their common foundation in a simple primal principle pervading infinite space, we can regard this last [the cosmic ether] as all-comprehending divinity, and upon this found the thesis: Belief in God is reconcilable with science." 1

They who agree with Haeckel may worship stones, if they see fit; but they seem to me to fail as completely as any South Sea islander to understand the nature of scientific evidence; for it is one thing to find sermons in stones, and quite another to see a 
divinity in the stone itself; "which, if with reason we may do, then let our hammers rise up and boast they have built our houses, and our pens receive the honour of our writings." I But everything must be determinate, says the pious evolutionist, or what would become of the fixed order of nature? Among the things that occupy the biologist are such aspects of nature as life, and consciousness, and volition, and reason, and right and wrong. Whatever these things mean, they are part of nature, and the zoölogist cannot push them out of sight, if others may. He does not know what their places in the system of nature are, but he would like to find out; and he knows no way to find out except to discover.

When they who worship at the shrine of evolution tell him there can be no spontaneity in nature, because the orcler of nature is fixed and unchangeable, he asks what reason there is for thinking that proof that everything in nature is mechanical, and no more than might have been expected, would show that anything is fixed, or predetermined, or necessary.

Science has nothing to do with the notion of "necessity," and is quite content to leave it in the hands of its originators, the metaphysicians and theologians and "philosophers," who alone are responsible for all the mental confusion it has brought about.

What the man of science asserts is that he will not admit that anything is "arbitrary." "It was the ignorance of man's reason that begat this very name, and by a careless term miscalled the Providence of God; for there is no liberty for causes to operate in a loose and straggling way." 1

Belief that everything in nature is mechanical is neither more nor less than belief that everything in nature is orderly and what might have been expected; and if any one thinks that discovery that things do take place in order is any reason why they should, his distrust of science is only reasonable; for science is not for such minds as his.

It is in my mind to ask a question. Will any amount of knowledge of matter and motion tell the evolutionist whether I shall ask it, or pass it by and go on to another subject? If he answer Yes, I ask my question: How does he know? If he 
assure me that a being so reasonable as I am known to be will not ask anything that might not have been expected, I thank him for the compliment; for I try to be a reasonable creature. But if he assert that his confidence in my thoughts and actions proves that they are necessary, I must ask him how he knows; for I faii to see how proof that an event is mechanical and neither less nor more than might have been expected, shows that it is nccessary; nor can I see any more reason why my confidence in my freedom proves that my acts are arbitrary.

The man of science quarrels with no man's opinions; but he will not be held responsible for perplexities which are none of his making.

I am unable to share the dread of the evolutionist that the basis of science may be destroyed if we do not admit that all nature must be determinate. All agree that the past is determinate, so far as the word means anything to us, and there seems to be valid ground for the belief that every part of the material universe contains a permanent record of every change which has ever occurred in any part.

"If on a cold polished metal, as a new razor, any object, such as a wafer, be laid, and the metal be breathed upon, and, when the moisture has had time to disappear, the wafer be thrown off, though now the most critical inspection of the polished surface can discern no trace of any form, if we breathe once more upon it, a spectral image of the wafer comes plainly into view; and this may be done again and again. Nay, more, if the polished metal be carefully put aside, where nothing can detcriorate its surface, and be kept so for many months, on breathing upon it again, the shadowy form emerges. A shadow never falls upon a wall without leaving thereupon a permanent trace, a trace which might be made visible by resorting to proper processes. Upon the walls of our most private apartments, where we think the eye of intrusion is altogether shut out, and our retirement can never be profaned, there exist the vestiges of all our acts." 1

Babbage has pointed out ("Ninth Briclgewater Treatise" pp. II3-II5) "that if we had power to follow and detect the minutest effects of any disturbance, each particle of existing matter would fur-

1 Draper, "Conßlict of Science and Religion." 
nish a register of all that has happened. The track of every canoe, of every vessel that has as yet disturbed the surface of the ocean, whether impelled by manual force or elemental power, remains forever registered in the future movement of all succeeding particles which may occupy its place. The furrow which it left is indeed instantly filled up by the closing waters, but they draw after them other and larger portions of the surrounding element, and these again, once moved, communicate motion to others in endless succession. The air itself is one vast library, in whose pages are forever written all that man has said or even whispered. There, in their mutable but unerring characters, mixed with the earliest as well as the latest sighs of mortality, stand forever recorded vows unredeemed, promises unfulfilled, perpetuating in the united movements of each particle the testimony of man's changeful will." 1

So far as we know, nothing that has ever been can be as if it had not been; and we seem to have good ground for believing that every portion of the material universe contains a record of every change that has taken place in all its parts, and also for believing that there is no limit to the power of minds like ours to read and interpret this record. Every new experience also shows that our expectation that the future will, on the whole, be like the past is reasonable. In these facts science finds a basis broad enough and firm enough for all our needs; for to this extent the data of science are latent in the physical universe, even if the future is, in part, to be what man and other living things make it.

If these evolutionists who hold that all nature is determinate and necessary are right, mind would seem to be useless. It may, for all I know to the contrary, be true that, when I perform an action because my reason approves it, neither the performance of the action nor the approval of my reason is anything more than exhaustive knowledge of the mechanism of my brain might have led one to expect; and if it follows that my action is necessary, and must take place, whether my reason approve it or not, reason would seem to be useless; but I cannot see why this should follow, for I fail to see how or why proof that my reason is mechanical and no more than might have been expected from my structure should be inconsistent with my confidence in its value, since I cannot con-

1 Quoted by Jevons, “Principles of Science," p. $75^{8}$. 
ceive how this proof could show that it is necessary, or predetermined, or useless.

I know the value of my reason by what seems to me the best of all evidence. If it were proved useless, I should be quite ready to believe; but the improbability of this opinion seems to me so much like impossibility, that I must ask for proof which is correspondingly conclusive; for I most assuredly refuse to give any weight to the "faith" of pious evolutionists, and I must insist on my right to demand more evidence if more is to be had, for I cannot accept the mind of the evolutionist as a measure of nature.

Living things are continually bringing about rearrangements of matter and motion which would never, so far as I can see, have come about without them, and many of the things which they thus bring about are useful to the beings which bring them about. The earth would be very different in many respects if man had never inhabited it, and the effects of his activity will last as long as matter, whatever may be his fate. His influence upon the carth would have been very different if the plants of Carboniferous times had not stored up solar energy and worked their changes in matter millions of years ago. If the dodo, and the great auk, and the halicore, and the American bison could tell their story, they would bear witness that man is a factor in the order of nature.

They who are discontented with reasonable or "moral" certainty, and tell us they want absolute certainty, must find this sort of certainty if they can and where they can, but their words seem strange to the zoölogist. He knows that the rocks are full of the remains of organisms which passed out of existence because they were born in evil times, when the adjustments to the order of nature, which had served the purposes of their ancestors for millions of years, ceased to hold good.

If our race should ever find itself where the old order changes; if our reasonable expectations should disappoint us; if what we call the "order" of nature should prove to be no more than natural selection would lead us to expect; and if a different selective standard should some time modify this order, - every zoölogist knows that the human species would not be the first to meet this evil fate.

If, with Aristotle, we believe "that is natural which holds good"; if, with Erigena, we hold that nature is the sum of all 
things, - we cannot believe that life and consciousness and reason and volition are anything but part of nature. The question the zoölogist would like to answer is, what their place in nature is. So far as I am aware, no one believes that these aspects of nature exist in themselves, without antecedents, for we know that many of their antecedents are physical, and we want to find out, if we can, whether this is true of all of them or not. For my own part, I fail to see what bearing this wish has on the question whether the order of nature is "fixed" or unfixed; nor can I see how proof that the conditions which, being given, are good reasons for expecting reason or the moral sense, are mechanical, should show that reason and morality are useless.

They who take refuge in an imponderable ether as soon as they find it difficult to discover, in ponderable matter, the key to all the antecedents to certain phenomena of light and electricity, have no reason to cry out that the fixed order of nature is threatened, because the modest zoölogist has not yet been able to find, in ponderable matter and physical energy, the key to all his problems.

Berkeley tells us that human knowledge has its basis in experience, and that its scientific value is to be measured by the amount of this experience; and Huxley assures us that there is but one kind of knowledge and but one way to acquire it. They hold our practical test of truth to be evidence, although a pious evolutionist, who admits that, for all he knows, they may be right, is a heretic; for Herbert Spencer tells him that the Philosophy of Evolution stands or falls with the assertion that the ultimate criterion of truth is inability to conceive its negative.

If you will read Part VII. of his "Principles of Psychology" with care, you will note that its author tells us that, unless we admit this, we cannot be his disciples. It is not enough to admit ignorance of things ultimate, or to confess that, for all one knows, inability to conceive its negative may sometime prove to be the ultimate criterion of truth. One may admit that he is unable to discover any line which separates the responsive actions of living things in general from the rational actions of thinking men; that he does not know how or where instinct and impulse and emotion give place to reason. One may have as little faith in the idealism of 
Berkeley as he has in Spencer's realism, or in the materialism of German physics, or in the monism of the psychologists; but unless he knows what the relation between mind and matter is, he cannot join the throng of worshippers before the shrine of this modern idol of the theatre; for its leader tells him that suspension of judgment on this difficult question is as fatal as disbelief.

Proof that we should not be here if our remote ancestors had not responded to the order of nature as they did is no proof that our minds are a measure of nature, or that our responses will be valuable in the future, or that nature is determinate.

Now the difference between belief that the ultimate test of truth is the inconceivability of its negative, and belief that our practical test of truth is evidence, is this: that while inability to conceive the negative of a proposition may be absolute to us, as nature has made us, at our present intellectual level, evidence is progressive, and can afford no basis for ultimate philosophy.

Our pre-Cambrian ancestors may have been unable to conceive the negative of many propositions; but what does the inability of a turnip or a sponge to conceive the negative of Newton's laws signify? Or what would our own inability signify if we should sometime find out that the ponderable matter which makes up what we call "our universe" has been sifted out or segregated from other forms of matter, by its property of weight? For no less distinguished an authority than Herschel held that there is proof of the existence of levitative matter as well as gravitative matter.

One volume of Herbert Spencer's "Philosophy" is devoted to proof that we primarily know objects; but to this long argument Berkeley answers: Granted. Most assuredly we primarily know objects; but he tells us that the objects we know primarily are objects of sense.

So the frozen river of philosophy grinds on, scratching the surface of the everlasting hills, and melting before the genial sunshine of science, only to receive new accretions from the unknown and frozen space beyond the snow-line.

Some fifteen hundred years have passed since we were told by Procles that "there are two sorts of philosophers. The one placed Body first in the order of beings, and made the faculty of 
thinking depend thereupon, supposing that the principles of all things are corporeal; that Body must really or principally exist, and all other things in a secondary sense, and by virtue of that. Others, making all corporeal things to be dependent upon Soul or Mind, think this to exist in the first place and primary sense, and the being of Bodies to be entirely derived from, and to presuppose that of Mind." I

While the modern psychologist tells us that there is a third point of view, and that, for all we know to the contrary, both mind and matter may ultimately prove to be phenomenal; that all mind may be matter in motion, and all matter in motion mind, or at least the raw'material of mind, I cannot see why the admission of this possibility compels us to take a side and make a choice; for may we not find a fourth alternative, in a humble confession that, while we do not know what the relation between mind and matter is, we wish to find out? "And, although it may, perhaps, seem an uneasy reflection to some that, when they have taken a circuit through so many refined and unvulgar notions, they should at last come to think like other men; yet, methinks, this return to the simple dictates of nature, after having wandered through the wild mazes of philosophy, is not unpleasant. It is like coming home from a long voyage: a man reflects with pleasure on the many difficulties and perplexities he has passed through, sets his heart at ease, and enjoys himself with more satisfaction for the future." 2

If the antecedents to consciousness are outside consciousness, it seems no more than natural that we should be unconscious of them; and the zoölogist who admits that he does not know whether they are or are not all to be found in that part of the universe which may be made manifest to sense, does not feel guilty of a threat to the fixed order of nature, or to anything or anybody else.

There are two reasons why biology and the "Philosophy of Evolution" should be associated.

In the first place, there is a wonderful analogy between the problems of the sensible universe and the unfolding of the latency of the germ into the potency of the fully developed living being.

1 Berkelcy, "Siris," p. 263.

${ }^{2}$ Berkelcy, Preface to "The Three Dialogues." 
It is not impossible that the key to the more specific problem may fit the lock which seals the greater.

In the second place, the two subjects are historically associated. So long as men believed that species are distinct creations, no philosophy of evolution could have gained general acceptance. By convincing all thoughtful persons that species have a history which may be studied by scientific methods, Darwin led many who would not otherwise have given it a hearing, to treat the new philosophy with respect: but natural science is not "philosophy," notwithstanding this intimate historical connection between the proof that species are mutable and the spread of belief in the "Philosophy of Evolution." I have selected the passage which I have put at the head of this chapter in order to show that the view of the matter which is here set forth is not new, even among advanced biologists.

Huxley's attitude will, no doubt, be a surprise to many who think they have read his books with diligence. He continually calls himself an "Evolutionist," and he can hardly blame a reader who, failing to draw nice distinctions, holds him to be one of the chief pillars in the temple of the new philosophy. Some confusion may be permitted to those who remember his public lectures on "Evolution," his essays with the same title, and his declaration that the work of his life has involved him "in an endless series of battles and skirmishes over evolution."

It is easy for one who understands his true position to see that his essays lend no countenance to the opinion that he has ever been or sought to be either a pillar or a disciple of any system of philosophy; for he has never ceased from affirming his ignorance of many of the subjects which philosophy seeks to handle.

His evolution is not a system of philosophy, but part of the system of science. It deals with history - with the phenomenal world - and not with the question what may or may not lie behind it.

During the last half-century natural science has become historical. We have opened and learned to read a new chapter in the records of the past. The attributes of living things, which seemed to the older naturalists to be complete and independent 
in themselves, have proved to have a history which can be studied by the methods of science. They have been found to be steps in a long sequence of events as orderly and discoverable as the events which are studied by the astronomer or the geologist.

The cultivation of natural science in this historical field, and the discovery that the present order of living things, including conscious, thinking, ethical man, has followed after an older and simpler state of nature, is not "philosophy," but science. It involves no more belief in the teachings of any system of philosophy than does the knowledge that we are the children of our parents and the parents of our children; but it is what Huxley means by "evolution." 1

His lectures on "Evolution" deal with paleontology, and narrate facts which are found in every text-book on the subject; but natural science, as it is taught in the text-books on botany and zoölogy and embryology and paleontology, is, most assuredly, no "Philosophy of Evolution." It fell to Huxley to fight and win a battle for science; and while he himself calls it a battle for evolution, his use of the word need mislead none, although it has misled many.

One word in its time plays many parts, and the word "evolution" has had many meanings. To-day, in popular estimation, an evolutionist is not a follower of Bonnet; nor one who is occupied with the binomial theorem, or with the evolutions of fleets and armies. Neither is he a cultivator of natural science. Whatever the word may have meant in the past, it has, in common speech, come to mean a believer in that philosophy of evolution which, according to such evolutionists as Huxley, is "premature." Since this is so, and since the growth of language is beyond individual control, would it not be well for those who stand where Huxley stands, and "have nothing to say to any philosophy of evolution," to stop calling themselves "Evolutionists," and to be content with the good old name of "Naturalist"?

To the pious evolutionist, who asks what will become of the fixed order of nature if we are not convinced that everything is determinate, we answer that, while this sort of reasoning is not new, it has a strange sound in the mouth of a student of science. 
The order of nature has outlasted many systems of philosophy, and it may survive others. We have found our astronomy and our geology and our law of the mutability of species, and none of the dreadful things predicted by "philosophers" have come about. There may still be more things in heaven and earth than are dreamed of in "philosophy."

History warns us that, as the price of progress in science, all the idols of the theatre, and all other idols, "must be abjured and renounced with firm and solemn resolution, and the understanding must be completely freed and cleared of them; so that the access to the kingdom of man, which is founded on the sciences, may resemble that to the kingdom of heaven, where no admission is conceded cxcept to children."

If the world thinks hard names are the just due of them who assert their living wish to know, while humbly confessing ignorance, the biologist must bear up as well as he can if he is called a "scientific Rip Van Winkle," or an "agnostic," or even "a malignant and a turban'd Turk."

If we seek admission to the temple of natural knowledge naked and not ashamed, like little children, hard names cannot hurt us, nor need they scare us. 


\section{LECTURE VI - PART II}

\section{A NOTE ON THE VIEWS OF GALTON AND WEISMANN ON INHERITANCE}

Two of the most prominent writers on inheritance, Weismann and Galton, base their views of variation on the assumption that at each remote generation, the ancestors of a modern organism were innumerable, although a little reflection will show that this assumption is quite untenable.

Weismann, in his earlier writings at least, finds the "cause of variation" in the recombination, by sexual reproduction, of the effects of the diversified influences which acted upon the innumerable protozoic ancestors of each modern metazoön; but this opinion deserves little consideration, as a contribution to our knowledge of inheritance, if we can prove that these protozoic ancestors must have been very few, and if we can also prove that, if these few were ancestors of any modern metazoön, they must have been the common ancestors of all the modern metazoa.

Galton's view of the diversity among individuals is much like Weismann's. He says: "It is not possible that more than onehalf of the varieties and number of the parental elements, latent or potential, can on the average subsist in the offspring. For if every variety contributed its representatives, each child would on the average contain, actually or potentially, twice the variety and twice the number of elements, whatever they may be, that were possessed at the same stage of its life by either of its parents, four times as many as any of its grandparents, Io24 times as many as any of its ancestors of the tenth degree, and so on."

As he holds that each offspring must therefore get rid, in some way, of half the variety transmitted from its ancestors, he finds an explanation of the diversity between individuals in the diversity of the retained halves of their variety. 
Each person has two parents, and four grandparents; but even in a country like ours, which draws its people from all quarters of the earth, each of the eight great-grandparents is not always a distinct person; for when the parents are cousins, this number is six, or five, or even four, instead of eight. Among more primitive folks, who stay at home generation after generation, and marry neighbors, a person whose ancestors have transgressed none of our social laws may have a minimum ancestry of only four in each generation. The maximum and the minimum fixed by our customs are given, for ten generations, in the two lines below:-

$$
\begin{array}{r}
2-4-8-16-32-64-128-256-512-1024 \cdot 4 \cdot 2046 \\
2-4-4-4-4-4-4-4-4-4.938
\end{array}
$$

Few persons who can trace their ancestry for ten generations with completeness are descended from IO24 distinct persons in the tenth gencration; and in all old stable communities of simple folks the number is very much smaller. In the long run, the number of ancestors in each generation is determined by the average sexual environment, and it must be a small and pretty constant number.

All genealogical study gives indirect evidence of this familiar fact, which has not been adequately recognized by students of inheritance. I have made a computation from the genealogical history of the people of a small island on our coast. These people lead a simple life, or at least they have done so in the past; but most of the men have been sailors, and have ranged much farther in search of mates than agricultural people. I have selected three persons whose ancestry is recorded in detail for some seven or eight generations. These three persons would not be popularly regarded as near relations, for they have no parents or grandparents with like names, although two of the grandparents were cousins. The generations are not quite parallel, for the period covered by eight in one line is covered by seven in the two others, and the average is about seven and a half.

In seven and a half generations the maximum ancestry for one person is 382 , or, for three persons, I I 46 . The names of 452 of them, or nearly half, are recorded, and these 452 named ancestors 
are not 452 distinct persons, but only I49; many of them, in the more remote generations, being common ancestors of all three in many lines. If the lines of descent from the unrecorded ancestors were interrelated in the same way, as they would surely be in an old and stable community, the total ancestry of these three persons, for seven and a half generations, would be 378 persons instead of I 146.

Few of us know even the names of all the living descendants of each of our sixty-four ancestors of the sixth generation; and, so far as our own choice is concerned, marriage with one of them may be an accident; for the probability of such a marriage depends upon things which are in great part independent of us, upon the size of the circle of acquaintances, and the distance of the places to which ancestors wandered. For if each pair of ancestors had only four children, more than twelve thousand of their descendants may now be living $(4048+8096)$.

If a city like Baltimore, where the strangers to each one of us outnumber our acquaintances a thousand fold, could be quarantined against people from outside for a thousand years, each successive generation would be much like the present, so far as known relationships are concerned, although, at the end of this period, the inhabitants would not be descended from the Baltimoreans of our day, but from only a very few of them. Most of our lines would be extinct; and the few that survived would include most of the Baltimoreans of the year 2898 .

All this is proved, indirectly but conclusively, by genealogical statistics; and while a thousand years are but as yesterday in the history of species, zoölogical phenomena furnish evidence that allied animals must be related to each other, at two widely separated generations, like these successive generations of Baltimoreans.

Of all the individual animals which make up the species at a given period, very few will have descendants at a later period, and these few will be the common ancestors of all the individuals which represent the stock at the later period.

The extinction of species is a familiar conception. The extinction of the lines of descent from individuals is no less real, and, in the study of inheritance, vastly more important; for it is the fact of which the extinction of species is only an expression. 
As we trace back the ancestral tree, it divides into two branches for the parents, and again into four, and into eight, for the grandparents and great-grandparents, and so on for a few generations; but a change soon takes place.

The student of family records may be permitted to picture genealogy as a tree whose branches become more and more numerous as we go farther and farther backwards from our starting-point into the past; but this cannot be permitted to the zoölogist; for the average number of ancestors in each generation cannot be greater than the average number of individuals in the average sexual environment. It may be very much less, however, for most of the individuals in each generation may fail to perpetuate their lines to remote posterity. Now, no animal in a state of nature ranges so far as man in search of a mate; and the sexual environment of such animals as the fishes in a brook or pond, or the parasites in the intestine of a mammal, is very narrow, as it is in many plants. While new blood no doubt finds its way in from time to time, its influence is more than balanced by the extinction of genetic lines. The series of ancestors of each modern animal is long beyond measure or conception, but the number of ancestors in each remote generation can never be very great, though it may be extremely small.

The data of systematic zoölogy also force us to believe the ancestry of all the individuals of a species has been practically identical, except for some slight divergence in the most recent part of their history.

Instead of picturing the genealogy of a species as a tree, the zoölogist must picture it as a slender thread, of very few strands, a little frayed at the near end, but of immeasurable length, and so fine that its thickness is as nothing in comparison. The number of strands is fixed by, but is very much smaller than, the average sexual environment. If we choose, we may picture a fringe of loose ends all along the thread, to represent the ancient animals which, having no descendants, are now as if they had never been. Each of the strands at the near end is important as a possible line of union between the thread of the past and that of the distant future.

The gist of the whole matter is this: that we must picture 
this slender thread as common to all the individuals of the species, whose divergence from each other is infinitesimal as compared with the ancestry which they share in common. The branches of a human genealogical tree diverge for a few generations by geometrical progression, but we soon find traces of a change, and if the record were long enough to have any zoölogical significance, we should surely find all the members of the species descended from a few ancestors in each remote generation, and these few the common ancestors of all. So too of the common ancestors of divergent species, or those of larger groups; if one metazoön is descended from pre-Cambrian unicellular ancestors, the same unicellular individuals must have been the common ancestors of all the metazoa; and we may be confident that there were not very many of them in any one generation. It is quite possible that they were so few as a single pair, or even one.

There is nothing novel in all this. Galton has himself devoted an appendix to the mathematical study of the extinction of family names; although he, like other writers on inheritance, seems to forget it when he assumes that the remote ancestors of two persons were, like the parents, distinct individuals, and that the child must therefore have twice as much ancestry as either parent, and consequently twice as much variety, unless there is some way to cancel half of it at each step.

I called attention to the bearing of this convergence of ancestry on the problem of inheritance, in 1883, in words which still seem clear; although the views of both Galton and Weismann on variation are based on the unfounded assumption that each sexual act brings together two totally dissimilar sets of factors, instead of two factors which are alike in innumerable features, for each one in which they differ.

My statement is as follows: "In order to breed together, animals must be closely related; they must belong to the same species, or to two closely related species. Since the individuals which belong to two closely related species are the descendants of a common and not very remote ancestral species, it is clear that almost the whole of their history has been shared by them in common; all their generic characteristics being inherited from this ancestor. Only the slight differences in minor points which 
distinguish one species from another have been acquired since the two diverged, and not even all of these slight differences.

"We know that the duration of even the most persistent species of the higher animals is only an infinitesimal part of the whole history of their evolution, and it is clear that the common characteristics of two allied species must outnumber, thousands of times, the differences between them. It follows that the parents of any possible hybrid must be alike in thousands of features for one in which they differ. Crossing simply results in the formation of a germ by the union of a male and a female element derived from tivo essentially similar parents, with, at most, only a few secondary and comparatively slight differences, all of which have been recently acquired."

I trust that you will agree with me that clue consideration of the subject which is here presented might have saved much unprofitable discussion of "the causes of variation"; for it seems clear that we must seek in the modern world, and not in the remote past, for an explanation of that diversity among inclividuals which passes under the name of "variation."

I have called your attention to these facts because they serve to introduce, and to throw light upon, the subject of the next lecture, The Statistical Study of Inheritance; although they seem to me to throw light upon other zoölogical problems.

If the extinction of a genetic line may be so slow that a failing stock may go on from bad to worse for many generations before it is utterly destroyed, is it not clear that we can seldom hope to discover what determines the ultimate survival or extinction of a genetic line? Is it not equally clear that artificial selection, by the sudden and utter destruction of the discarded, is no measure of natural selection?

Unless inclividuals with the same useful quality breed together it is hard to see how this useful quality can be intensified by natural selection, and as it also seems hard to find in nature any reason why these individuals should seek out and unite with each other, this criticism of natural selection seemed to Darwin to be a real clifficulty; but we must remember that while the sexual union of those individual animals whose descendants would be the fittest to survive may be rare and exceptional, the survival of a 
genetic line in remote generations is also rare and exceptional; for the posterity of most of the living beings that now exist is destined to speedy extinction.

While we may discover nothing in the modern world to draw together those individuals which, if they were so drawn together, might become the parents of the fittest, this is no evidence that the fittest may not be, in the long run, the descendants of ancestors who did bring together characteristics which, when thus intensified, were so transmitted to posterity as to give to this posterity an advantage over their competitors in the struggle for existence. 



\section{LECTURE VII}

GALTON AND THE STATISTICAL STUDY OF INHERITANCE 



\section{LECTURE VII ${ }^{1}$ - PART I}

\section{GALTON AND THE STATISTICAL STUDY OF INHERITANCE}

To talk about inheritance is much easier than to study it. Of the books and essays which meet us at every turn few have much basis in research, but among the few are those of Francis Galton. His works, which have appeared at intervals during the past twenty years, are not speculations, but studies. They describe long and thorough investigations, carried out by rigorous methods, in lines laid down on a plan which has been matured with great care and forethought.

The simplicity of their language is as notable as their substance. Dealing with conceptions which are both new and abstruse, their author finds our mother tongue rich enough for all his needs, and while the reasoning often taxes all our powers, there is never any doubt as to the meaning of the words.

When, in rare cases, a technical term is inevitable, some familiar word is chosen with so much aptness that it does its duty, and presents the new conception better than any which half a dozen dead languages could afford. The terms, "mid-parent" or " mid," "fraternity," "nurture," and " $Q$ " cannot mislead or convey any idea except the right onc.

My own debt to Galton is great, and it is acknowledged with gratitude. Such acquaintance with the statistical method as I possess, I owe to the study of these books, especially the ones on "Hereditary Genius" (1869), on "Natural Inheritance" (I 889), and on "Finger Prints" (1 892 ).

My attempt to question Galton's generalizations may therefore seem ungracious and presumptuous, but the uncertainties of vital

I A review of the works of Francis Galton; reprinted from the Popular Science Monthly for February and March, 1896. 
statistics are proverbial; and it is not impossible that Galton's data may fail to cover all the ground which they should in order to prove his general conclusions.

One of these generalizations is so far-reaching that it must, if well founded, lead to fundamental change in our view of the origin of species.

According to Darwin and Wallace, specific identity in living things is the outcome of the extermination, in the struggle for existence, of the individuals which depart too widely from that "type" which is, on the whole, the best adapted to existing conditions. As these conditions change, the type is also slowly modified through a change in the standard of extermination. According to this view, the type is the outcome of the statistical "law of error" or the deviation from the mean, that holds good in the environment; and while the "events" are properties of the organism, the type is fixed by the external world, and not by anything in the organism itself.

Galton holds that specific identity is not due to the process of extermination, but to "organic stability." As I understand him, he holds that this fills up the gaps made by extermination, and thus kecps the type intact. This "principle of stability," which is held to result in the persistency of types, is said to be quite independent of selection. "Genera and species may be formed without the slightest aid from either natural or sexual selection." "Organic stability is the primary factor by which the distinctions between genera are maintained." Galton holds, furthermore, not only that specific stability is independent of selection, but that selection is "scarcely competent" to effect a change of type "by favoring mere varicties" - that is, the ordinary slight differences between individuals; and that it is only when a "sport" has made its appearance, only when the type has actually changed, that selection can exert any influcnce. According to this view the agencies which cause sports are the real causes of the mutation of species, and natural sclection can do no more than to exterminate disadvantageous sports, and thus favor advantageous ones. The "organic stability" to which so much is attributed is held to be duc to the fact that the child inherits in part from its parents, and in part from more remote ancestors; and since the 
sum of its ancestry, or its "mid-parentage," is, on the average, nearer than any exceptional parent to the mean of the race, the children of selected parents are, on the average, more mediocie than their parents.

It is quite possible that Galton's data may be valuable, and that they may be trustworthy in the study of human faculties, and yet that they may fail to prove this generalization; and I shall try to show that this is the case, although I am not sure I fully grasp his point of view. I assume that he regards a zoölogical type, or species, as something which owes its origin to a "principle of stability" which is not itself due to selection. This is assuredly the current interpretation of his statements, and it is from this standpoint that I shall examine his writings. If this is not his opinion; if he in fact believes that this "principle" owes its existence to past selection; if from his data he deduces only the generalization that the results of past selection may persist after it has ceased to act, - I see no ground for criticism, for his data assuredly prove this much, although I cannot reconcile his statement that "the principle of stability is independent of selection" with belief that it is the result of past selection.

Before we discuss the subject it may be well to ask what evidence there is that the child does inherit from any ancestor except its parents, for descent from a long line of ancestors is not necessarily equivalent to inheritance from them, and it is quite possible that the conception of a "mid-parent" may be nothing but a logical abstraction, useful, perhaps, for statistical purposes, but without any real existence in nature.

Most of its support is derived from the phenomena of reversion or atavism; from the appearance, in children, of ancestral features which were not exhibited by the parents. While these phenomena are real and familiar, we may well doubt whether any of them are reversions in Galton's sense. In some cases we can show that a so-called reversion is simply the manifestation of a possibility which is latent in the structure of all the normal members of the species. The occurrence, in man, of a distinct premaxillary bone is an example of this sort of reversion. It is due to arrest of normal development, and this arrest might have happened to any member of the species, with the 
same result. We do not know what arrested development, but the view that this was some adverse circumstance in the history of the individual is surely more simple than the opinion that the child inherits its distinct premaxilla from any ancestor except its parent. The same thing is true of the polydactylism of horses, although this is sometimes attributed to reversion to miocene ancestors.

When the son of a beardless boy and a beardless woman grows up and acquires a beard, we may be permitted to say he has inherited his grandfather's beard; but this is only a figure of speech, for he actually acquires nothing except what was latent in his parents; nor would the case of a bearded man descended from a series of ten or a hundred beardless boys and beardless women be any different. If we were to propagate a plant by cuttings for ten or a hundred generations under conditions which dicl not permit it to flower, and if, finally, we put the last where it does flower, we should not be justified in saying that it does not inherit its flower from the preceding cutting; nor would the case be any different if, for some reason, this preceding cutting could not be made to bloom.

The phenomena of polymorphism in insects and hydroids present illustrations of the normal inheritance of latent characters, but we find in them no ground for the assertion that the ancestral characters of the medusa are not inherited from the hydroid which produces it.

The sum of the visible features of the parent, plus the sum of its latent potencies, may be called a "mid-parent" for statistical purposes, if we see fit, but there is no evidence that this "mid-parent" is anything else than the actual parent.

With this introductory note, we may now enter upon the study of Galton's works, the central point of which is as follows: If we select any one characteristic of a group of animals, such a characteristic as the weight of the individuals, or the ratio between the length of their arms and legs, or anything else which admits of exact numerical statement, - it will be found that, while no two members of the group are exactly alike, they nevertheless conform to a type, and show the existence of a standard, the mean or average, to which the majority 
adhere pretty closely, while other members of the group may be more abnormal, showing marked deviation from the mean. The deviation of these abnormal individuals from the mean is not accidental or due to "chance," for it is part of the orderly system of nature. If the cases tabulated are numerous enough, the individuals will conform, so far as this quality is concerned, to what is known in statistical science as the law of frequency of error. This agreement will be so close, when great numbers of individuals are compared, that the number which depart from the mean to any specified degree may be computed mathematically.

For example, the chest measurements of 5738 soldiers gave the following resuits:-

If the number of events had been five hundred thousand or five million instead of five thousand, the agreement between the computed and observed frequency of each degree of departure from the mean would have been very much closer. When the number of cases is unlimited, the agreement is perfect.

Galton gives the following illustration of the significance of a type: Suppose a large island inhabited by a single race, who intermarry freely and have lived for many generations under constant conditions, then the average height of the adult male of that population will undoubtedly

\begin{tabular}{|r|r|r|}
\hline INCHES & MEASURED & COMPUTED \\
\cline { 1 - 3 } 33 & 5 & 7 \\
34 & 31 & 29 \\
35 & 141 & 110 \\
36 & 322 & 323 \\
37 & 732 & 732 \\
38 & 1305 & 1333 \\
39 & 1867 & 1838 \\
40 & I 882 & 1987 \\
41 & 1628 & 1675 \\
42 & 1148 & 1096 \\
43 & 645 & 560 \\
44 & 160 & 221 \\
45 & 87 & 69 \\
46 & 38 & 16 \\
47 & 7 & 3 \\
48 & 2 & I \\
\hline
\end{tabular}
be the same year after year. Also - still arguing from the experience of modern statistics, which are found to give constant results in far less carefully guarded examples - we should undoubtedly find year after year the same proportion maintained between the number of men of different heights. I mean if the average stature were found to be sixty-six inches, and if it were also found in any one year that one hundred per million exceeded seventy-eight inches, the same proportion of one hundred per million would be closely maintained in all other years.

An equal constancy of proportion would be maintained between any other limits of height we please to specify, as 
between seventy-one and seventy-two inches, between seventy-two and seventy-three, and so on. Now, at this point, the law of deviation from an average steps in. It shows that the number per million, whose heights range between seventy-one and seventytwo inches, or between any öther limits we please to name, could be predicted from the previous datum of the average, and of any other one fact, such as that of one hundred per million exceeding seventy-eight inches.

Suppose a million of the men to stand in turn with their backs against a vertical board of sufficient height, and their heights to be dotted off upon it. The line of average height is that which divides the dots into two equal parts, and stands, in the case we have assumed, at the height of sixty-six inches. The dots will be found to be ranged so symmetrically on either side of the line of average that the lower half of the board will be almost a precise reflection of the upper. Next, let a hundred dots be counted from above downwards, and let a line be drawn below them. According to the conditions, this line will stand at the height of seventy-eight inches. Using the data afforded by these two lines, it is possible to reproduce with extraordinary closeness the entire system of dots on the board.

This law of deviation from an average is not restricted to vital phenomena, but holds true of all events which are the resultants of variable conditions, which remain the same through all the events recorded. If the marks on the board had been made by bullets fired at a horizontal line stretched in front of a target, they would have been distributed according to the same law, their average value would be constant, and the deviations of the several events from the average would be governed by the same law, which is identical with that which governs runs of luck at a gaming table.

Galton has described an apparatus which mimics in a very pretty way the conditions on which deviations from a mean depend. It is a long, shallow box set on end and glazed in front, leaving a depth of about a quarter of an inch behind the glass. Strips are placed in the upper part to act as a funnel. Below the outlet of the funnel stands a succession of rows of pins stuck fairly into the backboard, and below these, again, are a series of vertical compartments. A charge of small shot is 
enclosed. When the frame is held topsy-turvy, all the shot runs to the upper end; then when it is turned back into its working position, the desired action commences.

The shot passes through the funnel and, issuing from its narrow end, scampers deviously down through the pins in a curious and interesting way; each one of them darting a step to the right or left, as the case may be, every time it strikes a pin. The pins are so placed that every shot strikes a pin in each successive row. The cascade issuing from the funnel broadens as it descends, and at length every shot finds itself caught in a compartment immediately after freeing itself from the last row of pins. The outline of the columns of shot that accumulate in the successive compartments approximates to the mathematical law of frequency, and is closely of the same shape, however often the experiment is repeated.

The outlines of the columns would become more nearly identical with the normal law of frequency if the rows of pins were much more numerous, the shot smaller, and the compartments narrower; also, if a larger quantity of shot were used.

The principle on which the action of the apparatus depends is that a number of small accidents befalls each shot in its career. In rare cases a long run of luck continues to favor the course of a particular shot towards either outside place, but in the large majority of instances the number of accidents that cause deviation to the right balances in a greater or less degree those that cause deviation to the left. Therefore most of the shot finds its way into the compartments that are situated near to a perpendicular line drawn from the outlet of the funnel, and the frequency with which shots stray to different distances diminishes in a much faster ratio than these distances increase.

Types which are based upon vital statistics have peculiar interest, since they persist from generation to generation, according to the law of specific stability, while they also undergo slow changes according to the law of the mutability of species.

Individuals come and go, but the type persists, and its slow changes may be pictured as quite independent of and more substantial than the procession of individuals which files past only to vanish from the world. 
For more than fifteen hundred years men of the most acute and well trained intellect devoted their lives to efforts to find out in what sense a type exists, as contrasted with the individuals which exhibit it; yet the modern zoölogist still finds himself face to face with this old problem, which, when analyzed, proves to be the same as the question: What is the cause of nature?

The great intellectual difference between the schoolmen of the Middle Ages and the man of science seems to me to be this: that the modern student has at last come to see clearly that we find in nature no ultimate explanation of types; and no reason to believe that there is anything in nature which does not conform to statistical laws and exhibit types.

Statistical science, like all other branches of science, helps us to regulate our actions and to act with wisdom and prudence, by making known to us that order of events which makes up the system of nature; but discovery that cvents do take place in order is no reason why they should, or even why they should take place at all. The problem of the zoölogist is not the cxistence of types, but the fitness of living types for the world around them, and to my mind the problem of the "origin of species," as the zoölogist understands these words, would be greatly simplified if we clearly recognize the fact that science holds out no well-grounded hope for any final explanation of "species," in the logical sense of the word; for while we may prove that the occurrence of types is no more nor less than might have been cxpected, this cannot show us why the thing we expect should be the thing which comes about.

The statistical study of vital types affords a means for studying the phenomena of inheritance by the exact methods of mathematics, and it is capable of yielding definite and valuable results, so far as the vital phenomena which are studied can be treated as if they stood alone; but the attempt to generalize from vital statistics, and to deduce general laws of inheritance from them, is attended by peculiar difficulties, due in great part to the fact that the data which are studied are not separable from the organism which exhibits them. Stature, or size, or weight, may be treated abstractly for statistical purposes, but the stature of an organism is not an abstraction, for the organism is not only a bundle of properties, but a unit as well, and its stature is only one of many features which are all beauti- 
fully coördinated with each other in such a way as to promote the welfare of the species. A generalization which ignores this fact may, while proved by statistics, be untrustworthy as a contribution to our knowledge of inheritance.

In popular language, specific stability may be said to be due to inheritance, and specific mutability to variation; but in this connection these words have only a loose meaning. In so far as they convey the impression that the stability of species and mutability of species are antagonistic to each other, or are due to two distinct and opposing influences, these terms are unfortunate, for we have good ground for believing that they are only contrasted aspects of the same phenomenon - the extermination of certain individual peculiarities, and the preservation of others, by natural selection.

The older naturalists held that adherence to type is due to some innate principle of specific stability which is an essential and immutable attribute of each species of living things; but the accumulation of conclusive evidence of the mutability of species has driven this conception out of the field. Most naturalists now regard the type as nothing but that normal which is most perfectly fitted to the environment, and they hold that it is kept true through the extinction of aberrant individuals by selection.

According to this view, which seems to be supported by ample evidence, the stability of species is due to survival - to the same mechanism which brings about the mutability of species. They hold that neither the stability nor the mutability of species is anything more than the struggle for existence would lead one to expect; and that which we call inheritance and that which we call variation not two things, but one thing in two points of view.

Galton is led by his statistical studies of vital characters to a view which bears an odd resemblance to that of the older naturalists; for, according to him, the principle which results in the permanency of types is quite independent of selection.

He shows, for example, by the statistical study of stature, that the type of human stature is very constant from generation to generation, although the statistics of marriage show that there is no controlling tendency for persons of like stature to marry. He also shows that the children of parents who are both tall or both short do not on the average have the stature of their parents, but are nearer 
than they to the mean for the race. These facts, and others like them, are held to prove the existence of a principle of stability independent of selection.

In his more recent work on the patterns of human fingers he says that, since it has been shown (Chapter XII.) that the character of the finger prints is practically identical in Englishmen, Welshmen, Jews, negroes, and Basques, the same familiar patterns appearing in all of them with much the same degree of frequency, and that persons belonging to different classes, such as students in science and students in art, farm laborers, men of culture, and the lowest idiots in the London district, show no decided difference in their finger prints, it seems to be proved that no sensible amount of correlation exists between any of the patterns on the one hand and any of the bodily faculties and characteristics on the other. It seems absurd, therefore, to hold that, in the struggle for existence, a person with, say, a loop on his right middle finger has a better chance of survival or a better chance of early marriage than one with an arch. Consequently, genera and species are here seen to be formed without the slightest aid from either natural or sexual selection, and these finger patterns are apparently the only peculiarity in which panmyxia, or the effect of promiscuous marriage, admits of being studied on a large scale.

He says that the results of panmyxia in finger-markings corroborate his arguments in "Natural Inheritance" and elsewhere to show that "organic stability" is the primary factor by which the distinctions between genera are maintained. Consequently, the progress of evolution is not a smooth and uniform progression, but one that proceeds by jerks, through successive "sports," as they are called, some of them implying considerable organic changes, and each in turn being favored by natural selection.

Galton's explanation of this specific stability is as follows: The child inherits in part from the parents, in part from more remote ancestors; and since the sum of its ancestry, or, as Galton calls it, the "mid-parentage," is on the average nearer than the exceptional parents to the mean for the race, the children of selected parents are on the average more mediocre than their parents.

I have tried to show that, while the child is descended from a long line of ancestors, it inherits from none but the parents, and 
that it can only be said in a figurative sense to inherit from more remote ancestors. I shall soon refer to proof that the persistency of adaptive types is due to natural selection, and not to any principle of organic stability which is independent of selection, although this view itself at once brings up difficulties.

If it be true, if the stability of adaptive types is due to the survival of the fittest, why do we have a type and not a fixed standard? If speed and courage and strength are good things, why is not every surviving individual as swift as the swiftest, as brave as the bravest, and as strong as the strongest? Why does not every individual have every useful quality developed to the highest excellence which it may reach in any individual of the species? Why should we find that diversity among individuals which usually passes under the name of "variation"?

We can measure strength and can treat it abstractly, and we can artificially select and breed from the strongest members of a stock, neglecting all other features; but this is not what happens in nature. Here the most favored individuals are not the strongest, but the ones in which all the qualities of the species are most perfectly coördinated with each other in relation to the external world. Excessive strength may involve deficiency in some other essential, and the mean or average strength of the species is that degree of strength which is most in harmony with the mean degree of development of all the other characteristics of the species, and the individuals which depart too widely from this mean, either through excess or deficiency of strength, are the ones which are ultimately exterminated.

Galton has himself given such a clear statement of the way a type is established by selection that it cannot be improved upon, and I quote it in his own words: "Suppose," he says, "that we are considering the stature of some animal that is liable to be hunted by certain beasts of prey in a particular country. So far as he is big of his kind, he would be better able than the mediocres to crush through the thick grass and foliage whenever he was scampering for his life, to jump over obstacles, and possibly to run somewhat faster than they. So far as he is small of his kind, he would be better able to run through narrow openings, to make quick turns, and to hide himself. Under the general 
circumstances it would be found that animals of some particular stature had on the whole a better chance of escape than any other; and if their race is closely adapted to these circumstances in respect to stature, the most favored stature would be identical with the mean of the race. Though the impediments to flight are less unfavorable to this (stature) than to any other, they will differ in different experiences. The course of an animal might chance to pass through denser foliage than usual, or the obstacles in his way may be higher. In that case the animal whose stature exceeded the mean would have an advantage over mediocrities. Conversely, the circumstances might be more favorable to a small animal. Each particular line of escape might be most favorable to some particular stature, and, whatever this might be, it might in some cases be more favored than any other. But the accidents of foliage and soil in a country are characteristic and persistent, and may fairly be considered as approximating to a typical kind. Therefore those which most favor the animals of the mean stature will be more frequently met with than those which favor any other stature, and the frequency of the latter occurrence will diminish rapidly as the stature departs from the mean.

"It might well be that natural selection would favor the indefinite increase of numerous separate faculties if their improvement could be effected without detriment to the rest; then mediocrity in that faculty would not be the safest condition. Thus an increase of fleetness would be a clear gain to an animal liable to be hunted by beasts of prey, if no other useful faculty were thereby diminished.

"But a too free use of this 'if' would show a jaunty disregard of a real difficulty. Organisms are so knit together that change in one direction involves change in many others; these may not attract attention, but they are none the less existent. Organisms are like ships of war, constructed for a particular purpose in warfare, as cruisers, line-of-battle ships, etc., on the principle of obtaining the utmost efficiency for their special purpose. The result is a compromise between a variety of conflicting de. siderata, such as cost, speed, accommodation, stability, weight of guns, thickness of armor, quick steering power, and so on. It is hardly possible in a ship of any established type to make an 
improvement in any one of these respects without a sacrifice in other directions. If the fleetness is increased, the engines must be larger, and more space must be given up to coal, and this diminishes the remaining accommodation.

"Evolution may produce an altogether new type of vessel that shall be more efficient than the old one, but when a particular type has become adapted to its functions, through long experience, it is not possible to produce a mere variety of its type that shall have increased efficiency in some one particular without detriment to the rest. So it is with animals."

Neo-Lamarckians are fond of asserting that natural selection cannot bring about an adaptation which involves the coördinated modification of many correlated parts; and they may be interested in the clear demonstration which I have quoted from Galton of the way natural selection brings about coördination.

His assertion that after a coördinated type has been established it cannot be changed by the mere selection of individual differcnces, seems to be well founded, so far as the modification by artificial selection of a type which has been established by natural selection is in question. As it is with vessels, so it is with animals in the hands of a breeder who, having in mind some one point of excellence, picks out the individual animals in which the desired peculiarity is most marked, and, propagating from them, destroys all the others.

A breeder of domesticated animals or of cultivated plants, who devotes his attention to one or two characteristics, must soon reach a point where no further improvement is practicable unless the species is at the same time greatly modified in many other respects. This fact does not prove that spccific stability is due to anything elsc than sclection, but only that no grcat change is possible without the coördinated modification of all the corrclated features, and this is just what wc should expect, on Galton's own showing, as the effect of long ages of sclcction. Herc, as in so many other cases, artificial selection proves to be an imperfect analogy; for while the breeder may utterly destroy all the animals except the few which he positively selects, extcrmination in the struggle for existence is often so slow as to be imperceptiblc. Before a failing genctic line is utterly cut off, it may continue 
to lose ground for many generations, during which there are innumerable opportunities for every useful quality to count for all it is worth. The survivors are the ones in which all these useful qualities are most perfectly coördinated, and the effect of the struggle is to make this coördination more and more perfect, although we must remember that no essential change can occur in a type unless some change in the external world makes a place for a new type.

"That natural selection generally acts with extreme slowness," says Darwin, "I fully admit. It can act only when there are places in the natural polity of a district which can be better occupied by the modification of some of its existing inhabitants. The occurrence of such places will often depend on physical changes, which generally take place very slowly, and on the immigration of better adapted forms being prevented. As some few of the old inhabitants become modified, the mutual relations of others will often be disturbed; and this will create new places, ready to be filled up by better adapted forms; but all this will take place very slowly. Although all the individuals of the same species differ in some slight degree from each other, it would often be long before differences of the right nature in various parts of the organization might occur." 1

The passage I have quoted from Galton seems to indicate that, after all, he may believe that the specific types of zoölogy and botany are nothing more than the persistent effects of past selection, and that his statement that "organic stability is independent of selection" may refer to present selection only.

These statements are clear and explicit, however, and they have been interpreted by most readers as a flat contradiction of the view that the mechanism which leads to the formation of new types is identical, on its vital side, with that which preserves established types; the view that the differences between the two are differences in the external world.

He says (Nature, September, I885): "It is some years since I made an extensive series of experiments in the produce of seeds of different sizes, but of the same species. . . I It appears from these experiments that the offspring did not tend to resemble their 
parent seeds in size, but to be always more mediocre than they; to be smaller than they if the parents were large; to be larger than the parents if the parents were very small." He says that this regression is a necessary result of the fact that "the child inherits, partly from his parents, partly from his ancestors. Speaking generally, the further his genealogy goes back, the more numerous and varied will his ancestors become, until they cease to differ from any equally numerous sample taken at hap-hazard from the race at large. Their mean stature will then be the same as that of the race; in other words, it will be mediocre."

He illustrates this by comparing the results of the combination in the child of the mean stature of the race with the peculiarities of its parents to the result of pouring an uniform proportion of pure water into a vessel of wine. It dilutes the wine to a certain fraction of its original strength, whatever that strength may have been.

He then goes on to the deduction that the law of regression to the type of the race "tells heavily against the full hereditary transmission of any rare and valuable gift, as only a few of many children would resemble their parents. The more exceptional the gift, the more exceptional will be the good fortune of a parent who has a son who equals, and still more if he has a son who surpasses him. The law is even-handed; it levies the same heavy succession tax on the transmission of badness as well as goodness. If it discourages the extravagant expectations of gifted parents that their children will inherit all their powers, it no less discountenances the extravagant fears that they will inherit all their weaknesses and diseases. . . L Let it not for a moment be supposed that the figures invalidate the general doctrine that the children of a gifted pair are much more likely to be gifted than the children of a mediocre pair; what it asserts is that the ablest of the children of one gifted pair is not likely to be as gifted as the ablest of all the children of many mediocre pairs."

In his recent work on "Finger Prints" he says: "It is impossible not to recognize the fact so clearly illustrated by these patterns in the thumbs that natural selection has no monopoly of influence in the construction of genera, but that it could be wholly dispensed with, the internal conditions acting by themselves being 
sufficient. Not only is it impossible to substantiate a claim for natural selection that it is the sole agent in forming genera, but it seems, from the experience of artificial selection, that it is scarcely competent to do so by favoring mere varieties in the sense in which I understand the term. Mere varieties from a common typical centre blend freely in the offspring, and the offspring of every race where statistical characters are constant, necessarily tend, as I have shown, to regress toward their common typical centre. A mere varicty can never establish a sticking point in the forward course of evolution."

Galton therefore holds that, while specific stability is due to inheritance from a long line of ancestors, the transmutation of species is due to the sudden appearance of "sports," which, if useful, are seized upon and perpetuated by selection.

He says that a sport is a substantial change of type effected by a number of small changes of typical centre, each more or less stable, and each being in its turn favored and established by natural selection to the exclusion of its competitors.

"The distinction between a mere variety and a sport is real and fundamental."

This generalization, based upon numerical data, is so fundamental and far-reaching that a critical discussion of the evidence is most important. 


\section{LECTURE VII-PART II}

IT may be well to remind those who are not familiar with statistical reasoning that a type may exhibit the influence of inheritance, and yet be of no value as a basis for generalization on inheritance.

The bullet type shows the influence of aim, but if we use it to test the accuracy of aim or the excellence of the rifle, we may be led astray if some other influence, such as the weight of the bullet, act on all or on a majority of the shots, and escape detection. In this case the type may seem to prove that the rifle is inaccurate or improperly aimed when it is not, and we cannot assume that because a type shows the influence of aim it is a test of aim.

So a characteristic or a group of characteristics of living things may conform to the mathematical law of deviation from a mean, and may thus form a type, and this type may show the influence of inheritance, without being a safe basis for generalization regarding inheritance.

This may be illustrated by an example. If we were to tabulate the prices of all the horses sold within a given period, we should undoubtedly find that they would conform to a type; that there is a mean or average price; that the horses which fetch more than this price are equal in number to those which fetch less, and that the prices group themselves about the mean according to the law of error. If the term be long enough to include several generations, we shall find that inheritance or "blood" has a marked influence on price, and that the children of high priced horses are much more likely than horses selected at random to bring the same high prices. The type will exhibit the influence of inheritance, but it will be of no value in studying inheritance unless we can in some way separate the influence of blood from the influence of supply and demand which has far more to do with the average price and with the type. 
That the price of horses is, on the whole, fixed like that of other commodities, is obvious, and it is also clear that the type may be changed by events which have no relation to inheritance, such as the application of electricity to street cars.

A change of this sort, such as took place when steam replaced stage coaches, is a "sport" or sudden and fundamental change of type, but this may also be changed by slight and gradual modification with the slow growth of a complicated civilization and an increased demand for horses.

As inheritance has an influence on the price of horses, what will be the result if we destroy the children of all horses which fetch less than +2 of Galton's scheme, and breed from only that fourth of the whole which sell for more than 75 per cent of his centesimal scale?

We may, at first, get fancy prices for our expensive stock, but if selection cease with this first step, and we supply as many colts as before, the price will "revert" to the type, and the mean will become the same as it was.

Does this prove that those qualities in horses for which money is paid have "retrograded to mediocrity" in these descendants of high-priced horses? It proves nothing of the sort, for the qualities which command a price are one thing, and the price another. Even if the horses have much more of these qualities than the old stock, the price will still be fixed by the ratio between demand and supply, and while blood will tell in use, it will not tell in price.

It is clear, then, that characteristics of living things which are influenced by inheritance may conform to a type which exhibits "specific stability," "regression to mediocrity," an occasional "sport," and all the other properties of the types which Galton has studied, without furnishing proof that "inherited" qualities behave in the same way. To prove this, we must cancel, or neutralize, or make allowance for, all the factors which have an influence upon the type, except "inheritance."

Galton's generalizations upon the laws of inheritance from the statistical study of finger prints rest upon the belief that the patterns are inherited. If they are not, they can teach nothing of inheritance, when considered in themselves, without farther analysis. He proves that they are, to some degree, dependent, either directly or indirectly, upon inheritance, just as the price of 
horses is, but this is not enough. To warrant his deductions, he must either prove that inheritance is the controlling factor in fixing the type, or else he must show that, in the long run, all the other factors will balance; and this, it seems to me, he fails to prove. He has studied, in 150 fraternal couples, or children of the same parents, the frequency with which the same pattern occurs on the same finger of both, and he finds that, when marked on a scale in which $O$ indicates no resemblance, and $100^{\circ}$ the greatest possible relationship, they show $10^{\circ}$ of relationship. This number is great enough to prove the influence of inheritance, but it seems to me to be too small to show that the patterns are themselves directly inherited; for it seems to me to indicate that they are indirectly influenced by some other inherited character, such, perhaps, as the ratio between the growth in the embryo of the ball of the finger and that of the nail.

Inheritance is not, unfortunately, a word which is always used with scientific precision, for it has many meanings. Most of the qualities which give a horse its value in the market, as compared with other horses, are due to breeding, but this word has many meanings. Orlando says: "His horses are bred better; for besides that they are fair with their feeding, they are taught their manage, and to that end riders dearly hired." The "breeding jennet, lusty, young, and proud," seems to be a wild mare, with no breeding in the first sense, and the horse which did not lack what a horse should have, "Round-hoofed, short-jointed fetlocks shag and long, Broad breast, full eye, small head, and nostrils wide, High crest, short ears, straight legs, and passing strong, Thin mane, thick tail, broad buttocks, tender hide," is a thoroughbred.

Recent speculations have forced us to attend to the difference between these meanings of the word. In the last sense brecding is the influence of ancestry, and it may practically be treated as synonymous with the word ancestry. In the first sense, brceding, broadly used, is that influence of the ontogenetic environment for which that most objectionable term, "acquired characters," has been thoughtlessly adopted; for no one who believes that species are mutable can believe that there is any character which has not been "acquired." 
In his earlier writings Galton, borrowing, I suppose, from "The Tempest," uses the word nurture to designate what is commonly called acquired characters, and this term is so apt and expressive that it should not be permitted to pass out of use, for it may be given a definite technical meaning without violence to its ordinary use. Using murture instead of acquired characters for the influence of the environment of the individual, we may speak of the two elements of breeding as ancestry and nurture.

It is obvious at the present day that our studies of inheritance can have little value unless we distinguish between these two factors; for many naturalists hold that there is good ground for asking whether the effects of nurture are ever inherited, and most naturalists admit that it is possible that the value of these two elements in breeding may be very different.

If breeding is to be studied by the statistical method, for the purpose of exhibiting the laws of inheritance, we must employ types in which we can separate the effects of ancestry from the effects of nurture; for if we make use of types which do not admit of this analysis, our results may tell us no more of inheritance than the scheme of prices tells us of the value of blood in horses.

If, as many teach, inheritance is the equivalent to ancestry, and nurture is never inherited, no type in which these two factors are combined can tell us anything about inheritance.

It seems probable to me that the resemblance which Galton points out between the finger marks of fraternal couples may be due to nurture, in this broad sense of the word, and not to inheritance, for there is ample evidence that the value, in breeding, of a given parental characteristic does depend upon its origin, and that one due to nurture has a very different value from one which is itself inherited.

Of the 2459 deaf pupils of the American Asylum, nearly 600 have married, and have become the parents of over 800 children, of whom 104, or more than i2 per cent, were born deaf-a ratio which is great enough to prove that inheritance has some influence. Analysis of the record shows clearly, however, that these deaf children are not uniformly distributed among the married pupils of the asylum, but that the result is influenced by the character of the parental deafness. From 283 of the 596 
marriages no children are reported, while from three other families no report is made except that all the children hear, so that the SI I children which are reported are from only 304 families, and in many of these only one parent was deaf. Of the IOI children of 40 of these marriages none are reported as deaf, and all but I I are reported as hearing, and the 7 Io children are from the remaining 264 marriages. In 52 of the marriages both father and mother were congenitally deaf, and these are the parents of 48 out of the IO4 congenitally deaf children, but they are the parents of only. I5 I of the total number of 8II children, and nearly 32 per cent of all the children of these congenitally deaf parents are congenitally deaf.

In two of the groups in which the marriages may be classified the number of marriages and the number of children are about equal, but there is a most remarkable difference in the number of deaf children.

In 55 marriages, with 139 children, both parents are reported as adventitiously deaf, while in 52 marriages, with I5I children, both were congenitally deaf. In the latter group, 52 children, or $3 \mathrm{I} .78$ per cent, are congenitally deaf, only 88 are stated to hear, and no facts are given about the hearing of 15 of them. In the first group only 4 of the $\mathrm{I} 39$ children, or 3.87 per cent, are reported as congenitally deaf, I 29 are reported as hearing, and 6 are not reported.

I have divided all the marriages into four groups: In one all the children hear; in the sccond 5 to 6 per cent are deaf; in the third from 12 to 18 per cent are deaf; and in the fourth 3 I.78 per cent are deaf. In the first group, in which all the children hear, 5 of the marriages, with 18 children, are between a hearing husband and a wifc who is adventitiously deaf; I marriage, with 4 children, between a hearing man and a woman the source of whose deafness is not stated; 6 marriages, with 13 children, where wife hears and husband is adventitiously deaf; 23 marriages, with 5 I children, where husband is adventitiously deaf, and wifc deaf from unknown causes; 2 marriages, with 6 children, where both were deaf from unknown causes; I marriage, with 4 children, where husband is deaf from unknown causes and wife hears; and 2 marriages, with 5 children, where wife is con- 
genitally deaf, and husband deaf from unknown causes. None of the IOI children of these 40 marriages are reported as deaf.

In the second group, where 5 to 6 per cent of the children are deaf, 87 are the children of 37 marriages where the husband was congenitally deaf and wife adventitiously deaf; and I 39 are the children of 55 marriages where both husband and wife were adventitiously deaf. We must bear in mind, while considering this last case, that adventitious deafness may indicate an hereditary predisposition; for many of the pupils of the asylums who lost their hearing after birth have deaf relatives, and thus show that their deafness is not strictly adventitious, in the scientific sense, but is due to a congenital predisposition to deafness.

In the third class, where from 12 to is of the children are congenitally deaf, I24 are the children of 5 I marriages where husband was adventitiously and wife congenitally deaf; 66 were children of 16 marriages of hearing husband and congenitally deaf wife; 72 were children of 26 marriages where wife hears and husband is congenitally deaf; and $7 \mathrm{I}$ of 29 marriages of congenitally deaf husband with wife deaf from unknown causes. In all the families in this group one parent was congenitally deaf.

In the fourth class, where 31.78 per cent of the children are congenitally deaf, all the parents in the 52 marriages, with I5I children, are congenitally deaf.

While too.few to give quantitative results, these statistics prove that it is the congenital and not the adventitious deafness which descendants have to fear.

Careful study of the history of these pupils of the asylums shows that the relatives of deaf persons must also be taken into consideration, and that statistical data which do not include this factor are inadequate as a basis for generalization on inheritance. Of the 26 families in which both parents are deaf and have congenitally deaf children, there are 5 families in which one of the parents has a deaf parent, 17 families in which both parents have deaf relatives of the same generation, 4 in which one parent has deaf relatives of the same generation, and only 5 in which no deaf relatives of the same generation are reported.

Of the 26 families in which both parents are congenitally deaf and have hearing children only, there is not one parent, so far as 
reported, with a deaf parent; there are $\mathrm{I} 2$ families in which both parents have deaf relatives of the same generation; II in which one parent has deaf relatives of the same generation; and 3 in which neither parent has deaf relatives of the same generation.

This illustration proves that the origin of an individual peculiarity has much to do with the question of its inheritance, and that we cannot be sure that statistical data illustrate inheritance unless we can separate the phenomena of ancestry from those of nurture.

Furthermore, in order to prove that children always revert to the mean or type of the race, and are on the average more mediocre than their parents, we must prove that this is the case when both parents have the same inherited peculiarity. Galton shows that this is true of the stature of children both whose parents were tall or both short, but he has not shown that it is true when the peculiarity in the stature of both parents is the same inherited peculiarity. He points out that stature may be affected by diversity in the thickness of more than one hundred bodily parts, and it is plain that if the extra height of a tall father is due, for example, to a long femur, the chances are a hundred to one that the femur of the tall mother is normal, and that her extra height is due to some other peculiarity - thick intervertebral bodies, for example.

There is statistical evidence from other sources to show that if both the parents have long femurs and have brothers and sisters with long femurs, the children, instead of reverting to mediocrity, may be expected to have, on the average, femurs very much above the mean, and that some of them may have them longer than either parent.

Many facts in our stock of information regarding domesticated animals and cultivated plants show that hereditary peculiarities are often very persistent independently of selection, and the experience of all breeders shows that this tendency is greatly intensified when both parents have the same inherited peculiarity. Not only is this the case, but it may be proved by many observations that the normal or type to which the average children of exceptional parents tend to revert may itself be rapidly modified. In proof of this I refer to the following experiments in selection by Fritz Müller, ("Ein Zuchtungs-versuch an Mais," Kosmos, I 886, 2, I, p. 22) :- 
Yellow corn is very variable in many respects. The number of rows of kernels on the cob was, at the time Müller made his experiments, from 8 to 16 ; cobs with IO or 12 rows being the most common, while one with 8 or 20 rows was very seldom found. After searching through several hundred cobs he found one ear with 18 rows, but none with more.

In 1867 he sowed, at different times, and in such a way as to prevent crossing, (I) seed from the cob with I 8 rows; (2) the seed from the finest I6-rowed ear; and (3) the seed from the finest i4-rowed ear. In I 868 he sowed (I) seed from a I6-rowed ear which had grown from a I6-rowed ear; (2) seed from an I8rowed ear that had grown from I6-rowed seed; and (3) seed from an i8-rowed ear from i 8-rowed seed. In 1869 he sowed (I) seed from an 18 -rowed ear with i 8 -rowed parents and grandparents; (2) seed from a 20-rowed ear with I8-rowed parents and grandparents; and (3) seed from a 22 -rowed ear from seed from an is-rowed ear produced from seed from a i6-rowed ear. The results are given in the following table:-

\begin{tabular}{|c|c|c|c|c|c|c|c|c|c|}
\hline \multirow[b]{2}{*}{$\begin{array}{l}\text { Number of rows on } \\
\text { cob from which sccd } \\
\text { were takcn. }\end{array}$} & \multicolumn{3}{|c|}{1867} & \multicolumn{3}{|c|}{1868} & \multicolumn{3}{|c|}{1869} \\
\hline & I 4 & 16 & 18 & $\begin{array}{l}\text { I6 } \\
16\end{array}$ & $\begin{array}{l}16 \\
18\end{array}$ & $\begin{array}{l}\text { IS } \\
\text { I } 8\end{array}$ & $\begin{array}{l}\text { I } 8 \\
\text { I8 } \\
\text { I } 8\end{array}$ & $\begin{array}{l}18 \\
18 \\
20\end{array}$ & $\begin{array}{l}16 \\
18 \\
22\end{array}$ \\
\hline $\begin{array}{c}\text { Total number of cobs } \\
\text { produccd. }\end{array}$ & $65^{8}$ & 385 & 205 & I 789 & 262 & 460 & 2486 & 740 & 373 \\
\hline 8.rowcd cobs. & $\begin{array}{c}\text { Pcr c't } \\
0.3\end{array}$ & $\begin{array}{c}\text { Pcrc't } \\
\ldots\end{array}$ & $\begin{array}{c}\text { Per c't } \\
0.5\end{array}$ & $\begin{array}{c}\text { Per c't } \\
\text { O.I }\end{array}$ & Perc't & $\begin{array}{c}\text { Perc't } \\
\ldots\end{array}$ & $\begin{array}{c}\text { Per c't } \\
\ldots\end{array}$ & $\begin{array}{c}\text { Pcrc't } \\
\ldots\end{array}$ & $\begin{array}{c}\text { Perc't } \\
\ldots\end{array}$ \\
\hline Io-rowed cobs . & 14.4 & 3.0 & 1.0 & $\mathrm{I} .4$ & 0.8 & 0.2 & O.I & $\ldots$ & $\ldots$ \\
\hline I 2-rowed cobs . & 48.0 & 22.8 & 13.0 & 22.6 & 14.5 & 7.8 & 6.1 & 6.1 & 2.7 \\
\hline I4-rowed cobs . & 35.6 & 48.6 & 37.8 & 48.5 & 46.7 & $35 \cdot 4$ & $37 \cdot 3$ & 28.5 & $25 \cdot 3$ \\
\hline 16-rowed cobs . & 3.2 & 18.7 & $34 \cdot 5$ & 22.2 & 23.7 & 33.8 & $33 \cdot 5$ & 41.6 & 41.8 \\
\hline I8-rowed cobs . & 0.5 & 6.8 & 12.6 & $4 \cdot 9$ & 12.3 & I 8.2 & 18.6 & 20.2 & $24 . I$ \\
\hline 20-rowed cobs . . & $\ldots$ & 0.1 & 0.3 & 0.3 & $\mathrm{I} .2$ & $4 \cdot 4$ & $3 \cdot 9$ & 2.8 & 4.8 \\
\hline 22-rowcd cobs . . & $\ldots$ & ... & 0.3 & ... & 0.8 & 0.2 & 0.5 & 0.8 & I.O \\
\hline 26-rowed cobs... & $\ldots$ & ... & $\ldots$ & $\ldots$ & $\cdots$ & $\cdots$ & $\cdots$ & $\cdots$ & 0.5 \\
\hline Average . . . & I $2.6 \mathrm{I}$ & 14.08 & 14.9 & I4. I 5 & I 4.39 & $15 \cdot 5^{2}$ & I 5.57 & $15 \cdot 70$ & I6. I 5 \\
\hline
\end{tabular}

It will be seen from this table that the number of ears with few rows decreases very rapidly in plants grown from seed taken 
from ears with many rows, and that the greater the number of rows on the ear from which the seed is taken, the smaller is the number of ears produced with a small number of rows. It is also plain that, as the number of rows on the ear from which the seed was taken increases, the number of ears produced with a large number of rows increases, and that we have in each case a very considerable number of ears which equal their parents and a few which excel them, even when the parent seeds are far beyond the maximum for all ordinary corn. Fritz Müller says he has never under ordinary conditions, except in three instances, found an ear with more than 18 rows, and Darwin puts the maximum at 20 rows; yet we have among the children of seed from a 22-rowed ear no less than 4.8 per cent, or 18 ears out of 373 with 20 rows, and one ear out of 373 with 26 rows, and it will also be seen that the number of children which equalled their parents increases in each case in each successive generation.

Thus the seed planted in 1867 from an 18 -rowed ear produced 1 2.6 per cent of 18-rowed children. The 18 -rowed ear planted in 1868 from an 18 -rowed parent produced 18.2 per cent of $\mathrm{I} 8$ rowed children, and the 18 -rowed seed planted in 1869 from 18 rowed parents and grandparents produced 18.6 per cent of I 8-rowed children. The series is I2.6 per cent, I8.2 per cent, and 18.6 per cent. The rapid change which took place in the "type" after only three years of selection is well shown by the following table, which gives the dominant number of ears at each sowing and also the percentage of ears which had this number:-

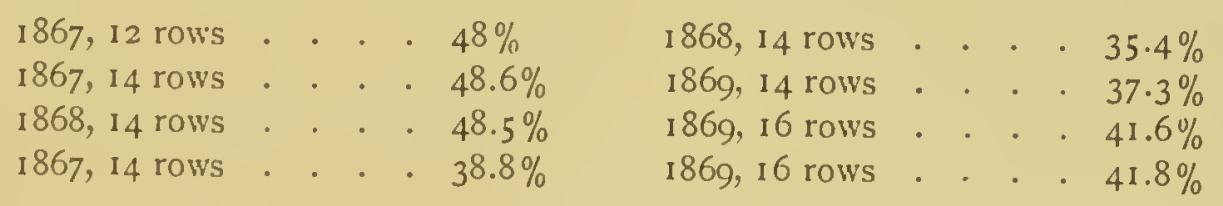

The minimum for the third generation is equal to the mean for the first; the mean for the third generation, I6 rows, is very near the maximum for ordinary corn, and the maximum for the third gencration is far beyond the maximum for the grandparents, and much beyond the maximum for the parents.

No one can dispute the well-known fact that this sort of pedigree sclcction for a single point quickly grows less and less effec- 
tive, and soon reaches a maximum; but this is no proof of any "principle of organic stability," or anything else except the truth that long ages of natural selection have made the organism such a unit or coördinated whole that no great and continuous change in one feature is possible, unless it be accompanied by general or constitutional change.

Nor must we forget that, in a state of nature, selection is not for one feature, nor is it pedigree selection, or breeding from the fittest. It is the extermination of the unfit, and unfitness may come from the imperfect coördination of the whole, or from defect in any quality whatever.

It is undoubtedly true that many of our domesticated races can be proved to have arisen as "sports," and that no great change of type can be effected, by the methods of the breeder, without sports; but there seem to be both evidence and theoretical ground for holding that, in this particular, artificial selection gives no measure of natural selection.

It seems to me that, notwithstanding the great value of Galton's data, they fail to prove that the "principle of organic stability" owes its existence to anything except past selection; that regression to mediocrity occurs when ancestry is studied uncomplicated by murture; that the "mid-parent" is anything else than the actual parent; that "sports" are fundamentally different from the ordinary differences between individuals; or that natural selection is restricted to the preservation of sports.

Our tendency to believe that a type is something more real and substantial than the transitory phenomena which exhibit it, is deeply rooted in our minds.

As the very nature of this belief renders disproof of it impossible, we can feel little surprise at its appearance and reappearance time after time in the history of thought, although science is based upon the well-warranted opinion that, whether types are real or unreal, we know them only as generalizations or abstractions constructed by our minds out of experience of the orderly sequence of phenomena.

In zoölogy and botany the conception of species is unquestionably valid and justifiable, and as its most obvious characteristic is its persistency, as contrasted with the fleeting procession of eva- 
nescent individuals, we cannot wonder at the vitality of the belief that specific types of life are more real than the individual animals, although Darwin's work has done away with whatever evidence may at one time have seemed to support this belief.

To the further question, whether specific types are inherent in living matter or external and objective to it, Darwin answers that they are both; that they are inherent, insomuch as all their data, or "events," are properties of the physical basis of life; but that they are external, inasmuch as the agreement of the "events" with the "law of frequency of error" is the effect of the environment.

Biology is not a closed science, and Darwin's view of the matter is not proved-possibly it is not provable; but its great value is in the proof that there is no shadow of evidence for any other view.

When embryologists talk about the doctrine of evolution in embryology as antagonistic to the doctrine of epigenesis; when biologists seek for the origin of species in "laws of variation" which are not the outcome of selection; when they talk about a "principle of organic stability" which does not owe its origin to the same agency, - it seems to me that they fail to grasp the significance of Darwin's work, and that they are wandering from the only path in which we can have any well-grounded hope for progress - the path which takes its departure from that conception of specific types which leads us to seek for the origin of the "events" which exhibit the type in the physical properties of living matter, and to seek in the order of nature external to the organism for the origin of the "law of error," which forms a type out of these events. 



\section{LECTURE VIII}

DARWIN, AND THE ORIGIN OF SPECIES 
"The idols of the market are the most troublesome of all; those, namely, which have entwined themselves around the understanding from the associations of words and names.

"There arises from a bad and unapt formation of words a wonderful obstruction to the mincl." - BACON.

"Language being accommodated to the pronotions of men and the uses of life, it is diffeult to express therein the preeise truth of things, which are so eontrary to our prenotions. But to one of due attention, and who makes my words an oceasion of his own thinking, I conceive the whole to be very intelligible; and when it is rightly understood I scarce doubt but it will be assented to." - BERKELEY. 


\title{
LECTURE VIII
}

\author{
DARIVIN, AND THE ORIGIN OF SPECIES
}

THE aim of this lecture is to show that most of the post-Darwinian criticism of natural selection might have been avoided if Darwin and Wallace, and they who have come after, had not been unconsciously led to make use of words and forms which have since outlived their meaning.

I do not allude to the assertion so often made that natural selection personifies nature, and attributes to it the power of deliberate choice; for no one who thinks for himself can attach any such meaning to Darwin's words, or be misled by them.

The Duke of Argyll, indeed, says Darwin's work is " essentially the image of mechanical necessity concealed under the clothes and parading in the mask of mental purpose," since natural selection "personifies an abstraction." If the roses in a garden differ among themselves in power to resist cold, and the more tender ones are found dead after a hard winter, the Duke of Argyll may, if he sees fit, charge him who says the toughest ones have been selected, with infantile belief in the personal agency of Jack Frost, but I cannot believe thoughtful men will support him.

If living things differ among themselves, and if those which survive the struggle for existence are the ones which might have been expected to survive, natural selection is a fact; and while opinions as to the value of this fact may differ, the name we call it by matters little.

One of the most familiar criticisms of natural selection is that, since it does not produce, but only preserves, the fitness which exists, it does not show why there should be any fit to survive, but only why the unfit are exterminated.

"Natural selection," says Darwin ("Origin," p. 75), "acts only 
by the preservation and accumulation of small inherited modifications, each profitable to the preserved being." This has seemed, and still seems, to many, a valid reason for questioning its value as a scientific explanation of the origin of species; although no one who makes Darwin's words an occasion of his own thinking need be perplexed by this criticism. If peas are rolled down an inclined board, the largest go fastest, the smallest slowest, and the round ones go straight to the bottom, while the irregular ones run off the sides. What if one were to assert that this device can have no value as a means for sorting peas until we know what makes one pea large and another small, one round and another irregular? Yet this is, in effect, asserted by those who declare that natural selection has no value as an explanation of the origin of species, because it does not show why there should be anything useful to select. Without knowing why one horse is more fleet than another, or even why horscs exist, breeders have increased the speed of horses by breeding from the most fleet; just as a pack of wolves may increase it in nature by destroying, generation after generation, all the horses they can run down. If at every stage in the ancestry of horses there has been need for greater speed, natural selection accounts for the whole history of this power, and even for the first vague beginnings of locomotion in sedentary or floating animals, which may have found shelter from their enemies, or more abundant food, by those slight changes of place which may, at first, have been the incidental result of changes of shape.

While it is obvious that a useful quality must exist before it can be useful, and before it can be influenced by selection, and while no Darwinian holds natural selection to be an ultimate explanation of fitness, all admit that horses do differ among themselves in speed, and that each may reasonably be expected to be more like its parents in speed than like a horse selected at random. As no one disputes the existence of these prerequisites to selection, the statement that selection could not act unless they existed is childish.

I have tried to show, page 178 , that the work of Darwin and Wallace teaches that the only path in which we can have any wellfounded hope of progress in the explanation of the origin of species 
is that which takes its departure from that conception of specific adaptive types, which leads us to seek the origin of the "events" that exhibit the type in the physical properties of living matter, and to seek the origin of the statistical "law of error" which forms an adaptive type out of these events in the order of external nature. I shall now try to illustrate the way in which the order of nature forms adaptive types, or zoölogical species, out of the events which are afforded by the properties of living beings.

While no one doubts that the paths of all the drops in a shower of rain might have been predicted from mechanical data, one who knows none of these data may, by an umbrella, make determinate the paths of all the drops which immediately concern him. In statistical language we may say that, even if we know nothing of the causes of the events, we may make an adaptive type out of them by means of an umbrella; and if we move the umbrella to another place, we may make a new type, identical in adaptive value, out of a different set of events; for the causes of the events have nothing to do with the use to which we put them, except in this, that we could not use them unless they occurred.

If before a long line of machine guns, scattering bullets to all quarters of the field, we set up a target, exhaustive knowledge of machine guns might enable one to say how many balls will strike it in a given time, and how they will be distributed, but, as we use words, we say certain balls chance to hit, for the target does not affect in any way the course by which a ball reaches it. If we now put before the target a screen with a hole in it, no one safely before the screen would wish to show his face at the hole inconsiderately, since, so far as it affects him, the course of the balls which concern him has been made determinate.

Now imagine an unlimited series of similar screens set in line, each within range of the next, and suppose, furthermore, that while each ball that hits a screen drops and is lost; each one that goes through a hole grows into a new machine gun. No two objects, natural or artificial, are exactly alike, and among the original machine guns some would put more balls through the first screen, and have more descendants than others, even if they had been set, one after another, in the same place before the target. 
If we suppose that while the guns in each generation differ among themselves like the original guns, each is more likely than a gun taken at random to resemble its parent, is it not clear that if the guns in each generation and the screens in the series are both innumerable, the ultimate outcome of this survival of the fittest will be the production of a race of guns adapted for sending their balls through the holes in this particular series of screens, and that if another series of screens arranged in a different line or of a different size or shape were set up, the guns in later generations would become adapted for sending their bullets through them? It is not necessary for us to know anything about the mechanism of guns, or the reason why they differ among themselves, or any data which might enable us to predict the paths of the bullets, in order to see that this result may be expected to follow, in course of nature, if only the trials be innumerable; if all the balls which fail to go through a hole are counted out, and if each gun is, on the average, more like its parent than a gun selected at random.

Each discharge of a bullet is an event; the race of guns adapted for driving the bullets through the holes is an adaptive type, and the series of screens is the equivalent of those conditions of life which, in course of nature, form a zoölogical type, or species, out of the events which the infinite diversity among living things affords. I have used the illustration as the simplest way to show the error of the opinion that natural selection does not account for the origin of species unless the differences between individuals are adaptive prior to selection; for it is plain that, in our illustration, the result is independent of the nature of the projectiles, and equally independent of the mechanism by which they are propelled, since our reason for expecting the result would be the same even if they were unknown projectiles propelled by unknown means. It is also clear that one who witnessed the process from the far end, through the holes in the targets, might suppose that the course of adaptive modification had been directed, from behind, to a definite end, since none of the balls that failed to go through the holes would be visible from this point of view; nor would the discovery of fossil machine guns do much to correct this error; for the difference between the exterminated guns and the survivors in the same gen- 
eration would be so slight as to be unrecognizable except by actual trial.

A living thing is a being which responds to the stimulus of one event in such a way as to adjust its actions to other events of which the stimulus is the sign, and as all that have not thus responded have been exterminated in the struggle for existence, the adjustment of the survivors is no more than might have been expected.

Natural selection seems to me a strictly scientific explanation of the fitness of living things, and they who assert that it is inadequate because it fails to show why beneficial response should ever follow a stimulus, and thus furnish fitness to be selected, must remember that all science is inadequate to exactly the same degree; for in no case does science tell us why natural phenomena do occur in order, although it does tell what order we may reasonably expect.

If we find in nature no reason why extended things should have weight, except that the fact is so, need we wonder if we fail to discover any ultimate or final reason why sensitive things should respond, for does not every scientific explanation rest upon something which is granted even if unexplained?

"It passeth with many, I know not how, that mechanical principles give a clear solution of the phenomena... But, things rightly considered, perhaps it will be found not to solve any phenomena at all."

They who challenge the sufficiency of natural selection, because it does not show why there should be any fitness to select, must find all science equally inadequate; although the common verdict of mankind is that scientific knowledge is very adequate and sufficient for all the practical needs of living beings; even if it does fail to show us in nature any efficient cause for any phenomenon at all.

The task which faced Darwin when the "Origin of Species" was written, was to convince those who deny that species are mutable. At the present day, when all naturalists admit this, many question the adequacy of natural selection as an explanation of the origin of species. Now the way of presenting the argument, and the choice of words, which are best adapted for con- 
vincing those who deny the mutability of species, may not be, in fact cannot be expected to be, the best for demonstrating the value of natural selection to those who admit that species are mutable.

Before Darwin's day most systematic zoölogists and botanists believed that certain characteristics of each living being have "specific value" while others are "varietal." The question how you are to tell, from a single specimen, what characters are specific and what varietal gave rise to interminable disputes, but there was general agreement that the distinction exists in nature, and that very dreadful consequences would attend doubt of its reality.

Specific characters, and those of generic or ordinal value as well, were held to be immutable; and while the individual members of a species were admitted to differ among themselves, or to "vary," in characters which are not of specific, or more than specific value, all were held to be exactly alike in their specific characters, and also in all characters of generic or of still higher taxonomic importance.

As an exact science the Taxonomy of the last century is as extinct as the dodo, for its very name is well-nigh forgotten; and since few zoölogists of the new school carry their so-called bibliographical researches into the dust-covered books in which it is entombed on the top shelves of old libraries, they fail to discover that the words variety, vary, and variation were technical terms when the "Origin of Species" was written.

Of the twenty years and more which were devoted to the preparation of the book, many were spent in the study of domesticated animals and cultivated plants, and in the comparison and measurement of each species part by part. Darwin devoted himself to this work until he had obtained conclusive proof that specific characters are as mutable as varietal characters, and until he had shown that there is no organ or structure or marking or measurement or habit or instinct which may not exhibit diversity if many representatives of the species are carefully compared.

These observations and measurements, which were afterwards published as a book under the title of "The Variation of Animals 
and Plants under Domestication," firmly planted the word variation in the literature of a generation which has forgotten that it is a technical term; although any one who will make the attempt will find few places, in this book, or in the "Origin of Species," or in the writings of Wallace, where diversity may not be substituted for variation without changing the meaning; and although Darwin has himself defined the word in the introduction to this work ("Animals and Plants," Amer. ed., p. I4) in the promise that "in a second work I shall discuss the variability of organic beings in a state of nature, namely, the individual differences presented by animals and plants, and those slightly greater and generally inherited differences which are ranked by naturalists as varieties or geographical races." "We shall see," he says, "how difficult, or rather impossible, it often is, to distinguish between races and sub-species, as the less well-marked forms have sometimes been denominated, and again between sub-species and species."

Now, as words are commonly used, the great practical difference between diversity and variation in this; that, while all admit the infinite diversity of nature, variation is a dynamical change, and is not held to be accounted for until a physical cause of the change has been discovered.

I cannot believe any one would have thought that natural selection fails to account for the origin of species until we discover some other explanation of the fitness of the variations which are selected, if Darwin and Wallace had not used the word with this technical meaning; for we may admit that living things do not differ from each other without cause, without admitting that the physical causes of this diversity are adaptive.

The objection to natural selection which has thus arisen is often formulated as an assertion that since natural selection does not produce, but only preserves, the variations which are fittest, it accounts for nothing in itself, since the real explanation of the origin of species is to be sought in the "laws of variation" or "causes of variation," which must, it is said, supply the raw material for selection before this can be selected.

As it is self-evident that natural selection originates nothing, 
this objection is a very subtle one. In one or another of its many forms it has afforded the basis for most of the post-Darwinian criticism of Darwin's work; nor do I hope to demonstrate its error, at this late day, to any who have mastered the first four chapters of the "Origin" without conviction ; for he who does not succeed in making Darwin's clear and simple words an occasion of his own thinking, reminds one of the five brethren of a certain rich man mentioned in history.

If the individuals which, in each generation, make up a species differ among themselves in innumerable characters, and yet tend, on the whole, to be more like their parents than individuals taken at random, and if, furthermore, the rate of increase of all living things tends to outrun the means of support, the survival of the fittest, and the gradual perfection of the adjustments of each species are no more than might have been expected.

Fifteen years before he published the "Origin," Darwin wrote to Hooker as follows: "Heaven forfend me from Lamarck nonsense, but I think I have found out the simple way in which species become adapted to various ends": although the assertion that natural selection is dependent upon laws of variation, or causes of varialion, for its raw material denies, explicitly or by implication, that he had found out, in natural selection, the simple means by which species become adapted to the conditions of their life, for we must look to these lazes or causes for the real explanation of the usefulness of the properties which natural selection picks out and accumulates.

It must not be supposed that the only advocates of this opinion are natural theologians who are so short-sighted as to fear that, if natural selection were admitted to be an explanation of the fitness of living things, this might show that their fitness is not real fitness; for while it has been made much of in what has been supposed to be the interest of natural theology, it has also been held by men of science who seek no alliance with the natural theologians. In fact, one modern writer who tells us that this reasoning has no value when used in their interest (Romanes, "Darwin and after Darwin," I., p. 336), himself makes use of it a few pages further on in the supposed interest of science; for he tells us that if the Lamarckian principles are in any 
degree operative at all, the great function of these principles must be that of supplying to natural selection the incipient stages of adaptive modification in all cases, where, but for this agency, there would be nothing of the kind to select.

I hope to show that formidable as this criticism appears, and grave as the difficulty has seemed to many able thinkers, it is, after all, verbal in origin; and that they who believe that natural selection fails to account for the origin of species until some other source for the incipient stages of adaptive modification has been discovered are misled by words; for no Darwinian supposes that selection produces either the incipient or final stages of any modification, adaptive or otherwise, although all are aware that there is, unfortunately, no incompatibility between the system of things and injurious modification.

Darwin very wisely made much of the history of domesticated animals and cultivated plants, for many reasons; and, as I believe, for this among others: that since the use or purpose of fancy breeds is the gratification of the whim of the breeder, or conformity to the arbitrary rules of fanciers' clubs, good common sense must decline serious consideration of the belief that the causes of variation stand in any relation, incipient or otherwise, to this purpose, except so far as all nature may be intended.

Darwin writes to Asa Gray: "You lead me to infer that you believe that variation has been carried along certain beneficial lines. I cannot believe this: and I think you would have to believe that the tail of the Fantail was led to vary in the number and direction of its feathers in order to gratify the caprice of a few men." Few, even among those who believe that all nature bears witness to intention, will hold it good common sense to expect to discover any natural laws, or causes of variation, competent to adapt pigeons to the arbitrary rules of pigeon clubs; for while we may be unable to belicve that fanciers can bring about any change which a sufficient knowledge of the nature of pigeons might not have led us to expect, I cannot imagine how this nature, or the history of its origin, can be thought to stand, prior to selection, in any specific adjustment to the caprice of pigeon-fanciers; for we are much more likely to find the physical causes of this adjustment in the mechanism of the breeders' structure than to find it in the nature of pigeons. 
The evidence that man has produced all the fancy breeds of pigeons from a single wild species is admitted to be satisfactory; and if these fancy breeds differ among themselves as much, and under continued selection keep as true to their kind as wild species, it seems clear that we need not call the causes of variation to the aid of natural selection to account for the origin of the various species of wild pigeons from a common stock. Now the evidence that these fancy breeds do thus resemble wild species, as it is summarized by Darwin, in the first chapters of the "Origin," is as convincing as it is familiar, and there would be no need to refer to it here, did not the strange impression prevail that selection can accomplish nothing unless some other source of adaptive modification furnish the raw material to be selected.

Of domesticated pigeons Darwin says: "The diversity of the breeds is something astonishing. Compare the English carrier and the short-faced tumbler, and see the wonderful difference in their beaks entailing corresponding differences in their skulls.

"The carrier, more especially the male bird, is also remarkable for the wonderful development of the carunculations about the head; and this is accompanied by greatly elongated eyelids, very large external orifices to the nostrils, and a wide gape of mouth. The short-faced tumbler has a beak in outline almost like that of a finch; and the common tumbler has the singular inherited habit of flying at a great height in a compact flock, and tumbling in the air head over heels.

"The runt is a bird of great size, with very long, massive beak and large feet; some of the sub-breeds of runts have very long necks, others very long wings and tails, others very short tails. The barb is allied to the carrier, but, instead of a long beak, has a very short and broad one. The pouter has a much elongated body, wings, and legs; and its enormously developed crop, which it glories in inflating, may well excite astonishment and even laughter. The turbit has a short and conical beak, with a line of reversed feathers down the breast; and it has the habit of continually expanding, slightly, the upper part of the œsophagus. The Jacobin has the feathers so much reversed along the back of the neck that they form a hood; and it has, proportionally to its size, elongated wing and tail feathers. The trumpeter and 
laugher, as their names express, utter a very different coo from the other breeds. The fantail has thirty or even forty tail feathers instead of twelve or fourteen, - the normal number in all the members of the great pigeon family; these feathers are kept expanded, and are carried so erect, that in good birds the head and tail touch : the oil-gland is quite aborted. Several other less distinct breeds might be specified.

"In the skeletons of the several breeds, the development of the bones of the face in length and breadth and curvature differs enormously. The shape as well as the breadth and length of the ramus of the lower jaw varies in a highly remarkable manner. The caudal and sacral vertebræ vary in number, as does the number of the ribs, together with their relative breadth and the presence of processes. The shape and size of the apertures in the sternum are highly variable; so is the degree of divergence and relative size of the two arms of the furcula. The proportional width of the gape of the mouth, the proportional length of the eyelids, of the orifice of the nostrils, of the tongue (not always in strict correlation to the length of the beak), the size of the crop and of the upper part of the œsophagus; the development and abortion of the oil-glands; the relative length of the wing and tail to each other and to the body; the relative length of the leg and foot, the number of scutellæe on the toes, - are all points of structure which are variable. The period at which the perfect plumage is acquired varies, as does the state of the down with which the nestling birds are clothed when hatched. The shape and size of the eggs vary. The manner of flight, and in some breeds the voice and disposition, differ remarkably. Lastly, in certain breeds the males and females have come to differ in a slight degree from each other. ... Altogether, at least a score of pigeons might be chosen which, if shown to an ornithologist, and he were told that they were wild birds, would certainly be ranked by him as well-defined species.

"Moreover, I do not believe that any ornithologist would, in this case, place the English carrier, the short-faced tumbler, the runt, the barb, pouter, and fantail in the same genus; more especially as in each of these breecls several truly inherited sub-breeds or species, as he would call them, could be shown him." 
As fancy pigeons are obviously adapted to the tastes of pigeonfanciers, and as they owe their continued existence to this adaptation, in the absence of which they would have been exterminated long ago by man, it is hard to see why any one who knows what changes man has brought about by selection should assert that natural selection cannot bring about adaptation unless it is first supplied, from some other source, with adaptive "variations" in, at the least, their incipient stages; yet the incompetency of natural selection to account for these incipient stages has been made much of, not only by those who believe that there is no scientific or natural explanation of these incipient stages, but also by those who attribute them to the direct adaptive action of the conditions of life.

In a book on the "Genesis of Species," published soon after the "Origin," Mivart argues that even if we admit that natural selection is worthy of consideration, it can be no explanation of any adaptation which is not so useful that it preserves the life of its possessor; and he asserts that while perfected adaptations may thus preserve life, we cannot believe that the first minute beginnings of adaptation are valuable enough to be preservative.

Mivart's argument has recently been revived, in a somewhat modified form, by Romanes ("Darwin and after Darwin," II.), who holds that there are cases of adaptation where the degree of usefulness is so small that we cannot believe it has "selective value," and that even when useful reflex mechanisms have been fully formed, "it is often beyond the power of sober credence to believe that they now are, or ever can have been, of selective value in the struggle for existence."

Darwin's work would not have gained a hearing from contemporaries if he had not emphasized the results of artificial selection, but I shall now try to show that this emphasis has led many to infer, consciously or unconsciously, that the resemblance between natural selection and the methods of the breeder is greater than it really is; and that the prevalence of the belief that selection cannot account for the incipient stages of useful structures, and that there may be useful adaptations without selective value, is itself a result of Darwin's choice of the word selection; for no one can doubt that domesticated animals and cultivated plants may have characteris- 
tics which fail to attract the breeder's notice, and that, so far as he is concerned, they may be without "selective value."

The breeder may either destroy, promptly and utterly, the animals and plants which he discards, or else, if he have some use for them which is independent of reproduction, as he has for horses, he may cut them off, at once and forever, from all part in history; but it is a mistake to infer from this analogy that extermination in the natural struggle for existence always or even generally, means sudden death. Nothing could be further from the truth; for the total extinction of a genetic line is usually slow, and it may be carried on for many generations before it is finally consummated. Among the terrestrial animals and plants which we know best, sudden death during the reproductive period, when the living being is in its prime, is not uncommon, but each organism is so well adjusted to the dangers and hardships which it may, on the average, expect that those which are cut off completely from posterity are exceptional. "I must premise," says Darwin, "that I use this term struggle for existence in a large and metaphorical sense, including dependence of one being on another, and including (which is more important) not only the life of the individual, but success in leaving progeny. .. A A plant which annually produces a thousand seeds, of which on an average only one comes to maturity, may be said to struggle with the plants of the same and other kinds which already clothe the ground." I

In a long series of generations all degrees of success or failure in rearing progeny are possible, and when we bear in mind that, so far as natural selection is 'concerned, success in leaving descendants is practically equivalent to survival, no matter what the after-fate of the individual may be, it is plain that the process of extinction, far from being sudden, may go on so slowly as to be imperceptible, and that there may be many opportunities for every useful quality, however slight its value, to count for something in the result. "Battle within battle must be continually recurring with varying success; and yet in the long run the forces are so nicely balanced, that the face of nature remains for long periods of time uniform, though assuredly the merest trifle would give the victory to one organic being over another." 2

$$
1 \text { “Origin," p. } 50 .
$$$$
2 \text { "Origin," p. } 57 .
$$ 
We must not think of natural selection, after the analogy of artificial selection, as a competitive examination in one subject, where failure to pass means loss of all future chances. Rather must we think of it as a long but indefinite series of examinations, each in innumerable subjects, some of which count for much, others for little, some for very little, but all for something. We must, furthermore, supposc that all candidates who do not fail utterly may try again and again, but that each partial failure may, if some othcr candidate does better, diminish, in so far, the chance for success in future trials.

"Many differcnt checks, acting at diffcrent periods of life, and during different seasons or ycars, probably comc into play; but all will concur in determining the rcsult. When we look at the plants and bushcs clothing an cntangled bank, we are tcmpted to attribute the proportional numbers and kinds to what we call chance. But how false a vicw is this! Every one has heard that when an Amcrican forest is cut down, a vcry differcnt vegetation springs up; but it has bccn observed that ancient Indian ruins in the southern United Statcs, which must formerly have bcen clcared of trecs, now display the same beautiful diversity and proportion of kinds as in the surrounding virgin forest. What a struggle must have gonc on during long centuries betwcen the scveral kinds of trces, cach annually scattering its sceds by the thousand; what a war betwcen insect and insect, between insects, snails, and other animals, with birds and beasts of prey, - all striving to increase, all feeding on each other, or on the trees, their seeds and seedlings, or on the other plants which first clothed the ground, and thus checked the growth of the trees! Throw up a handful of feathers, and all fall to the ground according to definite laws; but how simple is the problem where each shall fall, compared to the action and reaction of the innumerable plants and animals which have determined, in the course of centuries, the proportional numbers and kinds of trees now growing on the old Indian ruins !" 1

Whilc the breeder cannot consciously and deliberately select any peculiarity which has not enough selectivc value to attract his notice, I do not see how any onc who is familiar with Dar1 “ Origin," p. 58. 
win's explanation of the struggle for existence can believe any useful structure will, in nature, be without selective value. All who grasp the meaning of the struggle for existence, which nature exhibits to all who have eyes to see, must agree with Darwin that, " owing to this struggle, variations, however slight, and from whatever cause proceeding, if they be, in any degree, profitable to the individuals of a species, in their infinitely complex relations to other organic beings and to their physical conditions of life, will tend to the preservation of such individuals." 1

If the opinion that natural selection cannot account for the incipient stages of useful structures did not exhibit such vitality, there would be no reason to dwell upon it; but as Romanes's book shows that thoughtful men still find it a real difficulty, I shall now examine two adaptations which have been used to illustrate the difficulty.

In a chapter which he added to the later editions of the "Origin," Darwin says that "after reading with care Mr. Mivart's book, and comparing each section with what I have said on the same head, I never before felt so strongly convinced of the general truth of the conclusions here arrived at"; although few illustrations of the extent and accuracy and minuteness of Darwin's acquaintance with nature are more impressive than his demonstration of the existence of useful adjustments similar to the incipient stages in the very adaptations which Mivart uses to prove his assertion that "natural selection cannot account for the incipient stages of useful structures."

"The Greenland whale," says Darwin, "is one of the most wonderful animals in the world, and the baleen, or whalebone, one of its greatest peculiarities. The baleen consists of a row, on each side of the upper jaw, of about three hundred plates or lamina, which stand close together transversely to the long axis of the mouth. Within the main row there are some subsidiary rows. The extremities and inner margins of the plates are frayed with stiff bristles, which clothe the whole gigantic palate, and serve to strain or sift the water, and thus secure the minute prey on which these great animals subsist. The middle and longest lamina in the Greenland whale is ten, twelve, or even fifteen 
feet in length; but in the different species of Cetaceans there are gradations in length; the middle lamina being in one species, according to Scoresby, four feet, in another three, in another eighteen inches, and in the Balcenoptera rostrata only about nine inches in length.

"With respect to the baleen, Mr. Mivart remarks that if it had once attained such a size and development as to be at all useful, then its preservation and augmentation within serviceable limits would be promoted by natural selection alone. But how to obtain the beginning of such useful development?

"In answer it may be asked, why should not the early progenitors of the whales with balecn have possessed a mouth constructed something like the laminated beak of a duck? Ducks, like whales, subsist by sifting the mud and water; and the family has sometimes been called the Cribratores, or sifters. I hope I may not be misconstrued into saying that the progenitors of whales did actually possess mouths laminated like the beak of a cluck. I wish only to show that this is not incredible, and that the immense plates of baleen in the Greenland whale might have been developed from such laminæ by fincly graduated steps, each of service to its possessor.

"The beak of a shoveller-duck (Spatula clypeata) is a more bcautiful and complex structure than the mouth of a whale. The upper mandible is furnished on each side (in the specimen examined by me) with a row or comb formed of 188 thin elastic laminæe obliquely bevelled so as to be pointed, and placed transversely to the long axis of the mouth. They arise from the palate, and are attached by flexible membrane to the sides of the mandible. Those standing towards the middle are the largest, being about one-third of an inch in length, and they project fourteen-hundredths of an inch beneath the edge. At their bases there is a short subsidiary row of oblique transverse laminæ. In these several respects they resemble the plates, of baleen in the mouth of a whale. But towards the extremity of the beak they differ much, as they project inwards instead of straight downwards. The entire head of the shoveller, though incomparably less bulky, is about one-eightecnth of the length of the head of a moderately large Balanoptera rostrata, in which species the baleen is only nine inches long, so that if we 
were to make the head of the shoveller as long as that of the Balænoptera, the lamellæ would be six inches in length; that is, two-thirds of the length of the baleen in this species of whale. The lower mandible of the shoveller duck is furnished with lamellæ of equal length with those above, but finer; and in being thus furnished it differs conspicuously from the lower jaw of the whale, which is destitute of baleen. On the other hand, the extremities of the lower lamellæ are frayed into fine bristly points, so that they thus curiously resemble the plates of baleen. In the genus Prion, a member of the distinct family of the Petrels, the upper mandible alone is furnished with lamellæ, which are well developed and project beneath the margin, so that the beak of this bird in this respect resembles the mouth of a whale.

"From the highly developed structure of the shoveller's beak we may proceed, without any great break, as far as fitness for sifting is concerned, through the beak of the Merganetta armata, and in some respects through that of the Aix sponsa to the beak of the common duck. In this latter species the laminæe are much coarser than in the shoveller, and are firmly attached to the sides of the mandible; they are only about fifty in number on each side, and do not project at all beneath the margin. They are squaretipped, and are edged with translucent, hardish tissue, as if for crushing food. The edges of the lower mandible are crossed by numerous fine ridges, which project very little. Although the beak is thus very inferior to that of the shoveller as a sifter, yet this bird, as evcry one knows, constantly uses it for this purpose. There are other species in which the laminæ are considerably less developed than in the common duck, but I do not know whether they use their beaks for sifting the water.

"Turning to another group of the same family. In the Egyptian goose (Chcnoplax) the bcak closely resembles that of the common duck; but the laminxe are not so numcrous, nor do they project so far inwards; yet this goosc uses its bill like a duck by throwing the water out of the corncrs. Its chief food, however, is grass, which it crops like a common goosc. In the lattcr bird the laminx of the upper mandible are much coarser than in the common duck, almost confuent, about twenty-seven in number on each side, and terminating upwards in tooth-like knobs. The palate is also covered 
with hard, round knobs. The edges of the lower mandible are serrated with teeth much more prominent, coarser, and sharper than in the duck. The common goose does not sift the water, but uses its beak exclusively for tearing or cutting herbage, for which purpose it is so well fitted that it can crop grass closer than almost any other animal. There are other species of geese in which the laminæe are less developed than in the common goose.

"We thus see that in a member of the duck family with a beak constructed like that of the common goose, and adapted solely for grazing, or even a member with a beak having less well developed laminæ, might be converted by small changes into a species like the Egyptian goose, - this into one like the common duck, - and, lastly, into one like the shoveller, provided with a beak almost exclusively adapted for sifting the water; for this bird could hardly use any part of its beak except the hooked tip for seizing or tearing solid food.

"Returning to the whales. The Hyperoodon bidens is destitute of true teeth in an efficient condition, but its palate is roughened with small, unequal points of horn. There is, therefore, nothing improbable in supposing that some early Cetacean form was provided with similar plates of horn on the palate, but rather more irregularly placed, and which, like the knobs on the beak of the goose, aided it in seizing or tearing its food. If so, it will hardly be denied that the points might have been converted through variation and natural selection into laminx as well developed as those of the Egyptian goose, in which case they would have served exclusively as a sifting apparatus. From this stage, in which the laminæe would have been two-thirds of the plates of baleen of the Balcenoptera rostrata, gradations, which may still be observed in existing Cetaceans, lead us onwards to the enormous plates of baleen in the Greenland whale. Nor is there the least reason to doubt that each step in this scale might have been as serviceable to certain ancient Cetaceans, with the functions of the parts slowly changing during the progress of development, as are the gradations in the beaks of the existing members of the duck family. We should bear in mind that each species of duck is subjected to a severe struggle for existence, 
and that the structure of every part of its frame must be adapted to its conditions of life." 1

In Romanes's hands, Mivart's old argument, which made Darwin more strongly convinced of the correctness of his own views than before, assumes a new form; for he attempts to show that many reflex actions have been brought about by the coadaptation of parts which were "severally useless," and that the degree of adaptation exhibited by the resulting whole is often so slight as to be incompatible with belief that the reflex response has now, or ever had, "selective value."

While he holds natural selection incompetent to account for the mechanism which brings about a reflex action of this sort, he believes that this mechanism may be satisfactorily explained as the inherited effect of use; for he says that the doctrine that constantly associated use of the same parts for the performance of the same action will progressively organize these parts into a reflex mechanism, is the very essence of the theory of use-inheritance, - no matter how high a degree of coadaptation may thus be reached on the one hand, or how low a degree of utilitarian value on the other.

"In our organization," he says in illustration, "there is a reflex mechanism which insures the prompt withdrawal of the legs from any source of irritation supplied to the feet. For instance, after a man has broken his spine in such a manner as totally to interrupt the functional continuity of his spinal cord and brain, the reflex mechanism in question will continue to retract his legs when his feet are stimulated by a touch, a burn, etc. This action is clearly a responsive action, and, as the man neither feels the stimulus nor the resulting movement, it is as clearly a reflex action. The question now is as to its mode of origin and development.

"I ask whether we can reasonably hold that this particular reflex action - comparatively simple though it be - has ever been of selective value to the human species, or to the ancestors thereof? Even in its present fully formed condition it is fairly questionable whether it is of any adaptive value at all. The movement performed is no doubt an adaptive movement; but 1 “Origin," pp. 182-186. 
is there any occasion upon which the reflex mechanism concerned therein can ever have been of adaptive use? Until a man's legs have been paralyzed as to their voluntary motion, he will always promptly withdraw his feet from any injurious source of irritation by means of his conscious intelligence. True, the reflex mechanism secures an almost inappreciable saving in the time of response to a stimulus as compared with the time required for response to an act of will; but the difference is so exceedingly small, that we can hardly suppose the saving of it in this particular case can be a matter of any adaptive - much less selective - importance.

"Nor is it more easy to suppose that the reflex mechanism has been developed by natural selection for the purpose of replacing voluntary action when the latter has been destroyed or suspended by grave spinal injury, paralysis, coma, or even ordinary sleep. In short, even if for the sake of argument we allow it to be conceivable that any human being, ape, or still more distant ancestor, has ever owed its life to the possession of this mechanism, we may still be certain that not one in a million can have done so. And if this is the case with regard to the mechanism as fully constructed, still more must it have been the case with regard to all the previous stages of construction. For here, without claborating the point, it would appear that a process of construction by survival of the fittest is incomprehensible." 1

As Romanes says that this is a typical illustration of the difficulty he finds in explaining the production of reflex actions in general by selection alone, it may be worth while to examine it; although the source of Romanes's difficulty is hard to discover.

When all the complicated muscles of the foot and leg and trunk are at rest, the irritation of the sole may be followed by violent retraction of the foot, but when they are brought into balanced action in the complex movements of walking or running, this does no more than to counterbalance and thus arrest some of these movements. The importance of perfect locomotor coördination is so clear to all that a moment's thought must show that the past history of our race has furnished abundant opportunities for the perfection of this coördination by selection. No one who reflects how often the life of a barefooted savage and 
the lives of all who depend upon him for food must be staked upon his ability to creep silently and rapidly to the side of his unsuspecting enemy, or upon his power to elude his pursuers by stealth, or upon his skill in stalking his prey without warning it by any movements which may be detected by its delicate and alert senses, - no one who bears all this in mind can doubt that the ability to arrest the descending foot before it treads upon a thorn or cracks a dry twig, has selective value. But, says Romanes, even if we admit that the sole of the foot has selective value, the,savage is able to interpret its warnings and to adjust his footsteps inteliigently; and while the reflex mechanism acts a little more promptly, the saving of time is too small to have selective value. I am not aware that any one has measured the time required to drive into the foot a thorn which has scratched it, or the time required for cracking a dry twig which the foot has touched; but Romanes tells us in an other place ("Mind and Motion and Monism," p. 9) that while a nerve-centre requires only about one-twentieth of a second to perform its part in a reflex action, where no thought or consciousness is involved, the operations which are comprised in perceiving a simple sensation, and the volitional act of signalling the perception, cannot be performed in less than one-twelfth of a second, which is nearly twice as long as the time required by the lower nerve-centres for the performance of the reflex action.

It seems probable that, in less than a thirtieth of a second, a scratch from a thorn might have become a disabling injury, which would place a warrior at the mercy of his pursuer; or that the prey which might have preserved the hunter and his family from starvation might be alarmed by the crackling of a twig in as short a time; although the mere saving of time is, no doubt, less valuable than the freedom from care about his footsteps which permits the warrior or the huntsman to fix every sense and every faculty on the matter in hand, and to trust to this reflex mechanism for prompt warning by the mechanical arrest of a dangerous step long enough for conscious intelligence to seek a place to finish it.

But Romanes says he does not see how we are to explain either the origin or the development of a reflex mechanism by 
selection alone; for even if we admit all that has been said, it seems to him to be self-evident that a reflex action must, from its very nature, already be given in a state of working efficiency if it is to work at all so as to count for anything in the struggle for life.

The history of the adjustment between tactile and muscular sensations and the orderly balancing of all the movements concerned in locomotion has been so long and complicated that we know little of its details, but I am not sure I understand what Romanes means by working efficiency. While slight irritation of the sole is followed by retraction of the foot, more prolonged irritation is followed, especially in the young, who have not yet learned to repress them, by indefinite but violent involuntary movements in many parts of the body, and I fail to see why any of these vague movements might not have been picked out by natural selection, if peculiarly useful, and gradually made more delicate and more definite and more useful; nor can I see why each step in this process of gradual specialization may not have been beneficial, or why it may not have had selective value.

All admit that while natural selection picks out, and preserves, it produces nothing, and if we can show how it corrects our bodily movements and reduces them to exactness by giving us distinct actions instead of confused and perplexed ones, I fail to see why this process should not be gradual. Romanes, it is true, seems to believe that responses which are now brought about involuntarily or unconsciously, by adaptive structure, would be easier to understand if we could show that they arose as "consciously intelligent adjustments"; for he holds that the inheritance of the effects of use furnishes an explanation of the origin of the adaptations which natural selection picks out and preserves, inasmuch as it shows how natural selection has been aided by "consciously intelligent action"; but I cannot reconcile with other opinions which I find in Romanes's works, his belief that a reflex response would be any easier to understand if we could show that it was, at one time, rational and accompanied by consciousness and volition.

Many thinkers of no little eminence, Romanes among them, hold the opinion that not only instincts and habits, but rational 
actions as well, may some time prove to be reflex from the beginning to the end of their history. There are men of science who believe that it may some time be proved that when we perform an action because our reason approves it, neither the response nor the approval of our reason is anything more than exhaustive knowledge of our organic mechanism would lead one to expect. No one who admits that, for all he knows to the contrary, rational actions may be reflex in this sense, can, in consistency, believe that the origin of an adaptive mechanism which is used intelligently is any easier to understand than the origin of one which is used unconsciously.

Romanes is not content with the admission that, for all one knows, rational actions may thus be mechanical; for he accepts this as a thing proved and accomplished, and says, "I think we may fairly expect that within a time less remote than the two centuries which separate us from Hobbes, the course of ideas in a given train of thought will admit of having its footsteps tracked in the corresponding pathways of the brain. Be this, however, as it may, even now we know enough to say that, whether or not these footsteps will ever admit of being thus tracked in detail, they are all certainly present in the cerebral structure of each one of us. What we know on the side of mind as logical sequence is, on the side of the nervous system, nothing more than the passage of nervous energy through one series of cells and fibres rather than another; what we recognize as truth is merely the fact of the brain vibrating in tune with nature." 1

While thus convinced that rational actions are mechanical, Romanes holds that proof that instincts which are now mechanical arose as "consciously intelligent adjustments" would make the history of these adjustments easier to understand.

"If function produces structure in the racc, as it docs in the individual," he says ("Darwin and after Darwin," I., p. 86), "the voluntary and frequently repeatcd actions may vcry well have lcd to an organic intcgration of the neuro-muscular mechanism concerned.

"Thus with regard to the phenomena of reflcx action in general, all the facts arc such as this theory (the inhcritancc of the effects of use) rcquires, while many of the facts are such as the

1 "Mind and Motion, and Monism," p. 17. 
theory of natural selection alone cannot conceivably explain. Indeed, it is not too much," says he, "to say that most of the facts are such as directly to contradict the latter theory in its application to them. I have endeavored," he says, "to show that we have a large class of such cases in the domain of reflex action, and shall next endeavor to show that there is another large class in the domain of instinct. ...

"If instinct be hereditary habit, i.e. if it comprises an element of transmitted experience, we at once," says Romanes, "find a complete explanation of many cases of the display of instinct which otherwise remain inexplicable. In all cases where instincts become complex and refined, we seem almost compelled to accept the view - that their origin is to be sought in conscionsly intelligent adjustments on the part of ancestors.

"Thus, to give only one example, a species of Sphex preys upon caterpillars which it stings in their nerve-centres for the purpose of paralyzing, without killing them. The victims, when thus rendered motionless, are then buried with the eggs of the Sphex, in order to serve as food for her larvæ which subsequently develop from these eggs. Now, in order to paralyze a caterpillar, the Sphex has to sting it successively in nine minute and particular points along the ventral surface of the animal - and this the Sphex unerringly does, to the exclusion of all other points of the caterpillar's anatomy. Well," says Romanes, "such being the fact, it is conceivable enough that the ancestors of the Sphex, being, like many other hymenopterous insects, highly intelligent, should have observed that on stinging caterpillars in these particular spots a greater amount of effect was produced than could be produced by stinging them anywhere else; and therefore that they habitually stung the caterpillars in these places only, till, in course of time, this originally intelligent habit became by heredity instinctive. But now, on the other hand, if we exclude the possibility of this explanation, it appears to me incredible that such an instinct should ever have been evolved at all; for it appears to me incredible that natural selection unaided by originally intelligent action could ever have developed such an instinct out of merely fortuitous variations - there being, by the hypothesis, nothing to determine variations of an insect's mind in the direction of stinging 
caterpillars in only these nine intensely localized spots. Finally, in the case of our species, it is self-evident," says Romanes, "that the resthetic, moral, and religious instincts admit of a natural and easy explanation on the hypothesis of use-inheritance, while such is by no means the case if that hypothesis be rejected."

No phenomena in the whole realm of nature are more difficult to handle than those Romanes here refers to. Many, no doubt, think, with him, that they are inexplicable by natural selection, although few among those who, so far, think as he does, seem likely to find satisfaction in that view of morality and religion which attributes these things to the inheritance of the effects of use.

We have already asked, page 66, what evidence there is that function ever does produce structure, either in the race or in the individual; and we have seen that when organs are improved by normal use, structures for bringing this useful end about already exist. Capacity for improvement by practice is itself an adaptation which calls for explanation, rather than an explanation or cause of adaptation.

The opinion that deliberate acts, habits, instincts, and reflex acts form a descending series, in which each lower manifestation has, at some time in the past, climbed down from the top of the ladder seems to commend itself to many. For this reason I have quoted Romanes's recent statement at some length, although no one can, with logical consistency, find, in this opinion, even if it be well founded, any help in accounting for the origin of instincts, or that of reflex acts, if deliberate acts are themselves mechanical and dependent upon the presence of adaptive structure.

If practice does no more than to correct responsive actions and to reduce them to exactness by the repression of those that are vague and indefinite and by the preservation of those that are exact and definite, how can it add anything to the nature of organisms? Romanes not only considers it proved that deliberate acts are mechanical, but he also holds that the only way to escape what he regards as the materialistic consequences of this conviction is to be found in the monistic creed that "the antithesis between mind and motion - subject and object-is itself phenomenal or apparent; not absolute or real." "We have 
only to suppose," he says, "that the seeming duality is relative to our modes of apprehension; and, therefore, that any change taking place in the mind, and any change taking place in the brain, are not two changes, but one change." "To suppose mind the cause of motion, or motion the cause of mind, is equally to suppose that which is neither true nor untrue, but nonsensical." "It is equally nonsense to speak of mental action causing cerebral action, or of cerebral action causing mental action, nonsense of the same kind as it would be to speak of the 'Pickwick Papers' causing a storm at sea, or the eruption of a volcano causing the forty-seventh proposition of the first book of Euclid."

I am myself quite unable to see how one who holds it nonsense to suppose mind can cause motion, can for a moment think the origin of a reflex act or automatic response would be easier to understand through proof that it was, at one time, accompanied by conscious intelligence. Neither they who know no reason why thought should not, some day, be reduced to mechanics, nor they who believe, with Romanes, that this has already been accomplished, can, in consistency, believe that use directed by intelligence can either bring about adaptive structures, or supply to natural selection even the incipient stages of adaptive modification, unless they attribute this adaptive influence to mere use, in itself, and not to the guidance of use by intelligence. If the Lamarckians tell us that this is their contention, and that it is mere use in itself that brings about adaptive structures, is it not obvious that, inasmuch as rational actions are, as a rule, more complicated than those we call reflex, their origin is not easier, but harder, to understand?

If we agree with Romanes that "what we know on the side of mind as logical sequence is on the side of the nervous system, nothing more than the passage of nervous energy through one series of cells and fibres rather than another," how can practice in logical reasoning bring about any of these cells or fibres or direct nervous energy into one series rather than another, except so far as adaptive mechanism for bringing this about already exists?

If "what we know as truth is merely the fact of the brain vibrating in tune with nature," is the belief that natural know- 
ledge adds anything to our nature more or less than belief that the brain is made to vibrate in tune with nature by vibrating in tune with nature? Is this belief any more significant or any more instructive than belief that the brain is made to vibrate in tune with nature by the "Pickwick Papers"?

It may be well to dwell a little on the assertion that what we know as truth is merely the vibration of a brain in tune with nature; and to ask what these words mean. Vibrations are said to be demonstrated when, directly or indirectly, we are made to perceive them by our senses; nor do I suppose that Romanes could ask or hope for better proof of his assertion than the demonstration, to our senses, of the actual vibration of a brain in tune with nature whenever a truth arises in the mind. Whether we share his confidence that this proof will be found in the next two hundred years or not, we may ask what it would mean, if found.

It is a truth that stones are heavy, and the vibration of a brain in tune with heaviness under the visual stimulus of a stone would be a response; but we know no reason why extended bodies should have weight, except that the fact is so. Without, at present, asking Berkeley's old question whether sensible vibrations of the brain or of anything else can exist otherwise than in a mind, may we not ask whether the vibration of the brain in tune with heaviness would tell us why we should think the thought that stones are heavy, any more than the fact that stones are heavy tells us why they should be? Would the sensible perception of the vibrations of our brains in tune with nature, whenever a truth arises in our minds, tell us anything except that, with experience, comes knowledge? Would it be any reason why this should be the case except that the fact is so? And do we not now all admit this as a fact?

We have good reason to hope that practical advantage to mankind will follow progress in the physiology of the brain, as it has followed all progress in natural knowledge; although it is hard to see what use there could be in proof that truth is the vibration of a brain in tune with nature, unless we also discover, outside our brains, some way to tell when their vibrations are in tune. 
I cannot conceive what better basis for a philosophy of mind and matter one who had seen the vibrations of a brain would have than one who knows he sees, and, as a rule, sees to his advantage, when he opens his eyes.

Must we not also reflect that some of the things we see may be hallucinations, or illusions, or somnambulatory dreams? Must we not ask the difficult but preëminently practical question how, admitting the vibrations, we distinguish those that are in tune with nature from those that are out of tune? How, for example, do the vibrations that go on as we think the thought that a stick half in water is bent, differ from those that go on as we think that the stick in the air is straight? Is it not because "snap" judgments about our sensible perceptions often lead us into difficulties and tend to our physical destruction; while rectified judgments are beneficial; because, for example, the savage who has corrected his judgment spears his fish, while he who has not loses his dinner. May not the difference perhaps prove, in ultimate analysis, to be that adjustments that are preservative of life are said to be in tune with nature, and their corresponding mental states truths; while those that are injurious are said to be out of tune, and their corresponcling mental states errors or illusions? May it not be because our brains are the ones that have so far survived the struggle for existence that we hold their normal vibrations to be in tune with nature? If this should prove to be the case, would it not be due to natural selection that our brains vibrate in tune with nature? If it were not for natural selection, might not all seem delusion; nothing truth?

No Darwinian questions the benefit of training, and practice, and education, and experience; for all this is matter of fact, admitted by all. Who can ask whether a man educated is different from the man uneducated? or whether the beneficial effects of nurture are anything more than might have been expected?

While he admits that, in some practical sense of the words, he is a free agent, responsible for his thoughts and actions, and able to act wisely or foolishly and to do right and wrong; the Darwinian asks whether voluntary acts are efficient causes of structure, or only antecedents of the sort which we call physical causes, or occasions, or stimuli; and whether they do anything 
more than to make manifest what was latent or potential. When pressed for a definition of latent potency, can he do more than to assert that activity is latent in a body if, while this body does what he expects under certain conditions, knowledge of these conditions does not tell him why it should? He asks, furthermore, whether it is conceivable that one cubit can be added to his stature by taking thought, either for one lifetime or for a million; although he admits that no one could expect to attain to his normal or natural stature without the stimulus of healthy muscular and nervous activity. He also asks whether the improvement of our faculties by use is anything more than the correction of our natural responses, and their reduction to exactness, by the suppression of those that are confused and perplexed, and the survival of those that are definite and distinct; and, ultimately, by the extinction of the deluded minds and the survival of those that are sane; and whether the history of individual life is anything more than the continuance of the process of natural selection.

Some hold that our race has, by its intelligence, emancipated itself from natural selection, and escaped from its domain into the realm of reason; but if we agree with Berkeley that the work of experience "is to unravel our prejudices and mistakes, gradually correcting our judgment and reducing it to a philosophical exactness," may we not ask whether knowledge itself is anything more than conscious apprehension of the unceasing activity of the selective process?

Darwin points out, even in the first edition of the "Origin," many difficulties which he is not able to solve. Some of them have been ably treated by later writers. Some are still unexplained, and in the next lecture I shall try to throw new light upon one of them. 



\section{LECTURE IX}

NATURAL SELECTION, AND THE ANTIQUITY OF LIFE 



\section{LECTURE IX}

NATURAL SELECTION, AND THE ANTIQUITY OF LIFE

In the "Origin of Species" Darwin says that the sudden appearance of species belonging to several of the main divisions of the animal kingdom in the lowest known fossiliferous rocks is at present inexplicable, and may be truly urged as a valid objection to his views.

If his theory be true, he says that "it is indisputable that before the lowest Cambrian stratum was deposited long periods elapsed, as long as, or probably far longer than, the whole interval from the Cambrian age to the present day, and that during these vast periods the world swarmed with living creatures. Here," he says, "we eneounter a formidable objection; for it seems doubtful whether the earth, in a fit state for the habitation of living creatures, has lasted long enough. To the question why we do not find such fossiliferous deposits belonging to these assumed earliest periods prior to the Cambrian system I can give no satisfactory answer."

On its geological side this difficulty is even greater than it was in Darwin's day, for we now know that the fauna of the Lower Cambrian was rich and varied; that most of the modern types of animal life were represented in the oldest fauna which has been discovered, and that all its types have modern representatives. The paleontological side of the subject has been ably summed up by Waleott in an interesting memoir on the oldest fauna whieh is known to us from fossils, and his collection of one hundred and forty-one American species from the Lower Cambrian is distributed over most of the marine groups of the animal kingdom, and, except for the absence of the remains of vertebrated animals, the whole province of animal life is almost as completely covered 
by these one hundred and forty-one species as it could be by a collection from the bottom of the modern ocean. Four of the American species are sponges, two are hydrozoa, nine are actinozoa, twenty-nine are brachiopods, three are lamellibranchs, thirteen are gasteropods, fifteen are pteropods, eight are crustacea, fifty-one are trilobites, and trails and burrows show the existence of at least six species of bottom forms, probably worms or crustacea. The most notable characteristic of this fauna is the completeness with which these few species outline the whole fauna of the modern sea-floor. Far from showing us the simple unspecialized ancestors of modern animals, they are most intensely modern themselves in the zoölogical sense, and they belong to the same order of nature as that which prevails at the present day.

The fossiliferous beds of the Lower Cambrian rest upon beds which are miles in vertical thickness, and are identical in all their physical features with those which contain this fauna. They prove beyond question that the waters in which they were laid down were as fit for supporting life at the beginning as at the end of the enormous lapse of time which they represent, and that all the conditions have since been equally favorable for the preservation and the discovery of fossils. Modern discovery has brought the difficulty which Darwin points out into clearer view, but geologists are no more prepared than he was to give a satisfactory solution, although I shall now try to show that the study of living animals in their relations to the world around them does help us, and that comparative anatomy and comparative embryology and the study of the habits and affinities of organisms tell us of times more ancient than the oldest fossils, and give a more perfect record of the early history of life than paleontology.

While the history of life as told by fossils has been slow and gradual, it has not been uniform, for we have evidence of the occurrence of several periods when modification was comparatively rapid.

We are living in a period of intellectual progress, and among terrestrial animals cunning now counts for more than size or strength, and fossils show that, while the average size of mammals has diminished since the Middle Tertiary, the size of their brains has increased more than one hundred per cent; that the 
brain of a modern mammal is more than twice as large, compared with its body, as the brain of its ancestors in the Middle Tertiary. Measured in years the Middle Tertiary is very remote, but it is very modern compared with the whole history of the fossiliferous rocks, although more of brain development has been effected in this short time than in all preceding time from the beginning.

The later paleozoic and early secondary fossils mark another period of rapid change, when the fitness of the land for animal life, and the presence of land plants, brought about the evolution of terrestrial animals.

I shall give reasons for seeing, in the Lower Cambrian, another period of rapid change, when a new factor - the discovery of the bottom of the ocean-began to act in the modification of species, and I shall try to show that, while animal life was abundant long before, the evolution of animals likely to be preserved as fossils took place with comparative rapidity, and that the zoölogical features of the Lower Cambrian are of such a character as to indicate that it is a decided and unmistakable approximation to the primitive fauna of the bottom, beyond which life was represented only by minute and simple surface animals not likely to be preserved as fossils.

Nothing brings homc more vividly to the zoölogist a picture of the diversity of the Lower Cambrian fauna and of its intimate relation to the fauna on the bottom of the modern ocean than the thought that he would have found on the old Cambrian shore the same opportunity to study the embryology and anatomy of pteropods and gasteropods and lamellibranchs, of crustacea and medusæ, echinoderms and brachiopods, that he now has at a marine laboratory; that his studies would have followed the same lincs then that they do now, and that most of the record of the past which they makc known to him would have been ancient history then. Most of the great types of animal life show by their embryology that thcy run back to simple and minute ancestors which lived at the surfacc of the ocean, and that the common meeting point must be projected back to a still more rcmotc time, bcforc these ancestors had become differcntiatcd from each other.

Aftcr we have traced each great linc of modern animals as far backward as we can through the study of fossils, we still find these 
lines distinctly laid down. The Lower Cambrian crustacea, for example, are as distinct from the Lower Cambrian echinoderms or pteropods or lamellibranchs or brachipods as they are from those of the present day, but zoölogy gives us evidence that the early steps in the establishment of these great lines were taken under conditions which were essentially different from those which have prevailed, without any essential change, from the time of the oldest fossils to the present day, and that most of the great lines of descent were represented in the remote past by ancestors, which, living a different sort of life, differed essentially, in structure as well as in habits, from the representatives of the same types which are known to us as fossils.

In the echinoderms we have a well-defined type represented by abundant fossils, very rich in living forms, very diversified in its modifications, and therefore well fitted for use as an illustration. This great stem contains many classes and orders, all constructed on the same plan, which is sharply isolated and quite unlike the plan of structure in any other group of animals. All through the series of fossiliferous rocks echinoderms are found, and their plan of structure is always the same. Paleontology gives us most valuable evidence regarding the course of evolution within the limits of a class, as in the crinoids or the echinoids; but we appeal to it in vain for light upon the organization of the primitive echinoderm or for connecting links between the classes. To our questions on these subjects, and on the relation of the echinoderms to other animals, paleontology is silent, and throws them back upon us as unsolved riddles.

The zoölogist unhesitatingly projects his imagination, held in check only by the laws of scientific thought, into the dark period before the times of the oldest fossils, and he feels absolutely certain of the past existence of a stem from which the classes of echinoderms have inherited the fundamental plan of their structure. He affirms with equal confidence that the structural changes which have separated this ancient type from the classes which we know from fossils are very much more profound and extensive than all the changes which each class has undergone from the earliest paleozoic times to the present day. He is also disposed to assume, but, as I shall show, with much less reason, that the amount of 
change which structure has undergone is an index to the length of time which the change has required, and that the period which is covered by the fossiliferous rocks is only an inconsiderable part of that which has been consumed in the evolution of the echinoderms.

The zoölogist does not check the flight of his scientific imagination here, however, for he trusts implicitly to the embryological evidence which teaches him that still farther back in the past all echinoderms were represented by a minute floating animal which was not an echinoderm at all in any sense except the ancestral one, although it was distinguished by features which natural selection has converted, under the illfuence of modern conditions, into the structure of echinoderms. He finds in the embryology of modern echinoderms phenomena which can bear no interpretation but this, and he unhesitatingly assumes that they are an inheritance which has been handed down from generation to generation through all the ages from the prehistoric times of zoölogy.

Other groups tell the same story with equal clearness. A lingula is still living in the sand-bars and mud-flats of the Chesapeake Bay under conditions which have not effected any essential change in its structure since the time of the Lower Cambrian. Who can look at a living lingula without being overwhelmed by the effort to grasp its immeasurable antiquity; by the thought that while it has passed through all the chances and changes of geological history, the structure which fitted it for life on the earliest paleozoic bottom is still adapted for a life on the sands of the modern sea-floor?

The everlasting hills are the type of venerable antiquity; but lingula has seen the continents grow up, and has maintained its integrity unmoved by the convulsions which have given the crust of the earth its present form.

As measured by the time-standards of the zoölogist lingula itself is modern, for its life history still holds locked up in its embryology the record, repeated in the development of each individual, of a structure and a habit of life which were lost in the unknown past at the time of the Lower Cambrian, and it tells us vaguely but unmistakably of life at the surface of the primitive ocean at a time when it was represented by minute and simple floating ancestors. 
Broadly stated, the history of each great line has been like that of the echinoderms and brachiopods. The oldest pteropod or lamellibranch or echinoderm or crustacean or vertebrate which we know from fossils exhibits its own type of structure with perfect distinctness, and later influences have done no more than to expand and diversify the type, while anatomy fails to guide us back to the point where these various lines met each other in a common source, although it forces us to believe that the common source once had an individual existence. Embryology teaches that each line once had its own representative at the surface of the ocean, and that the early stages in its evolution have passed away and left no record in the rocks.

If we try to call before the mind a picture of the land surface of the earth we see a vast expanse of verdure stretching from high up in the mountains over hills, valleys, and plains, and through forests and meadows down to the sea, with only an occasional lake or broad river to break its uniformity.

Our picture of the ocean is an empty waste, stretching on and on with no break in the monotony except now and then a flyingfish or a wandering sea-bird or a floating tuft of sargassum, and we never think of the ocean as the home of vegetable life. It contains plant-like animals in abundance, but these are true animals and not plants, although they are so like them in form and color. At Nassau, in the Bahama Islands, the visitor is taken in a small boat, with windows of plate glass set in the bottom, to visit the "sea-gardens" at the inner end of a channel through which the pure water from the open sea flows between two coral islands into the lagoon. Here the true reef corals grow in quiet water, where they may be visited and examined.

When illuminated by the vertical sun of the tropics and by the light which is reflected back from the white bottom, the pure, transparent water is as clear as air, and the smallest object forty or fifty feet down is distinctly visible through the glass bottom of the boat.

As this glides over the great mushroom-shaped coral domes which arch up from the depths, the dark grottoes between them and the caves under their overhanging tops are lighted up by the sun, far down among the anthozoa or flower animals and the 
zoöphytes or animal plants, which are seen through the waving thicket of brown and purple sea-fans and sea-feathers as they toss before the swell from the open ocean.

There are miles of these "sea-gardens" in the lagoons of the Bahamas, and it has been my good fortune to spend many months studying their wonders, but no description can convey any conception of their beauty and luxuriance. The general effect is very garden-like, and the beautiful fishes of black and golden yellow and iridescent cobalt blue hover like birds among the thickets of yellow and lilac gorgonias.

The parrot fishes seem to be cropping the plants like rabbits, but more careful examination shows that they are biting off the tips of the gorgonias and branching madrepores or hunting for the small crustacea which hide in the thicket, and that all the apparent plants are really animals.

The delicate star-like flowers are the vermilion heads of boring annelids or the scarlet tentacles of actinias, and the thicket is made up of pale lavender bushes of branching madrepores, and green and brown and yellow and olive masses of brain coral, of alcyonarians of all shades of yellow and purple, lilac and red, and of black and brown and red sponges. Even the lichens which incrust the rocks are hydroid corals, and the whole sea-garden is a dense jungle of animals, where plant life is represented only by a few calcareous algæ so strange in shape and texture that they are much less plant-like than the true animals.

The scarcity of plant life becomes still more notable when we study the ocean as a whole. On land herbivorous animals are always much more abundant and prolific than the carnivora, as they must be to keep up the supply of food, but the animal life of the ocean shows a most remarkable difference, for marine animals are almost exclusively carnivorous.

The birds of the ocean, the terns, gulls, petrels, divers, cormorants, tropic birds and albatrosses, are very numerous indeed, and the only parallel to the pigeon roosts and rookeries of the land is found in the dense clouds of sea-birds around their breeding grounds, but all these sea-birds are carnivorous, and even the birds of the seashore subsist almost exclusively upon animals such as mollusca, crustacea, and annelids. 
The seals pursue and destroy fishes; the sea-elephants and walruses live upon mollusks; the whales, dolphins and porpoises and the marine reptiles all feed upon animals, and most of them are fierce beasts of prey.

There are a few fishes that pasture in the fringe of seaweed which grows on the shore of the ocean, and there are some that browse among the floating tufts of algæ upon its surface, but most of them frequent these places in search of the small animals that hide among the plants.

In the Chesapeake Bay the sheepshead browses among the algæ upon the submerged rocks and piles like a marine sheep, but its food is exclusively animal, and I have lain upon the edge of a wharf watching it crunch the barnacles and young oysters until the juice of their bodies streamed out of the angles of its mouth and gathered a host of small fishes to snatch the fragments as they drifted away with the tide.

Many important fishes, like the cod, pasture on the bottom, but their pasturage consists of mollusks and annelicls and crustacea instead of plants, and the vast majority of sea-fishes are fierce hunters, pursuing and destroying smaller fishes, and often exhibiting an insatiable love of slaughter, like our own bluefish and the tropical albacore and barracuda. Others, such as the herring, feed upon smaller fishes and the pelagic pteropods and copepods; and others, like the shad, upon the minute organisms of the ocean; but all, with few exceptions, are carnivorous. In the other great groups of marine animals we find some scavengers, some which feed upon micro-organisms, and others which hunt and destroy each other, but there is no group of marine animals that corresponds to the herbivora and rodents and the plant-eating birds and insects of the land.

There is so much room in the vast spaces of the ocean, and so much of it is hidden, that it is only when surface animals are gathered together that the abundance of marine life becomes visible and impressive; but some faint conception of the boundless wealth of the ocean may be gained by observing the quickness with which marine animals become crowded together at the surface in favorable weather. On a cruise of more than two weeks along the edge of the Gulf Stream I was surrounded continually 
night and day by a vast army of dark-brown jelly-fish (Linerges mcrcutia), whose dark color made them very conspicuous in the clear water. We could see them at a distance from the vessel, and at noon, when the sun was overhead, we could look down to a great depth through the centre-board well, and everywhere, to a depth of fifty or sixty feet, we could see them drifting by in a steady procession like motes in a sunbeam. We cruised through them for more than five hundred miles and we tacked back and forth over a breadth of almost a hundred miles, and found them everywhere in such abundance that there were some in every bucketful of water we dipped up; nor is this abundance of life restricted to tropical waters, for Haeckel tells us that he met with such enormous masses of Limacina to the northwest of Scotland that each bucket of water contained thousands. The tendency to gather in crowds is not restricted to the smaller animals, and many species of raptorial fishes are found in densely packed banks.

The fishes in a school of mackerel are as numerous as the birds in a flight of wild pigeons, and we are told of one school which was a windrow of fish half a mile wide and at least twenty miles long. But while pigeons are plant eaters, the mackerel are rapacious hunters, pursuing and devouring the herrings as well as other animals.

Herring swarm like locusts, and a herring bank is almost a solid wall. In 1879 three hundred thousand river herring were landed in a single haul of the seine in Albemarle Sound; but the herring are also carnivorous, each one consuming myriads of copepods every day.

In spite of this destruction and the ravages of armies of medusæ and siphonophores and pteropods, the fertility of the copepods is so great that they are abundant in all parts of the ocean, and they are met with in numbers that exceed our power of comprehension. On one occasion the Challonger steamed for two days through a dense cloud formed of a single species, and they are found in all latitudes, from the arctic regions to the equator, in masses which discolor the water for miles. We know, too, that they are not restricted to the surface, and that the banks of copepods are sometimes more than a mile thick. When we reflect 
that thousands would find ample room and food in a pint of water, one can form some faint conception of their universal abundance.

The organisms which are visible in the water of the ocean and on the sea-bottom are almost universally engaged in devouring each other, and many of them, like the bluefish, are never satisfied with slaughter, but kill for mere sport.

Insatiable rapacity must end in extermination unless there is some unfailing supply, and as we find no visible supply in the water of the ocean we must seek it 'with a microscope, which shows us a wonderful fauna made up of innumerable larvæ and embryos and small animals, but these things cannot be the food supply of the ocean, for no carnivorous animal could subsist very long by devouring its own children. The total amount of these animals is inconsiderable, however, when compared with the abundance of a few forms of protozoa and protophytes, and both observation and deduction teach that the most important element in marine life consists of some half-dozen types of protozoa and unicellular plants; of globigerina and radiolarians, and of trichodesmium, pyrocystis, protococcus and the coccospheres, rhabdospheres, and diatoms.

Modern microscopical research has shown that these simple plants, and the globigerine and radiolarians which feed upon them, are so abundant and prolific that they meet all demands and supply the food for all the animals of the ocean. This is the fundamental conception of marine biology. The basis of all the life in the modern ocean is found in the micro-organisms of the surface.

This is not all. The simplicity and abundance of the microscopic forms and their importance in the economy of nature show that the organic world has gradually taken shape around them as its centre or starting-point, and has been controlled by them. They are not only the fundamental food supply, but the primeval supply, which has determined the whole course of the evolution of marine life.

The pelagic plant life of the ocean has retained its primitive simplicity on account of the very favorable character of its environment, and the higher rank of the littoral vegetation and that of the land is the result of hardship.

On land the mineral elements of plant food are slowly supplied, 
as the rains dissolve them; limited space brings crowding and competition for this scanty supply; growth is arrested for a great part of each year by drought or cold; the diversity of the earth's surface demands diversity of structure and habit, and the great size and complicated structure of terrestrial plants are adaptations to these conditions of hardship.

At the surface of the ocean the abundance and uniform distribution of mineral food in solution, the area which is available for plants, the volume of sunlight and the uniformity of the temperature are all favorable to the growth of plants, and as each plant is bathed on all sides by a nutritive fluid, it is advantageous for the new plant-cells which are formed by cell-multiplication, to separate from each other as soon as possible, in order to expose the whole of their surface to the water. Cell-aggregation, the first step toward higher organization, is therefore disadvantageous to the pelagic plants, and as the environment at the surface of the ocean is so monotonous, there is little opportunity for an aggregation of cells to gain any compensating advantage by seizing upon a more favorable habitat. The pelagic plants have retained their primitive simplicity, and the most distinctive peculiarity of the microscopic food supply of the ocean is the very small number of forms which make up the enormous mass of individuals.

All the animals of the ocean are dependent upon this supply of microscopic food, and many of them are adapted for preying upon it directly, but a review of the animal kingdom will show that no highly organized animal has ever been evolved at the surface of the ocean, although all depend upon the food supply of the surface.

The animals which now find their home in the open waters of the ocean are, almost without exception, descendants of forms which lived upon or near the bottom, or along the seashore, or upon the land, and all the exceptions are simple animals of minute size. A review of the whole, animal kingdom would take more space than we can spare, but it would show that the evidence from embryology, from comparative anatomy, and from paleontology all bears in the same direction and proves that every large and highly organized animal in the open ocean is descended from ancestors whose home was not open water, but solid ground, either 
on the bottom or on the shore. Embryology also gives us guod ground for believing that all these animals are still more remotely descended from minute and simple pelagic ancestors, and that the history of all the highly organized inhabitants of the water has followed a roundabout path from the surface to the bottom and then back into the water. When this fact is seen in all its bearings, and its full significance is grasped, it is certainly one of the most notable and instructive features of evolution.

The food supply of marine animals consists of a few species of microscopic organisms which are inexhaustible and the only source of food for all the inhabitants of the ocean. The supply is primeval as well as inexhaustible, and all the life of the ocean has gradually taken shape in direct dependence upon it. In view of these facts we cannot but be profoundly impressed by the thought that all the highly organized marine animals are products of the bottom or the shore or the land, and that while the largest animals on earth are pelagic, the few that are primitively pelagic are small and simple. The reason is obvious. The conditions of life at the surface are so easy that there is little fierce competition, and the inorganic environment is so simple that there is little chance for diversity of habits.

The growth of terrestrial plants is limited by the scarcity of food, but there is no such limit to the growth of pelagic plants or the animals which feed on them, and while the balance of life is no doubt adjusted by competition for food, this is never very fierce, even at the present day, when the ocean swarms with highly organized wanderers from the bottom and the shore. Even now the destruction or escape of a microscopic pelagic organism depends upon the accidental proximity or remoteness of an enemy rather than upon defence or protection, and survival is determined by space relations rather than a struggle for existence.

The abundance of food is shown by the ease with which wanderers from the land, like sea-birds, find places for themselves in the ocean, and the rapidity with which they spread over its whole extent.

As a marine animal the insect Halobates must be very modern as compared with most pelagic forms, yet it has spread over all tropical and subtropical seas, and it may always be found skimming over the surface of mid-ocean as much at home as a Gerris 
in a pond. I have never found it absent in the Gulf Strcam when conditions were favorable for collecting.

The easy character of pelagic life is shown by the fact that the larvæ of innumerable animals from the bottom and the shore have retained their pelagic habit, and I shall soon give reasons for believing that the larva of a shore animal is safer at sea than near the shore.

There was little opportunity in the primitive pelagic fauna and flora for an organism to gain superiority by seizing upon an advantageous site or by acquiring peculiar habits, for one place was like another, and peculiar habits could count for little in comparison with accidental space relations. After the fauna of the surface had been enriched by all the marine animals which have become secondarily adapted to pelagic life, competition with those improved forms brought about improvements in those which were strictly pelagic in origin, like the siphonophores, and those wanderers from the bottom introduced another factor into the evolution of pelagic life, for their bodies have been utilized for protection or concealment and in other ways, and we now have fishes which hide in the poison curtain of Physalia, crustacea which live in the pharynx of Salpa or in the mouth of the menhaden, barnacles and sucking fish fastened to whales and turtles, besides a host of external and internal parasites. The primitive ocean furnished no such opportunity, and the conditions of pelagic life must at first have been very simple, and while competition was not entirely absent the possibilities of evolution must have been extremely limited and the progress of divergent modification very slow so long as all life was restricted to the waters of the ocean.

There can be no doubt that floating life was abundant for a long period when the bottom was uninhabited. The slow geological changes by which the earth gradually assumed its present character present a boundless field for speculation, but there can be no doubt that the surface of the primeval ocean became fit for living things long before the deeper waters or the sca-floor, and during this period the proper conditions for the production of large and complicated organisms did not exist, and even after the total amount of life had become very great it must have consisted of organisms of small sizc and simple structure. 
Marine life is older than terrestrial life, and as all marine life has shaped itself in relation to the pelagic food supply, this itself is the only form of life which is independent, and it must therefore be the oldest. There must have been a long period in primeval times when there was a pelagic fauna and flora rich beyond limit in individuals, but made up of only a few simple types. During this time the pelagic ancestors of all the great groups of animals were slowly evolved, as well as other forms which have left no descendants. So long as life was restricted to the surface no great or rapid advancement, through the influences which now modify species, was possible, and we know of no other influences which might have replaced them. We are therefore forced to believe that the differentiation and improvement of the primitive flora and fauna were slow, and that, for a vast period of time, life consisted of an innumerable multitude of minute and simple pelagic organisms. During the time which it took to form the thick beds of older sedimentary rocks the physical conditions of the ocean gradually took their present form, and during a part, at least, of this period the total amount of life in the ocean may have been very nearly as great as it is now without leaving any permanent record of its existence, for no rapid advance took place until the advantages of life on the bottom were discovered.

We must not think of the populating of the bottom as a physical problem, but as discovery and colonization, very much like the colonization of islands. Physical conditions for a long time made it impossible, but its initiation was the result of biological influences, and there is no reason why its starting-point should necessarily be the point where the physical obstacles first disappeared. It is useless to speculate upon the nature of the physical obstacles; there is reason to think one of them, probably an important one, was the deficiency of oxygen in deep water.

Whatever their character may have been, they were all, no doubt, of such a nature that they first disappeared in the shallow water around the coast, but it is not probable that bottom life was first established in shallow water, or before the physical conditions had become favorable at considerable depths.

The sediment near the shore is destructive to most surface animals, and recent explorations have shown that a stratum of 
water of very great thickness is necessary for the complete development of the floating microscopic fauna and flora, and it is a mistake to picture them as confined to a thin surface stratum. Pelagic plants probably flourished as far down as light penetrates, and pelagic animals are abundant at very great depths. As the earliest bottom animals must have depended directly upon the floating organisms for food, it is not probable that they first established themselves in shallow water, where the food supply is both scanty and mixed with sediment; nor is it probable that their establishment was delayed until the great depths had become favorable to life.

The belts around elevated areas far enough from shore to be free from sediment, and deep enough to permit the pelagic fauna to reach its full development above them, are the most favorable spots, and paleontological evidence shows that they were seized upon very early in the history of life on the bottom.

It is probable that colony after colony was established on the bottom and afterwards swept away by geological change like a cloud before the wind, and that the bottom fauna which we know was not the first. Colonies which started in shallow water were exposed to accidents from which those in great depths were free, and in view of our knowledge of the permanency of the sea-floor and of the broad outlines of the continents, it is not impossible that the first fauna which became established in the deep zone around the continents may have persisted and given rise to modern animals. However this may be, we must regard this deep zonc as the birthplace of the fauna which has survived, as the ancestral home of all the improved metazoa.

The effect of life upon the bottom is more interesting than the place where it began, and we are now to consider its influence upon animals, all whose ancestors and competitors and cnemies had previously been pelagic. The cold, dark, silent, quict depths of the sca are monotonous compared with the land, but they introduced many new factors into the course of organic evolution.

It is doubtful whether the animals which first settled on the bottom secured any more food than the floating ones, but they undoubtedly obtained it with less effort, and were able to devote their superfluous energy to growth and to multiplication, and thus 
to become larger and to increase faster than pelagic animals. Their sedentary life must have been favorable to both sexual and asexual multiplication, and the tendency to increase by budding must have been quickly rendered more active, and one of the first results of life on the bottom must have been to promote the tendency to form connected cormi, and to retain the connection between the parent and the bud until the latter was able to obtain its own food and to care for itself. The animals which first acquired the habit of resting on the bottom soon began to multiply faster than their swimming allies, and their asexually produced progeny, remaining for a longer time attached to and nourished by the parent stock, were much more favorably placed for rapid growth. As the animals of the bottom live on a surface, or at least a thin stratum, while swimming animals are distributed through solid space, the rapid multiplication of bottom animals must soon have led to crowding and to competition, and it quickly became harder and harder for new forms from the open water to force themselves in among the old ones, and colonization soon came to an end.

The great antiquity of all the types of structure which are represented among modern animals is therefore what we should expect; for, after the foundation of the fauna of the bottom was laid, it became, and has ever since remained, difficult for new forms to establish themselves.

Most of our knowledge of the sea-bottom is from three sources: from dredgings and other explorations, from rocks which were formed beyond the immediate influence of continents, and from the patches of the bottom fauna which have gradually been brought near its surface by the growth of coral reefs; and from all these sources we have testimony to the density of the crowd of animals on favorable spots. Deep-sea explorations give only the most scanty basis for a picture of the sea-bottom, but they show that animal life may thrive with the dense luxuriance of tropical vegetation, and Sir Wyville Thomson says he once brought up at one time on a tangle, which was fastened to a dredge, over twenty thousand specimens of a single species of sea-urchin. The number of remains of paleozoic crinoids and brachiopods and trilobites which are crowded into a single slab of fine-grained limestone 
is most astounding, and it testifies most vividly and forcibly to the wealth of life on the old sea-floor.

No description can convey any adequate conception of the boundless luxuriance of a coral island, but nothing else gives such a vivid picture of the capacity of the sea-floor for supporting life. Marine plants are not abundant on coral islands, and the animals depend either directly or indirectly upon the pelagic food supply, so that their life is the same in this respect as that of animals in the deep sea far from land.

The abundant life is not restricted to the growing edge of the reef, and the inner lagoons are often like crowded aquaria. At Nassau my party of eight persons found so much to study on a little reef in a lagoon close to our laboratory, that we discovered novelties every day for four months, and our explorations seldom carried us beyond this little tract of bottom. Every inch of the bottom was carpeted with living animals, while others were darting about among the corals and gorgonias in all directions; but this was not all, for the solid rock was honeycombed everywhere by tubes and burrows, and when broken to pieces with a hammer each mass of coral gave us specimens of nearly every great group in the animal kingdom. Fishes, crustacea, annelids, mollusca, echinoderms, hydroids, and sponges could be picked out of the fragments, and the abundance of life inside the solid rock was most wonderful.

The absence of pelagic life in the landlocked water of coral islands is as impressive and noteworthy as the luxuriance of life upon and near the bottom.

On my first visit to the Bahama Islands I was sadly disappointed by the absence of pelagic animals where all the conditions secmed to be peculiarly favorable.

The deep ocean is so near that, as one cruises through the inner sounds past the openings between the islets which form the outer barrier, the deep blue water of mid-ocean is seen to meet the white sand of the beach, and soundings show that the outer edge is a precipice as high as the side of Chimborazo and much stecper.

Nowhere else in the world is the pure water of the deep sea found nearer land or more free from sediment, and on the days 
when the weather was favorable for outside collecting we found siphonophores and pteropods, pelagic mollusks and crustacea and tunicates and all sorts of pelagic larvæ in great abundance in the open water just outside the inlets.

Inside the barrier the water was always calm, and day after day it was as smooth as the surface of an inland lake. When I first entcred one of these beautiful sounds, where the calm, transparent water stretches as far as the eye can reach, while new beauties of islets and winding channels open before one as those which are passed fade away on the horizon, I felt sure that I had at last found a place where the pelagic fauna of mid-ocean could be gathered at our door and studied on shore. The water proved to be not only as pure as air but almost as empty. At high water we sometimes captured a few pelagic animals near the inlets, but we dragged our surface nets through the sounds day after day only to find them as clean as if they had been hung in the wind to dry. The water in which we washed them usually remained as pure and empty as if it had been filtered, and we often returned from our towing expeditions without even a copepod or a zoea or a pluteus.

The absence of the floating larva is most remarkable, for the sounds swarm with bottom animals which give birth every day to millions of swimming larvæ. The mangrove swamps and the rocky shores are fairly alive with crabs carrying eggs in all stages of development, and the boat passes over great black patches of sea-urchins crowded together by thousands. The number of animals engaged in laying their eggs or hatching their young is infinite, yet we rarely captured any larvæ in the tow net, and most of these we did find were well advanced and nearly through their larval life.

It is often said that the water of coral sounds is too full of lime to be inhabited by the animals of the open ocean, but this is a mistake, for the water is perfectly fit for supporting the most delicate and sensitive animals, and those which we caught outside lived in the house in water from the sounds better than in any other place where I ever tried to keep them, for instead of being injurious, the pure water of coral sounds is peculiarly favorable for use in aquaria for surface animals. 
The scarcity of floating organisms can have only one explanation. They are eaten up, and competition for food is so fierce that nearly every organism which is swept in by the tide and nearly every larva which is born in the sounds is snatched by the tentacles around some hungry mouth.

Nothing could illustrate the fierceness of the struggle for food among the animals on a crowded sea-bottom more vividly than the emptiness of the water in coral sounds where the bottom is practically one enormous mouth. The only larvæ which have much chance to establish themselves for life are those which are so fortunate as to be swept out into the open ocean, where they can complete their larval life under the milder competition of the pelagic fauna, and while it is usually stated that the larvæ of bottom animals have retained the pelagic habit for the purpose of distributing the species, it is more probable that it has been retained on account of its comparative safety.

These facts show that competition must have come quickly after the establishment of the first fauna on the bottom, and that it soon became very rigorous and led to severe selection and rapid modification; and we must also remember that life on the bottom brought with it many new opportunities for divergent specialization and improvement. The increase in size which came with economy of energy increased the possibilities of variation and led to the natural selection of peculiarities which improved the efficacy of the various parts of the body in their functions of relation to each other, and this has been an important factor in the evolution of complicated organisms.

The new mode of life also permitted the acquisition of protective shells, hard-supporting skeletons, and other imperishable parts, and it is therefore probable that the history of evolution in later times gives no index as to the period which was required to evolve from small, simple pelagic ancestors the oldest animals which were likely to be preserved as fossils.

Life on the bottom also introduced another important evolutionary influence-competition between blood-relations. In those animals which we know most intimately, divergent modification, with the extinction of connecting forms, results from the fact that the fiercest competitors of each animal are its closest allies, 
which, having the same habits, living upon the same food, and avoiding enemies in the same way, are constantly striving to hold exclusive possession of all that is essential to their welfare.

When a stock gives rise to two divergent branches, each escapes competition with the other so far as they differ in structure or habits, while the parent stock competing with both at a disadvantage is exterminated.

Among the animals which we know best, evolution leads to a branching trec-like gencalogy, with the topmost twigs represented by living animals, while the rest of the tree is buried in the dead past. The connecting form between two species must therefore be sought in the records of the past or reconstructed by comparison. Even at the present day things are somewhat different in the open ocean, and they must have been very different in the primitive ocean, for a pelagic animal has no fixed home, one locality is like another, and the competitors and enemies of each individual are determined in great part by accidents. We accordingly find, even now, that the evolution of pelagic animals is often linear instead of divergent, and ancient forms, such as the sharks, often live on side by side with the later and more evolved forms. The radiolarians and medusa and siphonophores furnish many well-known illustrations of this feature of pelagic life.

No naturalist is surprised to find in the South Pacific or in the Indian Ocean a Salpa or a pelagic crustacean or a surface fish or a whale which was previously known only from the North Atlantic, and the list of species of marine animals which are found in all seas is a very long one. The fact that pelagic animals are so independent of those laws of geographical distribution which limit land animals is additional evidence of the casy character of the conditions of pelagic life.

One of the first results of life on the bottom was to increase asexual multiplication and to lengthen the time during which buds remain united to and nourished by their parents, and to crowd individuals of the same species together and to cause competition between relations. We have in this and other obvious peculiarities of life on the bottom a sufficient explanation of the fact that since the first establishment of the bottom fauna, evolution has resulted in the elaboration and divergent specialization of 
the types of structure which were already established, rather than the production of new types.

Another result of the struggle for existence on the bottom was the escape of varieties from competition with their allies by flight from the crowded spots and a return to the open water above; just as in later times the whales and sea-birds have gone back from the land to the ocean.

These emigrants, like the civilized men who invade the homes of peaceful islanders, brought with them the improvements which had come from fierce competition, and they have carried everything before them and produced a great change in the pelagic fauna.

The rapid intellectual development which has taken place among the mammals since the Middle Tertiary, and the rapid structural changes which took place in animals and plants when the land fauna and flora were established, are well known, but the fact that the discovery of the bottom initiated a much earlier and probably more important era of rapid development in the forms of animal life has never been pointed out.

If this view is correct, the primitive life of the bottom must have had the following characteristics:-

(I) It was entirely animal, without plants, and it at first depended directly upon the pelagic food supply.

(2) It was established around elevated areas in water deep enough to be beyond the influence of the shore.

(3) The great groups of animals were rapidly established from pelagic ancestors.

(4) The animals of the bottom rapidly increased in size and hard parts were quickly acquired.

(5) The bottom fauna soon produced progressive development among pelagic animals.

(6) After the establishment of the fauna of the bottom, elaboration and differentiation among the representatives of each primitive type soon set in and led to the extinction of connecting forms.

Many of the oldest fossils like the pteropods are the modified descendants of ancestors with hard parts, and there is no reason to suppose that the first animals which were capable of preserva- 
tion as fossils have been discovered, but it is interesting to note that the oldest known fauna is an unmistakable approximation to the primitive fauna of the bottom.

The Lower Cambrian fossils are distributed through strata more than two miles thick, some, at least, of them showing by their fine grain, and by the perfect preservation of tracks and burrows which were made in soft mud, and of soft animals like jelly-fish, that they were deposited in water of considerable depth. The sediment was laid down slowly and gently in water so deep as to be free from disturbance and under conditions so favorable that it contains the remains of delicate animals not often found as fossils.

While the fauna of the Lower Cambrian undoubtedly lived in water of very considerable depth, it was not oceanic but continental, for we are told by Walcott that "one of the most important conclusions is that the fauna of the Lower Cambrian lived on the eastern and western shores of a continent that in its gencral configuration outlines the Amcrican continent of to-day." "Strictly speaking, the fauna did not live upon the outer shore facing the ocean, but on the shores of interior seas, straits, or lagoons that occupied the intervals between the several ridges that ran from the central platform east and west of the main continental land surface of the time."

This fauna was rich and varied, but it was not self-supporting, for no fossil plants are found, and the primary food supply was pelagic. Animals adapted for a rapacious life, such as the pteropods, were abundant, and prove the existence of a rich supply of pelagic animals. All the forms known from the fossils are either carnivorous, like the medusæ, corals, crustacea, and trilobites, or they are adapted, like the sponges, brachiopods, and lamellibranchs, for straining minute organisms out of the water or for gathering those which rained down from above, and the conditions under which they lived were very similar to those on the bottom at the present day.

Walcott's studies show that the earliest known fauna had the following characteristics: It consisted, so far as the record shows, of animals alone, and these were dependent upon the pelagic food supply for support. While small in comparison with many modern 
- animals, they were gigantic compared with primitive pelagic animals. The species were few, but they represent a very wide range of types. All these types have modern representatives, and most of the modern types are represented in the Lower Cambrian. Their home was not the bottom of the deep ocean, but the shores of a continent under water of a considerable depth.

The Cambrian fauna is usually regarded as a halfway station in a series of animal forms which stretches backward into the past for an immeasurable period, and it is even stated that the history of life before the Cambrian is longer by many fold than its history since. So far as this opinion rests on the diversity of types in Cambrian times, it has no good basis; for if the views here advocated are correct, the evolution of the ancestral stems took place at the surface, and all the conditions necessary for the rapid production of types were present when the bottom fauna first became established.

As we pass backward toward the Lower Cambrian we find closer and closer agreement with the zoölogical conception of the character of primitive life on the bottom. While we cannot regard the oldest fauna which has been discovered as the first which existed on the bottom, we may feel confident that the first fauna of the bottom resembled that of the Lower Cambrian in its physical conditions and in its most distinctive peculiarities, - the abundance of types, and the slight amount of differentiation among the representatives of these types, - and we must regard it as a decided and unmistakable approximation to the beginning of the modern fauna of the earth, as distinguished from the more ancient and simple fauna of the open ocean. 



\section{LECTURE X}

NATURAL SELECTION AND NATURAL THEOLOGY 



\section{LECTURE $X$}

\section{NATURAL SELECTION AND NATURAL THEOLOGY}

DARwin's book on the "Origin of Species" did not make its way, even among men of science, without searching examination; and it is interesting to note that, in the early days of its history, all of its most prominent advocates were English in their intellectual training, although some, like Asa Gray, were not English by birth. Lyell, Wallace, Darwin, Gray, and Huxley knew Lamarck's writings well, and, in this day of Neo-Lamarckism, we may find profit in studying the influences that led all these vigorous and independent thinkers to condemn his speculations as worse than worthless, while they welcomed natural selection as one of the greatest triumphs of the human mind.

The story of the reception of the "Origin," as it is told in Darwin's letters, shows how it won its way in spite of prejudice. Belief that the problem is one that man may hope to solve was rapidly growing among the thoughtful; for a long series of brilliant discoveries in embryology, in anatomy, in paleontology, in geographical biology, and in many other fields, had shown that zoölogy is orderly, and exhibits laws, like other sciences; but the remains of so many failures lay beside the path of history that most cautious students, in England at least, were in a hostile rather than a sympathetic frame of mind, and were indisposed to welcome a new attempt to bring all these classes of phenomena into a single point of view.

To men like Huxley, who had refused to have anything to say to a necessary principle of universal progress, and had grown weary of speculation, Darwin's book commended itself as strictly scientific; for it is based upon the hard work of half a lifetime, and, making no attempt to account for the fundamental properties 
of living things, which it takes as it finds them, it demonstrates that the features in which the species of living things differ from one another, are due to influences that are still at work, and open to observation and experiment by scientific methods.

Darwin shows that individual animals and plants, even those of the same species, differ greatly among themselves; that these differences may be exhibited by any characteristic whatever those upon which the species and genera of the systematist are based, as well as those which had been held to be varietal or individual; that, notwithstanding these differences, offspring tencl to resemble their parents, and to be like them in the main; that man is able to bring about, and to fix or establish, changes of type, by breeding from selected parents; and that features exactly like those upon which species are based may be modified or produced by selection; and that what is thus accomplished by man may come about with equal certainty, even if more slowly, in nature through the struggle for existence and the cxtermination of the unsuccessful.

None of these propositions are very profound, or very difficult to grasp. They call for no unexampled powers of abstract thought, for they lie so near the surface that they have been formulated again and again.

Darwin says: "My brother, who is a very sagacious man, always said, "You will find that some one has been before you';" and on the first page of the first edition of the "Origin," which was published in November, 1859, he says, after telling the reader that the subject has occupied him steadily for twenty years: "My work is now (I 859) nearly finished; but as it will take me many more years to complete it, and as my health is far from strong, I have been urged to publish this Abstract. I have the more especially been induced to do this, as Mr. Wallace, who is now studying the natural history of the Malay archipclago, has arrived at almost exactly the same general conclusions that $I$ have on the origin of species. In 1858 he sent me a memoir on this subject, with a request that I would forward it to Sir Charles Lyell, who sent it to the Linnean Society, and it is published in the third volume of the Journal of that Society. Sir Charles Lyell and Dr. Hooker, who both knew of my work, - the latter 
having read my sketch of 1844 , - honored me by thinking it advisable to publish, with Mr. Wallace's excellent memoir, some brief extracts from my manuscript."

Soon after the publication of the "Origin," he writes to Lyell as follows: "Now for a curious thing about my book, and then I have done. In last Saturday's Gardener's Chronicle a Mr. Patrick Mathew publishes a long extract from his work on 'Naval Timber and Arboriculture,' published in $183 \mathrm{I}$, in which he briefly but completely anticipates the theory of Natural Selection." A few days later, in the Gardcner's Chronicle, he says: "I freely acknowledge that Mr. Mathew has anticipated by many years the explanation which I have offered of the origin of species, under the name of natural selection. I can do no more than offer an apology to Mr. Mathew for my entire ignorance of this publication. If another edition of my work is called for, I will insert to the foregoing effect."

A few years later Darwin writes to Hooker as follows: "Talking of the 'Origin,' a Yankee has called my attention to a paper attached to Dr. Wells's famous 'Essay on Dew,' which was read in 1813 to the Royal Society, but not then printed, in which he applies the principle of Natural Selection to the Races of Man. So poor old Patrick Mathew is not the first, and he cannot, or ought not, any longer to put on his title-page "Discoverer of the Principle of Natural Selection." "

In the "Historical Sketch" which is printed in all subsequent editions, Darwin fulfils his promise to Mathew, and also refers at length to Dr. W. C. Wells of Charleston, S.C., whose statement is contained in "An Account of a White Female, part of whose skin resembles that of a negro," afterwards (I8I8) published as part of an appendix to his "Two Essays on Dew and Single Vision."

After remarking that negroes and mulattoes enjoy an immunity from certain tropical diseases, he observes that all animals tend to vary to some degree, and that agriculturalists improve their domestic animals by selection, and that what is done in the latter case by art, seems to be done with equal efficacy, though more slowly, by nature, in the formation of varieties of mankind, fitted for the country which they inhabit. Of the accidental varieties of man, 
which would occur among the first few and scattered inhabitants of the middle regions of Africa, some one would be better fitted than the others to bear the diseases of the country. This race would consequently multiply, while the others would decrease, not only from their inability to sustain the attacks of disease but from their incapacity to contend with their more vigorous neighbors. The color of this vigorous race would be black for the reason given. The same disposition to form varieties still existing, a darker and a darker race would in course of time occur; and as the darkest would be the best fitted for the climate, this would at length become the most prevalent if not the only race in the particular country in which it had originated.

It is sometimes said that the success of the "Origin," and the independent enunciation of its central conception by so many thinkers, proved that the subject was in the air, or that men's minds were prepared for it; but Darwin says he does not think this was strictly true; for while he occasionally sounded not a few naturalists, he never happened to come across a single one who seemed to doubt about the permanency of species. Even Lyell and Hooker, though they would listen with interest, never seemed to agree. He says that he tried once or twice to explain to able men what he meant by Natural Selection, but signally failed; and Huxley bears witness, as do others, that the sentiment of the most profound naturalists was critical rather than sympathetic.

Darwin tells us the publication in 1858 of Mr. Wallace's clever and admirably expressed essay, together with an abstract from his own notes, "excited very little attention, and the only published notice of them which I can remember was by Professor Houghton of Dublin, whose verdict was that all that was new in them was false, and that what was true was old."

Darwin has himself tried to analyze the mental qualities and conditions on which his success has depended; and he is no doubt right in attributing much of his success as an investigator and much of his influence upon scientific thought to the indefatigable industry which is so clearly shown in all his works; and the success of the "Origin" was no doubt due to its vast array of demonstrated facts, rather than to the way in which the argument was stated; but Lamarck was also an earnest, simple- 
hearted, indefatigable student, whose interest in nature never halted or wavered, and whose most important work, the "History of the Invertebrates," was undertaken when he was old and blind, and in poverty and suffering.

We must, therefore, search more deeply for the secret of the rejection by English naturalists of Lamarck's hypothesis, and their welcome to the "Origin of Species."

In I844, or sixteen years before the publication of the "Origin," Darwin writes to Hooker: "I have been now ever since my return engaged in a very presumptuous work, and I know not one individual who would not say a very foolish one. I am so struck with the distribution of the Galapagos organisms, etc., and with the character of the American mammifers, etc., that I determined to collect blindly every sort of fact which could bear in any way on what are called species. I have read heaps of agricultural and horticultural books and have never ceased collecting facts. At last gleams of light have come, and I am almost convinced (quite contrary to the opinion I started with) that species are not (it is like confessing a murder) immutable. Heaven forfend me from Lamarck nonsense of a 'tendency to progression,' 'adaptations through the slow willing of animals,' etc. But the conclusions I am led to are not widely different from his: though the means of change are wholly so. I think I have found out (here's presumption) the simple way in which species become exquisitely adapted to various ends. You will now groan, and think to yourself, 'on what a man I have been wasting my time and writing to.' I should five years ago have thought so."

Darwin gives a list of thirty-five writers who, during the early part of the nineteenth century, expressed belief in the mutability of species, or, at least, disbelief in separate acts of creation, before his own work was published; and even at an carlier date the speculations of Oken, Gocthe, Buffon, and others had brought the subject into prominence.

Of all these writers Lamarck had put the question in the most definite form and discussed it most completely. His views are the only ones which had attracted much attention, but while they were well known in England they had little influence there upon the men of science, except to cast discredit on new attempts. "The hypoth- 
esis had been sadly damaged by its supporters," says Huxley, who "had studied Lamarck attentively," but had found no ground for changing his negative and critical attitude.

In I849 Darwin said of Lamarck, "his absurd though clever work has clone the subject harm" ; and I have quoted (p. 82) extracts from works written about the time the "Origin "was published, by naturalists who saw clearly that nurture can have no practical share in the origin of species unless it has a determinate influence in beneficial lines; nor are matters helped at all by attributing this determinate beneficial influence to a necessary law of universal progress; for natural laws are not rulers or governors over nature, but generalizations from an experience which seems to teach, among other things, that progress is neither necessary nor universal.

"If all organic beings thus tend to rise in the scale, how is it that throughout the world a multitude of the lowest forms still exist; and how is it that in each great class some forms are far more highly developed than others? Why have not the more highly developed forms everywhere supplanted and exterminated the lower? Lamarck, who believed in an innate and inevitable tendency towards perfection in all organic beings, seems to have felt this difficulty so strongly, that he was led to suppose that new and simple forms are continually being produced by spontaneous generation. Science has not yet proved the truth of this belief, whatever the future may reveal. On my theory the continued existence of lowly organisms offers no difficulty; for natural selection, or the survival of the fittest, does not necessarily include progressive development, - it only takes advantage of such variations as arise and are beneficial to each creature under its complex relations of life." 1

Even if it were shown that the sum of the conditions that make up the environment of organisms does, in the long run, make for fitness, the problem of the naturalist is not the existence of adaptations as such, but the existence of adaptive species; and if the fitness of the living world as a whole were to be explained by a general law of evolution, this would not tell us why we do not find innumerable transitional forms, living side by side with the actual species, and filling all the gaps between them.

While events in general take place, no doubt, according to the 1 "Origin," p. 98. 
mathematical law of probability, and exhibit statistical types, there is no necessary or inherent parallelism between the "generic types" of the physical world and those which are known to naturalists as species; for we find mollusks and crustacea and fishes living side by side in every little brook, the world over; and every part of the land and of the water, in all regions of the earth, has its own representatives of most of the great groups of animals and plants. Agassiz's "Essay on Classification" failed to deal that death blow to the "Origin," which was in the mind of the author, although Lamarckians might still study, with profit, its clear, earnest, and impregnable demonstration that there is no parallelism between the generic types of the physical environment of each species and the attributes of the species itself.

The most notable peculiarity of the English attitude of mind regarding the species question was the feeling so clearly expressed by Darwin, by Huxley, and by many other naturalists, that the attempts at a solution had so far been valueless, and that they had even excited hostility. Another notable fact is that, while the thirty-five authors, between 1800 and I 860 , to whom Darwin refers, wrote in many countries, in England, Ireland, Scotland, the United States, France, Belgium, Germany, and Russia, the four who definitely recognizcd and clearly stated the law of natural selection, Wells, Mathew, Wallace, and Darwin, were English in their intellectual training.

In order to grasp the full significance of the influences which led to the production and acceptance of the "Origin," it is clear that we must try to understand what caused a hostile frame of mind towards Lamarck, while thcre was no permanent hostility to the "Origin."

There secms to me to bc no doubt that this influence came, in part at least, from thc works of a school of writcrs on what was called natural theology, among whom John Ray (I624-I705), William Dcrham (I657-I735), and William Palcy (I743-I805) are best known. Nonc of thesc men was a notable contributor to scicnce: even Ray, who has the greatest claim to remembrance as a naturalist, was by no means the equal of contemporary students of science; and Derham did nothing in scicnce cxcept to edit Ray's works; while Paley makes no claim to originality, owing much, 
both facts and the manner of presenting them, to the Dutch writer, Nieuwentyt, who, in I716, wrote a book which was translated into English (I730) under the title of "The Religious Philosopher," although the real starting-point for the series of English books on natural theology, which culminated in the Bridgewater Treatises about I836, was the work on "The Wisdom of God Manifested in the Works of Creation," by Ray (I69I), who illustrates the delicacy and usefulness of all the parts of living creatures by such familiar examples of adaptation as the structure of the eye, the hollowness of the bones, the stomach of the camel, the armor of the hedgehog, etc.

Science formed no part of a "liberal" education in the early days of our century, and the youth who was born with the instincts of a naturalist found little to satisfy these instincts except books of this sort, which, scanty and inadequate as they are, have the charm, which often eludes the laboratory handbook, of emphasizing the environment as the complement of structure. The share of the writers on natural theology in shaping the education of English naturalists has not been adequately esteemed; for they substituted, for the vulgar ignorance which finds nothing but disgust spiced with immodesty in our bodily frame, a living sense of the grandeur and instructiveness of animated nature. No one can read Paley and fail to see that the mechanism of living things is at least as well worthy of study as the "humanities"; for whatever our opinion of the value of his conclusions may be, he shows that there is a field for the profitable employment of the best powers of the best minds in the most familiar plant; and that the humblest worm may furnish inexhaustible delight, and may lead us to questions which demand the utmost exercise of our highest faculties.

In I859 Darwin writes to Lubbock: "I do not think I hardly ever admired a book more than Paley's 'Natural Theology.' I could almost, formerly, have said it by heart"; and in his autobiography he says the logic of Paley's "Evidences" and of his "Natural Theology" "gave me as much delight as did Euclid. The careful study of these works, without attempting to learn any part by rote, was the only part of the academic course which, as I then felt, and as I still believe, was of the least use to me in the 
education of my mind. I did not at that time trouble myself about Paley's premises; and, taking these on trust, I was charmed and convinced by the long line of argumentation."

As most of the writers on natural theology were clergymen who united thorough literary education with professional training in the art of interesting untrained audiences, they made use of simple, familiar illustrations; and Paley, whose influence was greatest, bases his argument upon such things as the fitness of the eye for vision; the adaptation of the joints of our limbs to the movements which the limbs are fitted for making; the fitness of feathers for covering animals which fly; the advantage of symmetry in paired organs, like limbs and eyes; the compact arrangement of parts exhibited by the irregular viscera which are packed within the body without disturbing its external symmetry; and similar facts which may be easily verified by all: but early in our century there was published in England a series of books which, approaching natural science in the same way, appeal to more mature minds. The Rev. Francis Henry, eighth Earl of Bridgewater, who died Feb. II, I829, left by will to the Royal Society $£ 8000$, to be paid to the author or authors selected to write and publish a treatise "On the Power, Wisdom, and Goodness of God as manifested in Creation." The president of the society selected eight persons, each to undertake a branch of the subject and each to receive $£$ IOoO, together with any benefit which might accrue from the sale of his work.

The aim of these treatises is sufficiently indicated by the general title which was given to them in the will; but this is set forth, more at length, in the one on "Geology and Mineralogy considered with Reference to Natural Theology," by the Rev. William Buckland (1836).

"Its purpose," he tells us, "is to extend into the organic remains of a former world the same kind of investigation which Paley had pursued with so much success, in his examination of the evidences of design in the mechanical structure of the corporeal frame of man, and of the inferior animals which are placed with him on the present surface of the earth.

"Every comparative anatomist is familiar," he says, "with the beautiful examples of mechanical contrivances and compensations 
which adapt each existing species of herbivora and carnivora to its own position, place, and state of life. Such contrivances began not with living species; the geologist demonstrates their prior existence in the extinct forms of the same genera, which he discovers beneath the surface of the earth, and he claims for the author of these fossil forms under which the first types of such mechanism were cmbodied, the same high attributes of Wisdom and Goodness, the demonstration of which exalts and sanctifies the labors of Science in her investigations of the living world.

"The myriads of petrified remains which are disclosed by the researches of geology all tend to prove that our planet has been occupied in times preceding the creation of the human race by extinct species of animals and vegetables made up, like living organic bodies, of clusters of contrivances." It is the description of these "contrivances" which has given to this work and others like it their educational influence.

While all the books of this sort take special creation for granted, and are based, in one way or another, upon the assumption that fitness involves and implies "contrivance," they did good service to science by keeping clearly and distinctly before the minds of English naturalists the fact that, whatever the reason may be, adaptation or adjustment is the essential characteristic of living beings; that life is adjustment; and that what Aristotle sought to define as the "essence" of a living being, is its fitness for its place in nature.

As the facts of embryology and paleontology and geography began to press for explanation, and it became more and more obvious, during the first part of the nineteenth century, that species must owe their origin to some influence which is part of the discoverable order of nature, it is due to the writers on natural theology that the English naturalists repudiated all inadequate attempts, like that of Lamarck, and, maintaining a sturdy suspense, waited for some more adequate explanation.

Huxley says that in conversation with Herbert Spencer in 1852 and the years following, he himself took the ground that no suggestion respecting the causes of the transmutation assumed, which had been made, was in any way adequate to explain the phenomena; and Darwin's "Letters" show that his point of view was at first 
identical with that of Huxley, who says that the same influence which led him to put as little faith in the current speculations on this subject as in the venerable traditions recorded in the first two chapters of Genesis, was perhaps by a curious irony of fate more potent than any other in keeping alive a sort of pious conviction that the transmutation of species, after all, would turn out true.

He says, too, that most of his contemporaries who thought seriously about the matter were very much in his own state of mind, inclined to say to both creationists and evolutionists, "A plague on both your houses!" and disposed to turn aside from an interminable and fruitless discussion to labor in the fertile fields of ascertainable fact.

The publication of the work of Darwin and Wallace had, he tells us, the effect of "a flash of light, which to a man who has lost himself in a dark night, suddenly reveals a road which, whether it takes him straight home or not, certainly goes his way."

"That which we were looking for and could not find, was a hypothesis respecting the origin of known organic forms, which assumed the operation of no causes but such as could be proved to be actually at work."

The "Origin" provided us with the working hypothesis we sought. . . . My reflection, when I first made myself master of the central idea... was, How extremely stupid not to have thought of that!... the facts of variability, of the struggle for existence, of adaptation to conditions, were notorious enough; but none of us had suspected that the road to the heart of the species problem lay through them, until Darwin and Wallace dispelled the darkness, and the beacon-fire of the 'Origin' guided the benighted."

Clear and strong as was the light which fell on natural history with the discovery of the full significance of the fierce and unceasing struggle for existence which springs from the geometrical multiplication of organisms, the "beacon-fire of the "Origin'" shone with no less penetration on the basis of the argument of Ray and Paley and the authors of the Bridgewater Treatises; for it revealed the unbroken chain of natural causation which binds up, with the adaptations which Paley makes use of, those that 
are pointed out by Buckland, so that it is no longer possible to regard them as independent and distinct contrivances.

Darwin says: "The old argument from design in nature, as given by Paley, which formerly seemed to me so conclusive, fails now that natural selection is discovered. We can no longer argue that, for instance, the beautiful hinge of a bivalve shell must have been made by an intelligent being. There seems to be no more design in the variability of organic beings and in the action of natural selection than in the course which the wind blows."

If the supposed analogy between human contrivances and the works of nature be a mistake, Paley assuredly makes this mistake; although this is not pointed out in any hostile spirit, but solely for the purpose of showing those who are convinced, with Darwin, of the failure of the "old argument from design as given by Paley," that they may perhaps find a stronger argument; and that there may be more wisdom in Huxley's assertion that it is only "the commoner and coarser forms of teleology" that fail when tested by natural selection.

It is obvious to all that with the discovery of the significance of natural selection, the teleology which supposes that the eye, such as we see it in man or one of the higher vertebrates, was made with the precise structure which it exhibits, for the purpose of enabling the animal which possesses it to see, has undoubtedly received its death-blow; although Huxley, while pointing this out, reminds us that "nevertheless it is necessary to remember that there is a wider teleology, which is not touched by the doctrine of Evolution, but is actually based upon the fundamental proposition of Evolution."

Asa Gray, writing at the same or nearly the same time, soon after the "Origin" was published, says he cannot perceive that Darwin brings in any new kind of difficulty, and he expresses his conviction that they who think there is any incompatibility between belief in the mutability of species and belief in teleology occupy a position which is not only untenable, but "highly unwise and dangerous in the present state and present prospects of physical and physiological science." "We should," he says, "expect the philosophical atheist to take this ground; also, until better informed, the unlearned and unphilosophical believer; but we 
should think the thoughtful theistic philosopher would take the other side. Not to do so seems to concede that only supernatural events can be shown to be designed, which no theist can admit seems also to misconceive the scope and meaning of all ordinary arguments from design in nature."

Where can we find three more eminent naturalists, or three men more thoughtful, or more distinguished, than Darwin, Huxley, and Gray, for integrity of mind and for that sturdy conservatism which is not incompatible with independence?

What are we to infer if, after studying a subject they were all so preëminently fitted for handling, a subject which falls within a province to which all three had devoted their lives, they are led to such contradictory conclusions that one asserts that the old argument from design fails, now that natural selection is discovered, while another is convinced that natural selection presents to the believer in teleology no new difficulties, at the same time that a third tells us that although natural selection has given a deathblow to the commoner and coarser forms of teleology, there is a wider teleology which it does not touch at all?

Is it not clear that they have not all considered the same question? Must we not seek a meeting-point for Darwin and Gray in Huxley's more profound conception of the matter? May not the argument from design which Darwin had in mind be identical with the commoner and coarser teleology of Huxley? And may not the wider teleology which, as Huxley tells us, is untouched by natural selection, be that in which Gray finds no new difficulties?

Before we try to find out what this wider teleology is, it may be well to look more closely into the nature of the "death-blow" which science has given to "the old argument for design as given by Paley," and to this I shall devote this and the following lecture; while I shall try to show, in the lecture on the Mechanism of Nature, that zoölogy leaves ample room for a wider teleology, which may be independent of research into the sciences.

This blow cannot have come from the mere extension, as such, of the domain of natural causation; for Paley was as familiar as we with Newton's demonstration that all the hosts of heaven are a vast mechanism, regulated according to the same laws as those 
which are shown by a falling stone. When Paley's argument seemed so conclusive to Darwin, he had studied Lyell; nor did he doubt at all that the history of the earth, as we find it recorded in the rocks, is also part of the same orderly system of nature, and the changes now going on upon its surface part of the same orderly history. No one finds any death-blow to teleology in our confidence that the future history of the earth, and of the solar system, and of the stellar universe will be an orderly extension of its past history; and, far from asking whether this view of astronom $y$ is rational, the teleologist asserts that an impregnable basis for his argument must be sought in the fact that it is rational; for if instead of order we discovered only a chaotic or unintelligible history, which afforded no ground for reasonable expectation as to the future, it is hard to see where he could find any basis for his argument, for this seems to be founded on our confidence in the order of nature.

Paley himself points out that, far from weakening his argument, the appearance of new individual organisms, in the course of nature, by birth, is its very strength; and he argues that if the finder of a watch should find that it possessed the property of prodncing, in the course of its movements, other watches like itself, and so on indefinitely, this discovery would increase his admiration of the consummate skill of the contriver. "Though it be no longer probable that the individual watch which our observer had found was made immediately by the hand of an artificer, yet doth not the alteration in any wise affect the inference that an artificer hath been originally employed and concerned in the production. The argument from design and contrivance remains as it was. Marks of design and contrivance are no more accounted for now than they were before. Our going back ever so far brings us no nearer to the least degree of satisfaction upon the subject."

This passage shows that no death-blow can have been given to his argument by anything inherent in the demonstration of the mutability of species, in itself; and that the blow must have fallen upon some preconception of the matter; for if any find evidence of contrivance in the anatomical structure and in the functional activity of the human heart, for example, and in its 
development, according to nature, from a germ-cell which was part of the body of a preëxisting organism, I do not see how they can find anything but new reason for their opinion in the discovery that men and dogs and elephants and whales have all inherited their hearts from a common mammalian ancestor; nor need the proof furnished by the structure and development of the heart in all air-breathing vertebrates, of still more remote descent from ancestors that lived in the water and breathed by gills, fail to give new strength to the opinion.

Huxley, in I864, says: "If we apprehend the spirit of the 'Origin of Species' rightly, nothing can be more opposed to teleology as it is commonly understood than the Darwinian theory. According to teleology, each organism is like a rifle bullet fired straight at a mark; according to Darwin, organisms are like grapeshot, of which one hits something and the rest fall wide.

"For the teleologist an organism exists because it was made for the conditions in which it is found; for the Darwinian an organism exists because, out of the many of its kind, it is the only one which has been able to persist in the conditions in which it is found. Teleology implies that the organs of every organism are perfect and cannot be improved; the Darwinian theory simply affirms that they work well enough to enable the organism to hold its own against such competitors as it has met with, but admits the possibility of indefinite improvement. But an example may bring into clearer light the profound opposition between the ordinary teleological and the Darwinian conception.

"Cats catch mice, small birds, and the like, very well. Teleology tells us that they do so because they were constructed for so doing, - that they are perfect mousing apparatuses, so perfect and so delicately adjusted that no one of their organs could be altered, without the change involving the alteration of all the rest. Darwinism affirms, on the contrary, that there was no express construction concerned in the matter; but that among the multitudinous variations of the Feline stock, many of which died out for want of power to resist opposing influences, some, the cats, were better fitted to catch mice than others, whence they throve and persisted, in proportion to the advantage over their fellows thus offered to them. 
"Far from imagining that cats exist in order to catch mice well, Darwinism supposes that cats exist because they catch mice well, - mousing being not the end but the condition of their existence."

If this were all the difficulty natural selection puts in the way of the argument from contrivance, I cannot believe Paley would have found it serious; for it is obvious that "it is not necessary that a machine be perfect in order to show with what design it was made"; and I imagine Paley's answer to Huxley would be that, whether the cat exists for catching mice or because of catching mice, the adjustment between its mechanism and the life of mice is as real as the adjustment between the movements of the watch and the movements of the earth, and as useful to cats as watches are to those who make and buy them; although we must not forget to consider cats from the standpoint of the mouse.

Darwin's objection to Paley's argument has recently been developed, at greater length, by Romanes, who holds that while the origin of species by gradual development does not in itself affect the argument from contrivance, it does so, when contrasted with belief in special creation, because it reveals the possibility that structures like the human eye may have been proximately due to the operation of physical causes, whereas this possibility is excluded by the hypothesis of sudden or special creation.

If the eye, as we find it in man, owes its origin to the slow and gradual centralization and specialization, by natural selection, of a vague sensibility to light, which was originally diffused over the whole surface of the body, it follows "that each step in the prolonged and gradual development of the eye was brought about by the elimination of all the less adapted structures in any given generation, i.e. the selection of all the better adapted to perpetuate the improvement by heredity."

"Will the teleologist," asks Romanes, "maintain that this selective process is itself indicative of special design? If so, it appears to me," he says, "that he is logically bound to maintain that the little veins of colored sand, and of fragments of shells which we so often find on the seashore, separated out from the acres of yellow sand and brought together by the selective action of gravity, are all equally indicative of special design." "The general 
laws relating to specific gravity are at least of as much importance in the economy of nature as are the general laws relating to specific differentiation; and in each illustration alike [that is, in the eye and in the separation and segregation of the sands of the sea-beach] we find the result of the operation of known physical causes to be that of selection. If it should be argued in reply that the selective action in the one case is obviously purposeless, while in the other it is as obviously purposive, I answer that this is a pure assumption. It is, perhaps, not too much to say that every geological formation on the face of the globe is either wholly or in part due to the selective influence of specific gravity, and who can say that the construction of the earth's crust is a less important matter in the general scheme of things (if there is such a scheme) than is the evolution of the eye? Or who shall say that because we see an apparently intentional adaptation of means to ends as the result of selection in the case of the eye, there is no such intention served by the result of selection in the case of the seaweeds, stones, sand, mud? For anything that we know to the contrary, the supposed intelligence may take a greater delight in the latter than in the former process."

While Romanes's reasoning is identical with that which I have already quoted from Darwin, its failure to overthrow, or even to fairly meet, Paley's argument is made all the more clear by Romanes's more explicit statement of his difficulty; for Paley's contention is not that the eye is designed in any way which may not be equally true of nature as a whole, but that it gives peculiar evidence of design.

However we may have come by our eyes, we prize sight as a most useful and precious endowment, and we know that the adjustment between the mechanism of the eye and the data of optics is so useful to all who see that they may at any time owe to it their lives; while we are unable to attach any meaning to an assertion that the course which the wind blows is useful to the wind, whatever may be the unknown significance of either eye or wind in the economy of nature as a whole.

One may admit total ignorance of the significance, in the general scheme of nature, of the skill of cats in catching mice; one may fail to see how the way the grains of sand fall can be useful 
or important to the sand; and yet see clearly that skill in catching mice is useful to cats, even if the mouse might also have something to say on the subject if he could be heard.

As I understand "the old argument from design as given by Palcy," it is as follows:-

(I) Nothing accounts for watches but mind.

(2) Nothing accounts for living things unless it accounts for watches.

(3) Nothing but mind accounts for living things.

The resemblance between the watch and the eye is no less real, and no less obvious than it was before natural selection was discovered; and this discovery seems to me so far from destroying Paley's minor premise that it gives to human contrivances a significance of which Paley never dreamed; for it shows that the basis for his argument, which he finds in the resemblance between human contrivances and the attributes of living things, is impregnable.

If it be true that natural sclection has given a death-blow to his argument, Darwin and Huxley and Romanes fail, in the passages I have quoted, to show either the nature of the blow or how it hits the argument; for no one can see the whole meaning of natural selection without secing that we no longer have any reason to think that the history of watches differs in any fundamental way from the history of spiders' webs, and birds' nests, and eyes, and cats.

As the mind refuses to believe that the relation between cats and mice is due to "chance," the difficulty pre-Darwinian thinkers found in accounting for it, without attributing it to interference with the course of nature, was inability to find, in our knowledge of nature, any reason why the life of mice should ever be brought, in course of nature, into that peculiar relation to the structure of cats which we call physical causation.

Wallace and Darwin have shown that this causal relation actually exists, and that the life of mice is an important clement in that objective or physical environment of cats which has determined all that is distinctive or characteristic in their structure by extermination and survival. While it may be no explanation of 
the properties which cats have in common with other living things, and while it may leave the hardship which cats bring to mice as much of a puzzle as ever, natural selection is a strictly scientific explanation of the point in question: the specific adjustment of cats to the life of mice; for, when all the conditions of the problem are known, it shows that we have, through the discoveries of Darwin and Wallace, the same rational confidence that the life of mice will modify the structure of cats as we have for judicious expectation that a current in the ocean will modify the course of a ship; although there is no reason to suppose, in either case, that our confidence is more than reasonable and judicious; for we find in nature no ultimate or final reason why the current should modify the ship's course, or why the environment of cats should modify their structure, except that the fact is so. Neither do we find in nature any explanation of cats which seems to us perfectly satisfactory to mice.

It is obvious, however, that in so far as natural selection accounts for all that is distinctive or specific in the structure of living things, it accounts, at the same time and to exactly the same degree, for all that their structure does; and that the web the spider makes out of silk is no harder to understand than the web the radiolarian makes out of protoplasm.

So far as Paley's reasoning concerns the zoölogist, it is a treatise on the minor premise of his argument; for no one in his day seems to have thought that the major premise needs defence or is open to attack, although the modern zoölogist must ask whether we are sure that nothing but mind accounts for watches. In science we hold a thing accounted for when, certain conditions being given, we have every reason to expect it; and Paley's major premise - that nothing but mind accounts for watches - is worthless, if the conditions which, being given, are good reasons for expecting watches are physical.

If a watchmaker were to tell us he was so distracted by care or grief that he did not know what he was about when he made the watch, no one would think this incredible; for we are familiar with the unconscious performance of equally delicate and complicated and definite series of bodily movements, as in piano playing; nor would we see any reason to cloubt the assertion of 
the members of a church choir that they have been absorbed in trivial gossip while producing solemn harmony.

We all know the feeling of surprise that the time has passed and that so much has been done after an hour of absorbed study; and many profound thinkers on abstract subjects assure us that their best efforts in reasoning are those which go on in ecstatic unconsciousness of self or of the intellectual process. I imagine many a thinker grows conscious of cold feet and an empty stomach before he becomes aware what he has been about or how hard he has worked.

It may be said that while the piano player, or even the watchmaker, might carry on their acquired arts unconsciously, the training which has set apart and bound together the series of bodily movements was accompanied by conscious attention, but there is no reason to suppose that the mere repetition of these acts would not give the same result if it could be brought about in unconsciousness; for all teachers and all good students know that the effort to attend is more difficult than the mere act of acquisition. Training is most valuable and most rapid when attention comes without conscious effort; when the brain is a passive recipient.

No one except the Lamarckians supposes that training gives the watchmaker any new muscles or nerves, or that it enables him to execute any bodily movements which are not within the reach of any other normal human being whose muscles are equally plastic and delicate and definite in action. We have already seen, page 60 , that physical training is beneficial only so far as structural adjustments for bringing about improvement by use already exist, and that it corrects our actions by converting confused and perplexed movements into exact and definite ones; nor does there seem to be any good reason to believe that the case is any different when mental nurture is in question, or to believe that mental powers which come with training are different in kind from those that "come by nature."

"Newton said that he made his discoveries by intending his mind on the subject; no doubt, truly." "But to equal his success," says Huxley, "one must have the mind which he intended. Forty lesser men might have intended their minds till they cracked, without any like result." 
Fruits and vegetables must have good nurture to reach perfection, but the gardener knows his labor will be vain unless he starts with seed which is adapted by nature for improvement by judicious nurture; and while it is hard for us to consider the question whether the arts and accomplishments of normal men are due to anything else than training and education, we feel no such difficulty when the faculties of abnormal or exceptional individuals are in question; for the restriction of the powers of idiots is clearly correlated with deficient structure, and training and education are so obviously incompetent to account for the achievements of men of genius that we are apt to believe that their natural or innate powers are different in kind from anything in our own more commonplace selves.

"The child who is impelled to draw as soon as it can hold a pencil; the Mozart who breaks out into music as early; the boy Bidder who worked out the most complicated sums without learning arithmetic; the boy Pascal who solved Euclid of his own consciousness, - all these," says Huxley, "may be said to have been impelled by instinct as much as the beaver or the bee. And the man of genius is distinct from the man of mere cleverness, by reason of the working in him of strong innate tendencies - which cultivation may improve, but which it can no more create than horticulture can make thistles bear figs. Art and industry may get much music, of a sort, out of a penny whistle; but when all is done, it has no chance against an organ."

It is most important to bear in mind that while some animals acquire only slowly, and after long training and practice, faculties of which others are born fully possessed, there does not seem to be any corresponding difference in the excellence or in the usefulness of these faculties, or in those coördinations among them which fit their possessor for useful and beneficial response to the order of nature in the outer world.

Many birds and some mammais have perfect use of their senses, and have all their muscular movements perfectly coördinated at birth; while others-kittens, for example-are born blind, all their movements are as vague and aimless as those of the human infant, and even when they are half grown, each determinate movement in their frolics is accompanied by many pur- 
poseless and uncoördinated movements in all parts of the body; but it would be difficult to show that the vision of a dog, which is slowly "acquired" during early puppyhood, or the coördinations between it and the movements of the body, is any more perfect, or any more useful as a means for adjusting action to the external world, than that of the wild lamb which, in less than five seconds after its birth, was seen by Hudson to run freely at its mother's side, as she started off at a brisk trot after the flock; or the jacana which, as the egg which he held in his hand parted, leaped from the cracked shell, and from his hand, into the water, and "swimming rapidly to a small mound, and escaping from the water, concealed itself in the grass, lying down and perfectly motionless like a young plover."

Spalding tells us that when he placed a chick which had been blindfolded at birth, on rough ground, in sight of a hen, "it started off towards the hen, displaying as keen a perception of the qualities of the outer world as it was ever likely to possess in after life. It never required to knock its head against a stone to discover that there was no road that way. It leaped over the smaller obstacles that lay in its path, and ran round the larger, reaching the mother in as nearly a straight line as the nature of the ground would permit. This, let it be remembered, was the first time it had ever walked by sight."

The coördination between tactile and muscular impressions, and those we get through the eyes, which enables us to walk with sure feet, by sight, among the obstacles which beset our path through the world, comes with training which is accompanied by conscious judgment, but it would be difficult to show that human sight is superior in any way to that of birds; although the newly hatched bird may coördinate its visual and tactile and muscular impressions as it runs, and may be able, before its first sally into the world is fairly begun, to maintain its balance on rough ground, to leap over small obstacles, to go around larger ones, and to fitly adjust its actions to the invisible properties which are associated, in course of nature, with visible ones.

"A chick two days old," says Morgan, "had learned to pick out pieces of yolk from others of white of egg. I cut little bits of orange peel of about the same size as the pieces of yolk, and 
one of them was soon seized, but at once relinquished, the chick shaking his head. Seizing another, he held it for a moment in his bill, but then dropped it and scratched at the base of his beak. This was enough; he could not again be induced to seize a piece of orange peel. The obnoxious material was now removed, and pieces of yolk of egg substituted, but they were left untouched, being probably mistaken for orange peel. Subsequently, he looked at the yolk with hesitation, but presently pecked doubtfully, not seizing but merely touching, then he pecked again, seized, and swallowed."

The words, as they are here quoted, describe the facts as if they were known to be accompanied by consciousness, and to be in all respects like human actions; and as words are adapted to human needs, this is hard to avoid, although it is so obviously impossible to say whether the chick is conscious or not, that Morgan's assertion that his study of young chicks shows that they soon learn what is good to eat and what is unpleasant, and rapidly associate the appearance with the taste, would be more accurate if he had confined himself to some such statement as that his studies teach that they rapidly acquire power to respond to visual stimuli by actions adjusted to those flavors which are associated, in course of nature, with certain optical properties. While the restriction of our descriptions of the actions of animals to words which have no subjective implications would be intolerable to the reader and well-nigh impossible to the writer, we must discriminate, so far as possible, what we really learn by observation from what we infer from the analogy of our own actions. The important point is, that whether actions like those of the new-born lamb are conscious or unconscious, they are not determined by consciousness, but are the outcome of innate congenital structure; although, so far as their fitness for the needs of the animal goes, they are in no way inferior to actions which we acquire only after long training which is accompanied by consciousness and attention and intellectual apprehension of the desired end.

If adaptations like the muscular coördinations of the newborn lamb, which are manifested without previous experience of their use, are as perfect and as useful as those which are slowly acquired by long training accompanied by conscious effort and by 
rational apprehension of the desired end, like the muscular coördinations involved in making a watch, are we not forced to ask the question whether we can be sure that the mental states which have accompanied the watchmaker's training are anything more than the occasion of this training, or the stimulus under which it exhibits itself? Is it any harder to believe an imperfect watch or a rough, unfinished part of a watch might be made unconsciously than it is to believe a finished watch might be made in the same way? If a perfect art may be carried on unconsciously, when attention is otherwise occupied, why might not each imperfect step in its gradual acquisition be taken when all conscious knowledge of the process is lost through absorption in the work? The question is not whether men make watches voluntarily, for this all must admit, even if we see reason to ask whether their unconscious production is impossible.

Whether we can answer it or not, the progress of zoölogy has forced us to ask anew the old question whether a watch may not be part of the chain of physical causation just as truly as the spider's web or the cat. Thoughtful men in times long past have asked this question in one form or another without finding any answer which could command general assent, and while we may be no more able to solve it, it is plain that the discovery of natural selection has put the matter in a new light.

If, fifty years ago, one had asserted that there can be no causal relation between the mechanism of the watch and the movements of the earth, except that which is found in the thinking minds of those by whom watches are invented and made, I do not suppose any one could then show the mistake in this assertion; but Darwin and Wallace have shown that such a relation actually exists, in the external world, and as independent as the metal in the watch of human thinkers. Watches help the watchmaker to hold his own in the struggle for existence and to make and keep a place in a crowded world for himself and for his family, precisely as the spider's web helps the spider. While the external world of men is incomparably more vast and diversified than that of cats, the adjustment of our actions to the flight of time is useful and important to us just as adjustment to the life of mice is useful and important to cats; for the lives of thousands hang 
each day upon the accuracy of the ship's chronometer or on that of the watch of the railway engineer.

The Duke of Argyll tells us ("Reign of Law" p. 35) the method of creation by means of which the purpose of the serpent's poison is carried into effect, is utterly unknown.

"Take one instance out of a million. The poison of a deadly snake - let us for a moment consider what this is. It is a secretion of definite chemical properties which have reference, not only - not even mainly - to the organism of the animal in which it is developed, but specially to the organism of another animal which it is intended to destroy. Some naturalists have a vague notion that, as regards merely mechanical weapons or organs of attack, they may be developed by use, - that legs may become longer by fast running, teeth sharper and longer by much biting. Be it so; this law of growth, if it exist, is but itself an instrument whereby purpose is fulfilled. But how will this law of growth adjust a poison in one animal with such subtle knowledge of the organization of another that the deadly virus shall in a few minutes curdle the blood, benumb the limbs, and rush in upon the citadel of life? There is but one explanation, - a Mind having minute and perfect knowledge of the organization of both, has designed the one to be capable of inflicting death upon the other. The mode of secretion by which this purpose is carried into effect is utterly unknown."

Belief that this adjustment, and others like it, have been produced by the inheritance of the effects of use, is, as the Duke of Argyll points out, a notion too vague to have any value; but since natural selection is discovered, no one can assert that there is no scientific explanation; for the snake which has power to destroy its enemies has such an advantage in the struggle for existence that its survival is no harder to understand than any other natural phenomenon.

The question that faces the modern teleologist is not whether the contrivances of man and the adjustments of living nature are useful, for this all must admit; but whether the snare of the fowler gives any clearer or any different evidence of contrivance than that given by the bird in whose sight it is spread in vain. 
If we give a negative answer to questions like this, it is clear that belief that the works of nature prove design by their resemblance to human contrivances has indeed received its death-blow; not because Paley's analogy breaks down, but because it becomes impregnable.

Natural selection forces us to reconsider the argument from the analogy of human contrivances, not because it shows that the eye and the cat and the hinge of the bivalve shell have come about in order of nature; but because it gives to human contrivances a significance of which Paley never dreamed, and because it forces us to ask whether the hunter who contrives a net furnishes any different basis for analogy with the works of nature than the fish that contrives to get the bait without danger, or the spider and the sundew which also spread their snares, or the hydroid with its net of poisoned tentacles, or the radiolarian with its web of protoplasm. 


\section{LECTURE XI}

PALEY, AND THE ARGUMENT FROM CONTRIVANCE 



\section{LECTURE XI}

PALEY, AND THE ARGUMENT FROM CONTRIVANCE

PALEY sometimes argues that it is because watches are made by men that they prove design; while in other places, he holds that it because they are so put together as to point out the hours of the day.

We.must therefore ask what bearing natural selection has on this statement of his argument:-

(I) Living things, and their works, such as watches, exhibit peculiar evidence of usefulness.

(2) Evidence of usefulness is evidence of design.

(3) Living things and their works exhibit peculiar evidence of design.

If it is true that watches come about in order of nature, and are so joined, by natural causation, to the movements of the earth that no one who knows all the data would have the least reason to expect that men should not make and sell and buy and use them, this may well raise a doubt whether the contrivance of man is any interruption to the order of nature; but a moment's thought shows that it by no means does away with the teleological problem, or makes it any easier to solve; for it is still as true as ever it was that watches do not come about without human makers, and that they are useful to mankind and help to preserve the human species from destruction.

If the structure and orderly history of such things as eyes, and cats, and spiders' webs, and watches were all we discover in them, we might say these things are no harder to understand than inorganic bodics and their movements; for if living things are continually bringing about rearrangements of inorganic matter and physical energy, like watches, which never come about with- 
out them, lifeless bodies continually do the same. The tide produces changes of matter and energy which would never have been brought about in a tideless ocean, such as the gradual conversion of the earth's motion of rotation into friction between sea and land; but no one finds, in the friction which has brought the moon to rest upon its axis, anything that might not have been expected. If living bodies did no more than to bring about things which would never happen without them, no one could find in this any essential difference between them and lifeless bodies; but we do find a most significant difference in the sort of things they bring about, as Aristotle pointed out long ago. "To say what are the ultimate substances out of which an animal is formed is no more sufficient" now than it was two thousand years ago; for the distinctive things that are brought about by living beings are things that are useful to the beings which bring them about or to their species; and usefulness implies the continued existence of the user, as distinguished from the things that are used; for it does not consist in the act of use, but in something that comes after.

The words "survival of the fittest" are meaningless unless the being that survives the selective process is identical with the one that remains fit after the selective process has acted; and belief in the efficacy of natural selection involves belief in that continuity of life which, in the form we know most intimately, we call personal identity.

Just so far as natural selection tends to break down the distinction between the contrivances of man and the works of nature, just so far does it show that the distinction between subject and object; the distinction which is the fundamental problem of all systems of philosophy and the fundamental postulate of most systems of religion; the distinction between self and not-self; is coextensive with life. Since this is so, may we not still say with Paley: "Marks of design are no more accounted for than they were before. Our going back ever so far brings us no nearer to the least degree of satisfaction upon the subject"?

As the human child seems, so far as we can ascertain, to gradually discover its continued existence through consciousness and memory of the past, we are apt to think that personal identity implies con- 
sciousness, and is equivalent to intellectual or rational sameness or identity; but a moment's thought will show that this is not the case, for none of us have, or know whether we ever had, consciousness of our early infancy, our birth, or our embryonic history, although no naturalist can admit that there is any interruption in the continuity of our personal existence between the fertilized ovum and old age, for while birth is a notable event in the history of man and of most of the familiar animals, it is no necessary or universal stage in the development of organisms in general.

Does any one who, while unconscious, has undergone a surgical operation doubt whether he is personally identical with the unconscious patient? May not one carry to the verge of the grave the physical or mental or moral effects of an acciclent which occurred before his earliest recollection?

A moment's thought shows that we have the same sort of reason for belief in the continued existence of every being whose acts are useful to itself or to its species, as we have for belief in our own persistent identity through much of our own history; for, as Dr. Butler pointed out long ago, "we should really think it self-evident that consciousness of personal identity presupposes, and, therefore, cannot constitute, personal identity; any more than knowledge, in any other case, can constitute truth, which it presupposes." "To say that consciousness of our continued existence makes personal identity, or is necessary to our being the same person, is to say," as Butler shows, "that a person does not exist a single moment, or do one action, but what he can remember; indeed, none but what he reflects upon." "Present consciousness of past actions," says Butler "is not necessary to our being the same person who performed those actions," and he might have added that neither is past consciousness necessary; for it is not necessary that the acts of a being should be rational to prove personal identity, but only that they should be such that, if accompanied by mind, they would be rational. For all we know to the contrary the human ovum may be conscious, and so may the tree be, or, for that matter, the stone; but we do know that, whether living beings be conscious or not, they so respond to the changes which go on in the outer world that our reason approves their actions; and it is their fitness itself, not their consciousness of it, which proves their continued existence. 
For all we know the properties of the stone may be useful to the stone, and for all we know the stone may be conscious and rational, but these words mean nothing to us; although we can see clearly that the distinctive properties of living things are useful to them or to their species. If it is said that words which mean nothing are nonsense, and that we are not to talk nonsense, we must answer that no honest confession of ignorance can be nonsense, and that the burden of proving he is not talking nonsense rests with him who asserts that stones are not conscious.

So far as I am aware Butler is the only one of the older writers on natural theology who perceived that the responsive actions of living things prove that all living things have personal identity; and, whether he be the first or not, his reasoning seems conclusive, although modern science cannot permit him to escape any of the consequences of this admission by asserting that trees are not living things.

"Consider," he says, "a living being now existing, and which has existed for any time alive. This being must have done... what it has done... formerly, as really as it does... what it does... this instant. All these actions ... are actions ... of the same living being. And they are so prior to all consideration of its remembering or forgetting; since remembering and forgetting can make no alteration in the truth of past matters of fact. And suppose this being endowed with limited powers of knowledge and memory, there is no more difficulty in conceiving it to have the power of knowing itself to be the same living being which it was some time ago, of remembering some of its actions, sufferings, and enjoyments, and forgetting others, than in conceiving it to know or remember or forget anything else." 1

If Butler is right, if consciousness of personal identity does not make but presupposes personal identity, we may consider the continued existence of living things quite apart from the question whether they know their continued existence; but personal identity is, so far, a phenomenon, a part of the order of objective nature, which may be studied, like other natural phenomena, by

1 The reader who is familiar with Butler will note that the words I have omitted after "done," and in other places are "suffered and enjoyed," for the argument does not seem to demand any opinion as to the extent of the parallel between life and enjoyment and suffering. 
strictly scientific methods. It also seems clear that the significance of the argument from contrivance or interference with the order of physical nature, turns on the account which science gives of this aspect of personal identity; for the discovery of natural selection forbids us to assert, before this question is answered, that the evidence of contrivance afforded by living things and their works is different from that which is afforded by inorganic bodies and their movements, inasmuch as it shows us the chain of physical causation which joins the works of man and of other living beings to that part of the order of nature to which they are adjusted.

While I cannot agree with those enthusiastic zoölogists' who hold that life has been proved to be a matter of physics and chemistry, modern science seems, to me, to demand that we suspend judgment upon this difficult question, and wait for more evidence, for there seems to me to be no better basis for a negative than for an affirmative answer.

If science furnishes proof that the continuity of life is not only a natural phenomenon but a physical phenomenon, which may be expressed in terms of physical matter and mechanical encrgy, then, indeed, the argument from contrivance has received its death-blow; for we can no longer find, in the actions of living things, or in those of any living thing, evidence of interference with the order of physical nature. If, however, the answer which science gives is imperfect or indecisive, then I think we must admit that, while weakened by the discovery of natural selection, the argument from contrivance is not utterly destroyed. Finally, if science fails to throw any light on the origin and meaning of personal identity, then the argument from contrivance has the same value, whatever this may be, that it had before natural sclection was discovered.

Two hundred and fifty years ago no one thought of asking whether living beings ever arise out of dead matter, for all believed that they never arise in any other way; and that this may be illustrated by obscrving how quickly dead things, like dung and rotten meat and the carcasses of dead animals, breed maggots and flies under the influence of the hot sun.

"The proposition that life may, and docs, proceed from that which has no life was held alike by the philosophers, the peets, 
and the people of the most enlightened nations eighteen hundred years ago; and it remained the accepted doctrine of learned and unlearned Europe through the Middle Ages, and even to the seventeenth century."

It is clear that natural selection would have given the deathblow to the argument from contrivance if this opinion had been well founded; but it is equally well known that the progress of science has shown the worthlessness of all the evidence for spontaneous generation.

In my opinion the second alternative is most consistent with the present state of our knowledge; for while the discovery of natural selection has shown how all the endless forms of life, with all their admirable and wonderful adjustments to the diversity and harmony of the external world, may have arisen from a common starting-point in some primitive organism, so simple and so homogencous that its production out of inorganic matter does not seem improbable, the progress of our knowledge in other lines has demonstrated that, as a matter of fact, all the living things we know do arise from preëxisting living things.

The demonstration of the continuity of life which we owe to the embryologists and histologists of modern times, and to the students of pathology and hygiene, is a contribution to philosophy of the utmost value and significance. This law of continuity is a discovery as real as the law of natural selection itself, for we now have every reason to believe, not only that personal identity is coextensive with life, but also that there is no break in its continuity at any point in the whole history of life. Every living thing on earth, and, so far as we know, all that have ever lived, are personally identical with the primeval living being, in exactly the same sense as the mature, conscious, rational man is personally identical with the human fotus and the new-born babe.

The history of the great modern discovery of the continuity of life has been written by so many able students that there would be no reason to review any part of it here if the share of that great investigator and thinker, William Harvey, in the demonstration that the facts are, in this matter, opposed to vencrable authority, had not been so strangely misunderstood and misrepresented as to call for correction. 
No less careful a writer than Huxley, himself an ardent admirer and diligent student of Harvey, tells us ("Encyclopædia Britannica," article Evolution, p. 746) that "Harvey believed as implicitly as Aristotle did in the equivocal generation of the lower animals. Harvey shared the belief of Aristotle, whose writings he often quotes, and of whom he speaks as his precursor and model, with the generous respect with which one genuine worker should regard another - that such germs may arise by a process of 'equivocal generation' out of non-living matter"; but I am by no means confident that this assertion does justice to Harvey, or that the quotations from Aristotle prove anything except that Harvey was not fully prepared to demonstrate their error. While Huxley ("Spontaneous Generation," I870) tells us he can find no justification for the notion that Harvey doubted the occurrence of spontaneous generation, I find ample evidence that he had made many experiments which led him to distrust the opinion which prevailed in his day; although he may not have felt fully armed to attack the teachings of "my leader, Aristotle, . . . one of nature's most diligent inquirers, . . . whose authority has such weight with me that I never think of differing from him inconsiderately."

It is true that he quotes without comment, and often without credit, the very words in which Aristotle affirms spontaneous generation; but, as an offset to this, he tells us explicitly (Exercise the forty-first) that he shall show in another place "that many animals, especially insects, arise and are propagated from elements and seeds so small as to be invisible (like atoms flying in the air), scattered and dispersed here and there by the winds; and yet these animals are supposed to have arisen spontaneously, or from decomposition, because their ova are nowhere to be found."

He was far too courteous and too cautious to have ventured to criticise "The Philosopher," to even this extent without scientific evidence, and in Exercise the sixty-ninth he tells us why his researches were never published.

"Let gentle minds forgive me," he asks, "if, recalling the irreparable injuries I have suffered, I here give vent to a sigh. This is the cause of my sorrow: whilst in attendance on his majesty, the king, during our late trouble and more than civil 
wars, not only by the permission but by the command of the Parliament, certain rapacious hands stripped not only my house of its furniture, but what is subject for far greater regret with me, my enemies abstracted from my museum the fruits of many years of toil.

"Whence it has come about that many observations, particularly on the generation of insects, have perished, with detriment, I venture to think, to the republic of letters."

These extracts seem to prove that, while it is easy to find in his writings many passages in which belief in spontaneous gencration is asserted, usually in the words of Aristotle, the validity of these beliefs is admitted out of courtesy to Aristotle and for the sake of the argument, as a subject on which he is not yet prepared to make his researches public.

If the reader who is interested will turn to the title-page of the original edition of Harvey's Essay on Generation, he will note that not only deer and human infants and serpents, but insects, as well, are escaping from the bursting egg which Jove holds in his hand.

As that practical old traveller, Herodotus, suggests that the frogs and insects which are commonly supposed to be generated out of the mud and slime of the Nile, may, perhaps, come from eggs, Aristotle's readiness to believe in their spontaneous generation is hard to understand until we discover that the reason why he saw nothing suspicious in the generation of animals from dead and decomposing organic matter is to be found in his belief that all generation takes place in the same way.

Every conception, according to Aristotle, is a case of spontaneous generation out of excrement, and he regards the generation of insects out of putrescent slime as a simple example, what we should now call a primitive type, of generation in general, by comparison with which more complicated and obscure cases are to be interpreted.

As a bloody substance is discharged at intervals from the reproductive organs of the human female, he believed that the mammalian embryo is generated out of this excrement, just as other animals are generated out of decomposing matter of other kinds. As heat causes milk to curdle, so he says the geniture of 
the male causes the purest part of the catamenia to set and form a coagulum like curdled milk, and he believes that the embryo arises from this coagulum by spontaneous generation.

One modification or another of this opinion continued to prevail until Harvey's day, and it is plain that experiments on the generation of insects was mere skirmishing on the outposts of the problem until the belief in the generation of the higher animals out of excrement had been corrected; and Harvey wisely concentrated his attention on this citadel of the belief in the origin of living things from dead matter. If a mass of excrement exists in the uterus immediately after a fertile union, this ought to be discoverable; and Harvey, a true scientific investigator, set to work to hunt for it without a microscope, more than two hundred years before the discovery of the human ovum by Von Baer.

His facilities for making the search, and its results, are best described in his own words. He was the attending physician of the king of England, and he telis us "it was customary with his Serene Majesty, King Charles, after he had come to man's estate, to take the diversion of hunting almost every week, both for the sake of finding relaxation from graver cares and for his health; the chase was principally the buck and the doe, and no prince in the world had greater herds of deer. This gave me an opportunity of dissecting these animals almost every day during the whole season when they were rutting, taking the male, and falling with young. I had occasion so often as I desired it to examine and study all their parts, particularly those devoted to the offices of generation."

His researches had a very definite result. Repeated dissections performed in the course of the month of October, both before the rutting season was over and after it had passed, never showed a trace of coagulated blood or excrement of any sort. Neither the bloody coagulum of Aristotle nor the geniture of the medical men has any existence. The "conception" which should be discoverable, if their teachings are correct, cannot be found when search is made for it, and actual observation shows that the opinion which had been current for nearly two thousand years is erroneous and fanciful.

The keepers and huntsmen said that "I was both deceiving 
myself and had misled the king, and that there must of necessity be something of the 'conception' to be found in the uterus. These men, however, when I got them to bring their own eyes to the inquiry, gave up the point." Harvey tells us the king fully appreciated the value of the investigation, and in order that this important question might be the more satisfactorily settled in all time to come, provided means for isolating the does and thus proving that there was no error as to the fact of conception; but the physicians were still unconvinced, and "held it among their impossibilities that any conception should ever be found without the presence of excrement in one form or another." But the man who had proved the error of their teachings regarding the function of the heart and blood-vessels had little tolerance for their belief in anything they were unable to demonstrate.

If they had insisted that Harvey's resources were inadequate, and that the conception for which he sought is a living being too minute to be found by such rough means, but, to use the word he employs in another place, "like the youth who comes of age, made independent even from its first appearance, as the acorn taken from the oak, and the seeds of plants in general, are no longer to be considered parts of the tree or herb that supported them, but things made in their own right, and which already enjoy life," we now know they would have been in the right. But his proof of the non-existence in the uterus of the doe of the excrement, of which they had taught that the conception consists, is conclusive.

Harvey did not stop here, however; for he made careful observations on the fowl, the rabbit, the dog, and on many other animals, and proved that none of them are generated out of excrement or decomposing matter; that there is no basis in nature for Aristotle's opinion or that of the medical men of Harvey's day, and that all their teachings break down when brought to the test of actual observation.

It is no small thing to prove the error of the belief, which had been current for nearly two thousand years, and is even now embodied, through a quotation from St. Paul, in our burial service, that all forms of reproduction are, at bottom, examples of spontaneous generation out of dead putrescent matter. This Harvey accom- 
plished by methods which are rigorously scientific; and no scientific generalization, not even natural selection itself, has more profound significance than the great natural law which modern students have built upon his foundation; for we now know that there is no break in the continuity of life, and that every living thing with which we are acquainted is in direct unbroken vital continuity with the primeval living matter of pre-Cambrian times.

This being the case, is it not plain that, so far as the question of origin is concerned, we know only a single example of life? Our knowledge is, in this respect, a single experience; and it affords no basis for comparison with any other aspect of nature, or for scientific generalization, or for any other logical process, either positive or negative.

So far as I can see, there is no reason why we should not say now as Huxley said before natural selection was discovered : "It may be that, by and by, philosophers will discover some higher laws of which the facts of life are particular cases, - very possibly they will find out some bond between physico-chemical phenomena on the one hand and vital phenomena on the other. At present we assuredly know of none; and I think we shall exercise a wise humility in confessing that, for us at least, . . . this distinction between living bodies and those which do not live is an ultimate fact."

If any choose to believe life is different from matter and motion, I do not see how, in the present state of our knowledge, they can be proved wrong; nor can we in justice charge them with belief in the supernatural, for the assertion that belief in that which is not physical is belief in the supernatural is not reasoning until every natural phenomenon has been proved to be physical; neither is there any more reason in the assertion that the indestructibility of energy disproves spontaneity even if some form of dead matter should be proved to respond to the order of nature to its own advantage, like living things.

On the other hand, it scems clear that we can give no reason for disagreeing with those who believe life is a property of protoplasm except that this is not yet proved. Our inability to conceive that a thought or a response can be a property of matter is no reason why this may not be true. So far as I can discover, the only reason why we are able to conceive that weight can be 
a property of extended bodies is the fact that it is so; and if we had the same sort of evidence that life is a property of matter, I do not see why this might not be equally conceivable.

I have no sympathy with those who base their philosophical creed on their hope and their faith that we shall some day be able to see our way from the physical and chemical properties of protoplasm to the responsive actions of living things as clearly as we predict the movements of a watch from the form of its parts, nor have I any more sympathy with those who, on what seems to me an equal lack of proof, live in the hope and in the faith that this consummation is necessarily and forever beyond the reach of science; for faith and hope are not knowledge, nor a creed science.

"Those who take a monistic view of the physical world," says Huxley, "may fairly hold abiogenesis as a pious opinion, supported by analogy and defended by ignorance. But, as matters stand, it is equally justifiable to regard the physical world as a sort of dual monarchy. The kingdoms of living matter and of not-living matter are under one system of laws, and there is a perfect freedom of exchange and transit from one to the other. But no claim to biological nationality is valid except birth."

The assertion that there can be but one order of things, because it is so much neater than two, is, of course, unworthy the name of argument.

The essential characteristic of life is fitness. A living organism is a being that uses the world around it for its own good. I for one am unable to find, in inorganic matter, any germ of this wonderful attribute. It is possible that after chemistry has given us protoplasm this may be shaped by natural selection, or some other purely physical influence, into persistent adjustment to the shifting world around it, and that it may thus become alive.

Everything is possible to them who know nothing; but why should we believe anything on this matter until we have evidence?

"Knowledge and truth may be in us without judgment, and we may have judgment without them; yea, the acknowledgment of ignorance is one of the best and surest testimonies of judgment that I can find." 
Of one thing we may be sure. The artificial production of protoplasm would not be a solution of the problem of life; since the nature of this problem must be grasped, in all its length and breadth, with all its difficulties, before we can hope to solve it; for the transformation of the truth that protoplasm is the physical basis of life into a dogmatic assertion that life is the sum of the physical properties of protoplasm is no solution.

Life cannot go on without food; and we may say that bread is the staff of life; but the influence which shapes food into the specific structure of an organism exquisitely adapted to the conditions of the world around it is to be sought somewhere else than in the properties of bread.

One of the distinctive characteristics of this organizing influence is that it may exist without any corresponding visible organization; for while the germ which is to become a man has an organization of its own, we are most assuredly unable to find in it any traces of the organization of a man. Another characteristic is that, so far as we know, it has been handed down, in an unbroken line of continuity, for many million years, from the oldest living things, generation after generation, to the modern forms of life, so that it has leavened the whole lump of living matter.

While we know nothing of its origin, and while we must guard ourselves from all unproved assumptions, there seem, from our present standpoint, to be insuperable objections to the view that this influence is either matter or energy. While we know it only in union with protoplasm, it would seem that, if it is matter, it must long ago have reached the minimum divisibile. If it is physical energy, or wave motion, or perigenesis of plastidules, it is hard to understand why it has not all been dissipated long ago, or how it can multiply itself.

We know that it is, and this is in itself a fact of the utmost moment, even if we are never to find out what it is. We are told that belief that it has at some time arisen from the properties of inorganic matter is a logical necessity, but the only logical necessity is that where knowledge ends we should admit ignorance.

Honesty of purpose and expediency unite in the demand that we build biology upon a foundation which can never be shaken; 
and if our creed is a humble confession that while we do not know whether life is independent of matter or not; that while we do not know what the relation between mind and matter is; we should like to find out; we need fear no attack by anything in the universe or outside it.

This being the case, the discovery of natural selection may seem to some to have no bearing, either positively or negatively, upon the argument from contrivance; since the words "survival of the fittest" are meaningless unless the being which remains fit after the selective process has acted is the same as the one on which it acted.

I am not able to share this opinion; for while natural selection, inasmuch as it presupposes personal identity, may be only an imperfect explanation of life, it still remains a strictly scientific explanation of one great biological problem, the origin of species, revealing to us the "physical causation" of the division of the living world into more or less isolated species, characterized by fitness for that part of the order of nature which makes up the environment of each.

Aristotle believed that all living things, man included, are generated out of dead matter; and it seems clear that, before natural selection was discovered, we should have been warranted in demanding proof of Aristotle's view before admitting that living beings are inorganic in origin; but, nowadays, no one can logically demand that some one shall make out of dead matter a living human being, with a human mind, like the golden statues which Homer attributes to the skill of Vulcan, before he will make this admission.

Whether the production of a living man by physico-chemical methods be absolutely impossible or not, all admit that it is practically impossible; although few will assert with the same confidence that it is impossible to make in this way a being sufficiently like some living things to create a reasonable expectation that its history will be, in all essential particulars, like the history of life as we actually know it. If any are bold enough to make this assertion, their frame of mind seems to me to be highly injudicious in the present condition and present prospects of science; for the progress of knowledge may at any time compel them to abandon it. 
While I am unable to agree with Huxley that natural selection has given the death-blow to the belief that the contrivances of human artificers prove that nature is a contrivance and the work of an artificer, it has, in my opinion, so greatly weakened the value of the evidence for this belief that no one can safely hold that it is conclusive.

Now, no one who is trained in the methods of science can find in an inconclusive argument any legitimate basis for any other state of mind than a suspension of judgment and a desire for more evidence; for all must hold it unwise and precarious to base a positive opinion on absence of disproof.

The hardest of intellectual virtues is philosophic doubt, and the mental vice to which we are most prone is our tendency to believe that lack of evidence for an opinion is a reason for believing something else. This tendency has value in practical matters which call for action, but the man of science need neither starve nor choose. Suspended judgment is the greatest triumph of intellectual discipline, and while vacillation brands the man of affairs with weakness, no opinion on philosophical matters has any value unless it meets all possible contingencies.

I am neither a materialist nor a monist; and yet I think it wise to ask what would be the significance of the production of a living being by physico-chemical methods; and this I shall try to do in the next lecture; for even if living beings and their ways and works were shown to afford no peculiar evidence of purpose or intention, this would not be proof that there is no such evidence in nature; for it may be that all nature, inorganic and organic alike, affords equal evidence of purpose or intention. 

LECTURE XII

THE MECHANISM OF NATURE 
"Ideas which are observed to be connected together are vulgarly considered under the relation of cause and effect, whereas, in strict and philosophic truth, they are only related as the sign and the thing signified."-BERKELEY, "The Theory of Vision Vindicated and Explained" (13). 


\section{LECTURE XII}

THE MECHANISM OF NATURE

IN this lecture I shall review the evidence that has convinced many thoughtful men that natural knowledge is no more than knowledge of order. My reason for asking you to go with me over ground which is already familiar is this: I wish you to ask yourselves, as we make our review, if it is not obvious that the discovery that nature is orderly can throw no light on the origin of anything in nature. Order is not an explanation of anything; but something that itself calls for explanation.

It must not be supposed that no "philosopher" has attempted to account for order in nature; for many hold this a simple matter, easy to understand, although their reasoning may turn out, when examined, to be no more than an assertion that nature is orderly because there is order in nature.

Some tell us, for example, that the order we discover in nature is a necessary result of the conservation of energy. Like causes must be followed by like effects, they tell us, unless force has in the meantime come into existence or gone out of existence; and this cannot be the case if force is persistent. As proof that force is persistent we are told that like effects do follow like causes, or, in other words, that nature is orderly.

Some students of zoölogy go one step deeper into the heart of the matter, and tell us that our minds are unable to conceive the production or the destruction of energy, because the whole history of life has been a history of response to causation, and because all living things that did not thus respond have been exterminated in the struggle for existence, and because, for this reason, our confidence in the order of nature is no more than our history would lead one to expect; although it seems plain 287 
that our only reason for believing that the thing which we expect will be the thing which comes about is our confidence that nature is orderly; and that this way of accounting for order in nature brings us at last to the very point from which we set out.

Of all the strange errors that vex the mind of man, one of the strangest is the opinion that our faculties would lose their reality and their value if the history of man were proved to be orderly, and what might reasonably have been expected, for that our history cannot have the slightest bearing on the reality of anything in our nature secms so obvious that it is hard to see why any one should question it.

If one knows that he is refreshed by food and drink, I fail to sec what bearing on this conviction any amount of anatomical or physiological or historical acquaintance with his digestive organs can have, even if it should enable him to deduce these organs from physics and chemistry or to make others like them.

Scientific knowledge of digestion gives valuable information as to the conditions under which food and drink are beneficial, and it helps us to regulate our natural appetites and to avoid errors and excesses; but no one ever dreams that this is evidence that these appetites are not real.

You may perhaps find some reason to doubt whether you see me in this room or hear this lecture; for all I know, you may find still more reason to doubt whether you profit by so doing; but can you doubt that you see and hear, or that on the whole you profit by seeing and hearing? Would you not be just as sure even if you knew nothing of optics or acoustics or even of eyes or ears? For my own part I should be as sure I see and hear, and see and hear to my advantage, as I am now, even if my days were passed in a laboratory for the manufacture of seeing and hearing beings. Since my reason began to make itself known to me before I knew I had a brain, my conviction that I am a rational being, like my conviction that it is good to be a rational being, is independent of knowledge of the existence of my brain. Since my power to draw inferences from the data of sense and to profit by them is independent of acquaintance with the mechanism of my brain, I fail to see why my reason 
should be any the less real or any the less valuable even if a skilful physiologist should some time succeed in imitating all the manifestations of rational life by playing on a human brain with electrodes.

Knowledge of nature corrects our judgment by showing us the conditions under which it is trustworthy, and by revealing errors which rest upon imperfect experience; but I cannot conceive how any one should suppose that this fact has any bearing upon the reality or the value of reason.

Centuries of discussion warn us that the establishment of mechanical explanations of the phenomena of human life would, in the opinion of many, destroy volition, and right and wrong, and duty, and moral responsibility; and while I do not suppose my own inability to see why any of these dreadful things should happen will count for much, this inability is real.

So far as I can see, the reduction of all nature to mechanical principles would mean nothing more than that all the phenomena of nature are orderly and such as might have been expected; and I am quite unable to discover what bearing the fact that an event may be counted on with confidence has on the question whether it is "necessary" or "spontaneous," for the discovery that phenomena are orderly tells us nothing about their origin.

I cannot see, for example, how the man who is unstable in all his ways furnishes any better evidence of freedom than the man who may be counted on with confidence; nor can I see how the vagaries of a lunatic give better proof of moral accountability than the actions of the man who does what all his fellowmen expect from him.

In a word, I do not see why the ultimate establishment of a mechanical explanation of all the phenomena of nature should destroy or set aside any one thing we know now.

"The notions of guilt and merit, justice and reward, are in the minds of men antecedent to all metaphysical disquisitions; and according to these received notions, it is not doubted that man is accountable."

Huxley, who like Sir Isaac Newton tells us that he lives in the hope that all the phenomena of nature will be reduced to 
mechanical principles, also tells us ("Physical Basis of Life," I 868), that a wise man must be fully possessed of two beliefs: "The first, that the order of nature is ascertainable by our faculties to an extent which is practically unlimited; the second, that our volition counts for something as a condition of the course of events."

Again, twenty-five years later (1893), he says ("Evolution and Ethics") that fragile reed as man may be, "there lies within him a fund of energy, operating intelligently, and so far akin to that which pervades the universe, that it is competent to influence and modify the cosmic process."

While I see no reason why every living thing may not contain some small part of this influence which counts for something as a condition of the course of events, I am unable to see how or where this assertion is irreconcilable with the admission that, for all one knows to the contrary, all nature may ultimately prove mechanical.

If I admit my accountability, if I have every reason to believe, and no reason to doubt, that my volition will count, how can proof that I do nothing which might not have been expected show that my confidence is deceptive?

"If it is foreseen that such an action shall be done, may it not," asks Berkeley, "also be foreseen that it shall be an effect of human choice and liberty? To me, certain and necessary" seem very different; there being nothing in the former notion that implies restraint, nor consequently which may not consist with a man's being accountable for his actions. And though by abstract reasoning you would puzzle me, and seem to prove the contrary, this inward evidence of plain fact will bear me up against all your reasonings, however subtle and refined."

Even if one doubt whether volition be a good thing, whether ability to do wrong may not outweigh the ability to do right, how does this disprove responsibility? If what I will come about as I expect, I am responsible; whether the "causa causamum," or "I," or "physical causation," be the cause of the effect; or even if I know nothing of absolute or efficient causation.

The answer I give to the question whether my volition be within or without the chain of physical causation, has nothing to 
do with the reality of my freedom; for one who knows nothing, either positively or negatively, about absolute freedom may nevertheless be convinced that, as a practical matter, he is free and responsible.

While we may from premises infer a conclusion, it will not follow that we can argue reciprocally and from the conclusion infer the premises.

Proof that my voluntary acts are arbitrary and not mechanical might prove them free; but it does not follow that my confidence in my freedom proves that it is arbitrary and not mechanical; for if mechanical means orderly, the only contrasted meaning I can find for the word arbitrary is disorderly.

When we speak of the reduction of nature to mechanical principles, and when we compare the works of nature to a machine, what do these words mean?

Our notion of the human contrivances we call machines is clear and definite. A clock is a machine, and so is a steam-engine. The definition of machines in the "Encyclopædia Britannica" tells us they "produce some useful purpose," and use is the very essence of an artificial machine; for mechanical toys are not made without a purpose. In common speech a purposeless machine is, so far as may be, a contradiction in terms; and they who find difficulty in reconciling the mechanism of nature, or the mechanism of our minds, with purpose or intention must have some other meaning in mind. To put ourselves in their place, we must try to find out this meaning if we can, for it may be that the assertion that our minds are mechanical will prove to be only another way of saying that they are useful.

Mechanics divide artificial implements into instruments, structures, and machines. Clocks and locomotives are machines; railroads and bridges are structures; and the wrenches and files of the engineer are instruments. While these three classes are not sharply separated, I think they bring out the meaning we are seeking. Machines, instruments, and structures are alike useful, but they are not used in the same way. What the wrench and the bridge were before they were used, that they remain while used and after they have been used, and they are used only so long as they are 
actively employed by a user; but a clock wound up and started is different from a clock run down, and so long as its pendulum swings it counts the passing seconds and tells the flight of time whether we use it or not. Once set agoing, it is independent of a user, and it does its work "by itself" until it comes to rest; although its independence of a user does not imply that it is useless, for so long as it runs any one may use it who knows how. If it were kept wound up by a wheel under a waterfall, it would be part of the mechanism of nature; and, once started, it would, barring accidents, be independent of human users. When the mechanism of nature is compared to human machines, these often seem to be thought of in this way, as contrasted with instruments and structures. Attention is thus concentrated on their distinctive or specific characteristic, to the temporary neglect of that usefulness which is the common or generic characteristic of all artificial implements.

Water falls by gravitation and, winding up the weights, which also fall by gravitation, keeps in motion the pendulum which, so long as it moves, beats seconds by gravitation. As gravitation is said to be mechanical and "universal," it has seemed to some that the clock thus placed must go on recording the flight of time, since it is part of the mechanism of nature, and is independent of human support or intervention. In other words, the automatism of the clock - that is, its independence of human users - is held to show that it is self-sustaining; but they who infer from this analogy that the mechanism of nature is self-sustaining, while they deny that the analogy shows that this mechanism has a purpose, seem to me to play fast and loose with the analogy, and to reason like the demagogue who tells the workman cheap money will raise his wages, and bring down the price of those products of labor for which he spends his wages.

Must we not ask what we mean by the assertion that, once started, the movement of the clock is automatic? What does the word automatic mean in this connection? One thing it clearly means: that the movement is independent of human users. It also means that, the conditions being given, its movements may be counted on with confidence. What else does it mean? Do we find, in the clock or anywhere else, any ground for the belief that its automatic movements, once started, are necessary or self-sustain- 
ing? Or do we find any reason to think that its independence of a user has any bearing on its usefulness to those who know how to use it? As it is obvious that the clock will not go unless the water continues to run down hill, the assertion that it is selfsustaining clearly has no better basis than our confidence that water which is free to run down hill will do so; but this basis is so firm that I do not suppose any one looks for or holds that he has any other.

Water runs down hill by gravitation; and the predictions we base on the stability of gravitation command our utmost confidence. The nautical almanac, published several years in advance, gives the predicted places of the sun, moon, and principal planets from day to day, and in some cases, from hour to hour, through the whole year. Unless gravitation is stable, these predictions are worthless; yet no one hesitates to trust his fortune and his life and even the safety and honor of his country to the nautical almanac. Even if this prove at fault, if, in any particular, observation fail to verify its predictions, no one ever dreams that its principles are wrong. On the contrary, the astronomer himself, after making sure that computers and printers and those who use the predictions have made no mistake, uses this failure to correct his estimates of the sizes and distances and velocities of the heavenly bodies. Unknown planets and satellites, worlds which no human eye had seen, have been deduced from the data of astronomy with such exactness that the new world has been found when the telescope has been turned to the designated spot.

When we reflect upon the meaning of our confidence in gravitation, who can wonder if some think that the clock which is found to fall into a place in the same system with the facts of astronomy must go on of necessity, although no words can be more emphatic than those in which the men of science repudiate this belief? Huxley, for example, "anathematizes" it in the following words, to which all thoughtful men of science must subscribe:-

"What is the dire necessity and 'iron' law under which men groan? Truly, most gratuitously invented bugbears. I suppose that if there be an iron law, it is that of gravitation, and if there be a physical necessity, it is that a stone, unsupported, must fall to the ground. But what is all we really know about the latter 
phenomenon? Simply that in all human experience all stones have fallen to the ground under these conditions, and that we have not the smallest reason for believing that any stone so circumstanced will not fall to the ground, and that we have, on the contrary, every reason to believe that it will so fall. It is very convenient to indicate that all the conditions of belief have been fulfilled in this case, by calling the statement that the unsupported stone will fall to the ground a law of nature. But when, as commonly happens, we change will into must, we introduce an idea of necessity which most assuredly does not lie in the observed facts, and has no warranty that I can cliscover elsewhere. For my part I utterly repudiate and anathematize the intruder. Fact I know; and Law I know; but what is this Necessity save an empty shadow of my own mind's throwing?" 1

"Attraction," says Berkeley, "cannot produce, and in that sense account for the phenomena, being itself one of the phenomena produced and to be accounted for."

If words like these mean anything, they mean that they who think the movements of the mechanism of nature necessary utterly misapprehend the value and significance of natural knowledge. They mean that belief that the automatic clock is self-sustaining and must go finds no support in the teachings of science; except so far as it may be supported by something in our own nature.

If man were a pure intellect, the intensity of our confidence in gravitation might be identical with its logical value; but as a man is a ponderable body and not a pure intellect, serious bodily harm, or even death, may follow failure to respond to that part of the order of nature which we formulate as the law of gravitation.

The actions of most terrestrial animals large enough to be injured by a fall are so adjusted to this order that the practical value of their responses does not bear any exact relation to their opportunities for acquiring experience. When a mud-turtle or a marine crab is put on a table, it may walk over the edge without hesitation; but a land-crab, on reaching the edge, hunts for a safe place to climb down, and if forced to go over, clings to the table, or else drops with caution after preparation. Nestling birds, I "Physical Basis of Life," I868. 
before they learn to fly, climb on to the edge of the nest, but they seldom tumble; and they will cling to the finger, when this is inclined, in such a way as to keep their balance. They who believe instinct is inherited knowledge may say the land-crab knozes the danger of a fall by instinct; and they may be disposed to think that the intellectual value of our confidence in gravitation is in part innate and independent of experience.

A single hard tumble may do more to convince a child that unsupported bodies will fall than long impersonal experience; and the intensity of any conviction which is consistent with our natural adjustments cannot be measured by the amount of experience, although this is the only measure of its value as knowledge, for we have no other way to learn when and how far an adjustment is judicious, and when it is not, than through experience of the order of nature. The question we now seek to answer is not how strong our confidence in gravitation is, but what it is worth, and we find that its value as knowledge may be measured, quantitatively as well as qualitatively, by human experience, and that it has no inherent or a priori intellectual value; although the practical value, in preserving life, of the responses of living things to the stimulus of gravitation is often independent of experience; and although we may, in these cases, be quite unable to tell whether these responses are accompanied by mind or not.

Ignorance is not knowledge, as we use words; and one school of "philosophers" seems to me to have brought needless confusion into the discussion of the nature and sources of human knowledge by failure to distinguish the practical value to living things of response to the order of nature from the logical value of our own conscious intelligent confidence in the stability of this order; for whether these things are fundamentally different or not, they are practically different for us.

In another school of "philosophers," who teach that our minds would lose their value unless we have a monopoly of reason, equal confusion seems to me to follow failure to perceive that every responsive action in nature may, for all we know to the contrary, be accompanied by some small part of that which we call mind.

If our scientific creed is a modest confession that while we 
do not know what the relation between mind and matter is, we should like to find out, the controversies between the realists and the idealists and the monists and the evolutionists and the materialists will concern us as little as a summer shower concerns a duck.

Our knowledge of the stability of gravitation is accompanied by an innate or natural tendency to respond to it as a stimulus, - a tendency which we share with most terrestrial animals and plants, - and all knowledge is no doubt accompanied by similar emotional elements; nor does it seem possible to discover any sharp line between the responses which living things make by nature and prior to experience and our own conscious, rational adjustments; although the response of a germinating seed to gravitation and our own acquaintance with Newton's laws are things so different that it would do violence to the usage of common speech to call them both knowledge.

If we analyze in the same way the scientific or objective value of our confidence in the stability of the matter of the clock, of the iron and the brass, and the wheels and bearings and pinions, we find that this, like our confidence that its movements will be orderly, is reasonable and judicious, but not necessary or absolute.

We are led back, step by step, to the law of the indestructibility of matter, just as we are led, by the study of gravitation and similar phenomena, to the law of the conservation of energy; and finally we may perhaps be led to regard these laws as illustrations of a still more general mechanical principle, - the continuity of motion; but those men of science who see most reason to believe that all the phenomena of nature are phenomena of motion, reducible to mechanical principles, are the ones who are most emphatic in their assertion that, while it is folly to dispute these principles, they know no evidence that they are necessary or absolute. Our confidence in them is reasonable and judicious; but we know no reason why they must hold good.

"All the phenomena in nature," says Berkeley, "are produced by motion. Mechanical laws of nature or motion direct us how to act, and teach us what to expect. Nor are we concerned at all about the forces, neither can we know or measure them, 
otherwise than by their effects, that is to say, the motions; which motions, only, and not the forces, are indeed in the bodies. Bodies are moved to and from each other, and this is performed according to different laws. The natural or mechanical philosopher endeavors to discover these laws by experiment and reasoning. But what is said of forces residing in bodies, whether attracting or repelling, is to be regarded only as a mathematical hypothesis, and not as anything really residing in nature." 1

Of Newton's laws, we are told in the "Encyclopædia Britannica," article Mechanics, "These laws are to be considered as deductions from observation and experiment, and in no sense as having any a priori foundation."

Jevons tells us ("Principles of Science," p. 739): "I demur to the assumption that there is any necessary truth even in such fundamental laws of nature as the Indestructibility of Matter, the Conservation of Energy, or the Laws of Motion. With the statement of every law we ought properly to join an estimate of the number of instances in which it has been observed to hold good, and the probability [i.e. the reasonableness of the expectation] thence calculated, that it will hold true in the next case. No finite number of instances can warrant us in expecting with certainty that the next event will be of like nature."

Many who admit that since our knowledge of matter and motion is based on observation and experiment it has no more value than experience gives, hold, nevertheless, that there are certain necessary truths or axioms; although the word axiom docs not by derivation mean a necessary truth, but one that is worthy of confidence. So far as nature is believed to give evidence of a necessary law of causation, this opinion may be properly considered here, and we must ask what we mean by the asscrtion that this law is necessary. Philosophers may, if they see fit, define cause as "that which produceth a thing and maketh it to be what it is"; but it is one thing to define a word, and quite another to find in nature any corresponding reality. The discovery of a definition of "Mermaid" in the dictionary is no cvidence that mermaids exist in nature; although it may be evidence that they

$$
1 \text { "Siris," } 234 \text {. }
$$


exist, or have existed, in human minds; nor is proof that a thing exists in all human minds proof that it exists in nature outside human minds.

The "law of causation" seems to consist of two elements. Our whole history as living beings gives new strength continually to our confidence that, when event $A$, which we call a cause, exists, event $B$, which we call its effect, may be expected; and that in the absence of $A, B$ will not be found. The belief also prevails that $B$ cannot occur without $A$, and that it must occur with $\mathrm{A}$.

It does not seem difficult to consider these elements separately; and whatever may be our opinion of their separation in fact, the analysis may help us to examine the subject.

Every rational action is based upon our confidence that each event is, in course of nature, a sign of others that may be expected. This confidence gathers strength with every moment of our lives, and is so ingrained in our language, that we speak of the sign as if it were, in very truth, the thing signified. When we hear a pattering sound on the roof, we do not restrict ourselves to fact, and say we hear a sound. We say we hear it rain. I have tried to show that life itself, not only] the conscious, rational life of man and of the higher animals, but the life of every animal and every plant, is response. A living being is a being which when affected by $A$ makes preparations to meet $B$. The rhizopod which flows around and ingests small particles of food, while it retracts its pseudopodia when violently jarred, responds to the law of causation as much as the sailor who corrects his chronometer by observations on the satellites of Jupiter. Response to this law is admitted to be entirely organic in the lower living things, and to a great extent organic in all. As man has by nature structural adjustments to many of these relations between phenomena, the law of causation seems, to this extent, embodied in his organization as part of his nature, and we have already seen that, while the value of our confidence in this ordcr is measured by our experience, its intensity is not. There is no constant ratio between the intensity with which a burnt child dreads the fire and the number of times it has been burned. In this sense the law of causation seems to be necessary, inasmuch 
as we could not ignore it in our actions if we would without suffering the consequences; although belief in universal causation does not seem to be necessary, for we find men who think they are quite able to believe in luck or chance, as in the fall of dice, and others who hold that our own rational actions are no part of the order of nature.

It is clear, however, that, as living beings, we are compelled, by our nature, to respond to the law of causation or take the consequences, and that in this sense the law is necessary to man as man just as food and drink are necessary; but as it by no means follows that we are to have food and drink, or that a man may not starve himself, so it may not follow that, because confidence in causation is organic and natural, the external relations to which we respond are fixed or necessary.

The responses to causation which are part of our nature as living men are continually verified and amplified and perfected and corrected by new experience with every hour of our existence, until old age is inclined to suspect that experience has nothing new to offer; but the support which individual experience gives to this law is as nothing in comparison with that which we find in the annals of scientific progress, - in the systematic observations and controlled experiments which make up that organized and orderly summary of the experience of generation after generation which is now the common stock of all educated men.

"A single book tells us more than Methuselah could have learned, had he spent every waking hour of his thousand years in learning. When apparent disorders are found to be only the recurrent pulses of a slow-working order, and the wonder of the year becomes the commonplace of a century; when repeated and minute examination never reveals a break in the chain of causes and effects; and the whole edifice of practical life is built on our faith in its continuity, - the belief that the chain has never been broken and will never be broken becomes one of the strongest and most justifiable of human convictions." 1

To admit that response to causation is part of our human constitution is one thing, but it is quite another matter to assert that we know why one event must, or even that it must, be

1 IIuxlcy, "Hume," p. 153. 
associated with another. This second element in the "law of causation" would never have obtained a moment's credence if it were not brought before our minds in intimate relation with the great natural truth of the other element.

"There are," says Herschel, "truths so large, so general, so all pervading, that they make a part of all our experience, mix with our whole intellectual being, and imbue all our judgments, erroneous as well as correct; in this sense, at least, that we never err so far as to place ourselves in conscious opposition to them.

"Distorted and perverted as such truths may be in their enunciation, by their mixture with extraneous error, we find them still outstanding, redeeming by their presence and ever consecrating that error." 1

Such a truth I take the law of causation to be.

All writers on the principles of science agree that man has as yet discovered nothing except a little of the order of nature, and that the reason why events occur in one order rather than another, or even why they occur in any order, is a mystery to which nature gives us no answer; for even if natural selection should show that we should have been different if the selective standard had been different, and that this order is no more than might have been expected from our history, this is no reason why the things we expect should be the things that come about.

We can say no more about the relation between events and our expectations than that these things appear together, but that nature does not tell us why. If this is true, is it not clear that we are in no position to say of any event that it cannot come about in the absence of any other event, although we may have the utmost practical confidence that it will not come about?

We cannot well do without the word cause, and Mill has called attention to the obvious fact that the scientific method of investigating cause is independent of metaphysical analysis of what cause means; although exact reasoning about nature is impossible unless this distinction is sharply drawn. A recent writer on logic tells us: "A very simple analysis of 'cause' is sufficient for the purposes of scientific inquiry. What we call a canse is 
not merely antecedent or prior in time to what we call its effect; it is so relited to the effect that if it or its equivalent event had not happened, the effect roould not have happened. Anything in the absence of which a phenomenon would not have come to pass is a cause in the ordinary sense."

No one can object to this analysis of the ordinary sense of the word cause, if not only this word but all the words I have put in italics are used in the ordinary sense; but when using words in this sense, we say one event would not have happened in the absence of another, we mean only that belief that it might so happen seems inconsistent with what we chance to know of the past, and with those responses which we make in virtue of our nature. There may be no practical difference between certainty and this expectation, if it is shared by all persons in whom we have confidence, if every experiment which has tested it has verified it, if it is associated in our minds with other events regarding which we have the same confidence, and if our organic responses are so firmly adjusted to this association that we fail to discover any way to change them without disaster. Thus put, the analysis of the word cause is seen to have no bearing, either positively or negatively, upon the existence of a necessary law of causation; but it seems to me to be all science warrants, for our ability to believe in the order of nature changes daily with our knowledge and experience, and our organic responses change slowly through selection.

Perception of the truth that our knowledge of the world around us is knowledge of the order of events, and that we know no reason why events should be orderly except that the fact is so, is, in effect, an admission that all our knowledge of nature is sensible knowledge. Whether they agree with Berkeley that objects of sense, or, as he prefers to call them, ideas, are all that exist, most thoughtful men of science agree that they are all we know the existence of.

"Ideas which are observed to be connected together are," as Berkeley points out, "vulgarly considered under the relation of cause and effect, whereas, in strict and philosophic truth, they are only related as the sign and the thing signified" (13). 
"It seems evident," says he, "that an idea can be only like another idea, and that in our ideas, or immediate objects of sense, there is nothing of Power, Causality, or Agency included"(I2). "How, then, can you tell," he asks, "whether such unknown cause acts arbitrarily or necessarily? I see the effects or appearances, and I know that effects must have a cause, but I neither see nor know that their connection with that cause is necessary. Whatever this may be, I am sure I see no such necessary connection" $(30){ }^{1}$

To return to our automatic clock. We do know, as a matter of fact, that, once put in place and started, it may be expected to keep on going, without farther attention, until in course of nature something occurs to stop it. Some tell us, therefore, that while the mechanism of nature may need a starter, it is self-sustaining after it is once started. What meaning these reasoners attach to the word self-sustaining, I am unable to conjecture, unless they mean independent of human users; but their logic seems to have imposed upon no less shrewd a thinker than Bacon, who tells us that "notwithstanding God hath rested and ceased from creating since the first Sabbath, yet, nevertheless, he doth accomplish and fulfil his divine will in all things, great and small, as fully and exactly by Providence, as he would by miracle and new creation, though his working be not immediate and direct, but by compass, not violating nature, which is his own law upon the creature."

While Bacon took all knowledge for his patrimony, he failed to enjoy his birthright, for he was quite unable to profit by his acquaintance with true scientific men like Harvey, and when he speaks of violating or not violating nature, he exhibits superficial and erroneous notions of science, for nothing that is can be a violation of nature, since nature is neither more nor less than that which is. If that is miraculous which is not accounted for by natural law, all nature is miraculous; for natural laws tell us only what is, not why it is.

Some modern students unquestionably think as Bacon does. They have been told so often that the spread of mechanical conceptions of nature must necessarily end by pushing the Creator out 1 Berkeley, "Theory of Vision Vindicated and Explained." 
of creation that they have come to believe this; although every great teacher of the principles of science tells them their inference is worthless. We fail, on analysis, to discover any a priori foundation for the law of conservation of energy, the law of the indestructibility of matter, the law of the continuity of motion, the law of natural causation, or any necessary or universal law of nature. If we pass by, for the present, what animal automatism or human automatism would mean if it were established, all the meaning we are able to find in the automatic clock, or in the automatism of nature, for the meaning of the word automaton, as distinguished from instruments and structures, is an orderly mechanism which is worthy of confidence and independent of human users, and useful to them who know how to use it.

Unless sane men doubt whether the mechanism of nature is orderly and worthy of confidence and independent for the most part of human users, and useful to them who know how to use it, no philosopher has as yet found in physical science any basis for a philosophy of nature which is not the common property of all rational beings. I fail to see why any should dread the extension of mechanical conceptions of nature. If life is response to the order of nature, he who dreads or fears natural knowledge seems unworthy of the conscious life of manhood, and better fitted for that of a turnip or a clam. These things have the benefit of response to mechanical principles without seeming to know anything about it ; and he whom these principles oppress like a nightmare might be more at ease if he were a turnip. He might then have all the benefit of mechanical principles without the horror of physical science which seems as subjective as the horrors of delirium tremens. The sufferer should have our pity, but I cannot put myself in his place, for nothing seems clearer than that the natural common sense of man would preserve him from all horror of mechanics if he were left alone; that it would, on the contrary, assure him that each new discovery in this field is added proof of his sanity and of the value of his common sense.

If any believe they have evidence of a power outside nature, to which both its origin and its maintenance from day to day are due, physical science tells them nothing inconsistent with this belief. If failure to find any sustaining virtue in matter and motion 
is evidence of an external sustaining power, physical science affords this evidence; but no one who admits this can hope to escape calumny; although it seems clear that the man of science is right, and that theologians must some time admit he is right, and thank him for standing by the truth in evil report and in good report; for refusing to admit that he knows the laws of physical nature in any way except as observed order.

Stoutly and steadfastly has he refused to assert that he knows any event must happen because some other event has happened. He maintains that he knows nothing of causes as necessary antececlents; nothing of effects as necessary consequents. He has never ceased from declaring his repudiation of Pindar's conception of natural law as the Ruler of the Mortals and the Immortals; or as the ruler of anything else, even the fall of a stone or a sparrow to the ground.

With all the emphasis he can command does he affirm that they who charge him with belief that nature is governed by fixed or necessary mechanical principles are totally ignorant of the methods and accomplishments of science.

If any still fail to understand him, the failure must be due to the limitations of language, or to ignorance, or to natural incapacity; for he must bear in mind, with Aristotle, that reasoning does not appeal to all, but only to those whose minds are prepared, as ground is prepared for seed.

The belief that the establishment of scientific conceptions of nature shows that, after the first creative act, the Creator has remained subject, like a human legislator, to his own laws, is based upon utter misapprehension of science, and upon absurd and irrational notions of natural law.

All the student of physical science is able to discover in any automaton, artificial or natural, as distinguished from instruments and structures, is that its movements are orderly, and that confidence in them is reasonable and judicious. This seems to be what the word automaton means, and all it means; unless it means that onr confidence in the usefulness of automata, like our confidence in the usefulness of structures and instruments, is reasonable and judicious.

This thesis is the subject of the next section. 
No one who does not answer in the negative the absurd question whether life is worth living - a question which is answered affirmatively by every act of scientific inquiry - can ask with any serious doubt of the answer, whether the attributes of living things are useful.

"The opinion which disdaineth our life is ridiculous: For in fine it is our being. It is our all in all. It is against nature, we should disprise, and carelessly set ourselves at naught: It is a particular infirmitie, and which is not seene in any other creature, to hate and disdaine himself." 1

In Romanes's words, "wherever we tap organic nature it seems to flow with purpose." The whole history of zoölogy is a history of the discovery of the adjustment of the acts of living things to the order of nature.

The discovery of the chain of physical causation which joins this order of nature to these adjustments, by means of natural selection, tells us nothing except that these adjustments are no more than might have been expected; and I cannot put myself in the place of those who think this discovery shows that the fitness of living beings is not real fitness.

He who admits that cats are part of nature, and that skill in catching mice is important to the race of cats, must admit that nature is, so far, useful to itself; nor, while the standpoint of the mouse must not be forgotten, do I see how proof that cats are part of the order of physical nature would alter the case, for this would only prove that physical nature is, so far, useful to itself. Proof that cats are automatic and mechanical, from beginning to end, would show that their whole history has been orderly and what might have been expected, but it would not disprove anything we now know about them, nor tell us whether their actions are necessary or unnecessary, for the discovery that a natural event may be counted on with confidence tclls us nothing about its origin and nothing about its existence cxcept what we know already.

When we say nature is orderly, we mean each event may be a sign which leads us to expect other events with confidence. When we say the attributes of living things are useful to them, we 
mean that they are so constituted that the stimulus of one event initiates changes which are so adjusted to other events as to lead to survival in the struggle for existence. As this adjustment may be perfected and improved without discoverable limit, and as all natural knowledge may be put to use, has not our belief that nature is useful the same basis as our confidence in the stability of nature?

If man were a pure intellect, our conviction that nature is orderly might mean no more than that events are signs with a significance; but since man is not only a rational being but a living thing, each event is not only a sign which tells us what to expect, but a warning to tell us what, on peril of consequences, we should prepare for.

Our warrant for confidence in the stability of nature seems to me to be the continuity of life; and if we admit that life is worth living, we must also admit that the evidence that the order of nature is useful is identical with the evidence that there is order in nature.

If the artificial production of living beings out of inorganic matter should ever prove that their fitness is "deducible" from the physical properties of living matter, this would not mean that their fitness is imaginary, but only that the properties of certain forms of matter are useful to these forms of matter.

Some tell us, however, that the passage from the properties of matter to the phenomena of life is unthinkable; but they who infer that this passage is therefore impossible, must remember that the passage from the properties of the stone I hold in my hand to the fall of the stone would be equally unthinkable if I had no experience of gravitation, for I find in nature no reason why it should fall except my confidence that it will; and the only test of the objective value of this confidence is that which experience gives.

No great brilliancy or nimbleness of wit is called for to see that the discovery that things do take place in order is no reason why they should, or even why they should take place at all. They who hold that, while mind is free, matter is bond, seem to mean no more than that they know no reason why their mental events must take place in order; but unless they can show some reason 
why material events must take place in order, I do not see what reason they have for thinking matter is any more hond than mind.

Many authors have quoted with approval Tyndall's eloquent statement of his conviction that the passage from motion to mind is unthinkable, for his reasoning seems to be impregnable.

"The passage from the physics of the brain to the corresponding facts of consciousness is unthinkable. Granted that a definite thought and a definite molecular action in the brain occur simultaneously, we do not possess the intellectual organ, nor apparently any rudiment of the organ, which would enable us to pass, by a process of reasoning, from one phenomenon to the other. They appear together, but we do not know why. Were our minds and senses so expanded, strengthened, and illuminated, as to enable us to see and feel the very molecules of the brain; were we capable of following all their motions, all their groupings, all their electrical discharges, if such there be; and were we intimately acquainted with the corresponding states of thought and feeling, we should be as far as ever from the solution of the problem: How are these physical processes connected with the facts of consciousness? The chasm between the two classes of phenomena would still remain intellectually impassable."

While this statement of the case seems to me to be impregnable, it does not seem to have any relevancy or any particular significance, unless Professor Tyndall or others can show that we have some organ or some rudiment of an organ which gives us some other reason why an unsupported stone should fall than the fact that it does fall. I do not see what new light the expansion and strengthening and illumination of our minds and senses could be expected to throw on the matter; for the illumination of the molecules of the brain or those of any other body, until they appeared like cannon-balls rolling in a ten-acre lot, would not tell why a collision between two of them should change the rate or direction of their motion. We could only say, as we say now, that our implicit confidence that they will conform to Newton's laws is reasonable and judicious because in all human experience it has never been disappointed. If Professor Tyndall should assert that this implicit confidence is itself a passage from one physical phenomenon to another, and that this passage is so far thinkable, a 
little reflection will show that the passage from physical phenomena to psychical events is thinkable in exactly the same way, since all plain practical folks think it every day and every moment of their lives. As we use words, a mountain is physical, and to see a mountain is a state of mind. Is not our confidence that if Professor Tyndall were where the Alps could be seen, he might see them if he had his eycsight, as reasonable and as implicit as our confidence that a collision between two molecules will change their motion? If we can be said to pass by a process of reasoning from the motion of two molecules before impact to their motion afterwards, we can be said to pass, in the same way, from a physical burn to a psychical pain; for we have no reason to doubt and every reason to expect that a burn will hurt. Tyndall's assertion that the passage from the physics of the brain to the facts of consciousness is unthinkable, that they appear together, but that nature does not tell us why, might be a contribution to human wisdom if we were able to discover in nature any reason why physical phenomena themselves appear together except the fact that they do.

"Modern science," says Huxley, with an insight more profound than Tyndall's, "admits that there are two worlds to be considered, the one physical and the other psychical, and that though there is a most intimate relation and intercommunication between the two, the bridge from one to the other has yet to be found; that their phenomena run, not in one serics, but along parallel lines." 1

The reduction of the phenomena of life to those mechanical principles which hold good in the inorganic world would unquestionably show that these two worlds are in fact different aspects of one and the same world. If such a discovery should ever be made, we might well hope for untold practical benefits to mankind, like those which have followed every great advance in knowledge, but I cannot see how it could possibly show that man is anything else than man, or mind anything but mind; for when we say we are able to pass from one physical event to another physical event, all we mean is that one of these events is the sign which leads us to look for the other with confidence. We most 
assuredly know no reason why they should stand in this relation, and we can only say of them that they occur together, but that nature does not tell us why.

They who assert that the production of living beings out of inorganic matter would show that matter is the efficient cause of mind, totally mistake the nature of scientific evidence; for we may say of physical events that while they run on lines that are so far parallel that one may be the sign which leads us to expect others, the bridge which joins them has never been 'found in nature.

As matters are at present we have the same sort of reason for confidence that certain psychical events will follow certain physical events and that certain physical events will follow certain psychical ones; that the sensation of vision will follow the opening of our eyes, and that a quickened pulse will follow anger; that we have for confidence in the physical order of nature.

Even the fantastical desire to show we can do as we like by some capricious action, is no more than a shrewd witness might have expected; and psychical events are as orderly as physical events. Surely no one supposes that while physical matters are orderly, psychical matters are given over to chance.

"For what is meant by liberty, when applied to voluntary actions? We cannot surely mean that actions have so little connection with motives, inclinations, and circumstances that one doth not follow with a certain degree of uniformity from the other, and that one affords no inference by which we can conclude the existence of the other. For these are plain and acknowledged matters of fact." 1

If any one assert that while he acts from motives, like a rational being, and in the way he might reasonably be expected to act, he is nevertheless free to do as he likes, because there is no necessary connection between his actions and his motives, he must remember that, while no one disputes his freedom, we know no necessary connection between physical phenomena, and that, if the stone I drop from my hand were to assert that it is free to do as it likes, I should have to admit that, for all I know to the contrary, this assertion may be true; for all I know of the

1 Hume, as quoted by Huxley. 
matter is that all stones thus placed have done as I expected, and that I have not the slightest reason to suppose that any stone will act differently, or to believe that it either is or is not free to do as it likes.

The reason why the animistic belief that everything is alive, which once prevailed among all men, has passed out of the modern mind is not that it has been proved untrue, but that we find no evidence of its truth, and no value in its practical application.

I do find evidence that I am free, and while my reason has little value in open market, its value to me is great.

Every one who is called upon to develop and perfect the nature of a child takes its ability to do as it likes for granted, and tries to find out why it likes to do what it does, and to substitute wise and prudent motives for superficial or pernicious ones; and the method by which a crafty schemer manipulates his fellow-men for his own ends is essentially the same.

We know we are free to do as we like; and we also know there are reasons why we like to do as we do.

The reduction of all the phenomena of life to mechanical principles would show that our likings and dislikings are what they might have been expected to be.

It is hard to see why one who admits that the nature which tells us some actions are pleasant and others painful, some wise and others foolish, some right and others wrong, is natural, should dread the prevalence of mechanical explanations of human nature; for it seems clear that they would not alter or do away with any one thing that we know now. No one who believes duty and moral responsibility are natural would find any reason for changing his belief on proof that our nature is what it might have been expected to be.

The opinion that there is any incompatibility between natural law and liberty has arisen out of the belief that so far as nature is reducible to laws it is necessary; and the clear recognition of the truth that a natural law is simply a generalized statement of our confidence that nature is orderly, should show that this opinion is idle; for while the antithesis to necessary may be arbitrary, the antithesis to order is disorder. 
In the famous argument by which Butler shows that the assertion that nature is necessary is no answer to the question whether it is intended, he supposes that a fatalist and one who believes himself a free agent are disputing together.

The reasoning, while conclusive, is hard to follow; but if we substitute for fatalist, or one who believes whatever is is necessary, the word naturalist, or one who believes whatever is is orderly, and for the word nccessary the word orderly, the argument becomes so simple that it seems like a parody.

"Suppose," he would say if this change were made, "that one who was a naturalist and one who kept to his natural sense of things, and believed himself a free agent, were disputing together, and vindicating their respective opinions, and they should happen to instance a house; they would agree that it was built by an architect. Their difference concerning order and freedom would occasion no difference of judgment concerning this; but only concerning another matter, - whether the architect built it as might have been expected or not [necessarily or frecly, in the original.]

"When it is said by a naturalist that the whole constitution of nature, the actions of men, everything, and every mode and circumstance of everything is ordcrly, and could not reasonably have been expected to have been otherwise, it is to be observed that this order doth not exclude deliberation, choice, preference, and acting from certain principles, and to certain ends; because all this is a matter of undoubted experience acknowledged by all, and what every man may every moment be conscious of. Hence it follows that order, alone and of itself, is in no sort an account of the constitution of nature, and how things came to be and to continue as they are; but only an account of this circumstance relating to their origin and continuance, that they could not reasonably have bcen expected to have been otherwise than they are and have been. The assertion that everything is in order of nature is not an answer to the question whether the world came into being as it is by an intelligent Agent forming it thus, or not; but to quite another question, - whether it came into being as it is in that way and manner which we call ordcrly, or in that way and manner which we call ... ?" In the original the last word is frecly, as contrasted with necessarily; but while I have substituted ordcrly for necessarily, 
the substitution of disorderly for freely would make the reasoning so simple as to be almost ludicrous; yet I am not able to find any antithesis to order except disorder.

Nor can I discover what bearing proof that our actions are what might have been expected of us has on the question whether we are free to do as we choose, unless we choose to do and succeed in doing utterly inconsequent and irrational things.

Since the discovery that the phenomena of nature do take place in order does not show why they take place in order, or even why they should take place at all, is it not plain that the discovery of the order of nature has no bearing on the origin or on the reality of anything in nature?

Is it not equally clear that the reduction of all the phenomena of nature, including those of life and mind, to mechanical principles, would not disprove the reality or the value of any one thing we discover in our nature?

Many will, no doubt, receive with incredulity the assertion that the ultimate establishment of mechanical conceptions of life has no bearing, either positively or negatively, upon the validity of such beliefs as the doctrine of immortality, for example. The opinion that life may be deducible from the properties of protoplasm has, by almost universal consent, been held to involve the admission that the destruction of the living organism is, of nccessity, the annihilation of life. Yet it seems clear that this deduction is utterly baseless and unscientific; for if the views I have set forth in this lecture - views held by many thoughtful men of science; views in no way original with me-are accepted, and if it be admitted that we find in nature no reason why events should occur together except the fact that they do, is it not clear that we can give no reason why life and protoplasm should be associated except the fact that they are? And is it not equally clear that this is no reason why they may not exist separately?

Berkeley tells us it is to all intents and purposes atheistical "to make man a necessary agent"; but they who agree with him that while ideas which are observed to be connected are, vulgarly considered under the relation of cause and effect, they are, in strict and philosophic truth, known to be related only as the 
sign and the thing signified, will fail to see how proof that man is mechanical and automatic could show that he is a necessary agent; for science knows no necessity except the logical necessity for stopping where the evidence stops.

I fail to see why any one should find, in the extension of mechanical conceptions of nature, any evidence "that right deductions from true principles should ever end in consequences which cannot be maintained or made consistent."

So far as the word necessity means anything to us, as living beings, it is synonymous with the blindness of ignorance. The crab that finds and uses a house does nothing that might not have been expected; and since natural responses often mislead and prove injurious or even destructive, actions that are due to nature are commonly said to be blind or necessary; but our own conscious experience does not change our nature; for it only "unravels our prejudices and mistakes, untwisting the closest connections, distinguishing things that are different, instead of confused and perplexed, giving us distinct views, gradually correcting our judgment, and reducing it to a philosophical exactness."

Since this is so, does not each new discovery in the province of zoölogy give added meaning to the declaration that it is the truth that shall make us free? 



\section{LECTURE XIII}

LOUIS AGASSIZ AND GEORGE BERKELEY 
"Those highly magnifie Him, whose judicious inquiry into His Acts, and deliberate research into His Creatures, return the duty of a devout and learned admiration." - BRowne, "Religio Medici," 


\section{LECTURE XIII}

\section{LOUIS AGASSIZ AND GEORGE BERKELEY}

Whether the Origin of Species has or has not any bearing on the argument from design, it clearly has very obvious and positive bearing on certain arguments that have been thought to prove design; although belief that nature gives evidence of intention may be held by those who doubt whether it affords any proof of contrivance - of any use of instruments - that is not itself a part of the order of nature. While every phase of the teleological argument which our faculties permit has, no doubt, been considered by shrewd thinkers long ago, the work of Wallace and Darwin has brought clearly and distinctly before all the question whether it is contrivance - the use of means or instruments, and the overcoming of difficulties - or nature itself, which the teleologists believe to prove design. So far as the limitations of human speech are adequate to put it into words, the peculiar teleological problem of the nineteenth century seems to be whether we must prove contrivance, or interference with nature, in order to show intention; for it is now clear to us, as it never has been bofore, that, even if it be not impossible, it is very difficult to show the occurrence of any planning or contriving that is not itself a part of the orderly course of nature, admitting of a mechanical explanation; nor does it seem judicious or clear sighted to base natural theology upon anything else than nature.

These two elements, the argument from contrivance, and the argument from intention, are sometimes distinguished by the writers on natural theology, although none of them, so far as I can discover, keeps the distinction clearly and constantly in mind. In fact, most of them seem to me to so entangle these two points of view as to show that they fail to attach any importance to the distinction between them; although two great thinkers, George Berkeley and 
Louis Agassiz, base their reasoning upon nature itself, rather than upon evidence of contrivance in nature.

Agassiz's Essay on Classification, the last of the notable works on natural theology, was published in 1857 , as part of his "Contributions to the Natural History of the United States."

The writer was a man of transcendent genius for scientific discovery, with intense earnestness and enthusiasm for the pursuit of truth, and rare eloquence and literary skill. If any man was devoted to the cause of truth and determined to accept it whatever it might prove to be, that man was Agassiz; for while his impulses were notably devout and reverential, he proved, on many occasions, that he was fearless and independent in the search for truth. It is no disparagement to Buckland, and Bell, and Chalmers, and the other authors of the Bridgewater Treatises to assert that Agassiz far surpassed them all in acquaintance with the methods which lead to success in the interpretation of nature, and in ability to treat the problems of natural theology from the standpoint of the zoölogist.

He handles the subject in a far more comprehensive way than any of these writers, for he does not hesitate to assert that their attempts to find evidence of design in the contrivances of living bodies is unscientific and wrong in principle.

"The argument for the existence of an intelligent Creator," he tells us, "is generally drawn from the adaptation of means to ends, upon which the Bridgewater Treatises, for example, have been based. But this does not appear to me to cover the whole ground, for we can conceive that the natural action of objects upon each other should result in a final fitness of the universe, and thus produce a harmonious whole; nor does the argument derived from the connection of organs and functions seem to me more satisfactory, for beyond certain limits it is not even true."

He therefore attempts to put natural theology upon a much broader basis; for he finds reason to believe that the facts which are studied by the naturalist - the phenomena of geological succession and geographical distribution, of embryology and anatomy, of systematic botany and zoölogy; in a word, all the data of the natural sciences-are a language in which the Creator tells us the story of creation for our delight and instruction and advantage; and 
that when we use such phrases as the "language of nature," and the "interpretation of nature," our words are not figurative, but literal.

It is not because we find contrivances in nature, but because the order of nature is one consistent and harmonious whole, that he holds it to be intended.

"In their respective great types, the phenomena of animal life correspond to one another, whether we compare their rank as determined by structural complication with the phases of their growth, or with their succession in past geological ages; whether we compare this succession with their embryonic growth, or all these different relations with each other and with the geographical distribution of animals upon earth. The same series everywhere! The connection, however, between the facts, it is easily seen, is only intellectual, and implies, therefore, the agency of Intellect as its first cause."

He holds that this truth is most clearly shown by those systematic affinities which make out of the individual animals and plants a consistent and harmonious whole, a realm of nature; and he calls his work an Essay on Classification.

"The division of animals according to branch, class, order, family, genius, and species, by which we express the results of our investigation into the relations of the animal kingdom, and which constitute the first question respecting the systems of Natural History which we have to consider, seems to me to deserve the consideration of all thoughtful minds. Are these divisions artificial or natural? Are they the devices of the human mind to classify and arrange our knowledge in such a manner as to bring it more readily within our grasp and facilitate further investigation, or have they been instituted by the Divine Intelligence as categories of his mode of thinking? Have we perhaps thus far been only the unconscious interpreters of a Divine conception, in our attempts to expound nature? and when, in our pride of philosophy, we thought we were inventing systems of science, and classifying creation by the force of our own reason, have we followed only, and reproduced, in our imperfect expressions, the plan whose foundations in the dawn of creation, and the development of which, we are laboriously studying, - thinking as we arrange our frag. 
mentary knowledge, that we are anew introducing order into chaos? Is this order the result of the exertion of human skill and ingenuity, or is it inherent in the objects themselves, so that the intelligent student of Natural History is led unconsciously, by the study of the animal kingdom itself, to those conclusions, the great divisions under which he arranges animals being indeed but the headings to the chapters of the great book which he is reading?"

There may still be, here and there, a writer on "logic" who holds that since zoölogy is a "classificatory" science, the work of the naturalist is like that of one who arranges and tickets books in a library for ease of reference; but the modern student of science reads such assertions with a sad smile that one should be so ignorant; for he is as fully convinced as Agassiz that the realm of living nature is a consistent and harmonious whole, and that the work of the naturalist is to discover and not to create; for he bases all his work upon the conviction that "animals are linked together as closely by their mode of development, by their relative standing in their respective classes, by the order in which they have made their appearance upon earth, by their geographical distribution, and generally by their connection with the world in which they live, as by their anatomy."

Since all now admit the validity of this basis for the argument of Agassiz, why has the work of this man of great genius been without perceptible influence on modern thought; while the work of much less able men, like Paley, was for many years an important educational influence?

Why do not modern naturalists agree with Agassiz, that "all organized beings exhibit in themselves all these categories of structure and of existence upon which a natural system is founded, in such a manner that, in tracing it, the human mind is only translating into human language the Divine thoughts expressed in nature in living realities"?

Agassiz holds that " in one word, all these facts in their natural connection proclaim aloud the One God, whom man may know, adore, and love; and Natural History must, in good time, become the analysis of the thoughts of the Creator of the Universe, as manifested in the animal and vegetable kingdoms." 
The modern naturalist knows that while the best powers of the best minds may find endless pleasure and profitable employment in the study of those relations which bind the living world together into one coherent whole, these relations include far more than man can ever hope to master; more in delicacy and perfection than his microscope can ever reveal; more in intricacy and complexity than his senses can follow; more in extent of space and time than the utmost range of his powers; far more of the network of physical causation than his intellect can grasp.

If he also knows that his work is beneficial to himself and to all mankind; that his place among men is one of usefulness; that the study of living things and their ways and works is good and pleasant and instructive, - why does he hesitate to believe, with Agassiz, that all this is intended, and that it proves that nature is a language?

"If the power of thinking connectedly is the privilege of cultivated minds only; if the power of combining different thoughts, and of drawing from them new thoughts, is a still rarer privilege of a few superior minds; if the ability to trace simultaneously several trains of thought is such an extraordinary gift, that the few cases in which evidence of this kind has been presented have become a matter of historical record (Cæsar dictating several letters at the same time); if all this is only possible to the highest intellectual powers, - shall we by any false argumentation allow ourselves to deny the intervention of a supreme intellect in calling into existence combinations in nature by the side of which all human conceptions are child's play?"

It is a well-known fact that modern naturalists have refused to admit the cogency of Agassiz's reasoning, and all must fcel an interest in the reason why; for it may be that this is due to some error in the method by which Agassiz undertook to prove his thesis, rather than to any weakness in the thesis itsclf.

In order to prove that natural history is a language which we learn and listen to, to our entertainment and profit and instruction, he holds it essential to prove that it is nothing but a language; that the relations between living things and the world about them, being ideal relations, cannot possibly be physical ones also; that our "laws of biology" are not "necessary" but "arbitrary." 
The whole aim and purpose of the Essay on Classification is to prove that all the general laws of natural science are "categories of thought," by an attempt to show that they are nothing but categories of thought, and that no physical explanation of them is possible.

In 1859 , or less than two years after the publication of the Essay on Classification, the appearance of the "Origin of Species" brought about a revolution in our conceptions of natural history, for it made clear the mechanical explanation of some of the general laws of which Agassiz had told us no such explanation is possible. It is because the work of Wallace and Darwin has convinced naturalists that species have arisen, in course of nature, through influences that are still at work, that many modern students have refused to follow Agassiz in the assertion that the laws of their science are "arbitrary," for they hold that these laws are neither arbitrary nor nccessary, but natural.

As Agassiz used, as the basis of his thesis that nature is a language, the assertion that the laws of living nature are not mechanical, many of the working naturalists of our day, knowing, in part at least, the physical explanation of these laws, have refused to share his conviction that nature is a language; for it is the fate of beliefs which are upheld by fallacious reasoning to suffer from the mistakes of their supporters. It is clear, however, that error on the part of the advocate of an opinion is no proof of error in the opinion itself. The intuitions which told Agassiz that nature is a language, which we learn to our delight and profit and instruction, may have been sound and trustworthy and fruitful in results, even if the reasons he gives for this conviction are at fault.

An illustration may make this clear. As the same thought may be expressed in various ways in different languages, and as even in the same language the same sounds or letters may have many meanings, it is clear that there is no "necessary" connection between words and the things they signify; for we might call black white, and zehite black, without confusion, if all who use our language were agreed upon the meaning of these words. As the relation between words and the things they signify is not "necessary," it has seemed to some that it is "arbitrary"; 
but one of the results of the publication of the "Origin of Species" has been to awaken new interest in the science of philology, and to promote the progress of this science. We now know that, far from being arbitrary, words and phrases and grammatical forms contain in themselves a record of their history; a record which often shows how they have come to be used as they are. Nothing compels me to use one word rather than another, or even to write at all; yet it has been found, by statistical methods, that choice of words by an author is as mechanical and orderly as the chest measurements on page 157 ; for it is found that if the proportion in which common words are used be computed from a hundred pages of an author, this same proportion will be closely adhered to in all his works. His use of words is not necessary, for he is free to write and to speak as he chooses, and may justly, as well as legally, be held responsible for his words; but his choice conforms to a statistical type, and is as mechanical as the sizes and velocities of the planets in their orbits. I make my sentences long and complicated, or short and simple, as I think best for the reader, for no particular length is necessary; yet a tabulation will show that, while some are short and some long, there is, for each writer, a mean or average sentence-length, and that sentences which exceed this length in any specified degree are exactly equal in frequency to those which fall short of the average in the same degree.

Does any one think for an instant that language is any the less valuable now than it was before this discovery was made? No one ever dreams that the conversation of the wise is any less entertaining, or less instructive, or less profitable now than it was before men studied philology.

As I understand Agassiz, it is not because natural history is a language, that he holds it to be intended; but because it is delightful to listen to the language of nature, and because it abounds in beneficial instruction for mankind.

Is it not because this is true that the man of science holds his pursuit to be both the first and highest of cluties and the greatest of all pleasures?

"And if," says Agassiz, "this is indeed so, do we not find in this adaptability of the human intellect to the facts of creation, by 
which we become instinctively, and, as I have said, unconsciously, the translators of the thoughts of God, the most conclusive proof of our affinity with the Divine Mind? and is not this intellectual and spiritual connection with the Almighty worthy our deepest consideration?

"If there is any truth in the belief that man is made in the image of God, it is surely not amiss for the philosopher to endeavor, by the study of his own mental operations, to approximate the workings of the Divine Reason, learning, from the nature of his own mind, better to understand the Infinite Intellect from which it is derived. Such a suggestion may, at first sight, appear irreverent. But, which is the truly humble? He who, penetrating into the secrets of creation, arranges them under a formula which he proudly calls his scientific system? or he who, in the same pursuit, recognizes his glorious affinity with the Creator, and, in deepest gratitude for so sublime a birthright, strives to be the faithful interpreter of that Divine Intellect with whom he is permitted, nay, with whom he is intended, according to the laws of his being, to enter into communion?"

I find no reference to Berkeley in the Essay on Classification, although the Swiss naturalist would have found much to interest him in the works of the Irish bishop; for they have much in common, and the study of Berkeley might have taught Agassiz that there is no necessary antagonism between mechanical conceptions of nature and belief that nature is intended; for Berkeley holds that "all the phenomena in nature are produced by motion."

While something like that of Agassiz, Berkeley's reasoning compares with it much as Agassiz's reasoning itself compares with that of Paley and the authors of Bridgewater Treatises.

Berkeley neither reasons like Paley from the contrivances in living beings, nor like Agassiz from the relations of living things to each other and to the world about them, but from nature in itself, telling us that "setting aside all help of astronomy and natural phylosophy, all contemplation of the contrivance, order, and adjustment of things," there is a teleological argument which is "independent of research into the sciences."

Even Berkeley himself is not always consistent, however; for 
after giving, in the second dialogue between Hylas and Philonous, his reasons for believing that "the Supreme, unlimited Agent useth no tool or instrument at all," and after pointing out that we cannot "suppose that an all-perfect Spirit should need an instrument, or, not needing it, make use of it," he tells us in "Siris," (I5I-I6I) that "the mind presiding in the world" does use instruments, and that the fitness of nature for the needs of man is evidence of contrivance, or the use of means for the attainment of ends; for he holds that the mechanism of nature is "necessary to assist the governed"; and he tells us it is maintained in order that intelligent beings may exist, although one must ask whether proof that nature is useful is proof that it is necessary.

"Without a regular course," says Berkeley, "nature could never be understood; mankind must be always at a loss, not knowing what to expect, or how to govern themselves, or direct their actions for the obtaining of any end." As a matter of fact, we do have practical confidence in the stability of the order of nature, and we do not find ourselves at a loss except through ignorance, although we do not know whether we shall be alive an hour hence. We know what we expect, although nothing is more certain than that we never know whether what we expect will happen. We do govern ourselves, and we have, in the past, been able to direct our actions for the attainment of ends, so that on the whole our ends have been attained when we have made no mistakes; for whether the mechanism of nature is necessary or not, our confidence in its stability has not, so far, disappointed any expectations that were reasonable and well founded.

It is not even necessary that we should know the value of response to the order of nature in order to bring about beneficial ends, for many of our most important responses take place in unconsciousness. The value of our circulation did not begin with Harvey; nor need one know anything about the chemistry of respiration or nutrition in order to profit by it.

"Unconscious activity," says Holmes, "is the rule with the actions most important to life. The lout who lies stretched on the tavern-bench, with just mental activity enough to keep his pipe from going out, is the unconscious tenant of a laboratory where such combinations are constantly being made as never Wöhler 
or Berthelot could put together; where such fabrics are woven, such colors dyed, such a commerce carried on with the elements and forces of the outer universe, that the industries of all the factories and trading establishments in the world are mere indolence and awkwardness and unproductiveness compared with the miraculous activities of which his lazy bulk is the unheeding centre."

"We wish to remember something in the course of conversation. No effort of the will can reach it; but we say, 'Wait a little, and it will come to me,' and go on talking. Presently, perhaps some minutes later, the idea we are in search of comes all at once into the mind, delivered like a prepaid bundle, laid at the door of consciousness like a foundling in a basket."

"There are thoughts that never emerge into consciousness which yet make their influence felt among the perceptible mental currents, just as the unseen planets sway the movements of those which are watched and mapped by the astronomers. Old prejudices, that are ashamed to confess themselves, nudge our talking thoughts to utter their magisterial veto. The more we examine the mechanism of thought, the more we shall see that the automatic unconscious action of the mind enters largely into all its processes. Our definite ideas are stepping-stones; how we get from one to the other we do not know; something carries us, we do not take the step.

"It is not strange that remembered ideas should often take advantage of the crowd of thoughts, and smuggle themselves in as original. Honest thinkers are always stealing unconsciously from each other. Our minds are full of waifs and estrays which we think are our own. Innocent plagiarism turns up everywhere. Our best musical critic tells me a few notes from the air of 'Shoo Fly' are borrowed from a movement in one of the magnificent harmonies of Beethoven." 1

While it is as a metaphysician that Berkeley is best known in our day, no one can read any of his works without discovering that their purpose is practical and not speculative. The avowed object of "Siris" is to show why tar water must be a "catholicon"; but the whole aim of his other works is to show that immediately and in itself natural knowledge is a language by which we are instructed;

I Holmes, "Mechanism in Thought and Morals." 
and that no one who is convinced that natural knowledge is useful need ask whether nature is intended, with any doubt of the answer.

He holds, indeed, that we cannot be sure that nature is a language unless we are convinced that it is nothing but a language; for while his idealistic philosophy is only a means to an end, he holds it essential for the attainment of this end; although the modern zoölogist must ask whether he is right, or whether, on the contrary, one who does not know what the relation between mind and matter is may not agree with him that nature is a language.

Berkeley's teleological argument is set forth in all his writings; but it is, perhaps, less complicated by metaphysics in the fourth dialogue with Alciphron than anywhere else.

Alciphron asserts that no evidence which is not as conclusive as that which proves the existence of his fellow-men will convince him of the existence of a God.

He says: "Nothing so much convinces me of the existence of another person as his speaking to me. It is my hearing you talk that, in strict and philosophical truth, is to me the best argument for your being. And this is a peculiar argument, inapplicable to your purpose; for you will not, I suppose, pretend that God speaks to man in the same clear and sensible manner as one man doth to another?

"What I mean, is not the sound of speech merely as such, but the arbitrary use of sensible signs, which have no similitude or necessary connection with the things signified; so as by the apposite management of them to suggest and exhibit to my mind an endless variety of things differing in nature, time, and place; thereby informing me, entertaining me, and directing me how to act, not only with regard to things near and present, but also with regard to things distant and future. No matter whether these sounds are pronounced or written; whether they enter by the eye or ear; they have the same use, and are equally proofs of an intelligent, thinking, designing cause."

"But if it should appear that God really speaks to men, would this content you?" asks Euphranor.

"I am for admitting no inward speech, no holy instincts or suggestions of light and spirit," answers Alciphron. "All that, you must know, passeth with men of sense for nothing. If you do not 
make it plain to me that God speaks to me by outward sensible signs, of sueh sort and in sueh manner as I have defined, you do nothing."

Euphranor now asks Aleiphron to consider natural knowledge. He points out, in effect, that what we eall the laws of nature are no more than generalizations, based on experienee, and that we fail to find in nature any a priori demonstration of any one of them, any evidenee that they are neeessary, any reason why they must hold good. He shows that all natural knowledge is knowledge of appearanees or phenomena, or ideas, as he prefers to call them ; and that, while the events that make up the order of nature are vulgarly considered under the relation of eause and effect, they are, in striet and philosophie truth, only known to be related as the sign and the thing signified. He shows, in a word, that, so far at least as we are concerned with them or know anything about them, "natural plicuomena are only natural appearances."

Men of seience have themselves learned to refleet upon natural knowledge sinee Berkeley's day; and as they are now practieally of his way of thinking on this matter, it is no longer necessary to review, in detail, his demonstration that, behind phenomena, we diseover in nature nothing exeept the farther truth that all natural knowledge is useful and instructive and pleasant to learn-a truth whieh the modern man of seience should be the last to question.

Berkeley points out that, these things being admitted, it follows aeeording to Aleiphron's definition, that nature is a language; although we learn the language of nature so easily and gradually that we are uneonseious of the act.

"If we have all been praetising this language, ever sinee our first entranee into the world, it doth not seem to me at all strange that men should not be aware they had learned a language begun so early and praetised so constantly. And if we also eonsider that it is the same throughout the world, and not, like other languages, differing in different places, it will not seem unaccountable that men should mistake the conneetion between the proper objeets of sight and the things signified by them to be founded in necessary relation or likeness."

If Berkeley had been a modern zoölogist, he would, no doubt, have made this assertion still stronger; by pointing out that the 
whole history of life is a history of the acquisition of the language of nature; for each stimulus to a vital act is a sign with a significance; and we have seen, page $6_{3}$, that a living thing is a being which, when affected by a stimulus, prepares itself for the significance, of which, in course of nature, it is the sign. Berkeley himself saw clearly, and he tells us in many places, that it is not necessary that the language of nature be intelligently apprehended in order to be instructive, for human speech is often used to warn or to excite or to please, rather than to call up mental images; and one may be sure that all living things respond to the language of nature to their advantage, without knowing whether they consciously apprehend the benefit of response or not.

"It may also be worth while," says Berkeley, "to observe that signs, being little considered in themselves, or for their own sake, but only in their relative capacity, and for the sake of those things whereof they are signs, it comes to pass that the mind overlooks them, so as to carry its attention immediately on to the thing signified. Thus, for example, in reading we run over the characters with the slightest regard, and pass on to the meaning. Hence it is frequent for men to say they see words, and notions, and things in reading a book; whereas in strictness they see only the characters which suggest words, notions, and things. And by parity of reason, may we not suppose that men, not resting in, but overlooking the immediate and proper objects of sight, as in their own nature of small moment, carry their attention onward to the very things signified, and talk as if they saw the secondary objects, which, in truth and strictness, are not seen, but only suggested and apprehended by means of the proper objects of sight, which alone are seen."

"But, to cut short this chicane," says Alciphron, "I propound it fairly to your own conscience, whether you really think God Himself speaks every day and in every place to the eyes of all men."

"This is really and in truth my opinion," answers Euphranor, "and it should be yours too, if you are consistent with yourself and abide by your own definition of language. Since you.cannot deny that the great Mover and Author of nature constantly 
explaineth Himself to the eyes of men by the sensible intervention of arbitrary signs, which have no similitude or necessary connection with the things signified; so as, by compounding and composing them, to suggest and exhibit an endless variety of objects, differing in nature, time, and place; thereby informing and directing men how to act with respect to things distant and future as well as near and present.

"In consequence, I say, of your own sentiments and concessions, you have as much reason to think the Universal Agent or God speaks to your eyes, as you can have for thinking any particular person speaks to your ears.

"You, it seems, stare to find God is not far from every one of us; and that in Him we live, and move, and have our being. You, who in the beginning of this morning's conference, thought it strange God should leave Himself without a witness, do now think it strange the witness should be so full and clear."

The modern philologist knows that the relation between words and the things they signify is orderly and natural; for he studies, by scientific methods, the natural laws shown by the life and growth of language; but I am as unable to see why one must know that the relation between natural signs and their significance is "arbitrary," before he admits the reality of the language of nature, as I am to sce how the scientific study of language shows that discourse with the wise is not useful and instructive and entertaining.

In fact, Berkeley, who here asserts that the relation is "arbitrary," tells us, in "Siris" that it is "necessary." I am quite unable to sce how or why his reasoning should seem more convincing to an idealist than to one who is "of a vulgar cast," and simple enough to take things as he finds them.

Berkeley, the idealist, says nature is nothing but a language, but I fail to see how his reasoning turns on this, "nothing but."

Berkeley, the realist, tells us the language of nature "is necessary to assist the governed"; but if we are sure nature is useful, why should we care whether it, or any part of it, is necessary, or unnecessary?

The eternal paradox about necessity and freedom has no meaning to the humble-minded zoölogist, who admits his accountability 
even if he knows nothing about absolute necessity, nothing about arbitrary liberty; and is quite content to leave to Milton's fiends the discussion of "Fix'd fate, free will, foreknowledge absolute." This itself seems to me a great gain, and a prodigious conservation of energy, worth no little hard work.

May not one who is convinced with Berkeley that nature is a language, find reason to doubt whether he has correctly and fully understood what he has heard, or whether he will be able to understand what he may still hear?

While the Darwinian, like every other thoughtful student, admits that the adjustments of living things to the external world are useful, he asks whether, quite apart from all question of purpose or intention, these beneficial adjustments may not themselves be part of the mechanism of nature. He asks whether man may not have survived because he fits nature, and whether another line might not have survived if nature had been different.

As he knows no reason in the nature of things why all should not come to an end this instant, he is unable to discover any assurance of stability in nature itself; and if he is to find any such assurance anywhere, how is he helped by the assertion that "in the government of the world physical agents, or mechanical, or secondary causes, or instruments, are necessary," either to assist the governed or for anything else?

May not the Darwinian ask whether our confidence in the stability of nature may not be equivalent to, and whether it can ever exceed, our confidence in the continuity of life?

"That a thing should be really perceived by my senses, and at the same time not really exist, is to me a plain contradiction," says Berkeley, "since I cannot prescind or abstract, even in thought, the existence of a sensible thing from its being perceived. I might as well doubt of my own being as of the being of those things I see and feel."

"If a man should give me arguments that I do not see," says Holmes, quoting from Johnson, "though I could not answer them, should I believe I do not sce?"

May not one who cannot doubt the reality of the things he sees and feels, ask whether all the things he sees and feels tell him what to expect, or how to govern himself and direct his 
actions for the attainment of ends? May not some of the things we see and feel be illusions? He who is giddy feels the world turn round. One who has lost his legs may suffer from cold feet. We see the sun rise in the morning and run his course through the sky until the evening. From the windows of the moving train we sec the ranks of corn circle round the middle distance. The skilful dramatist makes us feel all the emotions and impulses a real tragedy would excite.

While all the things we see and feel are, no doubt, equally real, they are not all real in the same way; for while it is true that we cannot doubt the evidence of our senses, familiar experience teaches that our senses are often deceptive, since their evidence stands in need of continual correction; for delusion and hallucination and error are, unfortunately, as real as truth.

The most practical and important question which rational living beings can ask is how we may distinguish truth from error, in order that we may think wisely, and be sure about our actions, and rightly order our lives; and the greatest service of Charles Darwin to the intellectual life of mankind is that he has led us to ask whether we may not some time find a mechanical explanation of that rational judgment which is innate in intelligent human beings; whether this may not itself be part of the physical order of nature; whether language itself, even the most rational discourse, may not be a natural phenomenon, which lies entirely within the limits of physical causation; whether proof that nature is a language is proof that this language is supernatural.

$\mathrm{He}$ asks whether those judgments which we call errors may not be the ones which lead us into danger and tend to our physical destruction, and whether it may not be because a judgment has proved beneficial in the struggle for existence that we call it true.

On the other hand, he does not forget that hallucinations, even those of the insane, are themselves truths of nature, which, wisely interpreted, may help the physician to minister to a mind diseased. He therefore asks whether hallucinations are not use$\mathrm{ful}$ in the same way that all natural knowledge is useful; whether illusions and errors are not truths misunderstood; whether they are exceptions to the rule that all natural knowledge is useful and instructive to all who hear aright the language of nature. 
If future discovery should demonstrate that Darwin is right, - if the value of our rational minds should prove mechanical and no more than might have been expected from our structure and history, - how could this prove that their value is not real value? While individuals survive or fall in the struggle for existence, this struggle produces nothing, for natural selection, like all natural laws, is a generalization from experience, and not an efficient cause.

While no one can doubt his senses, we do continually doubt or question the value of our sensations; for if the Lamarckian holds that knowledge is produced by experience, the Darwinian asks whether what we call the evidence of our senses is anything more than a stimulus in the presence of which knowledge arises in the mind; anything more than the condition or occasion of knowledge.

"We know a thing when we understand it; and we understand it when we can interpret, or tell what it signifies. Strictly, the sense knows nothing. We perceive, indeed, sounds by hearing and characters by sight. After the same manner, the phenomena of nature are alike visible to all; but all have not alike learned the connection of natural things, or understand what they signify, or know how to vaticinate by them. There is no question, saith Socrates, concerning that which is agreeable to each person; but concerning what will in time to come be agreeable, of which all men are not equal judges. He who foreknoweth what will be in every kind is the wisest. According to Socrates you and the cook may judge of the dish on the table equally well, but while the dish is making, the cook can better foretell what will ensue from this or that manner of composing it. Nor is this manner of reasoning confined only to morals and politics; but extends also to the natural sciences.

"As the natural connexion of signs with the things signified is regular and constant, it forms a sort of rational discourse. Therefore the phenomena of nature, which strike on the senses, and are understood by the mind, do form not only a magnificent spectacle, but also a most coherent, entertaining, and instructive Discourse; and to effect this, they are conducted, adjusted, and ranged by the greatest wisdom. This Language or Discourse is studied with different attention and interpreted with different degrees of skill. But so far as, men have studied and remarked 
its rules, and can interpret right, they may be said to be knowing in nature." 1

I see no incompatibility between Darwin's view of fitness and belief that nature is a language and that mechanical principles "may be very naturally explained, and have a very proper and obvious use assigned to them when they are considered only as marks or signs for our information "; although I cannot see how this proves that they are necessary for this purpose, or that this is their only or chief use; for if natural selection casts doubt on the opinion that the language of nature is an instrument, I fail to see how it shows that nature is not a language.

Since the zoölogist must ask whether the realistic teleology of Berkeley's "Siris" furnishes any evidence of the use of instruments which is not itself instrumental or mechanical, is it not exposed to all the difficulty which we find in all instrumental teleology? It is, assuredly, very different from that earlier teleology which is said to be so independent of "any laborious research into the sciences" that we are told one need only open his eyes to see it.

"In vain do we extend our view into the heavens and pry into the entrails of the earth, in vain do we consult the writings of learned men, and trace the dark footsteps of antiquity-iwe need only draw the curtain of words to behold the fairest tree of knowledge, whose fruit is excellent, and within the reach of our hand.

"That, setting aside all help of astronomy and natural philosophy, all contemplation of the contrivance, order, and adjustment of things, an infinite mind should be necessarily [logically] inferred from the bare existence of the sensible world, is an advantage to. those only who have made this easy reflection: that the sensible world is" instructive, and entertaining, and delightful.

May not one who, being no philosopher, has no opinion, either positive or negative, about any physical universe except that which he perceives, or has perceived, or might perceive if he had time and opportunity, by means of his senses, make this "easy reflection" just as easily as one who believes nature is necessary, either to assist the governed or for any other purpose?

The same Berkeley who was led into the philosophy of evolution 
in his old age by his wish to find in nature some reason why tar water must be a universal panacea, seems to have made this easy reflection just as easily as the young idealist of the dialogues with Hylas. May we not therefore ask whether one need be an idealist to find evidence that nature is a language? May not this evidence be just as clear to one who is no philosopher as if he were an idealist, or a realist, or a nominalist, or a materialist, or a monist, or an evolutionist, or a disciple of any other school in the great college of scholastic philosophy?

"It is for me a sufficient reason not to believe the existence of anything, if I see no reason for believing it," says Berkeley; and a student of science who is "of a vulgar cast" and simple enough to believe his own senses and leave things as he finds them, may find as much reason as an idealist for refusing to believe that nature is necessary; nor need he be at all disturbed if some should call him an agnostic.

As I understand Berkeley, it is not because nature is orderly, but because the order of nature is useful, and instructive, and full of delights for living things, that he holds it to be a language. Even if the Darwinian asks whether the order of nature may not be mechanical, and explicable by physical science, I fail to see why he should challenge Berkeley's belief that it is intended, unless he doubts whether response to the order of nature is useful and profitable and delightful.

Does any man of science doubt whether the words "language of nature" and "interpretation of nature" are used with clear, intelligible meaning? Is not the question whether nature is a language which we learn to our delight and profit and instruction quite a different matter from the question whether the language of nature is necessary or unnecessary?

May not one who does not know what the relation between mind and matter is, one who is unable to find his way through the perplexities which schoolmen and metaphysicians and theologians and other "philosophers" have thrown around the question whether the language of nature is necessary or not, still find a plain and easy answer to the simpler question whether nature is a language by which we are entertained and instructed?

The student of science should be the last to doubt this possi- 
bility even for an instant; for he asserts that it is because exact science does help one to walk with sure feet where others grope and stumble, that the promotion of natural knowledge is the first and highest of duties. How can one who knows that natural knowledge does correct our judgment and help us to avoid the dangers that beset and destroy the ignorant, ask whether nature is a language profitable to direct?

"I sometimes feel," says Holmes, "as if I should like to found a school to teach the ignorance of what people do not want to know."

If we are sure nature is useful, need any one care to ask whether it is necessary or arbitrary? "What have you to do with liberty and necessity? or what more than to hold your tongue about it?" asks Johnson of Boswell.

"The attitude of Modern Science is erect, her aspect serene, her determination inexorable, her onward movement unflinching, because she believes herself, in the order of Providence, the true successor of those men of old who brought down the light of heaven to men. Humility may be taken for granted as existing in every sane human being; but it may be that it most truly manifests itself to-day in the readiness with which we bow to new truths as they come from the scholars, the teachers, to whom the inspiration of the Almighty giveth understanding." 1

Paley sometimes argues that even if the finder of the watch were without knowledge of watchmakers, or other human contrivers, proof of design is to be found in the adjustment between its movements and those of the earth; while it is equally clear that, in other passages, he bases his argument on the analogy between the mechanism of nature and the works of human mechanics. After comparing the eye with a telescope, he asks: "What could a mathematical instrument maker have done more to show his knowledge of his principles, his application of that knowledge, his suiting of his means to his ends?" On the other hand, his opening passage, in which his thesis is developed, makes no reference to human contrivers. "Suppose I found a watch upon the ground, and it should be inquired how the

I Holmes, "Mechanism in Thought and Morals." 
watch happened to be in that place, I should hardly think of the answer which I had before given. Yet why should not this answer serve for the watch, as well as for the stone? Why is it not as admissible in the second case as in the first? For this reason, and for no other, viz. that when we come to inspect the watch we perceive (what we could not discover in the stone) that its several parts are framed and put together for a purpose, e.g. that they are so formed and adjusted as to produce motion, and that motion so regulated as to point out the hour of the day."

Whether it is or is not possible to prove intention without proving contrivance, I do not believe one can read a dozen pages of Paley or of any other English writer on natural theology, without finding that they fail to draw any such distinction; and while the question what they believed may have only an historical interest, it is important to note that the point of view has changed.

We have seen that, like Paley, even Berkeley is not always consistent; but as his earlier works are by far the clearest and at the same time the most profound of all the writings on natural theology, I have tried to set forth his reasoning in the clearest way I can command in the space at my disposal; although I hope no one who does not know Berkeley at first hand will be contented with my summary; for his beautiful essays and dialogues are no small part of our birthright in English literature.

In my opinion, however, the modern zoölogist who studies Berkeley must also ask whether natural selection, so far as it accounts for living things and their works and ways, docs not, in the same measure, account for language; both that which men use among themselves, and that which we find in nature.

The tcleologist of our day is brought face to face with the question, What if we should some time find that we know no contrivances and no contrivers, except those that are part of the chain of natural causation? Unless he can show that this never can be proved, by proving its reverse, is it not clear that he must abandon his search for intention, or seck it clsewhere than in the contrivance of nature?

Is it not, when all is said, illogical to seck a supcrnatural basis 
for natural theology? If we are to find a basis for teleology anywhere, must we not seek it in nature rather than outside nature?

No one supposes that the scientific study of philology, and the proof that the life and growth of language are natural, has any bearing upon the reality or the value of language. He who fears that the discovery of mechanical explanations of the order of nature would destroy the proof that nature is a language, seems no more reasonable than one who, having enjoyed and profited by good books, should assert that these books have lost their use and their power to please and to instruct, through the discovery that they are made by machinery in printing-offices.

- As modern zoölogists find no reason to believe the laws of their science are any less mechanical than those of physics and chemistry, Agassiz's conviction that natural history is a language has failed to commend itself to them - because he holds it essential to assert that these laws are nothing but categories of thought, and because he holds that things physical cannot also be ideal.

As the modern man of science, while convinced that nature is orderly, does not know whether it is "arbitrary" or "necessary," he has failed to be convinced by Berkeley, who holds that, since a language must be arbitrary in order to be a language, none who do not admit that nature is arbitrary can hold it to be a language; although he himself asserts, in another place, that it is necessary.

It is no new thing in history for beliefs to suffer because their supporters have held to be essential certain opinions as to matters of fact which have proved erroneous.

"Every man is not a proper Champion for Truth, nor fit to take up the Gauntlet in the cause of Verity: many, from the ignorance of these maxims, and an inconsiderate Zeal unto Truth, have too rashly charged the Troops of Error, and remain as Trophies unto the enemies of Truth. A man may be in as just possession of Truth as of a City, and yet be forced to surrender." 1

Science tells us that the things that take place in nature are neither less nor more than one who knows the data has every reason to expect. With this the work of science ends; and here I must end my work on the Principles of Science; for these prin-

1 Browne, "Religio Medici," 7 . 
ciples fail to tell us why the things we expect should be the things that come about.

The question why the things we expect should be the things that come about is the one that concerns the natural theologian; for it is the same as the question, What is the Cause of Nature?

To this all must seek an answer for themselves; for each has at his command all the data within the reach of any student of science.

As for myself, I hope, with all my getting, to get understanding; for "the heart of him that hath understanding seeketh knowledge. The merchandise of it is better than the merchandise of silver, and the gain thereof than fine gold. She is more precious than rubies; and all the things thou canst desire are not to be compared unto her. Her ways are ways of pleasantness, and all her paths are peace.

For you who have, at this time, for my encouragement, called yourselves my students, I have written this book which has been my own so long that I should part from it with regret, did I not hope that, as you study the great works to which I have directed you, you may still call me teacher.

I have treated subjects which I should not dare to handle if the thoughts were my own; but the book contains little which you will not find far better presented by abler pens, although I hope that the words of one whose standpoint is the same as your own may help you to find the meaning of older writers.

If you are indeed my students, you are not afraid of hard work, so in this day of light literature, when even learning must be made easy, you must be my readers, and you must do double duty; for I take the liberty of a teacher with his pupils, and ask that, after you have read the book, you will some day read it again; since I hope that what may seem obscure, may, on review, be found consistent and intelligible.

BRIGHTSIDE, March 25, 1898. 

$\frac{\text { Alg }}{\text { UR }}$ 

